\title{
Industrial and Agricultural Process Heat Information User Study
}

W. W. Belew

B. L. Wood

T. L. Marle

C. L. Reinhardt
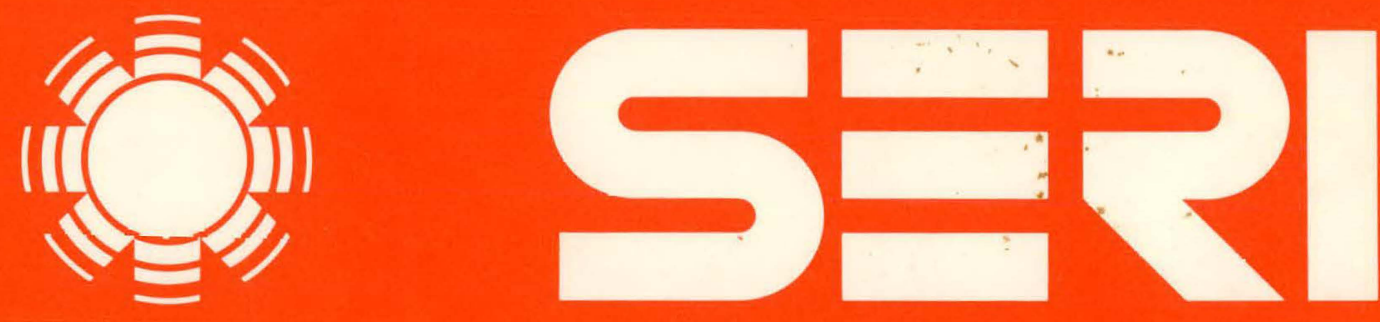

Solar Energy Research Institute

A Division of Midwest Research Institute

1617 Cole Boulevard

Golden, Colorado 80401

Operated for the

U.S. Department of Energy under Contract No. EG-77-C-01-4042 


\section{DISCLAIMER}

This report was prepared as an account of work sponsored by an agency of the United States Government. Neither the United States Government nor any agency Thereof, nor any of their employees, makes any warranty, express or implied, or assumes any legal liability or responsibility for the accuracy, completeness, or usefulness of any information, apparatus, product, or process disclosed, or represents that its use would not infringe privately owned rights. Reference herein to any specific commercial product, process, or service by trade name, trademark, manufacturer, or otherwise does not necessarily constitute or imply its endorsement, recommendation, or favoring by the United States Government or any agency thereof. The views and opinions of authors expressed herein do not necessarily state or reflect those of the United States Government or any agency thereof. 


\section{DISCLAIMER}

Portions of this document may be illegible in electronic image products. Images are produced from the best available original document. 
Printed in the United States of America Available from:

National Tcchnical Information Service

U.S. Department of Commerce

5285 Port Royal Road

Springfield, VA 22161

Price:

Microfiche $\$ 3.00$

Printed Copy $\$ 9.50$

\section{NOTICE}

This report was prepared as an account of work sponsored by the United States Government. Neither the United States nor the United States Department of Energy, nor any of their employees, nor any of their contractors, subcontractors, or their employees, makes any warranty, express or implied, or assumes any legal liability or responsibility for the accuracy, completeness or usefulness of any information, apparatus, product or process disclosed, or represents that its use would not infringe privately owned rights. 


\section{$\operatorname{Dr} .2546$}

SER I /TR-751-751

UC CATEgORIES: UC $-59 \mathrm{~b}, 58 \mathrm{c}$

INDUSTRIAL'AND AGR:ICULTURAL PRECESS HEAT INFORMATION USER STUDY

W. W. BELEW

B. L. WOOD

T. L. MARLE

C. L. REINHARDT

MARCH 1981

PREPARED UNDER TASK NO. 8420.11

\section{Solar Energy Research Institute}

A Division of Midwest Research Institute

1617 Cole Boulevard

Golden, Colorado 80401

Prepared for the

U.S. Department of Energy

Contract No. EG-77-C-01-4042
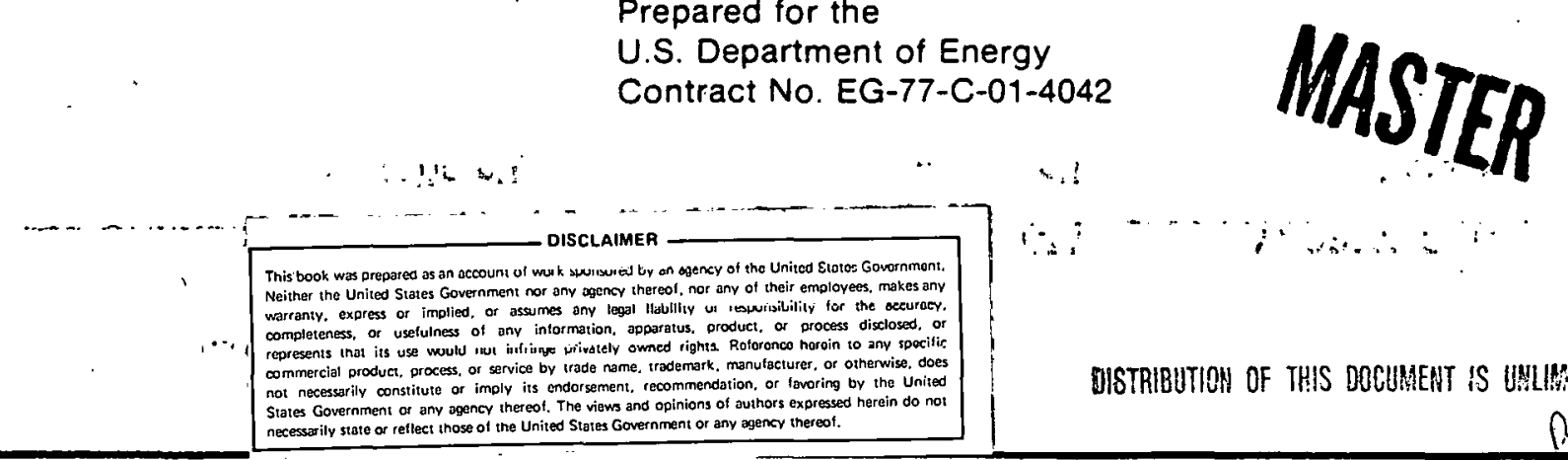

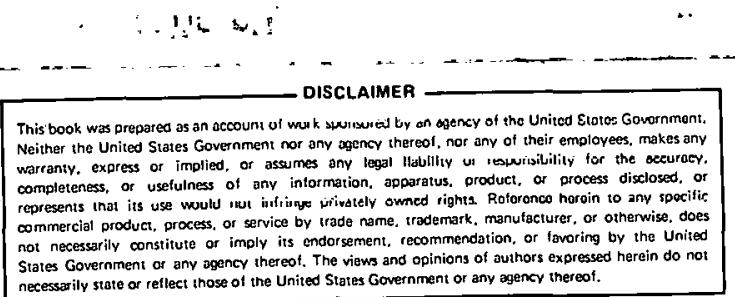

$\because !$

$\therefore \vdots$

$\therefore \therefore \therefore i$ 


\section{PAGES ii to iv WERE INTENTIONALLY LEFT BLANK}




\section{ACKNOWLEDGMENTS}

The authors would like to thank the following people for their valuable technical advice and review.

M. Branz

Southern Solar Energy Center

M. Burnett

Western Solar Utilization Network

J. Flynn

Division of Solar Thermal

Energy Systems

U.S. Department of Energy

B. Gupta

Solar Thermal Program Branch

SERI

J. Kreider

Consulting Engineer

Solar Energy
F. Kreith

Solar Thermal Research Branch SERI

J. Paull

Northeast Solar Energy Center

K. Rose

San Francisco Operations Office

U.S. Department of Energy

R. Talwar

Mid-American Solar Energy Complex

V. Wilson

Industrial Applications and

Policy Branch

SERI 


\section{PAGES vi to vii WERE INTENTIONALLY LEFT BLANK}




\section{STUDY CHARACTERISTICS :-}

Between 3 September 1979 and 13 October 1979 Market Opinion Research, Inc. of Detroit, Michigan-under subcontract to SERI-conducted telephone interviews with 86 distinct groups of solar information users taken from across the nine different technological areas. Approximately nine respondents were interviewed from each group. Interviews were based upon professionally reviewed and tested questionnaires that utilized a mixture of open-ended and closed-ended questions. The interviews took an average of 18 minutes to complete.

The respondents proved to be very cooperative. Considering the length and nature of the telephone interviews, it was surprising that only about $3 \%$ of the respondents terminated an interview or refused to be interviewed. This finding supported the interviewers' statements that the respondents were very interested in telling what they were doing in solar energy, in obtaining solar information, and in specifying what solar information would prove the most valuable.

\section{SAMPLE SIZE}

Studies of 86 groups, each interested either in one of nine specific solar technologies or in solar energy in general, provided an extremely broad view of the information needs of the solar community. Although the sample size of only nine respondents per group was small, the data still proved to be adequate for planning purposes. It was possible to determine the information most important to the respondents and the best channel for dissemination. A variety of valid statistical tests were performed, both to compare the priorities a group gave to different information items and to compare the priorities different groups gave to the same item (see Section 2.3 and Appendix. E).

\section{SOLAR INDUSTRIAL AND AGRICULTURAL PROCESS HEAT GROUPS STUDIED}

The results of an earlier study identified the groups of information users constituting the solar process heat community [1] and determined the priority (to accelerate commercialization of solar energy) of getting information to each user group. In the current study only high-priority groups were included. Considerable eff ort (e.g.; library searches, phone calls, subcontractors) went into obtaining the names of people professionally involved with solar process heat. When the phone interviews were conducted, an elaborate screening process was used to guarantee that the potential respondent was truly involved in solar industrial or agricultural process heat.

In this report, results for both industrial process heat and agricultural process heat have been included. . This was because of the vagueness (to the people interviewed) of the exact demarcation between the two processes. Respondents in the following 10 groups were queried about their need for information on solar process heat technologies:

- Solar Industrial Process Heat Résearchers,

- Solar Agricultural Process Heat Researchers,

- Representatives of Manuf acturers of Concentrating Collectors,

- Representatives of Manufacturers of Nonconcentrating Collectors,

- Plant Engineers involved with solar industrial process heat, 
- Agricultural Engineers involved with solar industrial process heat,

- Industrial Engineers involved with solar industrial process heat,

- Educators teaching college-level courses which included information on solar industrial process heat,

- State Agricultural Office Representatives interested in solar agricultural process heat, and

- Cooperative Extension Service (CES) County Agents who will be needing information on solar agricultural process heat.

Further, results from Total Manufacturers of Nonconcentrating Collectors (who were asked questions principally about active solar heating and cooling) have also been included.

Groups desirable to study, but for whom adequate lists of names could not be obtained, included potential users. Several of the groups discussed in another report from. this study [2]. also indicated an interest in information on solar process heat (see Section 2.2.4).

\section{RESULTS}

In most cases the results from both groups of researchers were similar. Thus, in the following tables the data for Researchers have been combined. Similarly, results from Plant Engineers and Industrial Engineers have been combined.

\section{Usefulness of General Types of Information}

The most important result obtained from this study was the identification of the solar process heat information categories ranked the most useful by each group of respondents (see Table S-1). Industrial and agricultural, process heat respondents in almost every group gave high ratings to inf ormation on:

- Cost/performance;

- Installation/operation costs;

- Climatological data;

- Tax credits, grants, incentives;

- Lists of information sources;

- Research in progress; and

- The state of the art.

Most notable, however, was the wide range of rankings the groups gave to the information items. For example, even for some of these generally high-ranked items, there were several groups who ranked the item 10th or worse. Similarly for the generally lowranked items, there were of ten several groups ranking the item 8th or better. This underlines the need to design most information products on a group by group basis. 


\section{PAGES $\quad \mathrm{x}$ to $\mathrm{xi}$ WERE INTENTIONALLY LEFT BLANK}


Table S-2. VALUE ASSESSMENT OF SPECIFIC INDUSTRIAL AND AGRICULTURAL PROCESS HEAT (I/PH) INFORMATION PRODUCTS

\begin{tabular}{|c|c|c|c|c|c|c|c|c|c|}
\hline $\begin{array}{l}\text { Specific Information } \\
\text { Products }\end{array}$ & $\begin{array}{c}\text { IAPH } \\
\text { Researchers }\end{array}$ & $\begin{array}{l}\text { Cencentrating } \\
\text { Collector } \\
\text { Manufacturer } \\
\text { Reps }\end{array}$ & $\begin{array}{c}\text { Total } \\
\text { Nonconcentrating } \\
\text { Collector } \\
\text { Manuf acturer } \\
\text { Reps }\end{array}$ & $\begin{array}{l}\quad \text { IPH } \\
\text { Plant and } \\
\text { Industrial } \\
\text { Engineers }\end{array}$ & $\begin{array}{c}\text { IPH } \\
\text { Agricultural } \\
\text { Engineers }\end{array}$ & $\begin{array}{c}\text { IPH } \\
\text { Educators }\end{array}$ & $\begin{array}{l}\text { APH State } \\
\text { Agricultural } \\
\text { Office } \\
\text { Reps }\end{array}$ & $\begin{array}{l}\text { APH } \\
\text { CES } \\
\text { Courity } \\
\text { Agents }\end{array}$ & $\begin{array}{l}\text { All } \\
\text { IAPH } \\
\text { Respon- } \\
\text { dents }\end{array}$ \\
\hline & Percent $^{a}$ & Percent & Percent & Percent & Percent & Percent & Percent & Percent & Percent $^{b}$ \\
\hline \multicolumn{10}{|l|}{$\begin{array}{l}\text { Bit-liography of Genera: } \\
\text { Readings on IAPH }\end{array}$} \\
\hline Systems & 44 & -0 & 10 & 44 & 78 & 33 & 50 & 33 & 33 \\
\hline $\begin{array}{l}\text { Calendar of IAPH Con- } \\
\text { ferences and Programs }\end{array}$ & 50 & 50 & 46 & 22 & 33 & 44 & 38 & 33 & 40 \\
\hline $\begin{array}{l}\text { IAPH System Diagrams } \\
\text { or Schematics } \\
\text { IAPH Svstem Design/ }\end{array}$ & 44 & 38 & 46 & 50 & 67 & 56 & 75 & 67 & 52 \\
\hline $\begin{array}{l}\text { Installation Handbooks, } \\
\text { Reference Tables }\end{array}$ & 56 & 50 & 48 & 72 & 67 & 33 & 63 & 56 & 56 . \\
\hline $\begin{array}{l}\text { Manual Analytical Tools for } \\
\text { IA.PH System Design } \\
\text { Computer Analytical T.ools } \\
\text { (Models) for IAPH }\end{array}$ & 67 & 75 & 46 & 61 & 78 & 67 & 38 & 44 & 58 \\
\hline $\begin{array}{l}\text { Sqstem Design } \\
\text { Lists of Local IAPH }\end{array}$ & 33 & 63 & 36 & 39 & 78 & 56 & 38. & 0 & 40 \\
\hline $\begin{array}{l}\text { Experts } \\
\text { c }\end{array}$ & 39 & 63 & 69 & 17 & 44 & 33 & 50 & 67 & 48 \\
\hline $\begin{array}{l}\text { Lists of LAPH Technicall } \\
\text { Experts }\end{array}$ & 33 & 75 & 24 & 17 & 33 & 33 & 50 & 89 & $x^{d}$ \\
\hline $\begin{array}{l}\text { Tezhnical Descriptions of } \\
\text { IfPH Systems }\end{array}$ & 78 & 63 & 55 & 72 & 56 & 78 & 50 & 44 & $x^{d}$ \\
\hline $\begin{array}{l}\text { Nantechnical Descriptions } \\
\text { o: IAPH Systems } \\
\text { List of IAPH Inf ormation }\end{array}$ & 0. & 13 & 21 & 44 & 11 & 44 & 88 & 89 & $x^{d}$ \\
\hline $\begin{array}{l}\text { Sources } \\
\text { Stition }\end{array}$ & 50 & 50 & 32 & 56 & 78 & 67 & 75 & 78 & $x^{d}$ \\
\hline Sample Size & 18 & 8 & 29 & 18 & 9 & 9 & 8 & 9 & 108 \\
\hline
\end{tabular}

"Percent is the percenlage of respondents rating the item as "essential" or "very useful" (as opposed to "somewhat useful" or "not at all useful").

bAlthough a percentage is given for All IAPH Respcndents, it may not be indicative of the percentage of the whole IAPH community interested in that item (since the proportion of each type of respondent in this study nay not correspond to the proportion that group constitutes of the entire population).

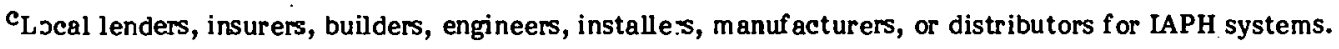

$d$ " $\mathrm{X}$ " indicates no overall percentage was calculated. For these items it may be necessary to develop different products/services for each group if their information needs are to be fully met. 
Table S-3. SOURCES USED TO OBTAN SOLAR INPORMATION (Percent ${ }^{a}$ )

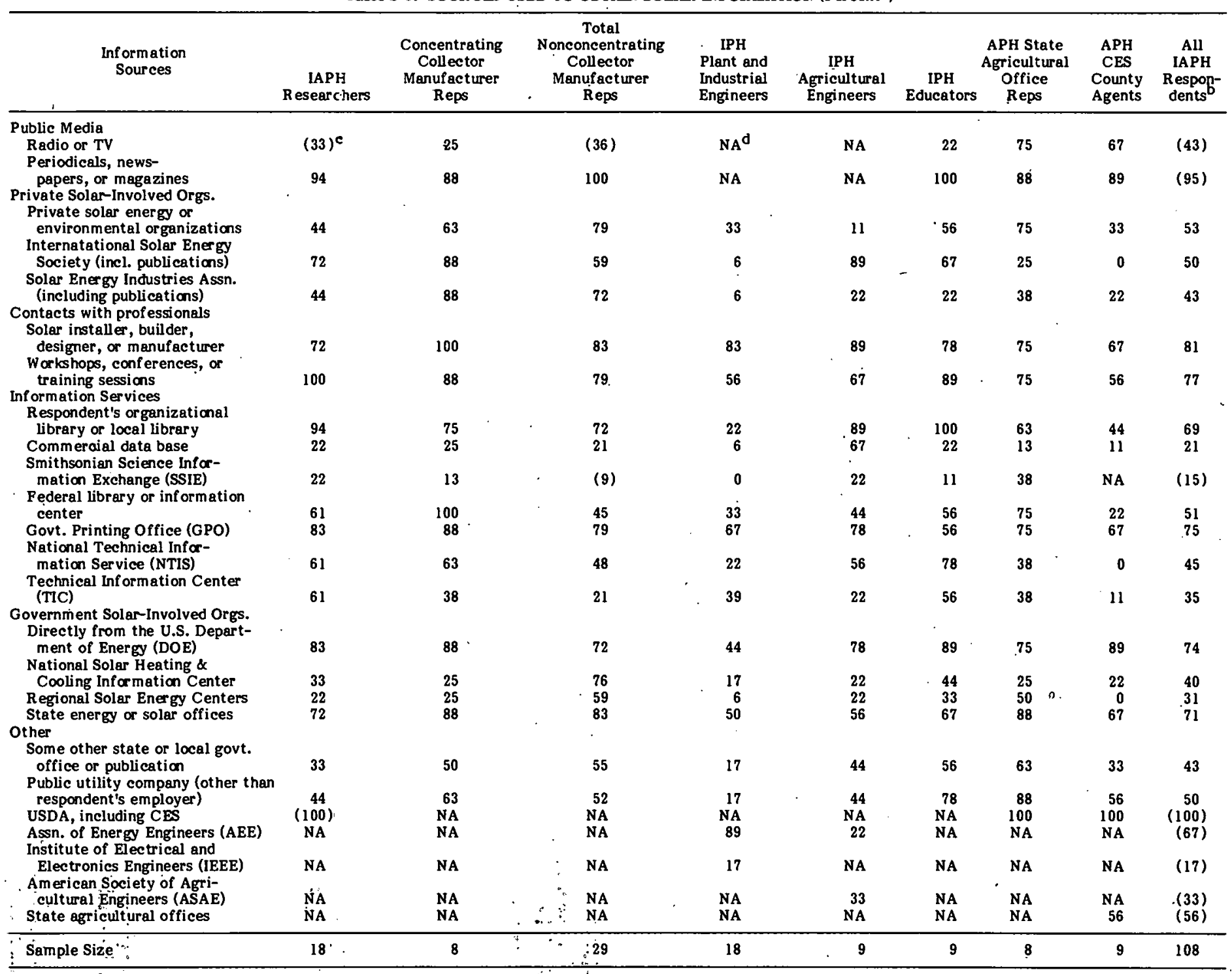

apercent is the percentage of respondents w 10 used the source to obtain any solar inf ornation in the past few years.

Aalthough a percentage is given for All IAPH. Respondents, it may not be indicative of the percentage of the whole IAPH community interested in that item (since the cin(,)" means the question was not asked of al of the groups in this particular set of respondents. For example, "(44)" means that 44\% of those who were asked had used

that source: In no case were fewer than nine respondents asked.
"NA" means the question was not asked of this particular set of respondents. 


\section{PAGES Xiv to XV WERE INTENTIONALLY LEFT BLANK}


Table S-5. INTEREST IN INFORMATION ON SOLAR AGRICULTURAI, PROCESS HEAT (APH) TOPICS

\begin{tabular}{|c|c|c|c|c|}
\hline Topics & 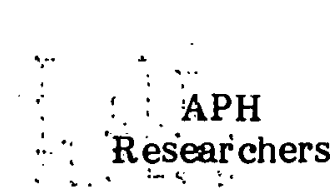 & $\begin{array}{c}\text { APH State } \\
\text { Agricultural } \\
\text { Office } \\
\text { Reps }\end{array}$ & $\begin{array}{c}\text { APH } \\
\text { CES } \\
\text { County } \\
\text { Agents }\end{array}$ & $\begin{array}{c}\text { All } \\
\text { APH } \\
\text { Respon- } \\
\text { dents }\end{array}$ \\
\hline . & $\because \quad$ Pereent ${ }^{\mathrm{a}}$ & Percent & Percent & Percent $^{b}$ \\
\hline $\begin{array}{l}\text { Livestock Shelter } \\
\text { Heating } \\
\text { Grain Drying } \\
\text { Crop Drying } \\
\text { Greenhouses } \\
\text { Food Processing }\end{array}$ & 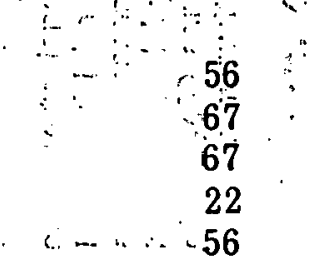 & $\begin{array}{l}88 \\
75 \\
88 \\
88 \\
88\end{array}$ & $\begin{array}{l}78 \\
789 \\
78 \\
78 \\
78 \\
67\end{array}$ & $\begin{array}{l}673 \\
777 \\
77 \\
62 \\
69\end{array}$ \\
\hline Sample Size & 9 & 8 & 9 & 26 \\
\hline
\end{tabular}

${ }^{\text {a }}$ Percent is the percentage of respondents interested in the application.

bAlthough a percentage is given for All IPH or APH Respondents, it may not be indicative of the percentage of the whole IPH or APH community interested in that item (since the proportion of each type of respondent in this study may not correspond to the proportion that group constitutes of the entire population). The data for Concentrating Collector Manufacturers and Total Nonconcentrating Collector Manufacturers is not included in All IPH Respondents. 
Table S-6. ADVANCED INFORMATION ACQUISTTION METHODS USED

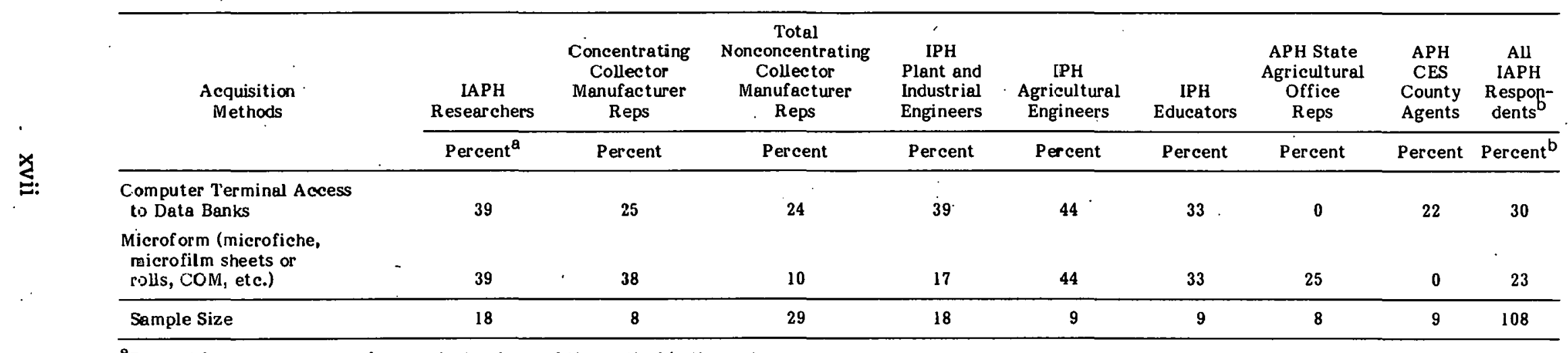

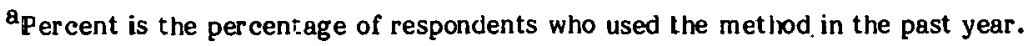

${ }^{b}$ A.lthough a percentage is given for All IAPH Respondents, it may not be indicative of the percentage of the whole IAPB community interested in that item (since the proportion of each type of respondent in this study nay not correspond to the proportion that group constitutes of the entire population). 
- State Agricultural Office Representatives felt a strong need for information. Compared to other groups they were well aware of available information sources, yet their top-rated inf ormation need was "lists of inf ormation sources."

- County Extensi on Agents wanted basic cost data and nontechnical APH systems' descriptions to pass on to the people in their county. They obtained such information from agricultural sources. 


\section{TABLE OF CONTENTS}

Page

Management Summary $\ldots \ldots \ldots \ldots \ldots \ldots \ldots \ldots \ldots \ldots \ldots \ldots \ldots \ldots \ldots \ldots \ldots \ldots$

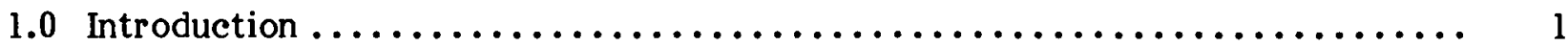

1.1 Background.................................... 1

1.2 Solar Energy Information Data Bank Program Planning ............. 2

1.3 Report Contents ..................................... 3

2.0 Study Description $\ldots \ldots \ldots \ldots \ldots \ldots \ldots \ldots \ldots \ldots \ldots \ldots \ldots \ldots \ldots \ldots \ldots \ldots \ldots$

2.1 Study Characteristics ............................... 5

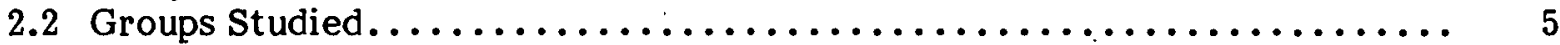

2.2.1 Target Audiences, Classes, and Groups ................. 6

2.2.2 Criteria for Selection of Groups to Study ................ 7

2.2.3 Groups Included in the Solar Industrial and Agricultural

Process Heat Study.......................... 7

2.2.4 Solar Process Heat-Concerned Groups

Included in the General Solar Study .................. 13

2.3 Data Interpretation............................... 14

2.3.1 Impact of the Sample Frames: Who was Sampled? ........... 14

2.3.2 Statistical Tests .............................. 15

2.3.3 Hypotheses Versus Conclusions ....................... 15

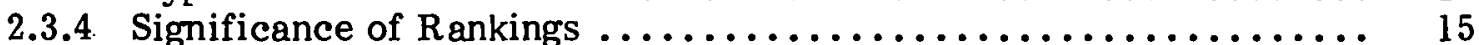

2.3.5 Alternative Measures of Usefulness .................... 15

2.3.6 Combining Results from Different Groups ................ 16

2.3.7 Specific Information Products.................... 16

2.3.8 Information Sources $\ldots \ldots \ldots \ldots \ldots \ldots \ldots \ldots \ldots \ldots \ldots \ldots \ldots \ldots \ldots \ldots$

3.0 Industrial and Agricultural Process Heat Researchers . . . . . . . . . . . . 19

3.1 Description of Respondents ......................... 19

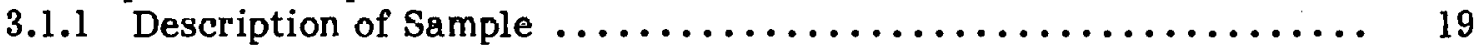

3.1.2 Current Status of Respondents .................... 20

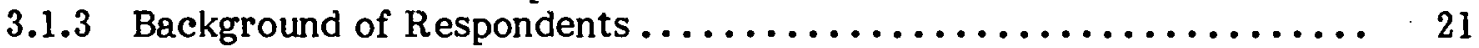

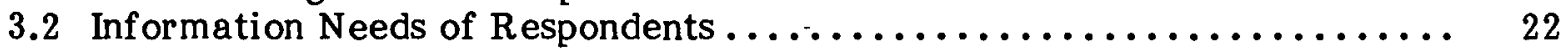

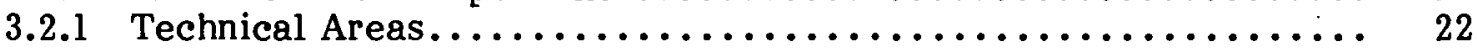

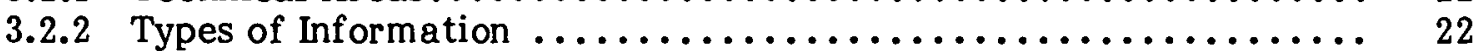

3.3 Acquisition of Information by Respondents $\ldots \ldots \ldots \ldots \ldots \ldots \ldots \ldots \ldots \ldots \ldots \ldots \ldots$

3.3.1 Use of Selected Inf ormation Sources .................. 27

3.3.2 Membership in Solar-Interested Organizations ............... 31

3.3.3 Exposure to Fublications on Solar Energy ................... 32

3.3.4 Use of Special Acquisition Methods ..................... 33

3.4 Summary and Comments ................................ 33 
TABLE OF CONTENTS (Continued)

$\underline{\text { Page }}$

4.0 Concentrating Collector Manufacturer Representatives .............. 35

4.1 Description of Respondents ......................... 35

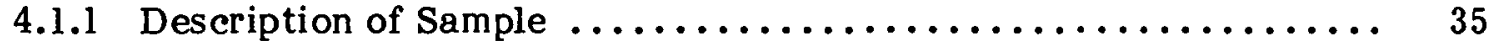

4.1.2 Current Status of Respondents .................... 36

4.1.3 Background of Respondents .......................... 37

4.2 Information Needs of Respondents $\ldots \ldots \ldots \ldots \ldots \ldots \ldots \ldots \ldots \ldots \ldots \ldots$

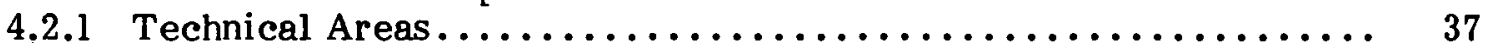

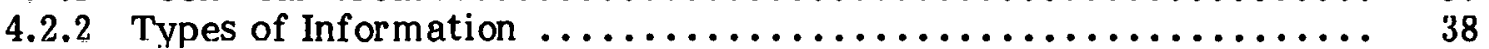

4.3 Acquisition of Information by Respondents................ 41

4.3.1 Use of Beleated Information Eourccs . . . . . . . . . . . . . . . . . . 41

4.3.2 Membership in Solar-Interested Organizations .............. 42

4.3.3 Exposure to Publications on Solar Energy ................. 45

4.3.4 Use of Special Acquisition Methods .................. 45

4.4 Summary and Comments ........................... 46

5.0 Nonconcentrating Collector Manufacturer Representatives ........... 47

5.1 Description of Respondents $\ldots \ldots \ldots \ldots \ldots \ldots \ldots \ldots \ldots \ldots \ldots \ldots \ldots \ldots \ldots \ldots \ldots$

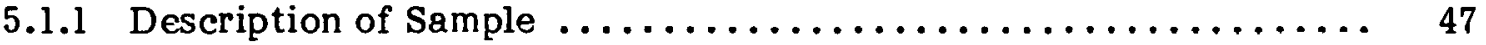

5.1 .2 Current Status of Respondents .................... 48

5.1.3 Background of Respondents ...................... 49

5.2 Information Needs of Respondents ..................... 49

5.3 Acquisition of Information by $\mathrm{R}$ espondents $\ldots \ldots \ldots \ldots \ldots \ldots \ldots \ldots \ldots$

5.3 .1 Use of Selected Information Sources ................. 53

5.3.2 Membership in Solar-Interested Organizations ............. 56

5.3 .3 Exposure to Publications on Solar Energy ................ 57

5.3 .4 Üse of Special Acquisition Methods ................. 58

5.4 Summary and Comments $\ldots \ldots \ldots \ldots \ldots \ldots \ldots \ldots \ldots \ldots \ldots \ldots \ldots \ldots \ldots$

6.0 Industrial Process Heat Engineers $\ldots \ldots \ldots \ldots \ldots \ldots \ldots \ldots \ldots \ldots \ldots \ldots \ldots$

6.1 Description of Kespondents .......................... 61

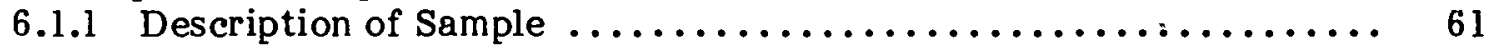

6.1 .2 Current Status of Respondents .................... 62

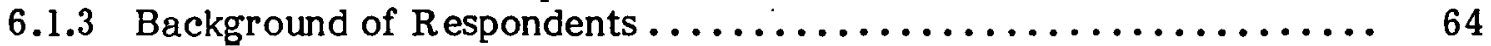

6.2 Information Needs of Respondents $\ldots \ldots \ldots \ldots \ldots \ldots \ldots \ldots \ldots \ldots \ldots \ldots \ldots$

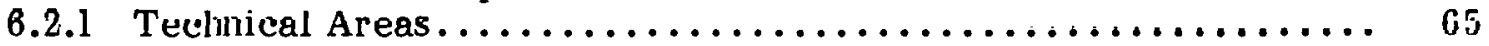

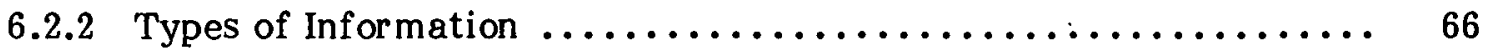

6.3 Acquisition of Information by $\mathrm{R}$ espondents $\ldots \ldots \ldots \ldots \ldots \ldots \ldots \ldots \ldots \ldots$

6.3.1 Use of Selected Information Sources .................. 74

6.3.2 Membership in Solar-Interested Organizations ............. 81

6.3.3 Exposure to Publications on Solar Energy ................ 82

6.3 .4 Use of Special Acquisition Methods ................... 84

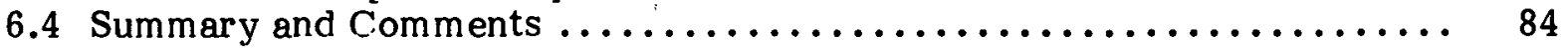


TABLE OF CONTENTS (Continued)

Page

7.0 Solar Industrial Process Heat Educators $\ldots \ldots \ldots \ldots \ldots \ldots \ldots \ldots \ldots \ldots \ldots \ldots$

7.1 Description of Respondents ......................... 87

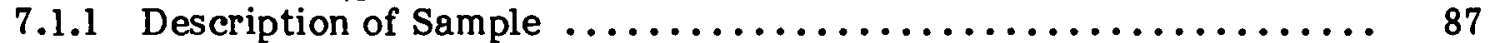

7.1 .2 Current Status of Respondents ................... 87

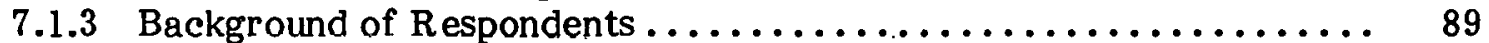

7.2 Information Needs of Respondents ...................... 89

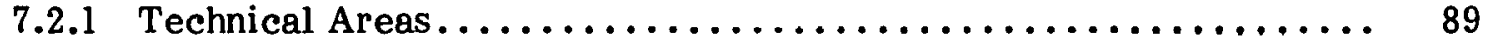

7.2 .2 Types of Information $\ldots \ldots \ldots \ldots \ldots \ldots \ldots \ldots \ldots \ldots \ldots \ldots \ldots \ldots \ldots$

7.3 Acquisition of Inf ormation by Respondents................. 93

7.3.1 Use of Selected Information Sources .................. 93

7.3.2 Membership in Solar-Interested Organizations .............. 96

7.3.3 Exposure to Publications on Solar Energy .................. 96

7.3.4 Use of Special Acquisition Methods ................... 97

7.4 Summary and Comments $\ldots \ldots \ldots \ldots \ldots \ldots \ldots \ldots \ldots \ldots \ldots \ldots \ldots \ldots \ldots \ldots \ldots$

8.0 State Agricultural Office Representatives ....................... 99

8.1 Description of Respondents .......................... 99

8.1.1 Description of Sample .......................... 99

8.1.2 Current Status of Respondents .................... 100

8.1.3 Background of Respondents ........................ 101

8.2 Information Needs of Respondents ...................... 101

8.2.1 Technical Areas............................... 101

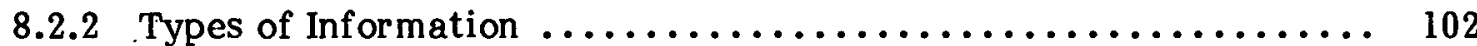

8.3 Acquisition of Inf ormation by Respondents.................. 104

8.3.1 Use of Selected Information Sources ................... 104

8.3.2 Membership in Solar-Interested Organizations .............. 106

8.3.3 Exposure to Publications on Solar Energy ................. 106

8.3.4 Use of Special Acquisition Methods ................... 106

8.4 Summary and Comments $\ldots \ldots \ldots \ldots \ldots \ldots \ldots \ldots \ldots \ldots \ldots \ldots \ldots \ldots \ldots \ldots \ldots$

9.0 County Agents, Cooperative Extension Service ................. 109

9.1 Description of Respondents ........................... 109

9.1.1 Description of Sample ........................... 109

9.1.2 Current Status of Respondents ...................... 110

9.1.3 Background of Respondents ...................... 111

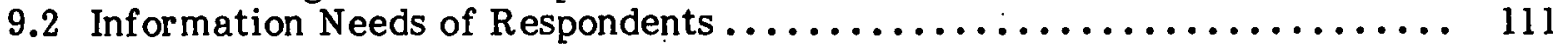

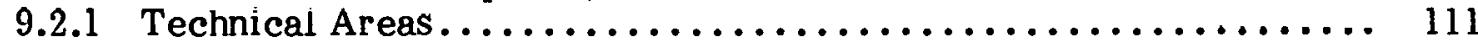

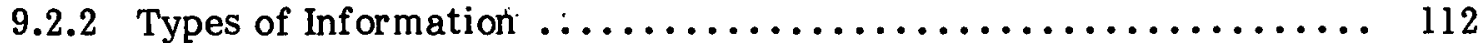

9.3 Acquisition of Information by Respondents.................. 116

9.3.1 Use of Selected Information Sources .................. 116

9.3.2 Memb́ership in Solar-Interested Organizations .............. 120

9.3.3 Exposure to Publications on Solar Energy ................ 120

9.3.4 Use of Special Acquisition Methods .................. 121

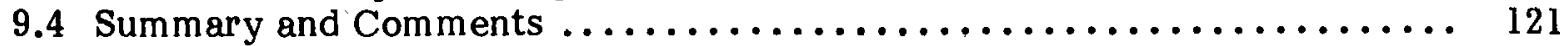


TABLE OF CONTENTS (Concluded)

$\underline{\text { Page }}$

10.0 References $\ldots \ldots \ldots \ldots \ldots \ldots \ldots \ldots \ldots \ldots \ldots \ldots \ldots \ldots \ldots \ldots \ldots \ldots \ldots \ldots \ldots$

Appendix A: Groups Included in Study $\ldots \ldots \ldots \ldots \ldots \ldots \ldots \ldots \ldots \ldots \ldots \ldots \ldots \ldots$

Appendix B: Study Development and Procedure $\ldots \ldots \ldots \ldots \ldots \ldots \ldots \ldots \ldots \ldots \ldots \ldots$

Appendix C: Letter of Introduction $\ldots \ldots \ldots \ldots \ldots \ldots \ldots \ldots \ldots \ldots \ldots \ldots \ldots \ldots$

Appendix D: $\quad$ Study Questionnaire .......................... 149

Appendix E: $\quad$ Statistical Testing............................ 175

Appendix F: Solar Industrial and Agricultural Process Heat Data Tables........ 179 


\section{LST OF FIGURES}

$\underline{\text { Page }}$

3-1 Usefulness of Selected Inf ormation Items: Industrial Process

Heat Resear chers ................................... 24

3-2 Usefulness of Selected Inf ormation Items: Agricultural

Process Heat Resear chers ............................... 25

3-3 Usef ulness of Selected Inf ormation Items: All Researchers . . . . . . . . . 26

3-4 Use of Selected Information Sources: Industrial Process

Heat Researchers ................................. 28

3-5 Use of Selected Information Sources: Agricultural Process

Heat Researchers .................................. 29

3-6 Use of Selected Information Sources: All Resear chers . . . . . . . . . . . . 30

4-1 Usefulness of Selected Inf ormation Items: Concentrating

Collector Manufacturer Representatives .................... 39

4-2 Usefulness of Selected Inf ormation Items: All

Manufacturer Representatives ............................ 40

4-3 Use of Selected Inf ormation Sources: Concentrating

Collector Manufacturer Representatives

4-4 Use of Selected Information Sources: All Manufacturer

Representatives .................................. 44

5-1 Usefulness of Selected Inf ormation Items: Total Nonconcentrating Collector Manufacturer Representatives............. 51

5-2 Usefulness of Selected Inf ormation Items: All Manuf acturer

Representatives ................................ 52

5-3 Use of Selected Inf ormation Sources: Total Nonconcentrating

Collector Manufacturer Representatives ...................... 54

5-4 Use of Selected Inf ormation Sources: All Manuf acturer

Representatives ................................. 55

6-1 Usefulness of Selected Inf ormation Items: Industrial

Process Heat Plant Engineers ........................ 67

6-2 Usefulness of Selected Inf ormation Items: Industrial

Process Heat Industrial Engineers ...................... 68

6-3 Usefulness of Selected Inf ormation Items: Industrial

Process Heat Agricultural Engineers 
LST OF FIGURES (Continued)

$\underline{\text { Page }}$

6-4 Usefulness of Selected Inf ormation Items: Active Solar

Heating and Cooling Industrial Engineers .

6-5 Usefulness of Selected Information Sour ces: All Engineers...........

6-6 Use of Sèlected Information Sources: Industrial Process

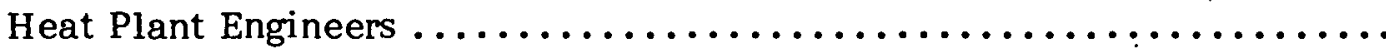

6-7 Use of Selected Information Sources: Industrial Process

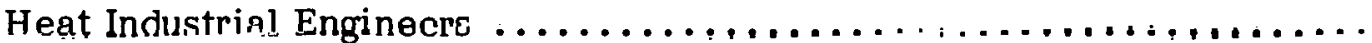

6-0 Use of Selected Inf'ormation Sources: Industrial Process

Heat Agricultural Engineers .........................

6-9 Use of Selected Information Sources: Active Solar Heating and Cooling Industrial Engineers $\ldots \ldots \ldots \ldots \ldots \ldots \ldots \ldots \ldots \ldots \ldots \ldots$

6-10 Use of Selected Information Sources: All Engineers ................ 79

7-1 Usefulness of Selected Inf ormation Items: Industrial Process Heat Educators ............................. 91

7-2 Usefulness of Selected Inf ormation Items: All Educators $\ldots \ldots \ldots \ldots \ldots \ldots \ldots$

7-3 Use of Selected Information Sources: Industrial Process

Heat Educators ...................................... 94

7-4 Use of Selected Information Sources: All Educators $\ldots \ldots \ldots \ldots \ldots \ldots \ldots \ldots$

8-1 Usefulness of Selected Inf ormation Items: State

Agricultural Office Representatives .......................

8-2 Use of Selected Inf ormation Sources: State Agricultural

Office Representatives ............................... 105

9-1 Usefulness of Selected Information Items: Agricultural Process

Heat Cooperative Extension Service (CES) County Agents

9.2 Usel'ulness of Selected Information Items: All Cooperative

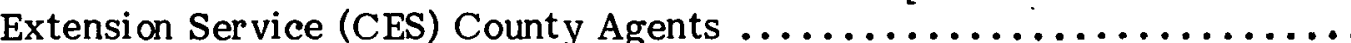

9-3 Usefulness of Selected Information Items: All Cooperative

Extension Service (CES) State Specialists...

9-4 Use of Selected Inf ormation Sources: Agricultural Process

Heat Cooperative Extension Service (CES) County Agents 


\section{LIST OF FIGURES (Concluded)}

Page

9-5 Use of Selected Information Sources: All Cooperative Extension Service (CES) County Agents ..................... 118

9-6 Use of Selected Inf ormation Sources: All Cooperative Extension Service (CES) State Specialists .................... 119

C-1 Letter of Introduction $\ldots \ldots \ldots \ldots \ldots \ldots \ldots \ldots \ldots \ldots \ldots \ldots \ldots \ldots \ldots \ldots$

D-1 Industrial Process Heat Questionnaire $\ldots \ldots \ldots \ldots \ldots \ldots \ldots \ldots \ldots \ldots \ldots \ldots$

D-2 Agricultural Process Heat Questionnaire $\ldots \ldots \ldots \ldots \ldots \ldots \ldots \ldots \ldots \ldots \ldots$

F-1 Solar Industrial and Agricultural Process Heat Data Tables........... 186 


\section{THIS PAGE}

WAS INTENTIONALLY

\section{LEFT BLANK}




\section{LIST OF TABLES}

Page

S-1 Comparative Usefulness of General Types of Information

on Industrial and Agricultural Process Heat (I/APH).

S-2 Value Assessment of Specific Industrial and Agricultural

Process Heat (I/APH) Information Products .................. xii

S-3 Sources Used to Obtain Solar Information................... xiii

S-4 Interest in Information on Solar Industrial Process

Heat (IPH) Topies .............................. xiv

S-5 Interest in Information on Solar Agricultural Process

Heat (APH) Topies ............................. xvi

S-6 Advanced Information Acquisition Methods Used $\ldots \ldots \ldots \ldots \ldots \ldots \ldots \ldots$ xvii

2-1 Solar Industrial and Agricultural Process Heat (I/APH)

Information Users .............................. 8

3-1 Completion of Interviews: Industrial and Agricultural

Process Heat (I/APH) Researchers ....................... 20

4-1 Completion of Interviews: Concentrating Collector

Manufacturer Representatives ....................... 36

5-1 Completion of Interviews: Total Nonconcentrating Collector

Manufacturer Representatives ...................... 48

6-1 Completion of Interviews: Industrial Process Heat (IPH)

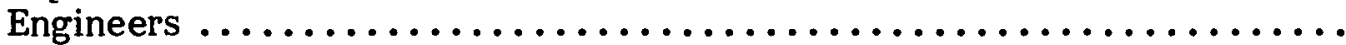

6-2 Levels of Involvement: Industrial Process Heat (IPH), Active

Solar Heating and Cooling (SHAC) Industrial, and All

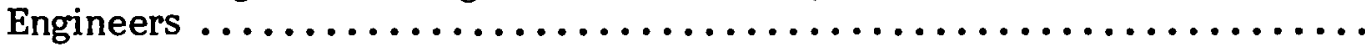

6-3 Levels of Informedness: Industrial Process Heat (IPH), Active

Solar Heating and Cooling (SHAC) Industrial, and All

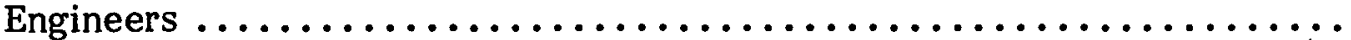

6-4 Years Since Most Recent Degree Awarded: Industrial

Process Heat (IPH) Engineers .......................... 64

6-5 Years In Current Profession: Industrial Process Heat (IPH)

Engineers ........................................... 65

6-6 Areas of Interest: Industrial Process Heat (IPH) Engineers . . . . . . . . . 65

6-7 Publications Read Which Included Information on Solar Energy:

Industrial Process Heat (IPH) Engineers 
LIST OF TABLES (Concluded)

Page

7-1 Completion of Interviews: Industrial Process Heat Educators $\ldots \ldots \ldots \ldots$

8-1 Completion of Interviews: State Agricultural Office

Representatives............................... 99

8-2 Areas of Interest: State Agricultural Office Representatives and Agricultural Process Heat (APH) County Agents ............. 101

9-1 Completion of Interviews: Agricultural Process Heat County $\Lambda$ gents $\ldots \ldots \ldots \ldots \ldots \ldots \ldots \ldots \ldots \ldots \ldots \ldots \ldots \ldots \ldots \ldots \ldots \ldots \ldots$

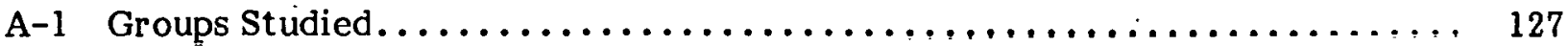

B-1 Cooperative Extension Service (CES): States Represented in Samples ........................................ 141

D-1 Selected Organizations About Which Industrial and Agricultural Process Heat (I/APH) Respondents Were Asked ................ 173

F-1 Groups and Combination Groups With Data Included in Appendix F . ................................. 182

F-2 Combination Groups $\ldots \ldots \ldots \ldots \ldots \ldots \ldots \ldots \ldots \ldots \ldots \ldots \ldots \ldots \ldots \ldots$

F-3 List of Solar Industrial and Agricultural Process Heat Duta Tubles 


\section{SECTION 1.0}

\section{INTRODUCTION}

This report describes the results of a series of interviews with potential users of information on solar industrial and agricultural process heat. These two applications have been combined in one report because of the confusion among those interviewed as to the exact demarcation between the two processes. These interviews, part of a larger st udy covering nine different solar technologies, attempted to identify:

- the type of information each distinctive group of information users needed, and

- the best way of getting information to that group.

This section explains the background of the study, places this report in the context of the overall program, and describes the structure of this report.

\subsection{BACKGROUND}

The rapid, widespread commercialization of solar energy will be necessary if the United States is to meet the energy crises of the next 50 years. But the use of solar energy will never reach meaningful levels without both the recognition that information transfer is essential to commercialization and the deliberate development of systems for the transfer of information. For example: scientists need the latest solar research results to enhance their own efforts; engineers and installers need performance data to design solar systems; public interest groups need environmental impact data to support solar technologies against conventional energy alternatives; potential owners of solar energy systems need cost information to make purchase decisions; the general public needs basic information to weigh which public policies to support.

In 1974 the Congress, noting the importance of information transfer and recognizing the value to the solar community of an integrated, comprehensive data collection and information dissemination system, called for the implementation of a Solar Energy Information Data Bank (SEIDB). In The Solar Energy Research and Development Act (P.L. 93-473) Congress stated that the SEIDB should be established "for the purpose of collecting, reviewing, processing, and disseminating information and data ... in all of the solar energy technologies."

The U.S. Department of Energy (DOE) has assigned the Solar Energy Resear ch Institute (SERI) the task of serving as the lead center to fulfill this Congressional mandate to collect all types of solar-related information, to convert it into a user-oriented format, and to disseminate this information to the widest possible range of persons and groups with an interest in solar energy. These groups range from decision makers at all levels of government to manufacturers of solar products; from solar architects, installers, and service persons to home or farm owners; and from banks and financial institutions to scientists and researchers. In accord, SERI's Inf ormation Systems Division (ISD) is now in the process of collecting solar information, building data bases, and preparing and disseminating information through a variety of products and services.

The long-range objective of the SEIDB is a centrally coordinated network to ensure that all individuals concerned with solar energy have prompt and efficient access to whatever 
information is necessary to support sound decisions. Ultimately this information will be accessible through a variety of means (publications, computer data systems, audiovisual products, the Solar Energy Information Center, inquiry and referral services, etc.) to serve the diverse requirements of the solar community.

\subsection{SOLAR ENERGY INFORMATION DATA BANK PROGRAM PLANNING}

In the past decade, information scientists have studied many organizations responsible for data collection and information product development. A consistent finding of this research is that a key to the successful, efficient operation of such an organization is to design the entire system with the potential information user in mind. It is essential that development of information products and data bases be targeted for specific users rather than merely developed spontaneously. The information users, their information needs, and the priority of those needs must all be identified before effective information products and services can be developed efficiently. To ensure that the SEIDB is responsive to the high-priority information needs of the solar community, the Information Market Research Section of ISW is performing the following tasks:

1. Defining the community of solar information users;

2. Setting priorities as to which groups of information users have the most important near-term information needs;

3. Determining the near-term information needs of the high-priority users;

4. Determining the information channels which can be effectively used to reach the high-priority users;

5. Determining what high-priority information needs are being met fully by existing products and services; and

6. Recommending additional, targeted, cost-effective information products and services to meet high-priority needs.

The results of the first two tasks are described in a previous document [1]. First, for each solar technology, those members or potential members of the solar community who will need solar information were identified; second, the relative importance of meeting the near-term inf ormation needs of each group of information users was described. This document provides guidelines to SEIDB planners as to who might be using the SEIDB and whose near-term needs are the most important.

The results of the third and fourth tasks are described in the current set of ten reports (see Section 1.3). 'I'hese reports document the high-priority information needs and the most familiar information channels for each of 86 groups which were interviewed by telephone.

There have been a few previous studies which asked homeowners what solar information they needed, but this is the only known study to provide data on the solar information that such groups as resear chers, manuf ac turers, ar chitects, engineers, instailers, lawyers, bankers, insurers, public interest groups, state energy offices, and agricultural extension agents themselves say they want.

The data from this study will be used along with other data to determine what new information products and services SERI, the SEIDB Network, and the entire solar infor- 
mation outreach community should be preparing for and disseminating to the solar community. These data will include (but not be limited to): contacts with SERI specialists; review of the Annual Operating Plans, Institutional Plans, and Program Plans of DOE and SERI; reviews of other solar literature; development of an "information user profile" data base from mailing list response cards; information user panels; direct contacts with members of the solar community at conferences, training sessions, etc.; visits to headquarters of national associations of users; and feedback provided by users of existing information products. Since information needs and priorities will continuously change, these tasks will necessarily be ongoing.

\subsection{REPORT CONTENTS}

This solar industrial and agricultural process heat report is one of ten issued on the results of these studies of solar energy information users. The full set of reports covers:

- Photovoltaics

- Passive Solar Heating and Cooling

- Active Solar Heating and Cooling

- Biomass Energy

- Solar Thermal Electric Power

- Industrial and Agricultural Process Heat

- Wind Energy

- Ocean Energy

- Solar Energy Storage

- General Solar Energy

Section 2.0 of this report describes the type of study conducted and the resulting constraints. The method used to select these groups is also described in Section 2.0. Several groups discussed in another report from this study also indicated an interest in informatinn on solar process heat. These groups are listed in Section 2.2.4. Sections 3.0 through 9.0 describe the results of studies of:

- Solar Industrial Process Heat Researchers and Agricultural Process Heat Researchers;

- Representatives of Manufacturers of Concentrating Collectors;

- Representatives of Manufacturers of Nonconcentrating Collectors;

- Plant Engineers, Industrial Engineers, and (nongovernment) Agricultural Engineers who had been involved with solar industrial process heat;

- Representatives of State Agricultural Offices who had been involved with solar agricultural process heat;

- Educators teaching college-level courses in solar industrial process heat; and

- Cooperative Extension Service (CES) County Agents who will be needing information on solar agricultural process heat. 
Except for the Manufacturer Representatives, these respondents were asked specifically about their needs for information on solar process heat. Manufacturer Representatives were asked the same questions, but about active solar heating and cooling or solar systems generally. In each of these sections describing study results, a standard presentation format has been used.

The appendices contain a list of all 86 groups interviewed (including the technologies other than process heat). They also contain a description of how the study was developed, a copy of the letter of introduction, a sample questionnaire, a description of the statistical tests used, and the data from the studies of the industrial and agricultural process heat groups. 


\section{SECTION 2.0}

\section{STUDY DESCRIPTION}

This section gives a brief description of the study. Appendix B gives additional information on how the study was designed and conducted. This section also explains how groups from the solar industrial and agricultural process heat community were selected as those to be sampled and gives a few comments on interpretation of study results. The study findings are reported in Sections 3.0 through 9.0.

\subsection{STUDY CHARACTERISTICS}

Between 3 September 1979 and 13 October 1979 Market Opinion Research, Inc. (INOR) of Detroit, Michigan-under subcontract to Solar Energy Research Institute (SERI)conducted telephone interviews with 86 distinct groups of solar information users. Approximately nine respondents were interviewed from each group. Interviews were based upon professionally reviewed and tested questionnaires (see Appendix D); they took an average of 18 minutes to complete. The 86 groups, selected to cover 9 solar technologies/applications, are listed in Appendix A. The results discussed in this report are from the 10 of those 86 studies which dealt specifically with solar industrial or agricultural process heat.

Studies of 86 groups, each interested either in one of nine different solar technologies or in solar technologies in general, provided an extremely broad view of the information needs of the solar community. Although the sample size of nine respondents per group was small, the data still proved to be quite adequate for planning purposes. It was possible to determine which information was the most important to the respondents and what was the best channel for disseminating that information. A variety of valid statistical tests were performed, both to compare the priorities a group gave to different information items and to compare the priorities different groups gave to the same item.

The respondents proved to be very cooperative. Considering the length and nature of the telephone interviews, it was surprising that only about $3 \%$ of the respondents terminated an interview or refused to be interviewed. This finding supported the interviewers' statements that the respondents were very interested in telling what they were doing in solar energy, in obtaining solar information, and in specifying what solar information would prove the most valuable. It was also observed that the number of respondents answering "don't know" or not answering a question was quite low. Including those cases where the potential respondent could not be reached within three attempts (or before the required number of interviews was completed), where the respondent refused to be interviewed, where the respondent terminated the interview prematurely, etc., the completion rate for the entire study was about $75 \%$. The completion rate for each individual group is given in the section in which that group is discussed.

\subsection{GROUPS STUDIED}

One of the most important tasks was the selection of the groups of potential users of solar information to be studied. Before this could be done, however, it was necessary to list the important groups constituting the solar industrial and agricultural process heat community and to develop a conceptual framework within which selections could be made. 


\subsubsection{Target Audiences, Classes, and Groups}

An important information science concept in developing information products and services is that of the "target audience" or "target group." These are generally defined as a collection of individuals or organizations who have similar information needs and information-acquiring habits. People in the same group tend to need information on the same subjects, at a similar technical level, and within a similar timeframe. In developing an inf ormation product program, it is important to begin with a typology that assigns information users who have similar needs to common groupings. This allows development of efficient, targeted inf ormation products to meet identified needs of specific users, without inundating other members of the solar community with unneeded information.

In Solar Information User Priority Study [1] such a typology was developed. Under this system members of the solar community were placed in distinct "user groups." A set of user groups formed a "user class" and a collection of user classes formed a "target audience." For more precise definitions:

- A User Group is the most basic category of information users who can be combined together under a single definitive title (e.g., Civil Engineers). A single information user group should be addressable by many specific information products. The purpose of defining distinct information User Groups is to identify a single set of users who can be served by the same information product (e.g., a civil engineers' handbook).

- A User Class is a set of information user groups which exhibit many common distinguishing characteristics (e.g., Facility or System Designers). A single inf ormation user class should be addressable by many general information products. The purpose of defining separate inf ormation User Classes is to identify sets of two or more groups of users who can be served by similiar information products (e.g., solar heating and cooling system design models).

- A Target Audience is a set of information user classes which exhibit some common distinguishing characteristics (e.g., Researchers). A single target audience should be addressable by one or more distinct types of information products. The purpose of defining sepurate information-user Target Audiences is to identify broad sets of users who can be served by the same generic types of information products (e.g., research-in-progress newsletters).

Following this system, all solar information users fall within one or more of five Target Audiences. These Target Audiences are:

Researchers - those who are actively involved in researching, developing, and testing of new state-of-the-art technical developments in solar energy.

Applications Technologists - those involved in translating research results into marketable equipment and services. This classification includes manufacture, distribution, sales, design, installation, and maintenance of solar systems or components.

Facilitators - those whose decisions or actions directly aid (in either a positive or negative manner) the commercialization of solar energy. Thus, Congressmen would be Facilitators in that they have the ability to pass legislation giving incentives; lobbyists in that they can affect legislation; state energy offices in that they can initiate demonstration projects; and the Environmental Protection Agency (EPA) in that it can forbid construction of a manufacturing plant at a specific site. 
Users or Prospective Users - those individuals or organizations who have already applied this type of solar energy technology in their operations or have a reasonable chance of doing so in the near future.

General Public - Individuals who are not likely to utilize solar energy in the near future. An important aspect of this audience is its ability to influence the course of solar development through political influence, pro or con.

Based upon this scheme, the solar process heat information user community has been defined. Table 2-l enumerates the user groups comprising the solar process heat information community and shows into which target audience each falls [1].

\subsubsection{Criteria for Selection of Groups to Study}

From Table 2-1, it is rapidly evident that there are many user groups who will eventually be needing inf ormation on solar industrial or agricultural process heat. The problem was, thus, to select those groups to be included as a part of this study. To determine which groups would be studied, each group was evaluated with respect to the following selection criteria:

- Appropriateness of using a structured telephone interview to collect information from the group on information needs and habits,

- Relative priority of the group's short-range or medium-range information needs, and

- Availability of a sample frame for the group.

First, for many groups, a structured telephone interview was not an appropriate method for defining information needs. It was not practical to interview DOE or an organization like the Electric Power Research Institute, or to survey a group like Congressional committee staff which would be too busy to respond. Rather than defining the information needs of these groups by telephone interview, they will be contacted directly in FY 1981 .

Second, only those groups with a high immediate or potential need for IAPH information were selected. Further, since fulfilling short-range information needs is critical, it was decided that in most cases those people who were already involved with solar process heat would be sampled. It was felt that these were the people who would be primary users of the SEIDB over the next few years. These groups had been identified earlier in the Solar Information User Priority Study [1].

Finally, for many of the groups, lists of persons to be inter viewed could not be developed or acquired. In the absence of sample frames, studies of such groups were not possible. (For more detail on sample frame development, see Appendix B.)

\subsubsection{Groups Included in the Solar Industrial and Agricultural Process Heat Study}

After all decision criteria and constraints had been applied, it was determined that studies of the following 10 groups would be conducted to ask respondents about their need for information on solar industrial or agricultural process heat: 
Table 2-1. SOLAR INDUSTRIAL AND AGRICULTURAL PROCESS HEAT (VAPH) INFORMATION USERS

Target Audiences

User Classes

User Groups

\subsection{Researchers}

1.1 DOE-Funded Researchers or Developers

Contractors

National Laboratories

1.2 Non-DOE, Federally-Funded Researchers or Developers

Nulimul Srienre Fonindation (NSH)

United States Department of Agriculture (USDA)

1.3 Non-Federally-Funded Researchers or Developers

Universities

Solar Manufacturers

Trade Research Associations

Independent Research Organizations

Fuel Industry

Chemical Industry

Other Industrial Solar Uses

State Agricultural Offices

Agricultural Solar Users

\subsection{Applications Technologists}

2.1 IPH- and APH-Related Manufacturers

Collector Manuf acturers

Component Manufacturers

2.2 IPH and APH Facility or System Designers

Industrial Architects/Engincers

System Designers/Engineers

Architectural/Engineering Design Firms

Mechanical Engineers

Mechanical; Heating, Ventilating and Air

Conditioning (HVAC) Engineers

Agricultural Engineers

2.3 Builders, Developers, or Contractors

General Contractors

$\Lambda$ rehitectural/Engineering Constu uetion Firms

Mechanical Engineering Contractors

Constr ucti on Engineers

Agricultural Engineering Contractors 
Table 2-1. SOLAR INDUSTRIAL AND AGRICULTURAL PROCESS HEAT (I/APH) INFORMATION USERS (Continued)

2.4 IPH and APH System Installers or Maintainers

Installers

Carpenters

Plumbers

Electricians

Sheet Metul Worker's

Solar Maintenance Workers

Construction Workers

2.5 IPH and APH Equipment Distributors

2.6 Technical Specialists for Utility, Government, Agricultural, Commercial, or. Industrial Organization Using an IPH and APH System Operations Managers Planners

2.7 Farm Managers, Greenhouse Managers, Livestock Breeders

\subsection{Facilitators}

3.1 Legislators or Staff Congressmen

Congressional Committee Staff

State Legislators

National Conference of State Legislators

3.2 Local Government Organizations

County Government Officials

Local Government Officials

Municipal Planners

Tax Assessors and Officials

County Agriculturul Offices

3.3 Government Solar-Active Organizations

DOE-Conservation and Solar Energy ( $C \& S E)$

DOE-Energy Inf ormation Administration (EIA)

DOE-Energy Research (ER)

DOE-Regional Solar Energy Centers (RSECs)

DUE-Kegional Energy Uffices

DOE-Energy Extension Service

United Stated Department of Agriculture (USDA)

Cooperative Extension Service

USDA-Other

National Center for Appropriate Technology (NCAT)

Tennessee Valley Authority (TVA)

DOE-Federal Energy Regulation Commission

International Energy Agency

State Governors' Offices

State Energy Offices 
Table 2-1. SOLAR INDUSTRIAL AND AGRICULTURAL PROCESS HEAT (I/APH) INFORMATION USERS (Continued)

State Solar Energy Offices

State Agricultural Offices

Municipal Energy Offices

3.4 Government Solar-Concerned Organizations

Food and Drug Administration (FDA)

Small Business Administration (SBA)

Internal Revenue Service (IRS)

Council on Environmental Quality (CEQ)

3.5 Nongovernment Solar-Active Organizations

Eolar Trade Associations

Solar Professional Societies

Sular Public Interest Gruups

Solar Lobbyists

3.6 Nongovernment Solar-Concerned Organizations

Public-Interest Organizations

Environmental Organizations

Chambers of Commerce

Nonsolar Professional Societies

Nonsolar Trade Associations

National Cattlemen's Association

Farmer Co-ops

Farmer's Education and Cooperative Union of America

American Farm Bureau Federation

Future Farmers of America

3.7 Regulatory, Codes, or Standards Community

Environmental Protection Agency (EPA)

Occupational Safety and Health Administration (OSHA)

American Society of Heating, Refrigerating and

Air Conditioning Engineers (ASHRAE)

American Nationai standards Institute (ANSI)

Building Officials and Code Administrators (BOCA),

Council of American Building Officials (CABO),

International Conf erence of Building Officials (ICBO),

Southern Building Code Congress (SBCC)

Am erican Soci ety of Ilechnical Engineers (ASME)

Better Business Bureaus

3.8 Utility Community

Electric Power Companies

Gas. Utilities

National Association of Regulatory Utility Commissioners

State Utility Commissions

Utility Trade Associations

Federal Power Marketing Agencies

Tennessee Valley Authority (TVA) 
Table 2-1. SOLAR INDUSTRIAL AND AGRICULTURAL PROCESS HEAT (VAPH) INFORMATION USERS (Continued)

3.9 Financial Community

Bankers

Vent ure Capital Brokers

Government Loan Agencies

USDA - Farmers Home Administration (FHA)

USDA - Commodity Credit Corporation (CCC)

Stock Brokers

\subsection{Legal Community}

3.11 Real Estate Community

3.12 Insurance Community

3.13 Educational Community

High School Science Teachers

University Faculty

Vocational Instructors

Career Counselors

Seminar Organizers and Instructors

3.14 Inf ormation Intermediaries

Federal Technical Libraries

Industrial Technical Libraries

Academic or Nonprofit Technical Libraries

Public Libraries

Federal Information Centers

On-Line Inf ormation Services

Bookstores

Film Distributors

3.15 Media

Newspapers or Magazines

Technical and Trade Journals

Television

Radio

Book Publishers

Newspaper Farm Editors of America

\subsection{Labor Organizations}

Steamfitters' Unions

Construction Unions

Sheet Metal Workers' International Association (SMWIA)

\subsection{Users or Prospective Users}

4.1 Government, Commercial, or Industrial Users

Uil Companies

Iron Foundaries 
Table 2-1. SOLAR INDUSTRIAL AND AGRICULTURAL PROCESS HEAT (VAPH) INPORMATION USERS (Concluded)

Alumina Industry

Cement Industry

Stone, Clay, and Glass Products Industry

Textile Mills

Brewers

Commercial Laundries

Food Processing Industry

Large Grain or Crop Drying Operations

Commercial Greenhouses

Forest Products Industry

Other Industrial Process Heat Users

1.2 Farming Uscr3

Farmers, Ranchers

\subsection{General Public}

Secondary School Students

College Students

Adults 
- Industrial Process Heat Researchers,

- Agricultural Process Heat Researchers,

- Representatives of Concentrating Collector Manufacturers,*

- Representatives of Nonconcentrating Collector Manufacturers,*

- Plant Engineers who were interested in industrial process heat,

- Industrial Engineers who were interested in industrial process heat,

- Agricultural Engineers who were interested in industrial process heat,

- Representatives of State Agricultural Offices who need information on agricultural process heat,

- Educators teaching college-level courses in industrial process heat, and

- Cooperative Extension Service (CES) County Agents who will be needing information on agricultural process heat.

The results from these studies are reported in Sections 3.0 through 9.0. Groups considered for the study, but for whom adequate sample frames could not be obtained included such groups as potential users of solar industrial process heat and potential users of agricultural process heat.

\subsubsection{Solar Process Heat-Concerned Groups Included in the General Solar Study}

Additionally, as a part of the overall study a number of groups were queried about their need for information on solar energy in general, rather than on a specific technology like solar process heat. While it was determined that all respondents in these groups had some involvement with solar energy, for many of them it was likely that this involvement was not, nor would it become, a primary factor in their professional work. Rather, for most-if not all-of them, solar energy was a new but minor issue which they were beginning to address within the scope of their existing jobs. Because each of these groups had peripheral interests in more than one solar technology, yet had not become fully involved with any, they were asked for general solar information needs rather than technologyspecific solar inf ormation needs.

The results of the general solar study are reported in another document [2]. For solar process heat the following seven groups were especially relevant because for each group at least five of the nine respondents indicated solar industrial or agricultural process heat was one of the areas in which they were "particularly interested in obtaining inf ormation":

- Public Interest Groups (APH, IPH),

- Utilities not known to have conducted solar experiments or demonstrations (APH, IPH),

- Real Estate Appraisers (APH, IPH),

*These Manufacturer Representatives were not asked specifically about process heat, but about solar heating and cooling generally. The results for both groups have been included for more than one technology in'reports in this series. 
- Information specialists at State CES Offices (APH),

- Agricultural engineering specialists at State CES Offices (APH),

- Insurers (APH), and

- Tax Assesors (APH).

The general solar energy report [2] also discusses the results of studies in which state solar/energy office representatives were asked about their general, rather than technology-specific, solar information needs. Ninety-four percent of these representatives were interested in solar industrial process heat information and $98 \%$ were interested in solar agricultural process heat information.

\subsection{DATA INTERPRETATION}

This subsection describes several points the reader should keep in mind in interpreting the data and results presented in the following sections.

\subsubsection{Impact of the Sample Frames: Who was Sampled?}

There were several ways in which the method of constructing the sample frames impacted the data. First, in some of the sample frames one geographic region was relatively over-represented, while another was relatively under-represented. For a study of sample size nine, however, such biases were generally not bothersome since the results were principally qualitative rather than quantitative.

Second, the sample frames were only as good as the sources. For example, the Smithsonian Science Information Exchange (SSIE) data base and DOE's Research in Progress (RIP) data base were principal sources in developing lists of researchers. The SSIE was not always current, of ten did not include the name of the correct principal investigator, and did not contain much of the nonfederally funded research. RIP had similar problems, varying greatly in quality according to which technology was involved. Each of these problems could cause biases as to which researchers were included and which were excluded from the samples.

Third, many arbitrary decisions were necessary in developing the sample frames. For example, it was important not to interview a respondent more than once, even if he or she was working in more than one technical area. Thus, if Researcher $\mathrm{X}$ at Company $\mathrm{Y}$ was listed as principal investigator both for one project in solar industrial process heat and for another in active solar heating and cooling, then $\mathrm{X}$ was arbitrarily assigned to one of the two technologies, usually to the one with the smaller set of names.

The most important advice for the reader is to study carefully the description of how the sample frame was developed for each individual group. Often a generic title was assigned to a group; the reader must review sample frame development carefully to understand just who was being studied. 


\subsubsection{Statistical Tests}

The statistical tests used are described in Appendix E. In the following sections test results are reported only if the statistical tests were significant at the $P<0.05$ level. Thus, if a test result indicated that a difference between two means was statistically significant $(P<0.05)$, it meant that there was a maximum of a 1 -in-20 chance that the two means were not different.

\subsubsection{Hypotheses Versus Conclusions}

Because of the limitations of sample size it was not always possible to draw definitive conclusions. In certain cases, when definitive conclusions could not be drawn, the authors have instead formed hypotheses based upon the results.

\subsubsection{Significance of Rankings}

One of the most valuable results of this study was the development of a ranked list of information topies or products which would be useful to the members of each group (for example, see Fig. 3-1). Typically, statistical significance tests (see Appendix E) indicated that the four-to-six top-ranked items were rated significantly higher than the bottom four-to-six items. Thus, typically there was no statistically significant difference between the top-rated item and the second-rated item-or even between the toprated and the fourteenth-rated item. If the sample size had been greater, the number of combinations in which one item was rated significantly higher than the other would also have been greater. Even if every sample size had been raised by a factor of 10, however, it is highly unlikely that all pairs of items would have had significantly diff erent ratings.

How, then, should the reader treat two items which were not significantly different in rating? Was there any meaning to the ranking system?

Yes, the fact that there were statistically significant differences between the top-rated and the bottom-rated items established the validity of the ranking scale as a whole. Despite the fact that two ratings are not significantly different, they still have the statistical property of being the Best Linear Unbiased Estimators. For example, even if Item . 1 (with a rating of 3.4) was not significantly greater than Item 2 (with a rating of 3.1 ), Item 1 should still be considered the more important need unless there is additional, outside information to the contrary. (In determining which information products to develop, of course, one must also consider additional factors such as the cost of the product, the proportion of the group which will be reached, and the degree to which the information need will be met.)

\subsubsection{Alternative Measures of Usefulness}

The ranking of selected information items (in usefulness to the respondent) was based upon the rating developed by assigning a "4" for each response of "essential," a "3" for "very useful," a "2" for "somewhat useful," and a " 1 " for "not at all useful;" summing the responses for the entire group; then dividing by the number of responses in the group. Using the rating was the preferable way to establish rankings within a group because it fully used the information on the differences between "essential" and "very useful," between "somewhat useful" and "not at all useful." 
There were several alternative ways of comparing the usefulness of items, one of which was to calculate the percentage of respondents who classified the item as either "essential" or "very useful." Using this percentage was quite handy in considering how useful a product designed for more than one group would be. For example, both "a calendar (of solar events)" and "lists of local lenders (etc.)" were examples of inf ormation products that would be designed for many groups to use. In comparing the two potential products as to usefulness, this method (calculating for each item the percentage of the respondents who considered the item either "essential" or "very useful") provided a much more meaningful comparison than, for example, summing the ranks for all groups.

\subsubsection{Combining Results From Different Groups}

It should be pointed out that combining results from all solar process heat groups interviewed will not provide unbiased estimates of the total solar process heat community. First, the proportions of respondents from one group interviewed in this study may not correspond to the proportion of such persons in the entire community. Second, the peculiarities of each individual sample frame were responsible for varying degrees of bias for each group. Third, some of the important groups in the solar process heat community were not interviewed (see Section 2.2).

Great care should be exercised in inter preting results from a combination of groups. It is too easy to get the impression that one product can fully meet the needs of all groups when, in fact, it may only partially meet the information needs of some of the groups involved.

\subsubsection{Specific Information Products}

Several specific information products were included among the items for which usefulness was assessed. It is important that responses to these items not be interpreted as totally generic responses. People who gave "a bibliography of general readings on solar industrial process heat" a low rating may have done so either because of the level and content of the subject matter (i.e., general readings on solar process heat) or because of the format (i.e., bibliography). These people may or may not want bibliographies on other topics.

\subsubsection{Information Sources}

Another important question investigated how many respondents had used specific information sources. In using these results to plan how specific information is to be transmitted, it will be essential to specify fully both the information products or services and the groups to be reached bef ore making the final decision of which inf ormation channels are to be used. One cannot assume, for example, that the two or three top-rated sources should be used for all, or even most, of the information transmissions to the group.

There were two other issues related to this question. The first was the decision not to ask respondents whether they had used SERI as an information source. The reasons are discussed in Appendix D.

The second issue concerned possible bias in responses to the question "have you obtained any solar information directly from the U.S. Department of Energy?" The intent of the 
question was to find out if respondents had contacted DOE directly for information, rather than if they had obtained DOE-produced information from other sources [such as SERI, National Technical Inf ormation Service (NTIS), Government Printing Office (GPO), National Solar Heating and Cooling Information Center (NSHCIC), Regional Solar Energy Centers (RSECs), libraries, etc.]. There was, however, no assurance that respondents interpreted the question in this light. In cases where the response "directly from DOE" was high, there was the possibility that respondents were referring to information authored or funded by DOE but obtained from other sources. 


\section{SE尺r|*}


SECTION 3.0

\section{NDUSTRIAL AND AGRICULTURAL PROCESS HEAT RESEARCHERS}

\subsection{DESCRIPTION OF RESPONDENTS}

\subsubsection{Description of Sample}

This section describes the results of two telephone studies to determine the needs of researchers for information on solar industrial and agricultural process heat. In one study 9 solar Industrial Process Heat (IPH) Researchers were interviewed; in the other, 9 solar Agricultural Process Heat (APH) Researchers were interviewed.

The sample frame for IPH Researchers was constructed by reviewing the September 1978 U.S. Department of Energy (DOE) Solar Energy for Agricultural and Industrial Process Heat (AIPH) Program Summary [3], and by searching the Current Research Information System (CRIS) [4], the Smithsonian Science Information Exchange (SSIE) [5], and the Energy Research in Progress (RIP) [6] data bases. Only those projects in progress during some part of FY 1978 or FY 1979 were included. From the data base searches, projects were identified by the terms solar process heat or IPH. APH projects were extracted by visual inspection of search output to identify those that were farm based (see below). Entries without contact names (i.e., principal investigator) were eliminated. Duplicates between this list and any other lists of Researchers were eliminated on all other lists. No organization was sampled more than once within this group. After all adjustments were made, the 9 interview candidates were randomly selected from a sample frame of 55 names.

The sample frame for APH Researchers was constructed by reviewing the DOE AIPH Program Summary [3] and by searching CRIS [4], SSIE [5], and RIP [6] files. Only those projects in progress during some part of FY 1978 or FY 1979 were included. Selection of APH (rather than IPH) projects and duplicates were handled the same as described for the IPH Researchers. Duplicates were individuals' names rather than organizations, so that the same organization may still have been sampled more than once in this study. The same organization was sampled more than once within the APH Researcher sample frame ( 2 organizations occurred twice). After all adjustments were made, the 9 interview candidates were randomly selected from a sample frame of 27 names.

Respondents. In making the telephone calls to contact the randomly-selected interview candidates, it sometimes occurred that the person could not be reached. In this event another randomly selected name was substituted for the original name. When individuals were contacted it was verified that they had been involved in solar process heat research (industrial or agricultural, as appropriate for each group) and that they would be needing information on solar process heat within the next year. If they were not both involved and needing information, they were asked if they could ref er the interviewer to someone else in their organization who would be an appropriate respondent. If such a referral was made, a call was then made to this new candidate; if no intraorganizational referral was made, a new candidate was randomly selected from the sample frame. The results of this process may be seen in Table $3-1$. 
Table 3-1. COMPLETION OF INTERVIEWS: INDUSTRIAL AND AGRICULTURAL PROCESS HEAT (VAPH) RESEARCHERS

\begin{tabular}{|c|c|c|}
\hline \multirow{2}{*}{ Event } & \multicolumn{2}{|c|}{ Number of Candidates } \\
\hline & IPH & APH \\
\hline Interview completed with sample frame candidate & 8 & 8 \\
\hline Interview completed with ref erral candidate & 1 & 1 \\
\hline Refusal or candidate termination & 0 & $\mathbf{0}$ \\
\hline \multicolumn{3}{|l|}{$\begin{array}{l}\text { Contact attempted: could not reach candidate } \\
\text { within three attempts or before interviews }\end{array}$} \\
\hline & 3 & 0 \\
\hline Sublotal & 12 & 9 \\
\hline \multicolumn{3}{|l|}{$\begin{array}{l}\text { Contact attempted: invalid candidate (e.g.; in- } \\
\text { appropriate field of interest, no telephone) }\end{array}$} \\
\hline TOTAL & 16 & 9 \\
\hline Sample frame error rate ${ }^{a}$ (Percent) & 25 & 0 \\
\hline Completion rate ${ }^{b}$ (Percent) & 75 & 100 \\
\hline
\end{tabular}

Comparisons. For additional insight into the information needs and information habits of these two groups of solar Process Heat Kesearchers, results from these groups are compared to the results from all of the researchers interviewed in this study (All Researchers). The list of all the groups contained in All Researchers can be found in Table F-2 of Appendix F. In performing any statistical comparisons, the totals for IPH Researchers and/or APH Researchers have been subtracted from the totals for All Researchers. The data for IPH Researchers, APH Researchers, and All Researchers can be found in Appendix F.

\subsubsection{Current Status of Respondents}

Role. Four of the IPH Researchers were employed by universities, 1 by the research center of a large manufacturer, 2 by other manufacturers, and 2 by national laboratories. Seven of the APH Researchers were employed by universities, 1 by a U.S. Department of Agriculture (USDA) research center and 1 by another agricultural research center.

Current activities of the IPH Researchers included three research projects: R\&D in collector design, applications for specific collectors, and the behavior and stability of saltgradient solar ponds used for water heating and refrigeration. Other activities included: managing solar IAPH projects, demonstration of solar industrial process steam applications, development of concentrating collector tracking controls, designing and supplying collector systems, marketing and operating a commercial dehydrator, kilndrying malt, hospital laundry clothes drying, and "wind-collector" design. 
Four of the 9 APH Researchers were currently involved with crop drying projects (corn, peanuts, fruits, and vegetables): research, exploration of concepts for solar drying, pilot tests of a variety of collectors, and testing of economic feasibility. Two were involved with agricultural space heating: animal shelters and evaluation of inexpensive collectors. Other activities mentioned included: building greenhouses to provide heat, crop drying at commodity "terminal storage systems" using solid dessicants, solar collectors for fish drying, collecting data, and writing reports.

Involvement. Seven of the 9 (78\%) IPH Researchers said that they were "very involved" with solar process heat compared to 4 of the 9 (44\%) APH Researchers. This compares to 107 of the 181 (59\%) All Researchers who were "very involved" with their respective solar technologies.

Informedness. Five of the $9(56 \%)$ IPH Researchers considered themselves "very informed" compared to 4 of the 9 (44\%) APH Researchers and 117 of the 181 (65\%) All Researchers.

Need for Information. All respondents indicated they would need information either on or off the job in the next year. Only 2 of the 9 (22\%) APH Researchers indicated they would need information on solar agricultural process heat outside the job while 8 expected to need information on the.job. IPH Researchers were not asked about off-thejob information needs, as it was considered unlikely that they would respond affirmatively. Only one other group of Researchers interviewed in this study was as unlikely as were the APH Researchers to need off-the-job information.

\subsubsection{Background of Respondents}

Four of the 9 IPH Researchers and 7 of the 9 APH Researchers held a PhD. The other 2 APH Researchers held master's degrees, while 3 of the IPH Researchers held master's degrees and 2 held bachelor's degrees. In terms of proportion of advanced degree holders (beyond bachelor's), the IPH Researchers with 78\% were more similar to All Researchers (80\%), than were the APH Researchers with 100\%.

Only 2 of the IPH Researchers had degrees granted within the past 10 years and 7 from 10-20 years ago. Four of the APH Researchers had received their most recent degree within the last 10 years, 3 from 10-15 years ago, and 2 over 25 years ago.

Most (6) of the IPH Researchers held degrees in engineering (aeronautical, chemical, mechanical, science). The remainder (3) held degrees in physics. Two respondents were currently teaching. Other professions described were: manager of solar projects, solar manufacturer, project engineer, agricultural or mechanical engineer, process heat engineer, research administrator, and research associate. Five of the IPH Researchers had been in their current profession for 3-5 years, 1 for 6-10 years, and 3 of them for over 10 years.

Most (7) of the APH group also had their most recent degrees in engineering (agricultural, electrical). One held a degree in agronomy and 1 in food science. Five were currently educators ( 1 was a researcher as well). Two respondents in this group gave their present prof ession as engineer, 1 as an agronomist, and 1 as an expert in fruit and vegetable harvesting operations. Two had been in their current profession for 5 years or less, 3 for 6-10 years, and 4 for over 10 years. 


\subsection{INFORMATION NEEDS OF RESPONDENTS}

\subsubsection{Technical Areas}

IPH Researchers were asked to choose those areas of solar industrial process heat in which they were "particularly interested in obtaining information." Eight of the 9 were interested in "hot water," 7 of the 9 in "low-temperature steam" and "refrigeration." Six were interested in "hot air" and 5 in "high-temperature steam," but only 3 were interested in "direct heat."

One IPH Researcher also volunteered an interest in electrical cogeneration.

When APH Researchers were asked to choose those areas of solar agricultural process heat in which they were "particularly interested in obtaining information," they were found to be most interested (6 of the 9 ) in "grain drying" and "crop drying." Five of the 9 were interested in "livestock shelter heating" and "food processing." They were least interested (2 of the 9) in "greenhouses."

Four of the APH Researchers volunteered that they were also interested in other areas: integration of solar and other renewable energy sources, water heating for farm buildings (including homes) (2), and design parameters for biomass heaters.

\subsubsection{Types of Information}

Both IPH and APH Researchers were asked to name the information about solar process heat that was important for them to obtain. All 9 of the IPH Researchers volunteered one or more items of information which they considered important. Three respondents considered cost information important. Other items included: operating experience from other projects (world-wide information), current reports on other projects (perhaps in newsletter form), concentrating collectors, storage and desiccant materials, amount of heat required for various applications, ways to provide lower costs with solar ponds, current opportunities for IPH, and potential incustrial partners.

Eight of the 9 APH Researchers volunteered one or more items of information which they considered important. Mentioned were; basic energy data, economic analyses, detailed meteorological data, poultry house heating, drying characteristios of grain, design parameters for air collectors, new hardware innovations, solar applications in food processing, up-to-date reference lists, solar collector designs, construction details, applications for agriculture, and feasiblity of APH systems.

Information that several IPH Researchers volunteered they needed but were unable to get included: results of other projects (including government- and private-sponsored and overseas), cost and performance, and good glazing materials.

Several APH Researchers also volunteered that there was information they needed but were unable to get. Two mentioned weather and insolation data (with more frequent readings and for wider geographic areas). Also mentioned were information on materials for solar system components, and standard design products and handbooks.

Choice Between Specific Needs. A list of 11 types of solar process heat information products and 13 or 14 types of solar process heat information categories was read to each 
respondent. Each respondent described the usefulness of each particular item by assigning it a value of "essential," "very useful," "somewhat useful," or "not at all useful." The results are given in Fig. 3-1 for IPH Researchers and Fig. 3-2 for APH Researchers. For the purpose of comparison, Fig. 3-3 displays the results for All Researchers and is not limited to process heat inf ormation items, but cuts across solar research technologies.

Both groups of Process Heat Researchers gave the cost information category high ratings as a class, including the following items in their five top-rated information categories/products:

- Costs of installing and operating a solar process heat system compared to a conventional system,

- Cost and performance of systems,

- Research in progress,

- Climatological data, and

- A technical description of how a particular system works.

IPH Researchers also gave high ratings to:

- System diagrams or schematics.

APH Researchers also gave high ratings to:

- Design handbooks, installation handbooks, or reference tables; and

- Manual methods for sizing and predicting performance or costs.

IPH Researchers assigned their lowest relative ratings to:

- Educational institutions and other organizations offering courses,

- A nontechnical description of how a particular system works; and

- Institutional, social, environmental, and legal aspects.

APH Researchers assigned the lowest relative ratings to:

- How to market and sell solar systems;

- A nontechnical description of how a particular system works;

- Local building codes or other regulations;

- Marketing statistics and sales projections; and

- Solar energy programs, research, industries, and markets outside the United States.

Statistical tests indicated that for IPH Researchers differences between the six highestrated and three lowest-rated items were significant $(P<0.05)$. Similarly, differences between the seven highest-rated and five lowest-rated items for APH Researchers were statistically significant $(P<0.05)$. 
Question \#8. I will read a list of potential information or information products on solar systems. For each, please tell me how useful that information would be to you. Would the following be: essential, very useful, somewhat useful, or not at all useful?

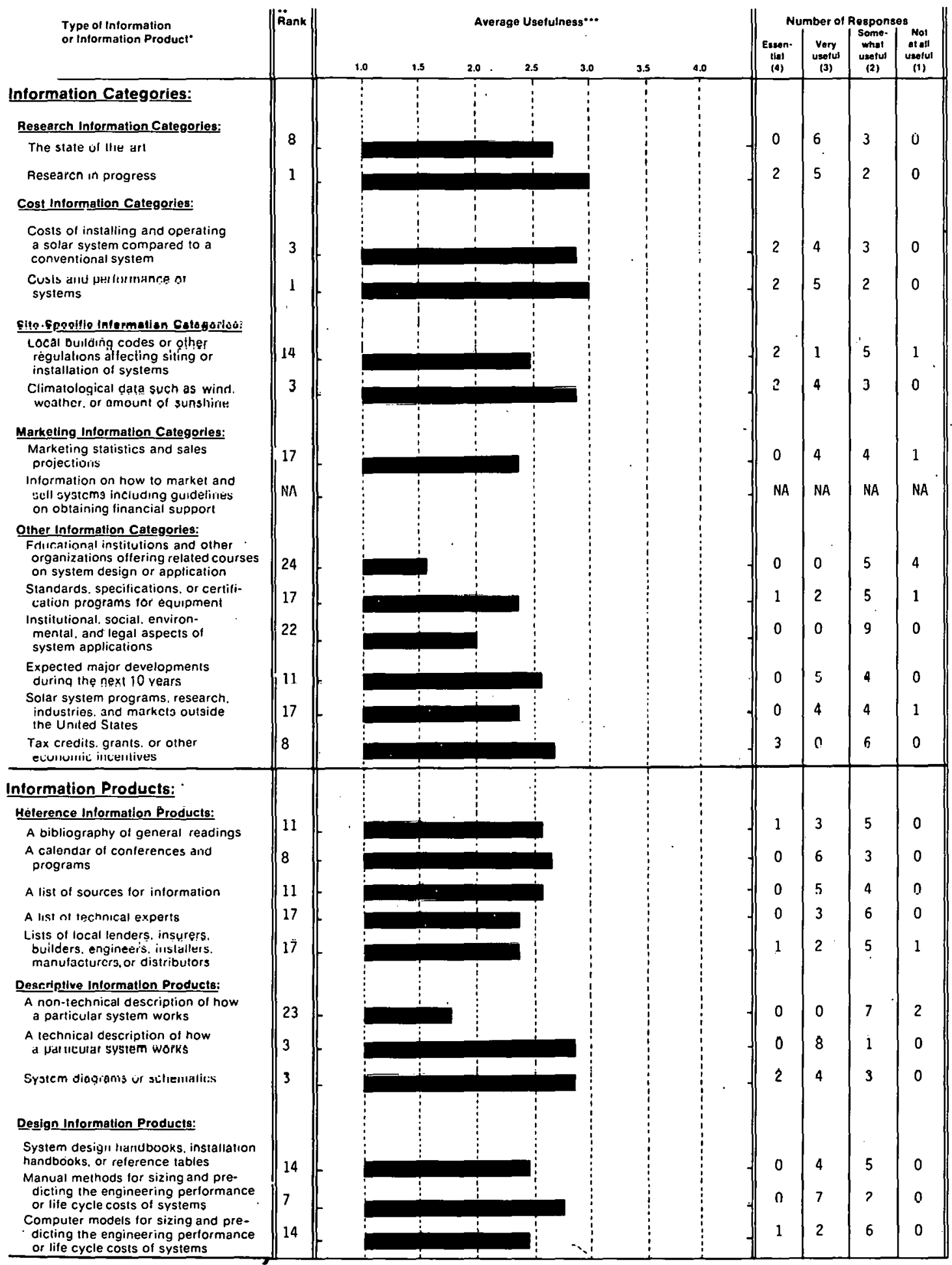

Each sample trame of users was questioned on intormation and intormation products in the context of their specific technology. For example, biomass siample trames wete

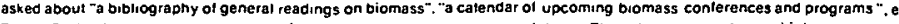
Rank-Eachintormalion proucl was assigned a rank based " nighesi ranking was then assigned a "4"

... Average usetulness was calculated by assigning the responses on a $1-4$ scale from a " 4 " tor "essential" to a " 1 " tor "not very usefur".

Figure 3-1. Usefulness of Selected Information Items: Industrial Process Heat Researchers 
Question \#8. I will read a list of potential information or information products on solar systems. For each, please tell me how useful that intormation would be to you. Would the following be: essential, very useful, somewhat useful, or not at all useful?

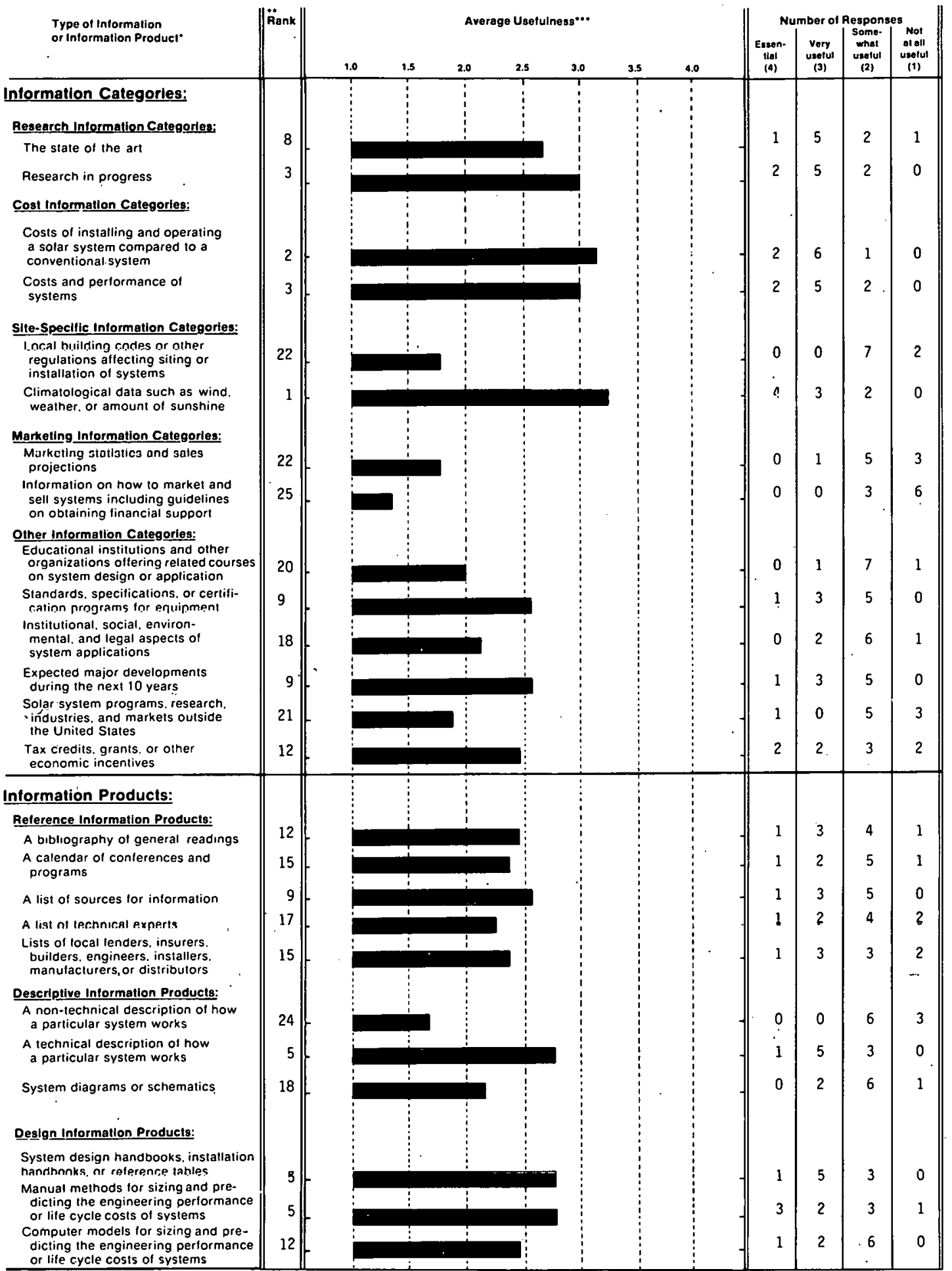

Far.h samnle trame of users was questinner nn intnrmatinn and intormation products in the contoxt of their specitic technology. Fol oxamplc. biomass sample frames weie

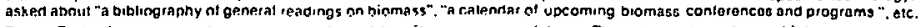

Rank - Eachintormation product was assigned a rank based on average uselulness. Thus. the product with the highest average usefulness was assigned the rank of "I": the product with ine lowest average useluiness would ber

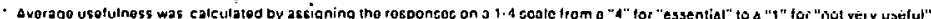

Figure 3-2. Usefulness of Selected Information Items: Agricultural Process Heat Researchers 
Question \#8. I will read a list of potential information or information products on solar systems. For each, please tell me how useful that information would be to you. Would the following be: essential, very useful, somewhat useful, or not at all useful?

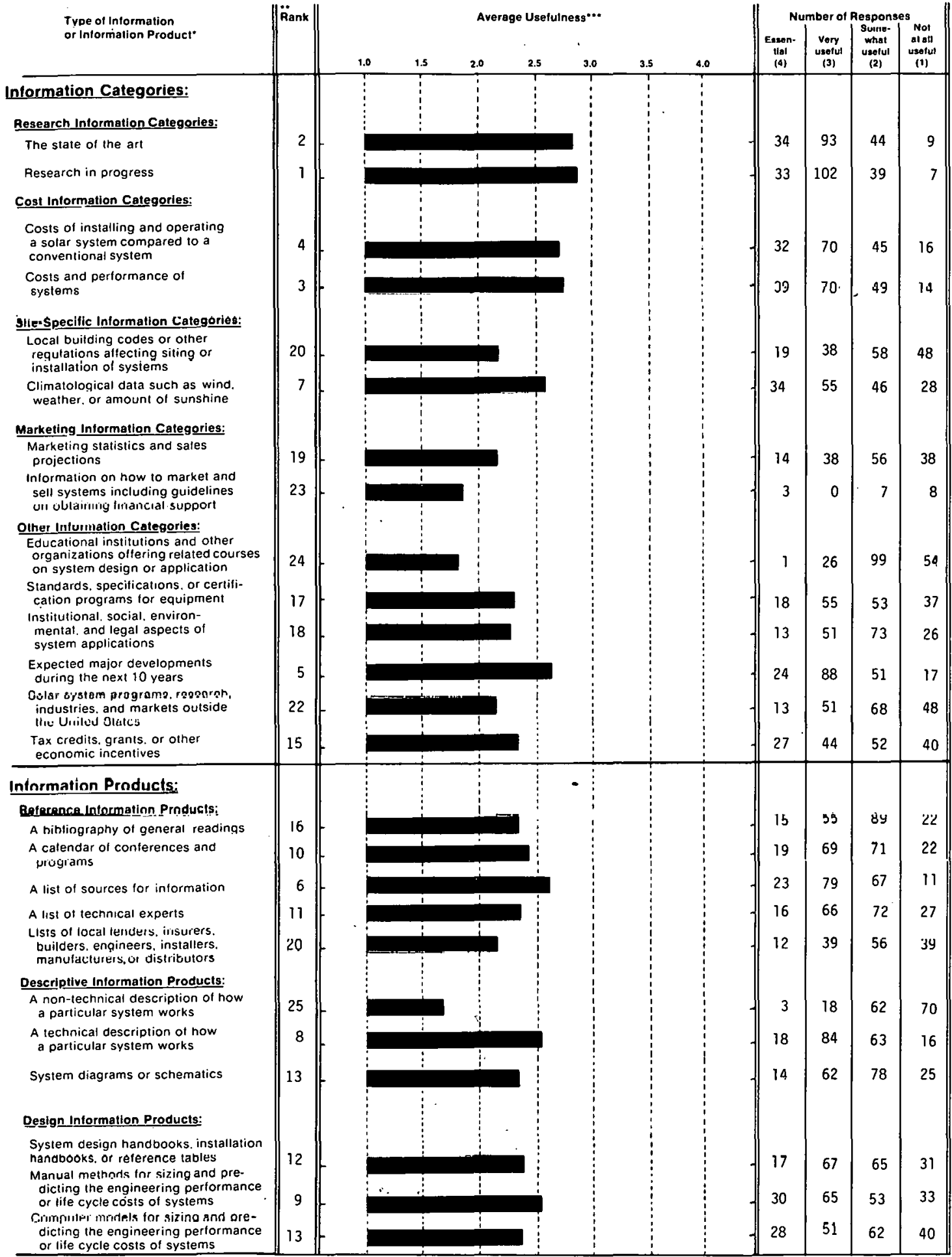
Each sample trame of users was questioned on information and information products in the contexl of their specific technology. For example, biomass sample trames were
asked about "a bibliography of general readings on biomass"." a calendar of upcoming biomass conferences and programs ". etc. Rank - Eachinformation producl was assigned a rank based on avefage usefulness. Thus, the product with the highest average usefulness was assigned the rank of " 1 -" the product with the lowest average usefulness would be ranked "25" where all items were asked. "It two or more information products were lied for 2 no, they were both assigned a "2". The nex

Average

Figure 3-3. Usefulness of Selected Information Items: All Researchers 
It should be noted that these lower-rated items were not necessarily of no worth to these Researchers. For example, 1 of the 9 (11\%) APH Researchers thought "solar energy programs ... outside the United States" was "essential." Thus, these information categories/products could be useful to some process heat Researchers, but were of a lower relative priority to each entire group.

Statistical tests were also used to determine whether the IPH Researchers rated any of these inf ormation items significantly higher (or lower) than they were rated by the APH Researchers or by All Researchers. Some groups, however, tended to give higher scores in general than did other groups. To compensate for this effect, these statistical tests compared the "relative rating" given by one group to the "relative rating" given by the other groups. The procedure for calculating the relative rating is described in Appen$\operatorname{dix}$ E. The average overall rating IPH Researchers gave to all items was 2.5l; for APH Researchers it was 2.40; and for All Researchers, 2.41.

In comparing the results for IPH Researchers with those for APH Researchers, IPH Researchers were found to give significantly $(P<0.05)$ higher ratings to "system diagrams or schematics" and significantly lower $(P<0.05)$ ratings to "educational institutions." It was interesting to note that IPH Researchers were less interested in "system diagrams or schematics" than APH Researchers.

IPH Researchers also gave significantly $(P<0.05)$ lower ratings than did All Researchers to "educational institutions." They gave somewhat higher ratings to "system diagrams or schematics" and "tax credits," but lower ratings to "state of the art" and "expected major developments."

APH Researchers gave significantly $(\mathrm{P}<0.05)$ higher ratings to "climatological data" than All Researchers, and somewhat higher ratings to "standards" and "system design handbooks." APH Researchers appeared less interested, however, in "state of the art" than were All Researchers.

\subsection{ACQUISTION OF INFORMATION BY RESPONDENTS}

\subsubsection{Use of Selected Information Sources}

Process Heat Researchers were asked which of 20 different potential sources of solar information they had used in the past few years. For this question the respondents were not asked if they had obtained information on solar process heat, but instead were asked if they had obtained any solar inf ormation from each specific source. Thus, the question sought to determine which information sources were the most familiar to respondents. The results for the IPH and APH groups are shown in Figs. 3-4 and 3-5. For comparison, Fig. 3-6 shows the results for All Researchers.

'l he inf ormation sources mentioned most of ten by IPH Reseur chers were:

- Workshops, conferences, or training sessions;

- Periodicals, newspapers, or magazines;

- An organizational library or a local library;

- 'I'he Government Printing Office (GPO); 
Question \#11. In the past few years, have you obtained any type of solar information from any of the following sources?

\section{Information Sources}

Public Media:

Radio or TV

Periodicals, newspapers or magazines

\section{Private Solar-Involved Organizations:}

Private solar energy or environmental organizations

The local chapter or national headquarters of International Solar Energy Society (ISES), including their publications

The local chapter or national headquarter's of Solar Energy

Industries Association (SEIA), including their publications Contacts witn prolessionals :

An installer, builder, designer or manufacturer of solar systems

Workshops. conferences or training sessions

\section{Information Services*:}

Your organizational library or a local library

A commercial data base; for example, Lockheed, SDC, BRS

Smithsonian Science Information Exchange (SSIE)

A Federal library or information center; for example, the National Agricultural Library or the Environmental Data System

The Government Printing Office (GPO)

National Technical Information Service (NTIS)

Technical Information Center at Oak Ridge (TIC)

\section{Government Solar-Involved Organizations}

Directly from the U.S. Department of Energy

National Solar Heating \& Cooling Information Cente

Regional Solar Energy Centers

State Eneryy or Solar Offices

Other:

Some other state or local government office or publication

A puplic utility company
Percentage Responding Yes *

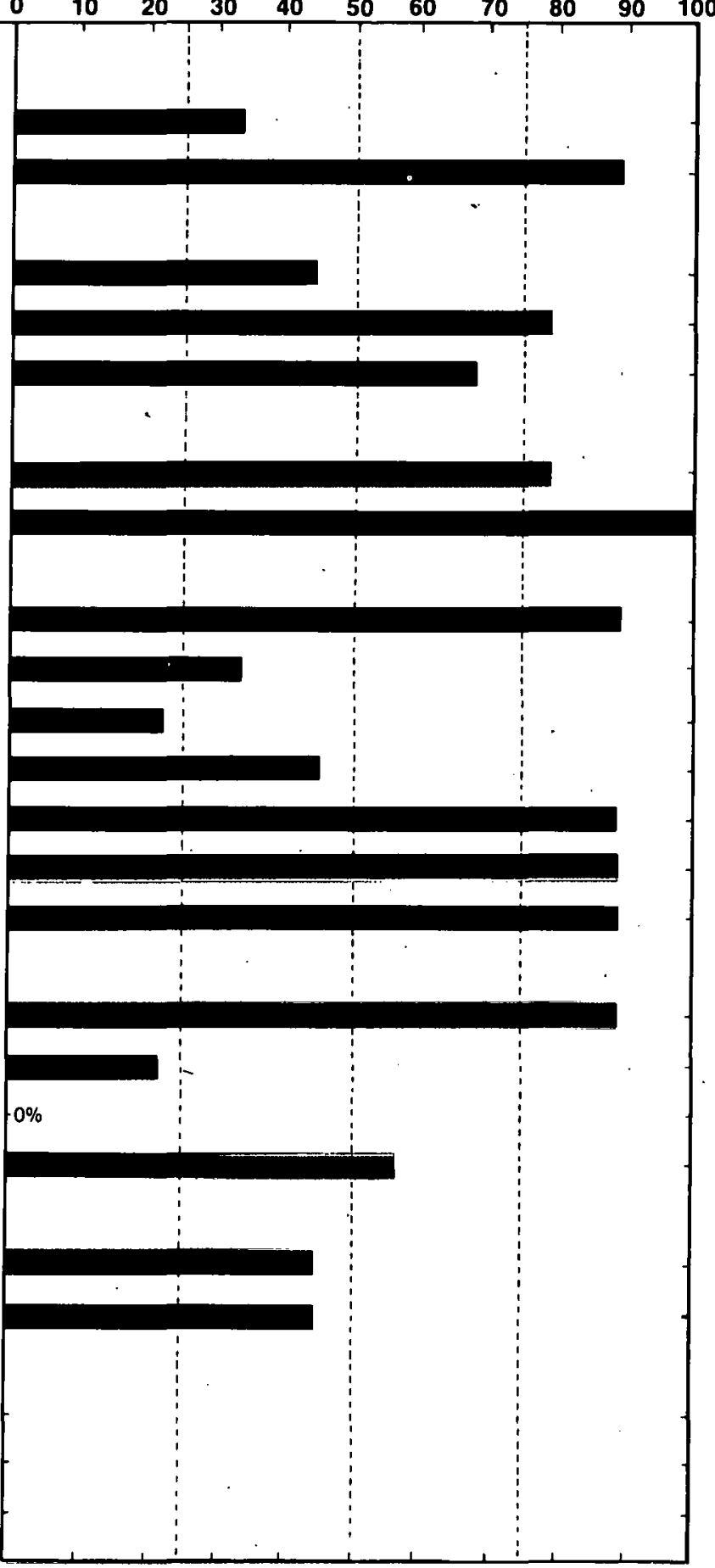

- Services and centers whose primary purpose is to disseminate information.

- These data are based upon a total of 9 respondents.

Figure 3-4. Use of Selected Information Sources: Industrial Process Heat Researchers 
Question \#11. In the past few years, have you obtained any type of solar information from any of the following sources?

Information Sources

Public Media:
Radio or TV
Periodicals, newspapers or magazines

Private Solar-Involved Organizations:

Private solar energy or environmental organizations

The local chapter or national headquarters of Internationa Solar Energy Society (ISES), including their publications

The local chapter or national headquarters of Solar Energy Industries Association (SEIA), including their publications Contacts with Professionals:

An installer, builder, designer or manufacturer of solar systems

Workshops, conferences or training sessions

\section{Information Services*:}

Your organizational library or a local library

A commercial data base: for example. Lockheed. SDC. BRS

Smithsonian Science Information Exchange (SSIE)

A Federal library or information center: for example, the National Agricultural Library or the Environmental Data System

The Government Printing Office (GPO)

National Technical Information Service (NTIS)

Technical Information Center at Oak Ridge (TIC)

\section{Government Solar-Involved Organizations}

Directly from the U.S. Department of Energy

National Solar Heating \& Cooling Information Centel

Regional Solar Energy Centers

State Energy or Solar Offices

Other:

Some other state or local government office or publication

A public utility company

Sources for this specific sample frame**:

USDA, including the Cooperative Extension Service
Percentage Responding Yes $\cdots$

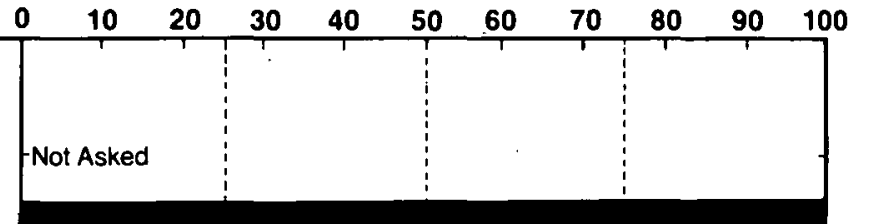
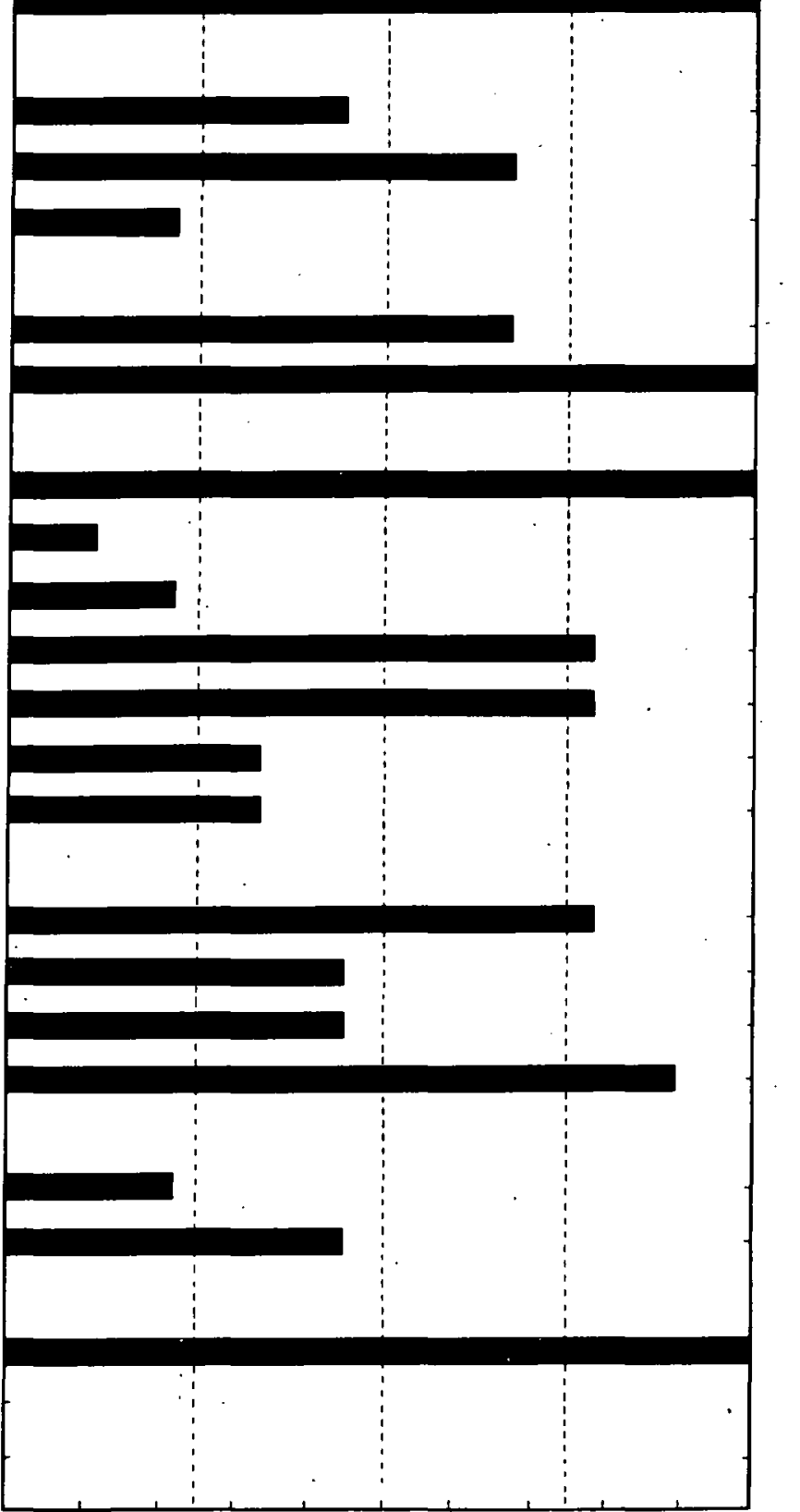

- Services and centers whose primary purpose is to disseminate information.

- Some sample frames were questioned about additional information sources which are applicable to their technology. For example. the manufacturers of biomass conversion equipment were also asked if they have obtained any type of solar information from: "the local or national office of the U.S. Uepartment oi Agriculuture, Inc.luding Extensiunl dild Fuitesliy."

... These data are based upon a total of 9 respondents.

Figure 3-5. Use of Selected Information Sources: Agricultural Process Heat Researchers 
Question \#11. In the past few years, have you obtained any type of solar information from any of the following sources?

Information Sources

Percentage Responding Yes “

\section{Public Media:}

Radio or TV

Periodicals, newspapers or magazincs

Private Solar-Involved Organizations:

Private solar energy or environmental organizations

The local chapter or national headquarters of International Solar Energy Society (ISES), including their publications

The local chapter or national headquarters of Solar Energy Industries Association (SEIA), including their publications Contacts with Professionals:

An installer, builder, designer or manufacturer of solar systems

Workshops, conferences or training sesșions

\section{Information Services*:}

Your organizational library or a local library

A commercial data base; for example, Lockheed, SDC, BRS

Smithsonian Science Information Exchange (SSIE)

A Federal library or information center; for example, the National Agricultural Library or the Environmental Data System

The Government Printing Office (GPO)

National Techniçạl !ntọrmation Service (NTIS)

Technical Information Center at Oak Ridge (TIC)

Government Solar-Involved Organizations

Directly from the U.S. Department of Energy

National Solar Heating \& Cooling Information Center

Regional Solar Energy Centers

State Energy or Solar Offices

Other:

Some other state or local government office or publication

A puhlir: utility company

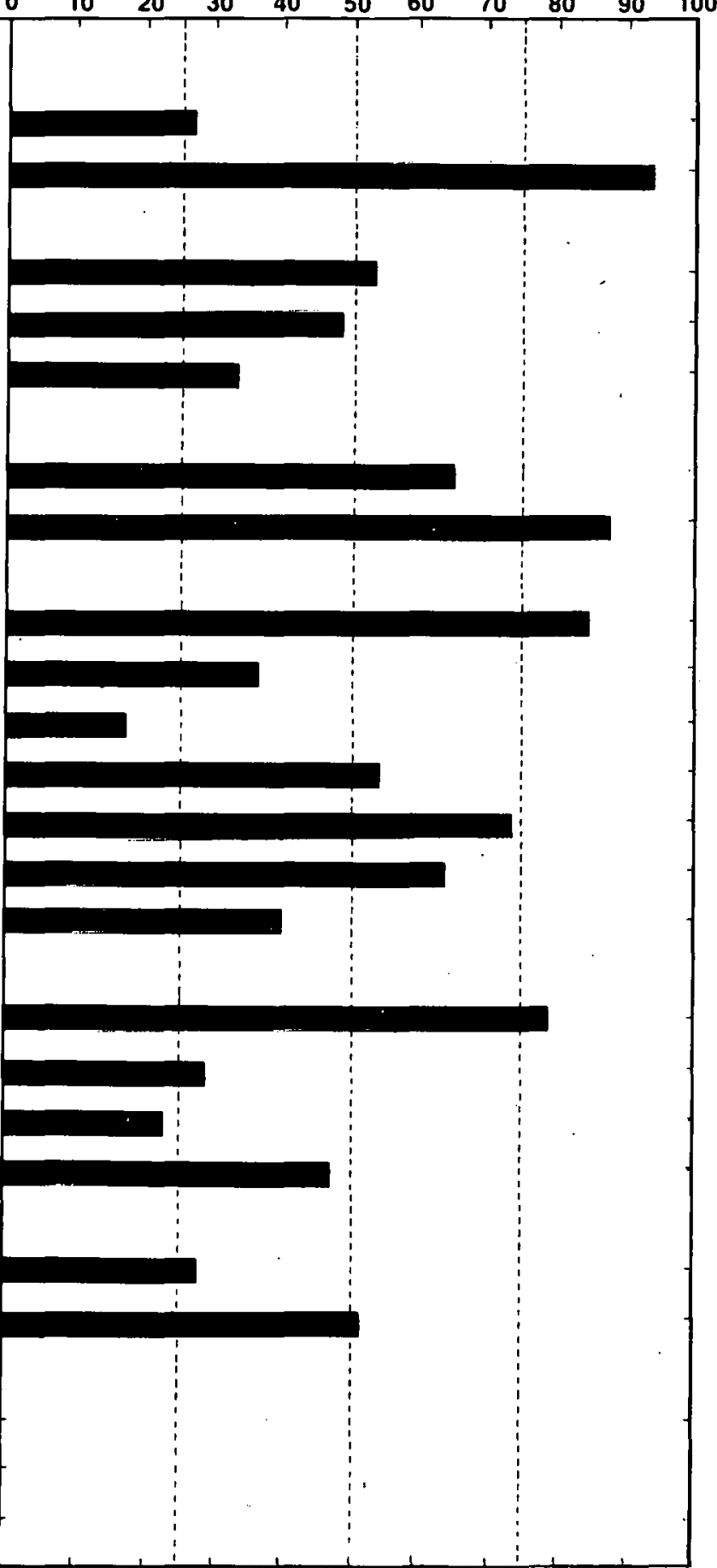

$\therefore$ Services and centers whose primary purpose is to disseminate information.

These data are based upon a total of 181 respondents. 
- National Technical Inf ormation Service (NTIS);

- Technical Information Center (TIC);

- Directly from DOE;

- The International Solar Energy Society (ISES); and

- An installer, builder, designer or manufacturer of solar systems.

Those mentioned most often by APH Researchers were:

- Periodicals, newspapers, or magazines;

- Workshops, conferences, or truining sessions;

- An organizational library or a local library;

- USDA;

- State energy or solar offices;

- A federal library or information center;

- GPO; and

- DOE.

The information sources mentioned least often by IPH Researchers were:

- Regional Solar Energy Centers (RSECs),

- Smithsonian Science Information Exchange (SSIE),

- National Solar Heating and Cooling Information Center (NSHCIC),

- Radio or TV, and

- A commercial data base.

The information sources used leust often by APH Researchers were:

- A commercial data base,

- Solar Energy Industries Association (SELA),

- SSIE,

- Some other state or local government office or publication,

- NTIS, and

- TIC.

The most interesting difference was the much lower use of SEIA, NTIS, and TIC by the APH Researchers.

\subsubsection{Membership in Solar-Interested Organizations}

Eight of the 9 IPH Researchers studied were members of a professional, technical, or other organization with an interest in solar enegy. The organizations (and the numbers of times mentioned) were: 
- American Association of Physics Teachers,

- American Institute of Chemical Engineers,

- American Physical Society (2),

- American Society of Agricultural Engineers (ASAE) (2),

- American Society of Heating, Refrigerating and Air Conditioning Engineers (ASHRAE),

- American Society of Mechanical Engineers (3),

- California Solar Energy Association,

- Institute of Electrical and Electronics Engineers (IEEE),

- ISES (2),

- National society of Professional Engineers (NSPE),

- Northern California Solar Energy Association,

- Optical Society of America (2), and

- SEIA.

Also mentioned was "ISE" [Institution of Structural Engineers (British) or International Society of Electrochemistryl, an organization which could not be verified by the authors.

All of the 9 APH Researchers studied were members of professional, technical, or other organizations with an interest in solar energy. These organizations (and the number of times mentioned) included:

- ASAE (6),

- American Society for. Engineering Education,

- ASHR $\Lambda E(2)$,

- IEEE,

- ISES (2), and

- NSPE.

Also mentioned were "Food Technicians" and "POA," organizations which could not be verified by the authors.

\subsubsection{Exposure to Publications on Solar Energy}

During the past 6 months, 8 of the 9 IPH Researchers and all 9 of the APH Researchers had read publications which included information on solar process heat. The publications which the IPH Researchers identified (and the number of times mentioned) included:

- DOE reports,

- ISES publications,

- NTIS publications (including "Daily Reports") (2),

- Solar Energy Research Institute (SERI) reports, 
- Solar Age (4),

- Solar Energy (3), and

- Solar Engineering.

Also mentioned were an "AICG Paper," "industrial heat publication," "Industrial Process Heat," "ISSE," and "Oakland, California paper." These publications could not be verified by the authors.

The publications which the APH Researchers could identify (and the number of times mentioned) included:

- ASAE Transactions (2),

- ASHRAE Journal,

- DOE reports,

- Energy Digest,

- ISES publications(2),

- Solar Energy(2),

- SERI publications,

- Solar Grain Drying Symposium Proceedings (USDA, DOE), and

- Symposium on Peanut Drying, Forages, and Tobacco (USDA, DOE).

Also mentioned were publications which could not be verified by the authors. These included "AES Journal," "Solar (ENIS)," and "Solar Heating of Greenhouses."

\subsubsection{Use of Special Acquisition Methods}

The respondents were asked whether they had obtained any information (not just process heat or solar energy) in the past year by computer terminal, by Computer Output Microform (COM), or by other microform (e.g., microfiche, microfilm sheets or rolls). Three of the 9 (33\%) IPH Researchers had used computer terminals, compared to 4 of the 9 (44\%) APH Kesearchers and 62 of the 181 (34\%) All. Researchers. While none of the APH group had used COM, 1 (11\%) of the IPH group had, as had 16 of the 181 (9\%) All Researchers. In addition, more (4 or 44\%) of the IPH Researchers than APH Researchers ( 3 or $33 \%$ ) had used other microf orms, compared to 72 of the 181 (40\%) All Researchers.

\subsection{SUMMARY AND COMMENTS}

Two types of solar process heat researchers were interviewed: solar industrial process heat researchers were asked about solar industrial process heat information, and solar agricultural process heat researchers were asked about solar agricultural process heat inf ormation. The IPH Researchers had somewhat lower levels of education than did APH Researchers, but the majority still held advanced degrees. IPH Researchers were employed by universities, manufacturers, and national laboratories; APH Researchers were employed by universities and research centers. The IPH Researchers tended to be both more involved with and more informed about solar process heat than did the APH Researchers. 
Both groups of Solar Process Heat Researchers attributed the greatest utility to information on:

- Costs of installing and operating a solar process heat system compared to a conventional system,

- Costs and performance of solar process heat systems,

- Solar process heat research in progress,

- Climutological data, and

- A technical description of how a solar process heat system works.

Both groups gave low ratings to "a nontechnical description." IPH Researchers also did not find "educational institutions" or "institutional ... aspects" very useful. APH Researchers were not very interested in marketing information, "local building codes," or " programs ... outside the United States."

IAPH researchers had recently obtained information from "periodicals, newspapers, or magazines," "workshops, conf erences, or training sessions," libraries, and DOE. The IPH group also reported recent use of GPO and NTIS, while for the APH Researchers, state energy and solar offices and USDA were important sources of solar information. It was interesting to note that at least 6 of the 9. IPH Researchers had used SELA, NTIS, and TIC, but that APH Researchers generally had not (a maximum of 3 of the 9). Most of these Researchers belonged to organizations which also acted as information sources, most importantly: ASAE, ASHR AE, ISES, and ASME. Nevertheless, there was a substantial body of information which these researchers felt they could not obtain. 
SECTION 4.0

\section{CONCENTRATING COLLECTOR MANUFACTURER REPRESENTATIVES}

\subsection{DESCRIPTION OF RESPONDENTS}

\subsubsection{Description of Sample}

This section describes the results of a telephone study to determine the needs of manufacturers of concentrating collectors, solar thermal electric power equipment, reflectors, or refractors for information on solar energy. A total of 8 representatives of such manufacturers were interviewed; in this report they will be referred to as Concentrating Collector Manufacturer Representatives. Concentrating Collector Manufacturer Representatives were asked about their involvement in solar energy in general, rather than in process heat specifically. Thus, results in this section for those questions which deal with a specific technology differ somewhat in context from those in other sections of this report.

The sample frame for Concentrating Collector Manufacturer Representatives was constructed from two sources. The MITRE Solar Energy Technical Information Dissemination Program. Reference Directory: Solar Thermal Power [7] listed manufacturer/ distributors (under commercializers). The second source was the Solar Energy Information Data Bank (SEIDB) Manufacturers Data Base [8] which included manufacturers of concentrating collectors, solar thermal electric power equipment, reflectors, and refractors. Products specified for these manufacturers were one or more of the following: parabolic trough collectors, focusing solar collectors, parabolic dish collectors, tracking or nontracking concentrating collectors, vacuum tube collectors, linear trough collectors, compound parabolic concentrating collectors, solar thermal systems, reflectors, refractors, or alzak reflectors. Manufacturers with no contact name and duplicates with all other manuf acturer's sample frames were eliminated. Af ter all adjustments were made, 8 interview candidates were randomly selected from a sample frame of 80 names.

Respondents. In making the telephone calls to contact the randomly selected interview candidates, it sometimes occurred that the person could not be reached. In this event another randomly selected name was substituted for the original name. When individuals were contacted, it was verified that the company they worked for really was a "Concentrating Collector Manufacturer" and that they would be needing information on solar energy within the next year. If they were not both involved and needing information, they were asked if they could refer the interviewer to someone else in their organization who would be an appropriate respondent. If such a referral was made, a call was then made to this new candidate; if no intraorganizational referral was made, a new candidate was randomly selected from the sample frame. The results of this process may be seen in Table $4-1$. 
Table 4-1. COMPLETION OF INTERVIEWS: CONCENTRATING COLLECTOR MANUPACTURER REPRESENTATIVES

Event

Number

of Candidates

Interview completed with sample frame candidate

Interview completed with referral candidate

Refusal or candidate termination

Contact attempted: could not reach candidate within three

attempts or before interviews were completed

Subtotal

4

4

0

1

9

Contact attempted: invalid candidate (e.g.; inappropriate

field of interest, no telephone)

TOTAL

Sample frame error rate (Percent) $^{\mathbf{a}}$

36

Completion rate ${ }^{\text {(Percent) }}$

anvalid candidates divided by TOTAL

${ }^{b}$ Completed interviews divided by Subtotal

Comparisons. For additional insight into the information needs and the information habits of these representatives of Concentrating Collector Manufacturers, results from this group are compared to results from representatives of Total Nonconcentrating Collector Manufacturers (see Section 5.0) and representatives of All Manufacturers. In performing any statistical comparisons, the totals for Concentrating Collector Manuf acturer Representatives have been subtracted from the totals f or All Manuf acturer Representatives. The data for Concentrating Collector Manufacturer Representatives, Total Nonconcentrating Collector Manufacturer Representatives, and All Manufacturer Representatives can be found in Appendix F.

\subsubsection{Current Status of Respondents}

Role. The 8 Concentrating Collector Manufacturer Representatives were involved in the production of the following types of collectors: parabolic trough (3), evacuated tube (2), semicircular trough, V-trough, and compound parabolic. Three also manufactured hot. water systems, 2 manufactured space heating systems, and 1 each manuf actured space cooling systems, line focus concentrators, power tower plants, and heliostats. Some Concentrating Collector Manufacturer Representatives were also involved in the manufacture of: heat pumps (2); steam supply systems; decentralized power plants; educational aids; irrigation systems; radiation measurement devices; large wind turbine generator systems; and solar cell panels, modules and array fields.

Involvement. Seven of the 8 (88\%) representatives of Concentrating Collector Manufacturers felt that they were "very involved" in solar energy and 1 felt he/she was "moderately involved." In comparison with Total Nonconcentrating Collector Manufacturer Representatives [23 of the 29 or $79 \%$ "very involved" in active solar heating and cooling 
(SHAC)] and All Manufacturer Representatives (77 of the 96 or $80 \%$ "very involved" in their respective technologies), the level of involvement by Concentrating Collector Manufacturer Representatives was not significantly different.

Informedness. Representatives of Concentrating Collector Manufacturers felt they were very well informed, with 7 stating that they were "very informed" and 1 "moderately informed." The level of informedness by Concentrating Collector Manufacturer Representatives did not significantly differ from that of Total Nonconcentrating Collector Manufacturer Representatives (26 of the 29 or $90 \%$ "very informed") nor All Manufacturer Representatives (72 of the 96 or $75 \%$ "very inf orm ed").

Need for Information. All respondents indicated they would need information on solar energy on the job during the next year. Three of the $8(38 \%)$ also expected to need information on solar energy outside the job, which was slightly lower than both the Nonconcentrating Collector group (16 of the 29 or 55\%) and All Manufacturer Representatives ( 47 of the 96 or $49 \%$ ).

\subsubsection{Background of Respondents}

Four of the $8(50 \%)$ representatives of Concentrating Collector Manufacturers held bachelor's degrees, three (38\%) held master's degrees, and one held a doctoral degree. More Concentrating Collector Manufacturer Representatives (50\%) had advanced degrees (beyond bachelor's) than Total Nonconcentrating Collector Manufacturer Representatives (20\%). The degree field most common to the representatives of Concentrating Collector Manuf acturers was engineering, with such degrees received by 7 of the $8(88 \%)$ respondents. The one remaining degree was in business. Engineering degrees were also most common for Total Nonconcentrating Collector Manufacturer Representatives; however, the proportion was significantly lower at 8 of the $27(30 \%)$. One Concentrating Collector Manufacturer Respresentative received his/her most recent degree over 60 years ago, 4 were received 20-30 years ago, and 3 were received 10-20 years ago. No degrees were received within the past 10 years, differing from Total Nonconcentrating Collector. Manufacturer Representatives, where 10 of the 21 (48\%) of those citing dates had received degrees within the past 10 years.

One of the representatives of Concentrating Collector Manufacturers had been in his/her current profession for 2 or fewer years, 1 for 3-5 years, 1 for 6-10 years, and 5 for over 10 years. Although the length of current professional experience was slightly longer than that of Total Nonconcentrating Collector Manufacturer Representatives and All Manufacturer Representatives, the difference was not statistically significant. When asked about their current profession, all 8 Concentrating Collector Manufacturer Representatives said they were in managerial, administrative, or executive positions. Two of the respondents specifically mentioned working in marketing, 1 in product development, and 1 in operations.

\subsection{INPORMATION NEEDS OF RESPONDENTS}

\subsubsection{Technical Areas}

Representatives of Concentrating Collector Manufacturers were asked to choose those areas in which they were "particularly interested in obtaining information" from a list of 
selected technical areas of solar energy. All 8 of the respondents were interested in "energy storage" and 7 of the 8 were interested in "photovoltaics," "agricultural process heat," and "industrial process heat." Six were interested in "SHAC" and 5 in "solar thermal electric power." (See Section 4.1.1.)

\subsubsection{Types of Information}

Representatives of Concentrating Collector Manufacturers were asked to name the information about solar energy that was important for them to obtain. All 8 of the Concentrating Collector Manufacturer Representatives volunteered one or more items of information which they considered important. Four felt information on government progress (planning, funding, cycles, program priorities, legislation, and state and federal tax incentives) was important. Also mentioned were cost information (2), marketing information (2, including 1 mention of "where to sell"), and information on international programs (2, including 1 mention of "programs such as IEA involvement in Germany in small central receiver development"). Other topics included: new innovations, new inventions, technical information on system installations, and global insolation data on an hourly basis.

Information that the Concentrating Collector Manufacturer Representatives,volunteered they needed but were unable to get included: performance data; actual savings on solar hot water, space heating and space cooling systems; and marketing information on projects and installations completed on an annual basis.

Choice Between Specific Needs. A list of 11 types of solar energy information products and 14 types of solar energy information categories was read to each respondent. Each respondent described the usefulness of each particular item by assigning it a value of "essential," "very useful," "somewhat useful," or "not at all useful." The results are given in Fig. 4-1. For the purpose of comparison, the results for All Manufacturer Representatives (Fig. 4-2) are also provided. The results for Total Nonconcentrating Collector Manufacturer Representatives are presented in Section 5.0.

Concentrating Collector Manufacturer Representatives selected economic information (including tax credits and costs) as most important. Their seven top-rated information categories/products were:

- Standards, specifications, or certification programs;

- Tax credits, grants, or other economic incentives;

- Costs and performance of systems;

- Climatological data;

- Research in progress;

- Costs of installing and operating a solar system compared to a conventional system; and

- Marketing statistics and sales projections.

Total Nonconcentrating Collector Manufacturer Representatives also rated most of these information categories/products among their most important items. 
Question \#8. I will read a list of potential information or information products on solar systems. For each, please tell me how useful that information would be to you. Would the following be: essential, very useful, somewhat useful, or not at all useful?

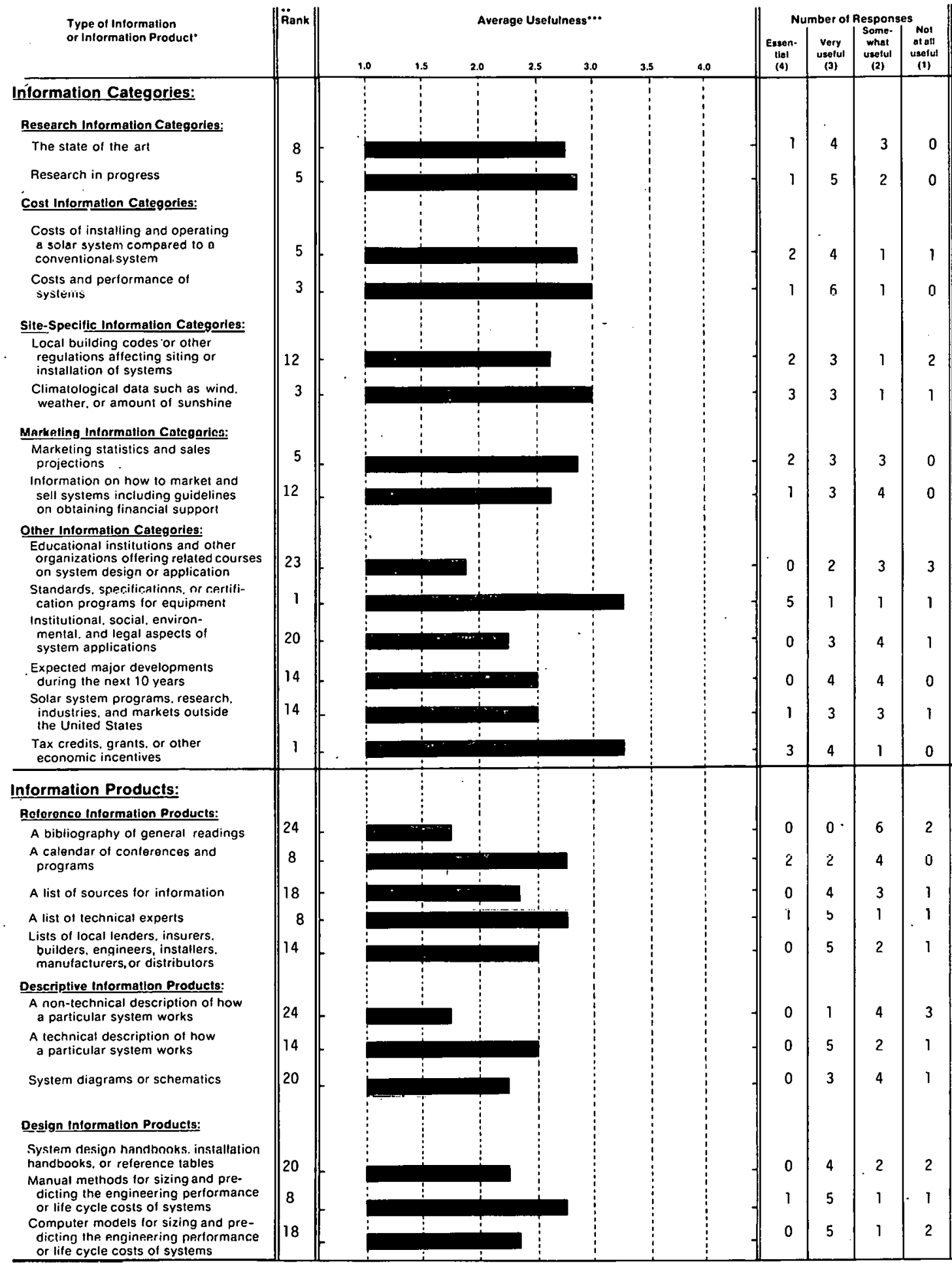

Each sample frame of users was questioned on inlormation and inlormation products in the context of their specific technology. For example, biomass sample frames were asked about "a bibliography of general readings on biomass". "a calendar of upcoming biomass conlerences and programs ". eic. "Rank-Each inlormation producl was assigned a rank based on average usefulness. Thus. the product with the highest average usetulness was assigned the rank of " 1 ": the produc with ine lowesi average uselu

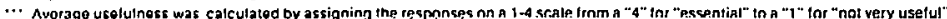

Figure 4-1. Usefulness of Selected Information Items: Concentrating Collectors Manufacturer Represèntatives 
Question \#8. I will read a list of potential information or information products on solar systems. For each, please tell me how useful that information would be to you. Would the following be: essential, very useful, somewhat useful, or not at all useful?

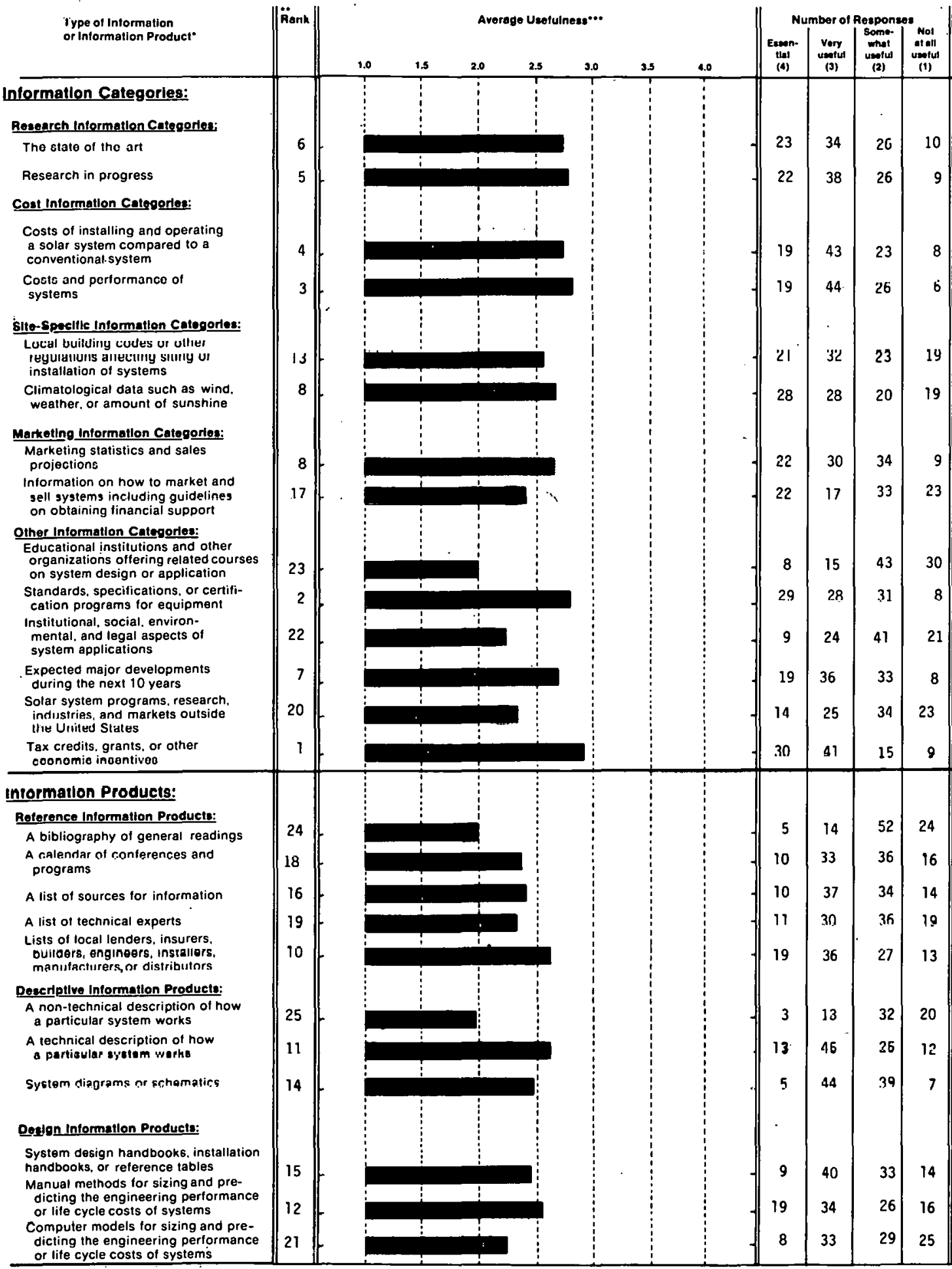

Each sample trame of users was questioned on intormation and information producis in the context of their specific technotogy. For example, biomass sample trames were

the producl with the highest everage uselulness was assigned the rank of " 1 ": the product with the lowest average usetutness would
hignest ranking was then assigned a "4:"

.. Average usefulness was calcutated by assigning the responses on a 1.4 scate from a " " " for "essential" to a "1" for "not very usoful".

Figure 4-2. Usefulness of Selected Information Items: All Manufacturer Representatives 
Representatives of Concentrating Collector Manufacturers assigned the lowest relative ratings to:

- A bibli ography of general readings,

- A nontechnical description of how a particular system works, and

- Educational institutions and other organizations off ering courses.

These three information categories/products were identical to those rated lowest by Total Nonconcentrating Collector Manufacturer Representatives.

Statistical tests indicated all seven of the top categories/products were rated significantly $(P<0.05)$ higher than were the three lowest-rated items.

It should be noted that these lower-rated items were not necessarily of no worth to the Concentrating Collector Manufacturer Representatives. For example, 3 of the 8 (38\%) Concentrating Collector Manufacturer Representatives thought "institutional . .. . aspects" was "very useful." Thus, these information categories/products could be useful to some Concentrating Collector Manufacturer Representatives but were of a lower relative priority to the entire group.

Statistical tests were also used to determine whether the representatives of Concentrating Collector Manuf acturers rated any of these inf ormation items significantly higher (or lower) than they were rated by the representatives of Total Nonconcentrating Collector Manuf acturers and representatives of All Manufacturers. Some groups, however, tended to give higher scores in general than did other groups. To compensate for this effect, these statistical tests compared the "relative rating" given by one group to the "relative rating" given by the other groups. The procedure for calculating the relative rating is described in Appendix E. The average overall rating Concentrating Collector Manufacturer Representatives gave to all items was 2.57; for Total Nonconcentrating Collector Manufacturer Representatives it was 2.42; and for All Manufacturer Representatives, 2.51.

In comparison to Total Nonconcentrating Collector Manufacturer Representatives, Concentrating Collector Manufacturer Representatives were found to rate the importance of "lists of technical experts" significantly $(P<0.05)$ higher. They also appeared to give a higher priority to "climatological data," "solar energy programs ... outside the United States," "a calendar of conferences and programs," and "manual methods" while giving a relatively lower priority to "lists of local lenders, insurers (etc.)" and "system diagrams." In comparison to All Manufacturer Representatives, the information needs of Concentrating Collector Manufacturer Representatives did not significantly differ. However, the Concentrating Collector Manufacturer Representatives did appear to value more highly "lists of technical experts" and "calendars."

\subsection{ACQUISTION OF INFORMATION BY RESPONDENTS}

\subsubsection{Use of Selected Information Sources}

Representatives of Concentrating Collector Manufacturers were asked which of 20 different potential sources of solar inf ormation they had used in the past few years. For this question the respondents were asked if they had obtained any solar information from 
each specific source. Thus, the question sought to determine which information sources were the most familiar to the respondents. The results are shown in Fig. 4-3. For the purpose of comparison, the results for All Manufacturer Representatives (Fig. 4-4) are also provided. The results for Total Nonconcentrating Collector Manufacturers are presented in Section 5.0 .

The information sources mentioned most of ten (at least 6 of the 8) by representatives of Concentrating Collector Manuf acturers were:

- An installer, builder, designer, or manuf acturer;

- A federal library or inf ormation center;

- Periodicals, newspapers, or magazines;

- International Solar Enorgy Society (ISES);

- Solar Energy Industries Association (SEIA);

- Workshops, conf erences, or training sessions;

- The Government Printing Office (GPO);

- Directly from the U.S. Department of Energy (DOE);

- State energy or solar offices; and

- An organizational or local library.

Similarly, with the exception of ISES, Total Nonconcentrating Collector Manufacturer Representatives also listed the same information sources most of ten.

The information sources mentioned least often by representatives of Concentrating Collector Manuf acturers were:

- Smithsonian Science Information Exchange (SSIE),

- Radio or TV,

- A commercial data base,

- National Solar Heating and Cooling Information Center (NSHCIC), and

- Kegional Solar Energy C'enters (RSECs).

Total Nonconcentrating Collector Manufacturer Representatives also did not make much use of SSIE nor "a commercial data base." In comparison to Total Nonconcentrating Collector Manufacturer Representatives, significantly $(\mathrm{P}<0.05)$ more Concentrating Collector Mlanufacturer Representatives had used "a federal library or information center" and significantly fewer had used NSHCIC.

\subsubsection{Membership in Solar-Interested Organizations}

Six of the 8 representatives of Concentrating Collector Manufacturers studied were members of a professional, technical, or other organization with an interest in solar energy. These organizations (and the number of times mentioned) included:

- American Institute of Aeronautics and Astronautics (AIAA) (2);

- National Security Industrial Association, Energy panel; 
Question \#11. In the past few years, have you obtained any type of solar information from any of the following sources?

Information Sources

Percentage Responding Yes :

Public Media:

Radio or TV

Periodicals, newspapers or magazines

Private Solar-Involved Organizations:

Private solar energy or environmental organizations

The local chapter or national headuuarters of International. Solar Energy Society (ISES), including their publications

The local chapter or national headquarters of Solar Energy Industries Association (SEIA), including their publications

\section{Contacts with Professionals:}

An installer, builder, designer or manufacturer of solar systems

Workshops, conferences or training sessions

Information Services*:

Your organizational library or a local library

A commercial data base; for example, Lockheed, SDC, BRS

Smithsonian Science Information Exchange (SSIE)

A Federal library or information center; for example, the National Agricultural Library or the Environmental Data System

The Government Printing Office (GPO)

National Technical Information Service (NTIS)

Technical Information Center at Oak Ridge (TIC)

Government Solar-Involved Organizations

Directly from the U.S. Department of Energy

National Solar Heating \& Cooling Information Center

Regional Solar Energy Centers

State Energy or Solar Offices

Other:

Some other state or local government office or publiçation

A public utility company

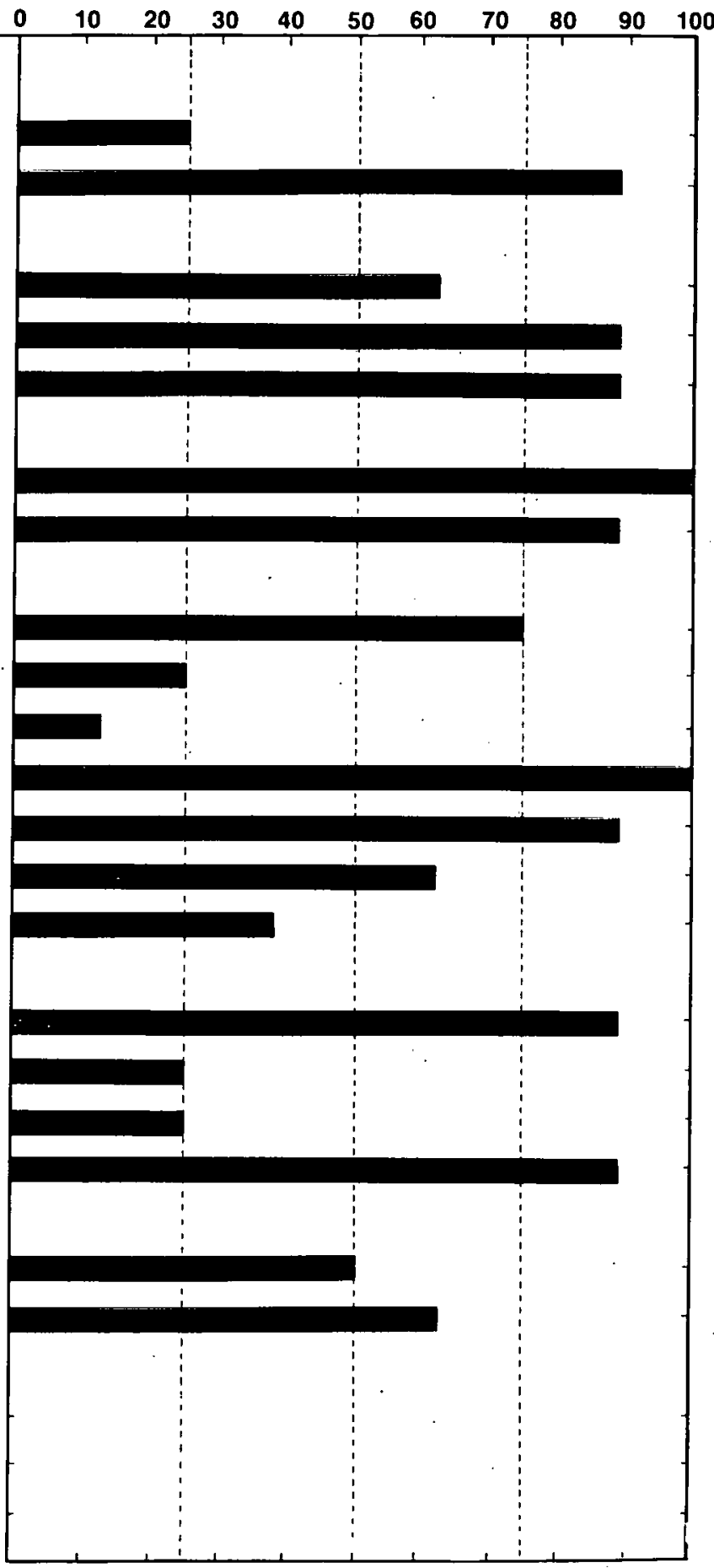

- Services and centers whose primary purpose is to disseminate information.

- These dala are based upun a lulal of 8 responderils.

Figure 4-3. Use of Selected Information Sources: Concentrating Collectors Manufacturer Representatives 
Question \#11. In the past few years, have you obtained any type of sotar information from any of the following sources?

Information Sources

Public Media:
Radio or TV
Periodicals, newspapers or magazines

Private Solar-Involved Organizations:

Private solar energy or environmental organizations

The local chapter or national headquarters of International Solar Energy Society (ISES), including their publications

The local chapter or national headquarters of Solar Energy Industries Association (SEIA), including their publications

Contacts with Professionals:

An installer, builder, designer or manufacturer of solar systems

Workshops, conferences or training sessions Information Services*:

Your organizational library or a local library

A commercial data base; for example, Lockheed, SDC, BRS

Smithsonian Science Information Exchange (SSIE)

A Federal library or information center; for example, the National Agricultural Library or the Environmental Data System

The Government Printing Office (GPO)

National Technical Information Service (NTIS)

Technical Information Center at Oak Ridge (TIC)

Government Șolar-Involved Organizations

Directly from the U.S. Department of Energy

National Solar Heating \& Cooling Information Center

Regional Solar Energy Centers

State Energy or Solar Offices

Other:

Some other state or local government office or publication

A public utility company
Percentage Responding Yes

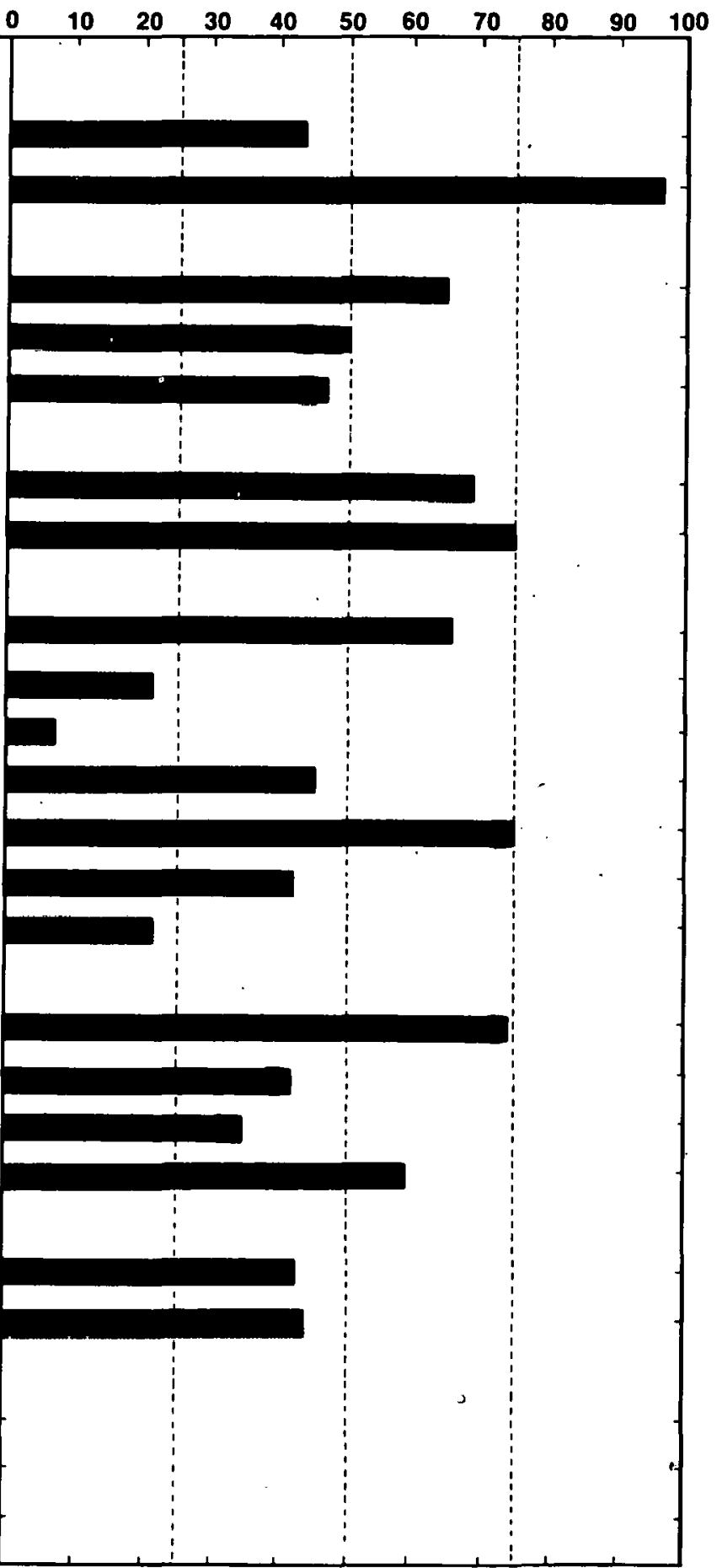

- Services and centers whose primary purpose is to disseminate information.

These data are based uoon a total of 96 resoondents. 
- Northern California Solar Energy Association; and

- SEIA (5).

Some organizations which the authors could not verify were also mentioned. These were "Energy Engineering Society," "Society of Energy Engineers," and "Solar Energy Research Association."

\subsubsection{Exposure to Publications on Solar Energy}

During the past 6 months, all 8 of the representatives of Concentrating Collector Manufacturers had read publications which included information on solar energy. The publications they could specify (and the number of times mentioned) included:

- AIAA Journal,

- Energy Daily,

- Energy User News,

- In Review,

- Mother Earth News,

- Optical Spectra,

- Plant Engineering,

- Solar Age (3),

- Solar Energy (2),

- Solar Energy Intelligence Report (3),

- Solar Engineering (7),

- Solar Heating and Cooling, and

- Sun Up.

Some publications which the authors could not verify were also mentioned. These were "Solar Inf ormutiun" and "Southern Calif ornia Solar Energy publications."

\subsubsection{Use of Special Acquisition Methods}

The respondents were asked whether they had obtained any information (not just solar energy) in the past year by computer terminal, by Computer Output Microf orm (COM), or by other microform (e.g., microfiche, microfilm sheets or rolls). Few representatives of Concentrating Collector Manufacturers appeared accustomed to using these special acquisition methods, a trait common to representatives of manufacturers in all technologies studied. In the past year, only 2 of the 8 (25\%) Concentrating Collector Manufacturer Representatives had used a computer terminal, 1 (13\%) had used COM, and 3 (38\%) had used other microf orm. 


\subsection{SUMMARY AND COMMENTS}

Mast representatives of Concentrating Collector Manufacturers ( 7 of the 8 , or $88 \%$ ) were very involved and very informed in solar energy; most had engineering degrees. Compared to representatives of Total Nonconcentrating Collector Manufacturers, Concentrating Collector Manufacturer Representatives appeared to be slightly better educated and had more years of experience in their current profession.

All 8 Concentrating Collector Manufacturer Representatives expressed an interest in energy storage and 7 of the $8(88 \%)$ were interested in industrial process heat, agricultural process heat, and photovoltaics. Six were interested in SHAC and 5 in solar thermal electric power. (See Section 4.1.1.)

Representatives of Concentrating Collector Manufacturers gave the highest priority to:

- Standards, specifications, or certification programs;

- Tax credits, grants, or other economic incentives;

- Costs and performance of systems;

- Climatological data;

- Research in progress;

- Costs of installing and operating a solar system compared to a conventional system; and

- Marketing statisties and sales projections.

They gave low ratings to "a bibliography," "a nontechnical description," "educational institutions," and "institutional, social ... aspects."

Concentrating Collector Manufacturer Representatives frequently relied on contacts with professionals ("an installer, builder (etc.)" and "workshnps (etc.)") for information on sular energy. They also relied on private solar involved organizations and federal services including "a federal library," ISES, SEIA, GPO, DOE, and state energy or solar offices. The publication Solar Engineering also served as an important information source. Their use of NSHCIC was significantly lower (only 2 of 8 ) than that of Total Nonconcentrating Collector Manuf acturer Representatives (24 of 34). 


\section{SECTION 5.0}

\section{TOTAL NONCONCENTRATING COLLECTOR MANUFACTURER REPRESENTATIVES}

\subsection{DESCRIPTION OF RESPONDENTS}

\subsubsection{Description of Sample}

This section describes the combined results of three telephone studies to determine the needs of representatives of manuf acturers of nonconcentrating collectors for information on solar energy. A total of 29 representatives of Total Nonconcentrating Collector Manuf acturers were interviewed. Data from the three studies are also included in the Active Solar Heating and Cooling (SHAC) Information User Study [9]. Although most of these respondents were asked principally about information on SHAC, and the others were asked about information on solar energy in general, the results are also presented in this document because of the applicability to low temperature industrial and agricultural process heat.

The sample frame for Total Nonconcentrating Collector Manufacturer Representatives was constructed from the Solar Energy Information Data Bank (SEIDB) Manufacturers Database [8]. Manufacturers who produced one or more of the following were chosen: flat plate collectors (liquid or air), liquid type collectors, freon charged collectors, or special liquid collectors. Manufacturers of concentrating collectors were eliminated. Manuf acturers without a contact name were eliminated. After all adjustments were made, 29 interview candidates were randomly selected from a sample frame of 177 manuf acturers.

Respondents. In making the telephone calls to contact the randomly selected interview candidates, it sometimes occurred that the person could not be reached. In this event another randomly selected name was substituted for the original name. When individuals were contacted, it was verified that the company they worked for was really a Nonconcentrating Collector Manufacturer and that they would be needing information on solar energy within the next year. If they were not both involved and needing information, they were asked if they could refer the interviewer to someone else in their organization who would be an appropriate respondent. If such a referral was made, a call was then made to this new candidate; if no intraorganizational referral was made, a new candidate was randomly selected from the sample frame. The results of this process may be seen in Table 5-1.

Comparisons. For additional insight into the information needs and the information habits of these representatives of Total Nonconcentrating Collector Manufacturers, the results are compared to those of representatives of All Manufacturers. Comparisons of Total Nonconcentrating Collector Manuf acturers to Concentrating Collector Manufacturers may be found in the previous section (Section 4.0). The Concentrating Collector Manufacturers group consisted of representatives of manuf acturers of concentrating collectors, reflectors, and refractors. In performing any statistical comparisons, the totals for Total Nonconcentrating Collector Manufacturers have been subtracted from the totals for All Manufacturers. The list of groups contained in All Manufacturers can be foind in Table F-2 of Appendix F. The data for these groups can be found in Appendix F. 
Table 5-1. COMPLETION OF INTERVIEWS: TOTAL NONCONCENTRATING COLLECTOR MANUFACTURER REPRESENTATTVES

\begin{tabular}{|c|c|}
\hline Event & Number of Candidates \\
\hline $\begin{array}{l}\text { Inter view completed with sample frame candidate } \\
\text { Interview completed with referral candidate } \\
\text { Refusal or candidate termination } \\
\text { Contact attempted: could not reach candidate } \\
\text { within three attempts or before interviews } \\
\text { were completed. }\end{array}$ & $\begin{array}{r}17 \\
12 \\
1\end{array}$ \\
\hline Subtotal & 34 \\
\hline $\begin{array}{l}\text { Contact attempted: invalid candidate (e.g.; } \\
\text { not a colloctor manufaoturor, no tclcphonc) }\end{array}$ & 11 \\
\hline 'TO'TAL & 45 \\
\hline $\begin{array}{l}\text { Sample frame error rate }{ }^{a} \text { (Percent) } \\
\text { Completion rate }{ }^{b} \text { (Percent) }\end{array}$ & $\begin{array}{l}24 \\
85\end{array}$ \\
\hline
\end{tabular}

\subsubsection{Current Status of Respondents}

Role. Twenty-six of the 29 Total Nonconcentrating Collector Manufacturers manufactured collectors for liquid systems and 10 of the 29 manufactured collectors for air systems. Eight of the 29 also manufactured swimming pool heating systems and 14 of the 29 manuf actured other components.

Involvement. Twenty-three of the 29 (79\%) Total Nonconcentrating Collector Manufacturer Representatives felt that they were "very involved" in solar energy and 3 of the 29 (10\%) felt they were "moderately involved." The level of involvement by Total Nonconcentrating Collector Manuf acturers did not significantly differ from that of All Manufacturer Representatives, in which 77 of the 96 (80\%) were "very involved" and 10 of the 96 (10\%) "moderately involved."

Informedness. Of the Total Nonconcentrating Collector Manufacturer Representatives, 26 of the 29 (90\%) representatives felt they were "very informed" and 2 of the 29 (7\%) felt "moderately informed." This level of informedness was significantly $(P<0.05)$ higher than All Manufacturer Representatives, in which 75 of the 96 (75\%) were "very informed" and 21 of the 96 (22\%) "moderately involved."

Need for Information. All respondents indicated they would need information on solar energy either on the job and/or outside the job. On the job, 28 of the 29 (97\%) Total Nonconcentrating Collector Manufacturers expected to need information. Sixteen of the 29 (55\%) Total Nonconcentrating Collector Manufacturers also expected to need information on solar energy outside the job. 


\subsubsection{Background of Respondents}

Sixteen (55\%) of the representatives of Total Nonconcentrating Collector Manufacturers held bachelor's degrees, 4 (14\%) held master's degrees, 1 held a doctoral degree, and 1 a law certificate. The educational level of Total Nonconcentrating Collector Manufacturers was similar to that of All Manufacturers. The degree field most common to Total Nonconcentrating Collector Manufacturers was engineering, received by 7 of the 22 (32\%) respondents with degrees. The remaining 15 respondents had received degrees in various fields including: architecture (3), business (2), chemistry, management, banking, law, education, marine transportation, marine science, aeronautics, geology, and history. One received his/her most recent degree over 30 years ago, 7 from 20-30 years ago, 4 from 10-20 years ago, and 10 within the past 10 years. The educational level and the year of most recent degree for Total Nonconcentrating Collector Manufacturers were similar to those of representatives of All Manuf acturers.

The number of years of professional experience was dispersed among the group, with 1 in his/her current profession for 2 or fewer years, 11 for 3-5 years, 9 for 6-10 years, and 8 for over 10 years. Similarly, the professional experience of All Manufacturers also varied widely. As their current prof ession, 9 of the 29 representatives of Total Nonconcentrating Collector Manufacturers mentioned they were in management, 10 were engineers, and the other 10 mentioned manufacturer (4), solar energy specialist (2), marketing (2), architect (1), and salesman (1).

\subsection{INFORMA'TION NEEDS OF RESPONDENTSS}

Representatives of Total Nonconcentrating Collector Manufacturers were asked to name the infor mation about solar energy that was important for them to obtain. Twenty-seven of the 29 (93\%) volunteered one or more items of information which they considered important. Seven felt marketing information was important (including sales trends, market analysis, pricing, and how to sell). This seemed to be a typical response for manufacturers; for example, Passive Manufacturers also mentioned marketing information as a ligh-priority need. Other topics cited as important by Total Nonconcentrating Collector Manufacturers included: new products/new development and design breakthroughs (4), government and financial incentives (3), nontechnical descriptions (3), standards (2), cost information (cost versus efficiency of systems and comparative costs of collectors) (2), insolation data (2), and a single mention each for test results, research on cooling, product availability, "storage capacity of solar ovens," low temperature collectors, solar demonstration projects, industrial and commercial applications data, information on hybrid systems of solar-assisted heat pumps, conference papers from ISES, information on "how to get government out of the business," and performance test data on the longevity of various solar systems on the market.

Eleven representatives of Total Nonconcentrating Collector Manufacturers stated that there was information that they needed but were unable to get. This included climatological data (3), performance/reliability information (including verification of heat pump loadings for homes) (2), marketing information (2), computer and manual methods for computation of passive applications, information on retrofits, transport components, piping, control equipment, government projects on solar energy, data on installations by geographical area, building codes, air collectors, and data on etched glass for reduction of reflection. 
Choice Between Specific Needs. A list of 11 types of solar energy information products and 14 types of solar energy information categories was read to each respondent. Each respondent described the usefulness of each particular item by assigning it a value of "essential," "very useful," "somewhat useful," or "not at all useful." The results for Total Nonconcentrating Collector Manufacturer Representatives are shown in Fig. 5-1. For the purpose of comparison, the results for. All Manufacturer Representatives are shown in Fig. 5-2.

The type of information on which Total Nonconcentrating Collector Manufacturers placed the highest priority was "tax credits, grants, or other economic incentives." This item received a significantly $(P<0.05)$ higher rating than any of the other items. This information category was also rated number one by All Manufacturers. The six inf ormatíon categories/products rated highest by 'lotal Nonconcentrating Collector Manufacturer Representatives were:

- Tax credits, grants, or other economic incentives;

- Costs and performance of systems;

- Standards, specifications, or certification programs;

- Costs of installing and operating a solar heating and cooling system compared to a conventional system;

- Marketing statistics and sales projections; and

- Lists of local lenders, insurers, builders, engineers, installers, manufacturers, or distributors.

Total Nonconcentrating Collector Manufacturer Representatives assigned the lnwest ratings to:

- A bibliography of general readings;

- Educational institutions and other organizations off ering courses;

- A nontechnical description of how a particular system works;

- Solar energy programs, research, industries, and markets outside the United States; and

- Lists of technical experts.

Statistical tests indicated all six of the top categories/products were rated significantly $(\mathrm{P}<0.05)$ higher than were the ten lowest-rated items.

It should be noted that these lower-rated items were not necessarily of no worth to Total Nonconcentrating Collector Manufacturers. For example, 7 of the 29 (24\%) representatives of Total Nonconcentrating Collector Manufacturers thought "lists of technical experts" was "very useful." Thus, these information categories/products could be useful to some Nonconcentrating Collector Manufacturers, but were of a lower relative priority to the entire group.

Statistical tests were also used to determine whether the representatives of Total Nonconcentrating Collector Manuf acturers rated any of these inf ormation items significantly higher (or lower) than they were rated by the representatives of All Manufacturers. Some groups, however, tended to give higher scores in general than did other groups. To 
Question \#8. I will read a list of potential information or information products on solar systems. For each, please tell me how useful that information would be to you. Would the following be: essential, very useful, somewhat useful, or not at all useful?

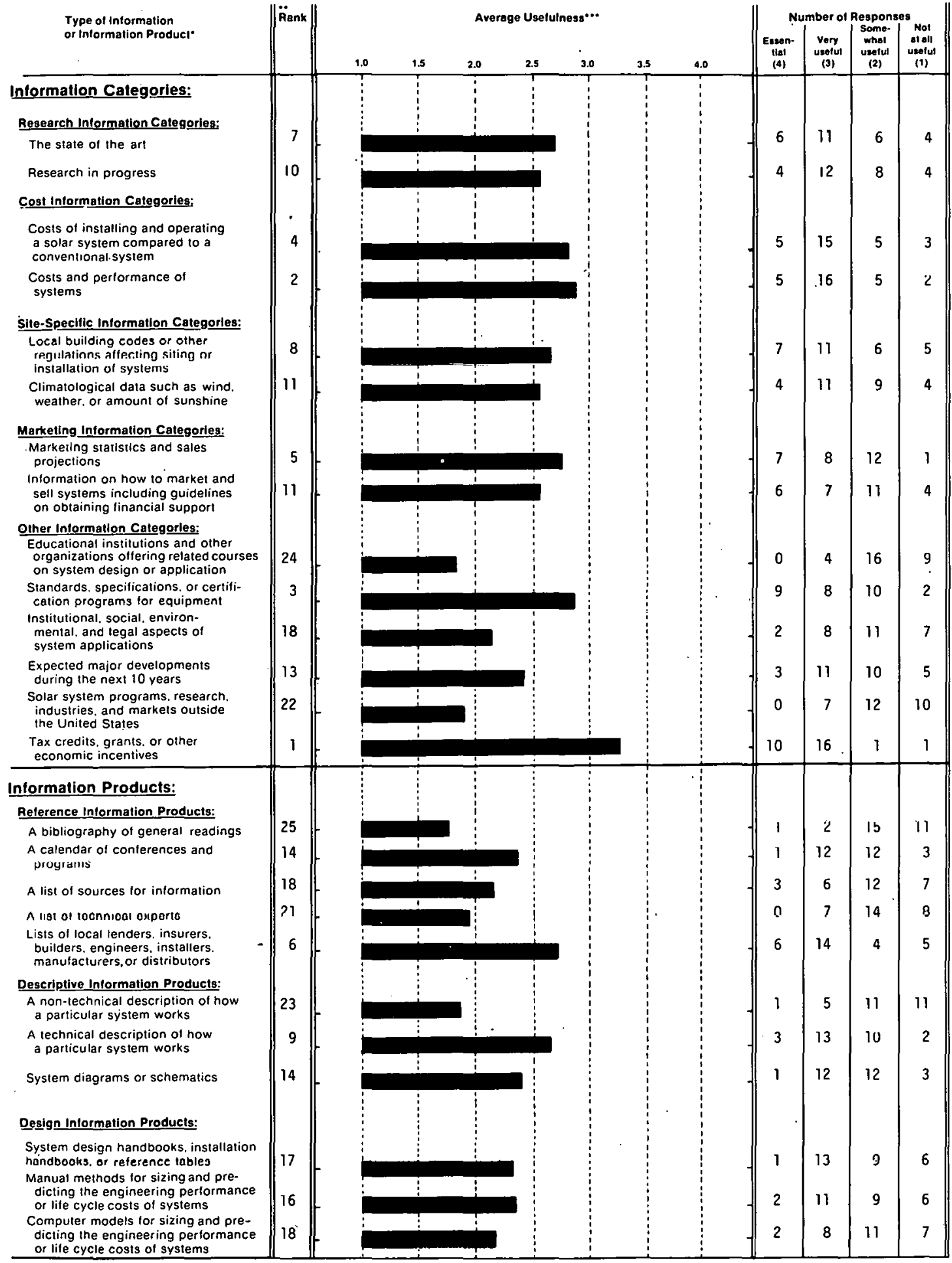

- Cach sample lrame of users was questioned on information and informalion producte in tho contoxt of thoir specilic teohnology. For oxamplo, biomass sample irames were

Rank-Each intormation producl was assigned a rank based on average uselulness. Thus, the product with the highest average usefulness was assigned the rank of "I": the product with the lowest average usefulness would
niqhęs: tạnhing was then assioned a "4:"

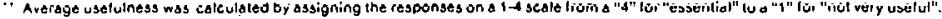

Figure 5-1. Usefulness of Selected Information Items: Total Nonconcentrating Collectors Manufacturer Representatives 
Question \#8. I will read a list of potential information or information products on solar systems. For each, please tell me how useful that information would be to you. Would the following be: essential, very useful, somewhat useful, or not at all useful?

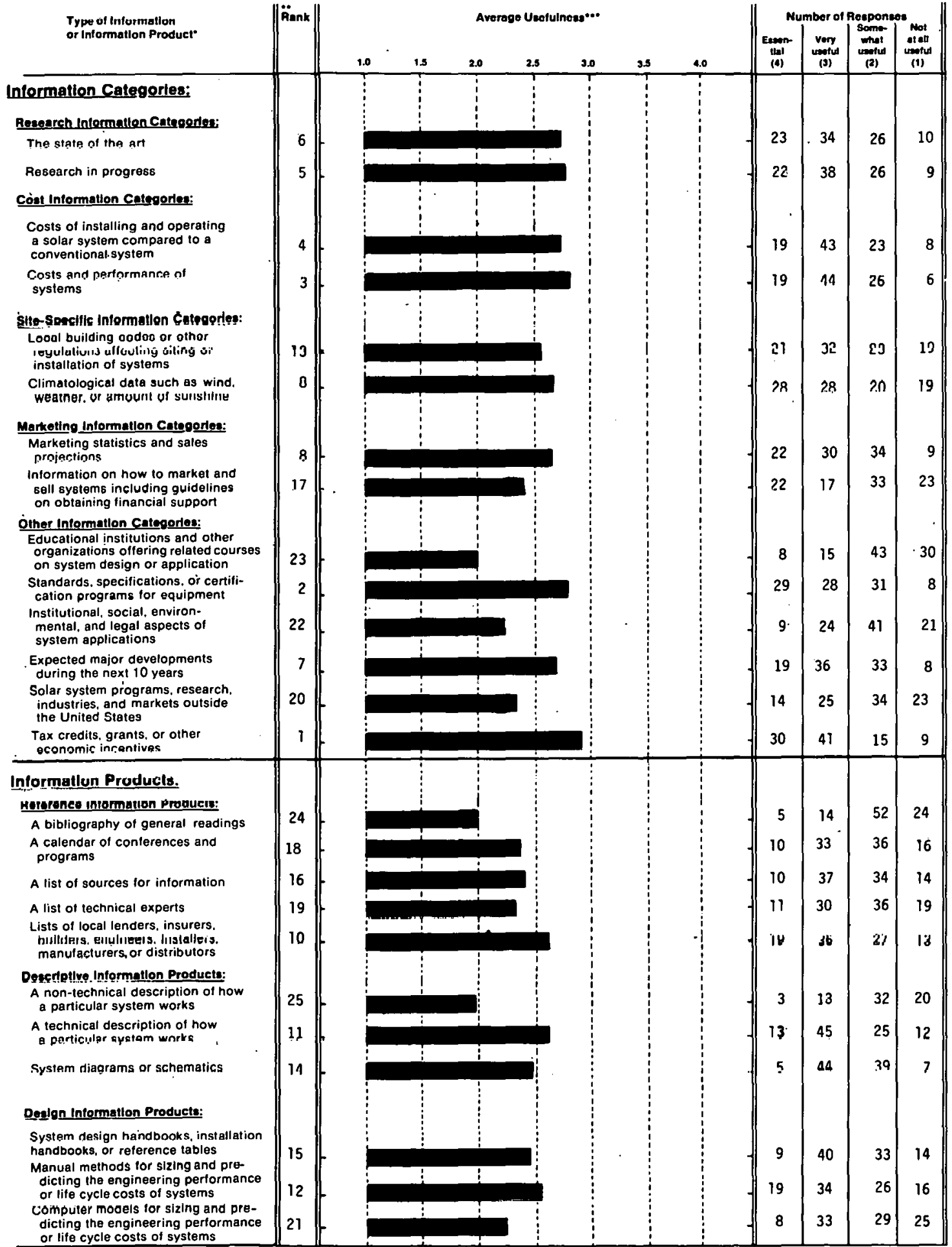
Each semple trame of users was questioned on intormation and information products in the context of their specitic tochnology. For example, biomass sample lrames were

Rank-Each intormation product was assigned a rank based on average usefulness. Thus, the product with the highest average usefulness was assigned the rank of " "1": the product with the lowest average usefulness woutd ber

... Average usefulness was calculated by assigning the responses on a it scate from a "4" for "essential" to a " 1 " for "not very usefur ".

FIgure 5-2. Usefulness of Selected Information Items: All Manufacturer Representatives 
compensate for this effect, these statistical tests compared the "relative rating" given by one group to the "relative rating" given by the other groups. The procedure for calculating the relative rating is described in Appendix E. The average overall rating for Total Nonconcentrating Collector Manufacturer Representatives was 2.42, for All Manufacturer Representatives it was 2.51 .

Comparisons between Total Nonconcentrating Collector Manufacturer Representatives and All Manufacturers showed that both groups wanted cost-related information, but neither wanted design information products. Representatives of Total Nonconcentrating Collector Manufacturers were significantly $(P<0.05)$ more interested in "tax credits (etc.)," but less interested in "lists of technical experts" and "programs, research . . . outside the United States." All Manuf acturers appeared to be oriented more towards monitoring research and technological progress ("expected major developments") of their respective solur technologies. One explanation for these variations may be the differences in levels of commercial readiness of the products manufactured. With the exception of Passive Manufacturers, the majority of products produced by the other solar manufacturers have not progressed to the same commercial level as nonconcentrating collectors.

\subsection{ACQUISITION OF INFORMATION BY RESPONDENTS}

\subsubsection{Use of Selected Infarmation Sources}

Representatives of Total Nonconcentrating Collector Manufacturers were asked which of 18-20 different potential sources of solar information they had used in the past few years. The question sought to determine which information sources were the most familiar to the respondents. The results are shown in Fig. 5-3. For the purpose of comparison, those for All Manufacturers are shown in Fig. 5-4.

The information sources mentioned most of ten by representatives of Total Nonconcentrating Collector Manufacturers were:

- Periodicals, newspapers, or magazines;

- An installer, builder, designer, or manufacturer (outside your own organization);

- State energy or solar offices;

- Private solar energy or environmental organizations;

- Workshops, conferences, or training sessions;

- The Government Printing Office (GPO);

- National Solar Heating and Cooling Information Center (NSHCIC);

- Solar Encrgy Industries Association (SEIA);

- An organizational library or a local library; and

- Directly from the U.S. Department of Energy (DOE).

Each of these sources was mentioned by at least $60 \%$ of all respondents. 
Question \#11. In the past few years, have you obtained any type of solar information from any of the following sources?

Information Sources

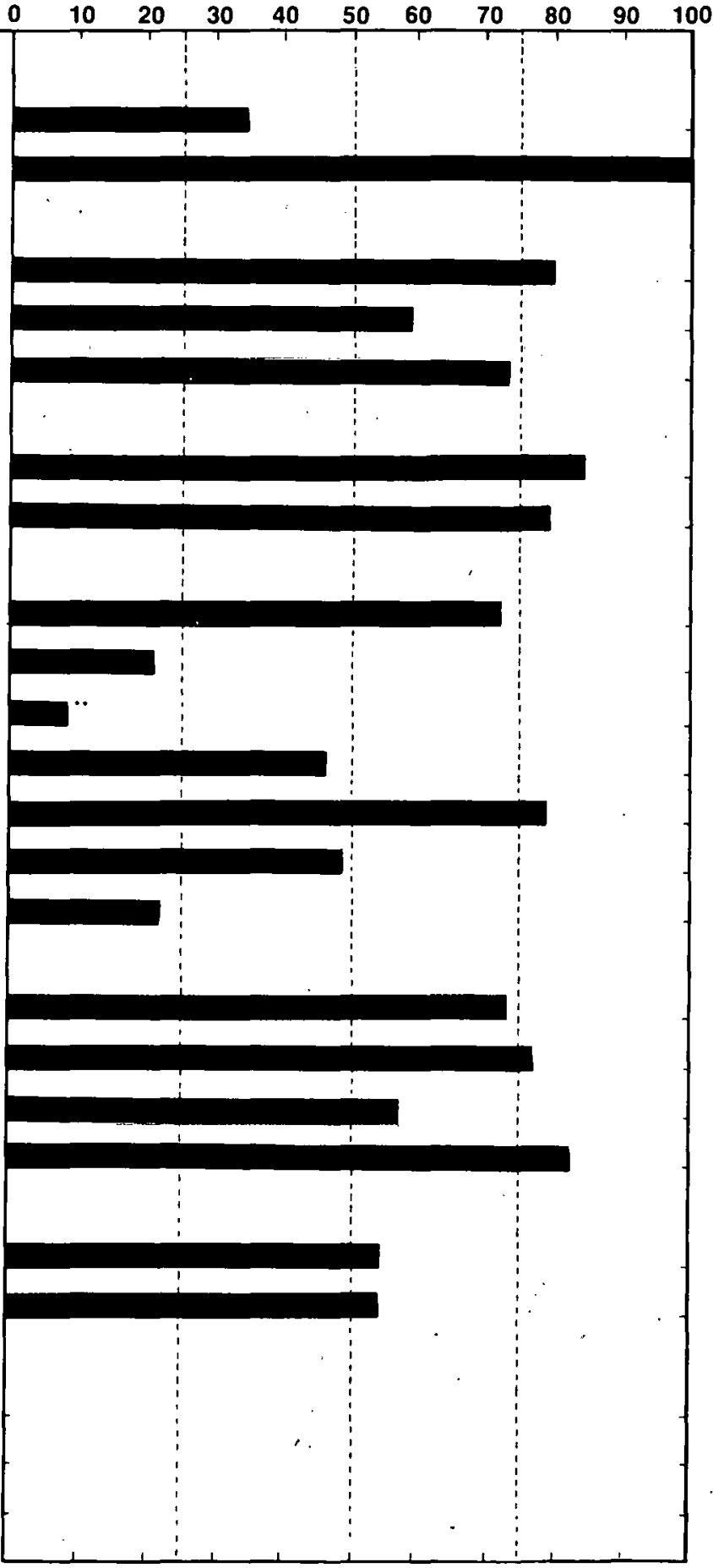

Percentage Responding Yes $\cdots$

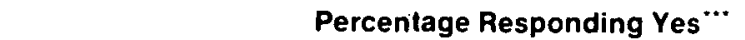

Private solar energy or environmental organizations

The local chapter or national headquarters of International Solar Energy Society (ISES). including their publications

The local chapter or national headquarters of Solar Energy industries Association (SE|A). including their publications

Contacts with Professionals:

An installer, builder. designer or manufacturer of solar systems

Workshops. conferences or training sessions

Information Services*:

Your organizational library or a local library

A commercial data base: for example. Lockheed. SDC. BRS

Smithsonian Science Information Exchange (SSIE)

A Federal library or information center: for example. the National Agricultural Library or the Environmental Data System

The Government Printing Office (GPO)

National Technical Information Service (NTIS)

Technical Information Center at Oak Ridge (TIC)

Government Solar-Involved Organizations

Directly from the U.S. Department of Energy

National Solar Heating \& Cooling Information Centel

Regional Solar Energy Centers

State Energy or Solar Offices

Other:

Some other state or local government office or publication

A public utility company 
Question \#11. In the past few years, have you obtained any type of solar information from any of the following sources?

Information Sources

Public Media:
Radio or TV
Periodicals, newspapers or magazines

Private Solar-Involved Organizations:

Private solar energy or environmental organizations

The local chapter or national headquarters of International Solar Energy Society (ISES), including their publications

The local chapter or national headquarters of Solar Energy

Industries Association (SEIA), including their publications

\section{Contacts with Professionals}

An installer, builder, designer or manufacturer of solar systems

Workshops, conferences or training sessions

Information Services*:

Your organizational library or a local library

A commercial data base; for example, Lockheed, SDC, BRS

Smithsonian Science Information Exchange (SSIE)

A Federal library or information center; for example, the National Agricultural Library or the Environmental Data System

The Government Printing Office (GPO)

National Technical Information Service (NTIS)

Technical Information Center at Oak Ridge (TIC)

Government Solar-Involved Organizations

Directly from the U.S. Department of Energy

National Solar Heating \& Cooling Information Cente

Regional Solar Energy Centers

State Energy or Solar Offices

Other:

Some other state or local government office or publication

A public utility company
Percentage Responding Yes

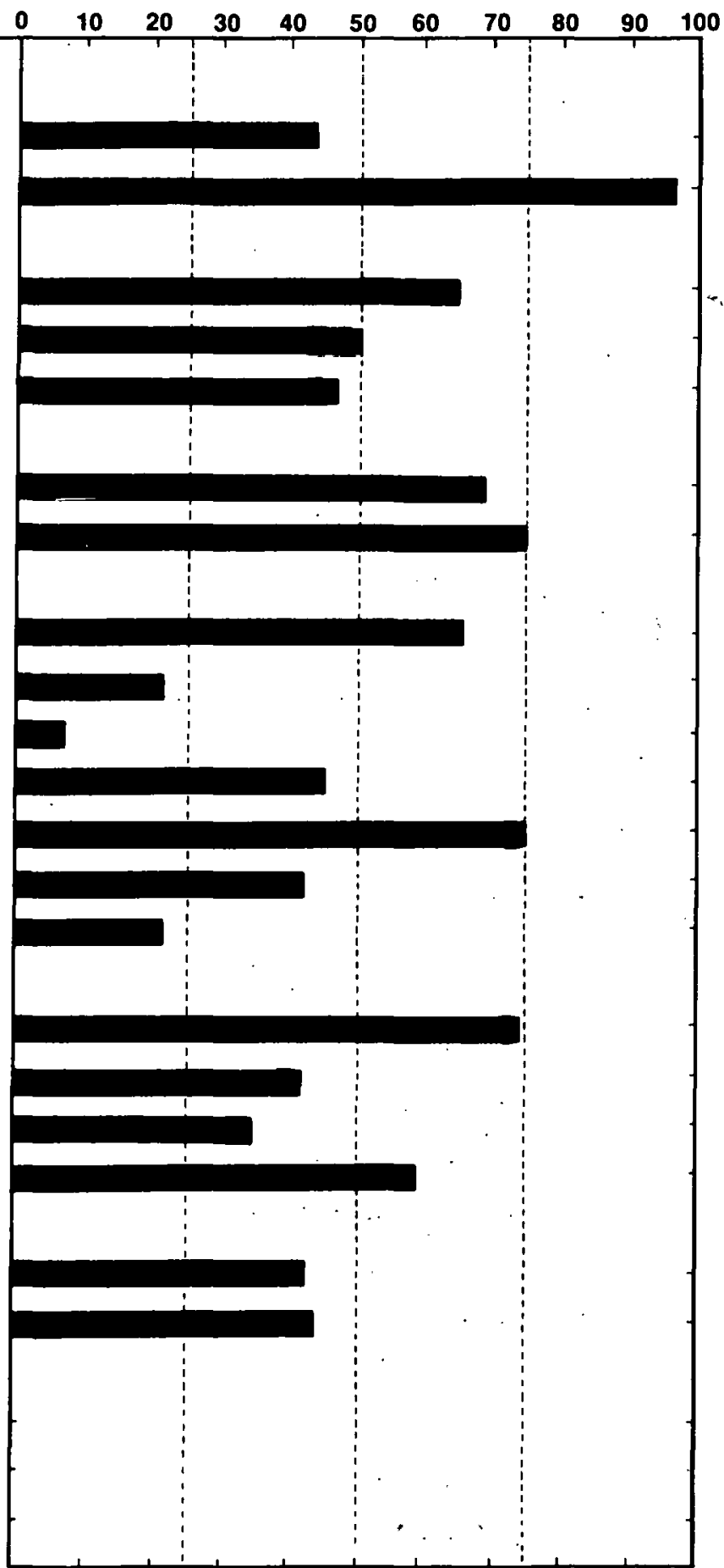

- Services and centers whose primary purpose is to disseminate information

- These data are based upon a total of 96 respondents. 
The information sources mentioned least of ten by Nonconcentrating Collector Manufacturer Representatives were:

- Smithsonian Science Information Exchange (SSIE),

- A commercial data base,

- Technical Information Center (TIC), and

- Radio or TV.

In comparison to All Manufacturer Representatives, Total Nonconcentrating Collector Manufacturers mentioned Regional Solar Energy Centers (RSECs) and state energy or solar offices significantly $(P<0.05)$ more often.

\subsubsection{Membership in Solar-Interested Organizations}

Representatives of 20 of the 29 Nonconcentrating Mlanufacturers studied were members of a professional, technical, or other organization with an interest in solar energy. These organizations (and the number of times mentioned) included:

- Air Conditioning and Refrigeration Institute (ARI);

- American Chemical Society;

- American Physical Society;

- American Society of Heating, Refrigerating and Air Conditioning Engineers (ASHRAE);

- American Society for Testing Niaterials (ASTM);

- Arizona Solar Energy Society;

- Association of Energy Engineers (AEE);

- Florida Solar Energy Center;

- Home Builders Association;

- International Solar Energy Society (ISES) (9);

- Maine Solar Energy Association;

- National Solar Energy Society;

- North Carolina Solar Energy Association (SEA) (2);

- Northern California Solar Society;

- Ohio Solar Association;

- SEIA (19 total);

Arizona SEIA,

Calif ornia SEIA (2),

Colorado SEIA,

Florida SEIA,

Michigan SEIA, 
Mid Atlantic SEIA,

Pennsylvania SEIA;

- Solar Energy Research and Education Foundation;

- Southern California SEA (2); and

- World Trade Council.

Some organizations were also mentioned which the authors could not verify. These were "Solar Equipment Manuf acturers Association" and "National Swimming Pool Institute."

\subsubsection{Exposure to Publications on Solar Energy}

During the past 6 months, 28 of the 29 representatives of Total Nonconcentrating Collector Manufacturers had read publications which included information on solar energy. The publications they could specify (and the number of times mentioned) included:

- Air Conditioning and Refrigeration Business;

- American Society of Mechanical Engineers papers;

- Builder (American Housing Industry organ);

- Contractor;

- DOE publications, newsletters, and reports (e.g., on solar water heating ) (2);

- Edmund Scientific Co. Catalog;

- Fuel Oil News (2);

- Heating, Piping and Air Conditioning (2);

- Department of Housing and Urban Department (HUD) solar demonstration project in east;

- National Aeronautics and Space Administration (NASA) reports;

- New England Solar Energy Association Newsletter;

- NESEC Update;

- News Roots;

- Passive Solar Energy Book, Miazria;

- Popular Nechanics;

- Popular Science;

- R.S.I. (Roofing, Siding, Insulation);

- San Diego publication on solar cooling;

- Solar Age (14);

- Solar Energy (3);

- Solar energy conference proceedings (in Colorado);

- SEIA News;

- SEIA publications; 
- Solar Energy Intelligence Report (4);

- Solar Engineering (19);

- Solar Heating and Cooling (6);

- Sun Times; and

- Sun Up (2).

Also mentioned were "Leonard Eiserer's publication (Silver Springs, Florida)," "Eric Farber's publication," "Heating and Cooling," "International Solar Engineer," "Passive Systems by Bruce Anderson," "Solar Energy Newsletter," "Solar Primer by David Wright," "Sun Digest," "newspapers," "technical journals," "swimming pool trade journals," "Pool and Spa News," "Solar Heating and Air Conditioning," "Solar Engineer and Cooling," and "trade magazines."

\subsubsection{Use of Special Acquisition Methods}

The respondents were asked whether they had obtained any information (not just solar energy) in the past year by computer terminal, by Computer Output Microform (COM), or by other microform (e.g., microfiche, microfilm sheets or rolls). Few Total Nonconcentrating Collector Manufacturer Representatives appeared accustomed to using these special acquisition methods, a trait common to Manufacturers in all technologies studied. In the past year, only 7 of the 29 (24\%) Total Nonconcentrating Collector Manufacturer Representatives had used a computer terminal, 2 of the $29(7 \%)$ had used COM, and only 3 of the $29(10 \%)$ had used other microf orm.

\subsection{SUMMARY AND COMMENTS}

Total Nonconcentrating Collector Mianufacturers included representatives from 29 manufacturers of Nonconcentrating Collectors. The degree of involvement and the educational level of representatives of Total Nonconcentrating Collector Manufacturers were similar to those of All Manufacturer Representatives. The level of informedness, however, was significantly higher $(P<0.05)$ for Total Nonconcentrating Collector Manufacturer Representatives.

Representatives of 'l'otal Nonconcentrating Collector Vianufacturers gave significantly high $(P<0.05)$ priority to receiving inf ormation on:

- Tax credits, grants, or other economic incentives for solar systems.

They also gave high ratings to:

- Costs and performance of solar systems;

- Standards, specifications, or certification programs for solar systems;

- Costs of installing and operating a solar system compared to a conventional system;

- Marketing statistics and sales projections for solar equipment; and

- Lists of local lenders, insurers, builders, engineers, installers, manufacturers, or distributors for solar systems. 
Total Nonconcentrating Collector Manufacturers gave low ratings to "a bibliography," "educational institutions," "a nontechnical description," "solar energy programs, research ... outside the United States," and "lists of technical experts."

Representatives of Total Nonconcentrating Collector Manufacturers were similar to All Manuf acturer Representatives in their need for information on costs. Beyond this point, however, Total Nonconcentrating Collector Manufacturers differed in that they were significantly $(\mathrm{P}<0.05)$ more interested in "tax credits (etc.)" and appeared to be more marketing oriented. In contrast, manufacturers in other technologies appeared to be more oriented towards monitoring research and technological progress. This was most likely a result of the more advanced stage of commercialization of nonconcentrating collectors compared to products produced by manufacturers in other solar technologies.

Representatives of Total Nonconcentrating Collector Manufacturers most of ten received solar information through "periodicals (etc.)," contacts with professionals including "an installer (etc.)," and "workshops (etc.)," "state energy or solar offices," "private solar energy or environmental organizations," and GPO. Compared to All Manufacturers, Total Nonconcentrating Collector Manufacturers were more frequent users of the "Regional Solar Energy Centers" and "state energy or solar offices." At least 20 of the 29 (69\%) representatives of Total Nonconcentrating Collector Manufacturers were members of a local or national solar energy association. Solar Age, Solar Engineering, and Solar Heating and Cooling served as important information disseminators. 
SEPㄴ. 
SECTION 6.0

\section{INDUSTRIAL PROCESS HEAT ENGINEERS}

\subsection{DESCRIPTION OF RESPONDENTS}

\subsubsection{Description of Sample}

This section describes the results of three telephone studies to determine the needs of plant engineers, industrial engineers, and agricultural engineers for information on solar industrial process heat (IPH). A total of 9 IPH Plant Engineers, 9 IPH Industrial Engineers, and 9 IPH Agricultural Engineers were interviewed.

The sample frame for IPH Plant Engineers was constructed from two sources. Five percent of the engineers listed in the category of Plant and Facilities Engineering in Who's Who In Engineering [10] were selected. Names were also taken from The Association of Energy Engineers (AEE) Directory of Energy Professionals [11] if their title specified plant engineer and their area of expertise specified "plant." Engineers used were not necessarily solar or IPH related. Duplicate names with Engineer sample frames for other technologies, with related researcher sample frames, and with other IPH sample frames were eliminated. After all adjustments were made, 9 interview candidates were selected from a sample frame of 111 names.

The sample frame for IPH Industrial Engineers was taken from the AEE Directory [11]. Names were picked if their area of expertise included: solar energy, industrial process heat, process heat, heat recovery, energy recovery, waste heat recovery, gasification of organic material, use of industrial or wood waste, industrial furnaces, cogeneration, or refinery operation; or if the industrial engineer worked for a manufacturer or (food) processor. Duplicate names with Engineer sample frames for other technologies, with related researcher sample frames, and with other IPH sample frames were eliminated. After all adjustments were made, 9 interview candidates were selected from a sample frame of 42 names.

The sample frame for IPH Agricultural Engineers was taken from the 1979 Directory of the American Section of the International Solar Energy Society [12]; names from the agricultural division with professional codes of "engineer" were used. Subsampling was used to allow no more than 3 names per state. Duplicate names with Engineer sample frames for other technologies, with related researcher sample frames, and with other IPH sample frames were eliminated. After all adjustments were made, 9 interview candidates were selected from a sample frame of 139 names.

Respondents. In making the telephone calls to contact the randomly selected interview candidates, it sometimes occurred that the person could not be reached. In this event, another randorily selected name was substituted for the original name. When individuals were contacted, it was verified that they really were plant engineers, industrial engineers, or agricultural engineers, and that they would be needing information on solar industrial process heat within the next year. If they were not both involved and needing information, they were asked if they could refer the interviewer to someone else in their organization who would be an appropriate respondent. If such a referral was made, a call was then made to this new candidate; if no intraorganizational referral was made, a new candidate was randomly selected from the sample frame. The results of this process may be seen in Table 6-1. 
Table 6-1. COMPLETION OF INTERVIEWS: INDUSTRIAL PROCESS HEAT (IPH) ENGINEERS

Number of Candidates

\begin{tabular}{|c|c|c|c|}
\hline \multirow[b]{2}{*}{ Event } & \\
\hline & $\begin{array}{c}\text { IPH } \\
\text { Plant } \\
\text { Engineers }\end{array}$ & $\begin{array}{l}\quad \text { IPH } \\
\text { Industrial } \\
\text { Engineers }\end{array}$ & $\begin{array}{l}\text { IPH } \\
\text { Agricultural } \\
\text { Engineers }\end{array}$ \\
\hline $\begin{array}{l}\text { Interview completed with sample frame } \\
\text { candidate }\end{array}$ & 6 & 7 & 8 \\
\hline $\begin{array}{l}\text { Interview completed with referral } \\
\text { candidate }\end{array}$ & 3 & 2 & 1 \\
\hline Refusal or candidate termination & 0 & 0 & 1 \\
\hline $\begin{array}{l}\text { Contact attempted: could not reach } \\
\text { candicate within three attempts } \\
\text { or before interviews were completed }\end{array}$ & 3 & 4 & 1 \\
\hline Subtotal & 12 & 13 & 11 \\
\hline $\begin{array}{l}\text { Contact attempted: invalid candidate } \\
\text { (e.g.; inappropriate field of } \\
\text { interest, no telephone) }\end{array}$ & 2 & 5 & 3 \\
\hline TOTAL & 14 & 19 & 14 \\
\hline $\begin{array}{l}\text { Sample frame error rate }{ }^{a} \text { (Percent) } \\
\text { Completion rate }^{\mathrm{b}} \text { (Percent) }\end{array}$ & $\begin{array}{l}14 \\
75\end{array}$ & $\begin{array}{l}32 \\
69\end{array}$ & $\begin{array}{l}21 \\
82\end{array}$ \\
\hline
\end{tabular}

Invalid candidates divided by TOTAĹ

$\mathrm{b}_{\text {Completed interviews divided by Subtotal }}$

Comparisons. For additional insight into the information needs and the information habits of these IPH Plant Engineers, IPH Industrial Engineers, and IPH Agricultural Engineers, results from these groups are compared to each other and to All Engineers. In addition, IPH Industrial Engineers are compared to Active Solar Heating and Cooling (SHAC) Engineers. In performing any statistical comparisons, totals for each IPH Engineer group have been subtracted from the totals for All Engineers. The data for IPH Plant Engineers, IPH Industrial Engineers, IPH Agricultural Engineers, SHAC Industrial Engineers, and All Engineers can be found in Appendix F.

\subsubsection{Current Status of Respondents}

Role. All 9 IPH Plant Engineers were working for industries; none were consultants. None were directly involved with an existing application of industrial process heat. One respondent was heating his/her facilities with solar energy and 1 was in the planning stage of constructing a solar energy office building. Feasibility studies on IPH were being conducted by 1 respondent and had been completed by another ("an analysis of four different applications which resulted in deferring the project because the payback period was determined to be in 11 to 15 years"). Of the remaining 5 IPH Plant Engineers interviewed, 3 were keeping up-to-date and gathering data on industrial process heat, while 2 stated no current involvement in the technology. 
Two of the 9 IPH Industrial Engineers were consulting engineers, the remaining 7 worked for industries. Similar to IPH Plant Engineers, none of the 9 IPH Industrial Engineers were found to be directly involved with an existing application of industrial process heat. Four of the respondents were evaluating the process and economics of IPH, 1 was an advisor on the use of solar panels on roofs and factory buildings, 1 was using a form of passive solar heating, and 4 stated no current involvement in the technology.

Three of the 9 IPH Agricultural Engineers were working for universities, 2 for national laboratories, 2 for manufacturers, 1 for an engineering firm, and 1 for a U.S. Department of Agriculture (USDA) research center. IPH related activities mentioned by the IPH Agricultural Engineers group included installing a system (1) and involvement in system design through an engineering service (1). Five respondents were involved with IPH research activities including: research on drying crops (3); research on evaluating methods for fabricating copper panels (1); research on collection and storage in applications such as heating greenhouses, rural houses and for distilling alcohol (1); and research in agricultural applications (1). Of the remaining 2 IPH Agricultural Engineers interviewed, 1 was not currently involved, but needed information for future use; the other one was only involved in other solar technologies, including installing a limited number of solar collectors and considering photovoltaics energy.

Involvement. Of the three IPH engineer groups studied (plant, industrial, and agricultural), the IPH Agricultural Engineers appeared to be most involved in industrial process heat. Compared to SHAC Industrial Engineers and All Engineers, the IPH Industrial Engineers were significantly $(P<0.05)$ less involved. IPH Plant Engineers were also significantly $(P<0.05)$ less involved than All Engineers. Table 6-2 compares the levels of involvement by the three IPH engineer groups, SHAC Industrial Engineers, and All Engineers.

\section{Table 6-2. LEVEIS OF INVOLVEMENT: INDUSTRIAL PROCESS HEAT (IPH), ACTTVE SOLAR HEATING AND COOLING (SHAC) INDUSTRIAL, AND ALL ENGINEERS}

\begin{tabular}{lrrrrrrrr}
\hline \multicolumn{1}{c}{ Engineer Group } & \multicolumn{2}{c}{$\begin{array}{c}\text { Very } \\
\text { Involved }\end{array}$} & $\begin{array}{c}\text { Moderately } \\
\text { Involved }\end{array}$ & $\begin{array}{c}\text { Slightly } \\
\text { Involved }\end{array}$ & $\begin{array}{c}\text { Not at All } \\
\text { Involved }\end{array}$ \\
\cline { 2 - 9 } & No. & $\begin{array}{c}\text { Per- } \\
\text { cent }\end{array}$ & No. & $\begin{array}{c}\text { Per- } \\
\text { cent }\end{array}$ & No. & $\begin{array}{r}\text { Per- } \\
\text { cent }\end{array}$ & No. & $\begin{array}{r}\text { Per- } \\
\text { cent }\end{array}$ \\
\hline IPH Plant Engineers & 0 & 0 & 1 & 11 & 5 & 56 & 3 & 33 \\
IPH Industrial Engineers & 0 & 0 & 1 & 11 & 7 & 78 & 1 & 11 \\
IPH Agricultural Engineers & 3 & 33 & 1 & 11 & 4 & 44 & 1 & 11 \\
SHAC Industrial Engineers & 3 & 33 & 3 & 33 & 2 & 22 & 1 & 11 \\
All Engineers & 25 & 26 & 21 & 22 & 43 & 45 & 7 & 7 \\
\hline
\end{tabular}

Informedness. The IPH Agricultural Engineers were significantly $(\mathrm{P}<0.05)$ more informed than the IPH Plant Engineers and slightly more informed than the IPH Industrial Engineers. SHAC Industrial Engineers also appeared to be slightly more informed than the IPH Industrial Engineers. Overall, IPH Engineers stated that they were more informed than they were involved. Table 6-3 compares the levels of informedness of the three IPH engineer groups, SHAC Industrial Engineers, and All Engineers. 
Table 6-3. LEVELS OF INFORMEDNESS: INDUSTRIAL PROCESS HEAT (IPH), ACTTVE SOLAR HEATING AND COOLING (SHAC) INDUSTRIAL, AND ALL ENGINEERS

\begin{tabular}{|c|c|c|c|c|c|c|c|c|}
\hline \multirow{2}{*}{ Engineer Group } & \multicolumn{2}{|c|}{$\begin{array}{c}\text { Very } \\
\text { Informed }\end{array}$} & \multicolumn{2}{|c|}{$\begin{array}{l}\text { Nioderately } \\
\text { Informed }\end{array}$} & \multicolumn{2}{|c|}{$\begin{array}{l}\text { Slightly } \\
\text { Informed }\end{array}$} & \multicolumn{2}{|c|}{$\begin{array}{l}\text { Not at All } \\
\text { Informed }\end{array}$} \\
\hline & No. & $\begin{array}{l}\text { Per- } \\
\text { cent }\end{array}$ & No. & $\begin{array}{l}\text { Per- } \\
\text { cent }\end{array}$ & No. & $\begin{array}{l}\text { Per- } \\
\text { cent }\end{array}$ & No. & $\begin{array}{l}\text { Per- } \\
\text { cent }\end{array}$ \\
\hline IPH Plant Engineers & 2 & 22 & 2 & 22 & 5 & 56 & 0 & 0 \\
\hline IPH Industrial Engineers & 1 & 11 & 5 & 56 & 3 & 33 & 0 & 0 \\
\hline IPH Agricultural Engineers & 3 & 33 & 6 & 67 & 0 & 0 & 0 & 0 \\
\hline SHAC Industrial Engineers & 5 & 56 & 4 & 44 & 0 & 0 & 0 & 0 \\
\hline All Engineers & 35 & 36 & 44 & 16 & 17 & 18 & u & u \\
\hline
\end{tabular}

\subsubsection{Background of Respondents}

Of the three IPH engineer groups studied, the IPH Agricultural Engineer respondents appeared to be slightly more educated. All respondents in all three groups held a minimum of a bachelor's degree. Advanced degrees, however, were held by 5 of the 9 (56\%) IPH Agricultural Engineers (1 master's and 4 doctoral degrees) compared to 1 of the 9 (11\%) IPH Plant Engineers (a master's degree) and 3 of the 9 (33\%) IPH Industrial Engineers (2 master's and 1 prof essional engineering degree). The educational level of Total IPH Engineers did not differ significantly from SHAC Industrial Engineers or from All Engineeršs.

Engineering degrees were held by 8 of the 9 (89\%) IPH Plant Engineers, 5 of the 9 (56\%) IPH Industrial Engineers and all 9.of the IPH Agricultural Engineers. The types of engineering degrees held by the $8 \mathrm{IPH}$ Plant Engineers included: electrical (3), mechanical (2), chemical (1), ceramic (1), and not specified (1). The 1 other respondent in the IPH Plant Engineer group held a degree in industrial management. The types of engineering degrees held by the 5 IPH Industrial Engineers included: industrial (2), electrical (2); and chemical (1). The other 4 degrees included industrial technology, industrial management, physics, and pre-med. The types of engineering degrees held by the 9 IPH Agricultural Engineers included: electrical (5), agricultural (2), metallurgical (1), and not specified (1). The years in which the IPH Engineers received their most recent degree are summarized in Table 6-4.

Table 6-4. YEARS SINCE MOST RECENT DEGREE AWARDED: INDUSTRIAL PROCESS HEAT (IPH) ENGINEERS

\begin{tabular}{lcccc}
\hline \multicolumn{1}{c}{ Engineer Group } & $\begin{array}{c}\text { Less Than } \\
\text { 10 Years Ago }\end{array}$ & $\begin{array}{c}10-20 \\
\text { Years Ago }\end{array}$ & $\begin{array}{c}20-30 \\
\text { Years Ago }\end{array}$ & $\begin{array}{c}\text { Over 30 } \\
\text { Years Ago }\end{array}$ \\
\hline IPH Plant Engineers & 4 & 3 & 1 & 1 \\
IPH Industrial Engineers & 2 & 5 & 1 & 1 \\
IPH Agricultural Engineers & 3 & 4 & 2 & 0 \\
\hline
\end{tabular}


As their current profession, the IPH Plant Engineers stated their roles as: plant engineer (4), chief environmental manager/pollution control/energy conservationist (1), energy conservation manager (1), corporate energy manager (1), prof essional engineer (1), and not specified (1). Current professions mentioned by the 9 IPH Industrial Engineers interviewed included: industrial engineer (4), engineer (1), consulting engineer (1), energy conservation engineer (1), senior project engineer (1), and energy manager (1). Of the 9 respondents in the IPH Agricultural Engineer group, 5 stated their current profession as engineers [electrical (2), agricultural (1), professional engineer (1), and engineering manager (1)] and the other 4 as a researcher/teacher, college professor (2), and a research scientist.

The combinations in levels of professional experience were similar for all three IPH engineer groups. The number of years in which each IPH Engineer group had been in their current profession is summarized in Table 6-5.

Table 6-5. YEARS IN CURRENT PROFESSION: 'INDUSTRIAL PROCESS HEAT (IPH) ENGINERRS

\begin{tabular}{lcccc}
\hline \multicolumn{1}{c}{ Engineer Group } & $\begin{array}{c}0-2 \\
\text { Years }\end{array}$ & $\begin{array}{c}3-5 \\
\text { Years }\end{array}$ & $\begin{array}{c}6-10 \\
\text { Years }\end{array}$ & $\begin{array}{c}\text { Over } 10 \\
\text { Years }\end{array}$ \\
\hline IPH Plant Engineers & 0 & 1 & 3 & 5 \\
IPH Industrial Engineers & 0 & 3 & 2 & 4 \\
IPH Agricultural Engineers & 1 & 1 & 3 & 4 \\
\hline
\end{tabular}

\subsection{INPORMATION NEEDS OF RESPONDENTS}

\subsubsection{Technical Areas}

The three groups of IPH Engineers were asked to choose those areas in which they were "particularly interested in obtaining information" from a list of selected technical areas of solar industrial process heat (see Table 6-6). All three groups expressed the highest interest in "hot water" (8 of the 9 in each group) and significantly $(P<0.05)$ less interest in "high-temperature steam." Differences between the groups were not statistically significant.

Table 6-6. AREAS OF INTEREST: INDUSTRIAL PROCESS HEAT (IPH) ENGINEERS

\begin{tabular}{lcccccc}
\hline & \multicolumn{2}{c}{$\begin{array}{c}\text { IPH Plant } \\
\text { Engineers }\end{array}$} & $\begin{array}{c}\text { IPH Industrial } \\
\text { Engineers }\end{array}$ & \multicolumn{2}{c}{$\begin{array}{c}\text { IPH Agricultural } \\
\text { Engineers }\end{array}$} \\
\cline { 2 - 7 } & No. & Percent & No. & Percent & No. & Percent \\
\hline Hot Water & 8 & 89 & 8 & 89 & 8 & 89 \\
Hot Air & 5 & 56 & 8 & 89 & 7 & 78 \\
Refrigeration & 6 & 67 & 7 & 78 & 7 & 78 \\
Low-Temperature Steam & 5 & 56 & 7 & 78 & 6 & 67 \\
Direct Heat & 3 & 33 & 2 & 22 & 3 & 33 \\
High-Temperature Steam & 1 & 11 & 2 & 22 & 2 & 22 \\
\hline
\end{tabular}


Two IPH Plant Engineers volunteered that they were also interested in information on heat pumps ( 1 ) and the feasibility of converting from oil heating systems to solar hot water systems (1). Three IPH Agricultural Engineers volunteered interest in passive heating (1), agricultural applications for crop drying (1), and the use of dessicants for crop drying (1).

\subsubsection{Types of Information}

Respondents were asked to name the information about industrial process heat that was important for them to obtain. Two IPH Plant Engineers wanted information on the cost of systems (cost and payback) and 2 on technical breakthroughs in (economical) applications. Other topies mentioned included: the availability of systems, the availability of equipment, documentation on the performance of existing installations, state-of-the-art information, applications data, the amount of heat recoverable by area, methods to determine equipment requirements (the square footage in collectors required), and data on collectors for hot water heating.

IPH Industrial Engineers felt information on the cost of systems was important (3) including cost, cost justification, and the method to calculate return on investment. Other topics mentioned included: new industrial applications of solar energy, new developments in IPH, performance data, design applications, the benefits of different applications, availability of products, marketing information, data on using solar heat for drying textiles, and information on precombustion air heating and heat sources (hot water or steam) sufficient to preheat heat process tanks to $180^{\circ} \mathrm{F}$.

Three of the 9 IPH Agricultural Engineers felt economics information was important including mentions of design information and procedures for economical systems (1), economical energy storage systems (2), types of economical collectors (1), and cost study information (1). Two of the 9 IPH Agricultural Engineers mentioned case studies on operating experience of IPH systems and new developments as important, and 2 mentioned applications information. Other topies mentioned included: state-of-the-art information, performance data, engineering specifications for IPH systems, procedures for designing systems, a list of IPH systems currently in use and their locations, general information on water heating, and the availability of photovoltaics cells and equipment. Other technical information also considered important included information on: highly efficient electric motors, corrosion control and control strategies, and collector design to get a particular quality of heat exchange.

Some of the respondents volunteered that there was information they needed but were unable to get. Two IPH Industrial Engineer respondents were in need of data on the legality of building codes (1) and the cost of industrial process heat compared to conventional systems (1). Information needed by IPH Agricultural Engineers included data on the type of equipment necessary to get a good payback (1), government sponsored programs on agricultural process heat (1), and research/developments in the field of industrial process heat (1).

Choice Between Specific Needs. A list of 11 types of solar process heat Information products and 13 solar process heat information categories was read to each respondent. Each respondent described the usefulness of each particular item by assigning it a value of "essential," "very useful," "somewhat useful," or "not at all useful." The results are given in Figs. 6-1, 6-2, and 6-3. For the purpose of comparison, the results for SHAC Industrial Engineers (Fig. 6-4) and for All Engineers (Fig. 6-5) are also included. 
Question \#8. I will read a list of potential information or information products on solar systems. For each, please tell me how useful that information would be to you. Would the following be: essential, very useful, somewhat useful, or not at all useful?

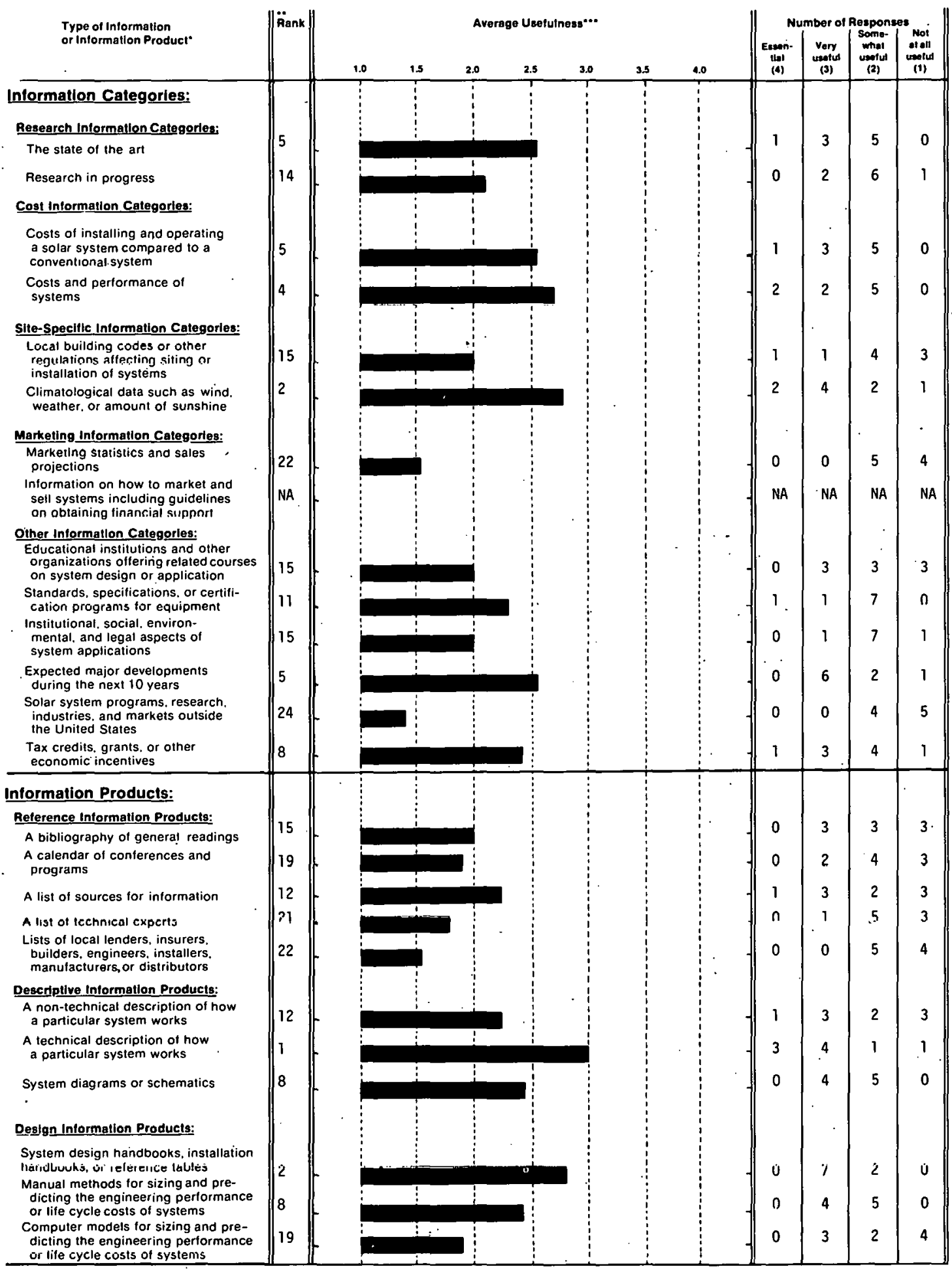

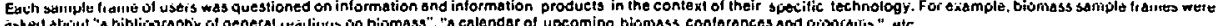

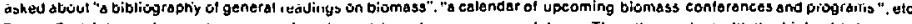

"Aank-Eachintormation product was assigned a rank based on average usefulness. Thus, the product with the highest average usefulness was assigned the rank of " 1 ; : the product hiohesi ranking was then assioner a "4:"

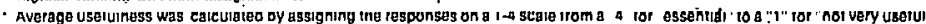

Figure 6-1. Usefulness of Selected Information Items: Industrial Process Heat Planil Enyliuers 
Question \#8. I will read a list of potential information or information products on solar systems. For each, please tell me how useful that information would be to you. Would the following be: essential, very useful, somewhat useful, or not at all useful?

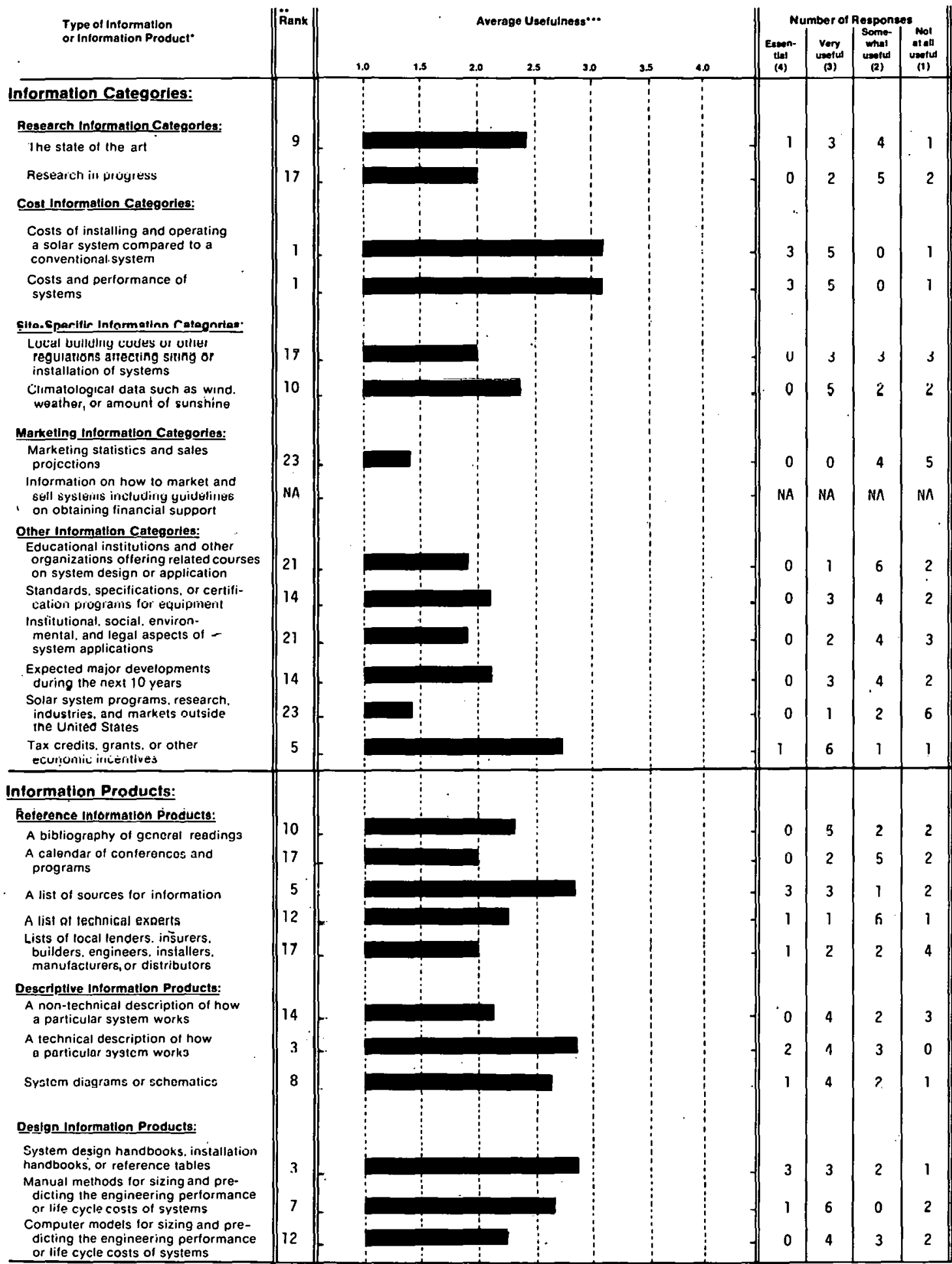

-Each sample trame of users was questioned on information and intormation products in the context of their specific technology. For example, biomass sample trames were asked about "a bibliography of general readings on biomass"." "a calendar of upcoming biomass conterences and programs ". etc.

Rank-Each intormation product was assigned a rank based on average usetulness. Thus. The product with the highest average usefutness was assigned the rank of " 1 "; the product with ine low

... Average usefulness was calculated by assigning the responses on a 1 -4 scale trom a " " " for "essentigl" to a " 1 " tor "nol very usetul".

Figure 6-2. Usefulness of Selected Information Items: Industrial Process Heat Industrlal Engineers 
Question \#8. I will read a list of potential information or information products on solar systems. For each, please tell me how useful that information would be to you. Would the following be: essential, very useful, somewhat useful, or not at all useful?

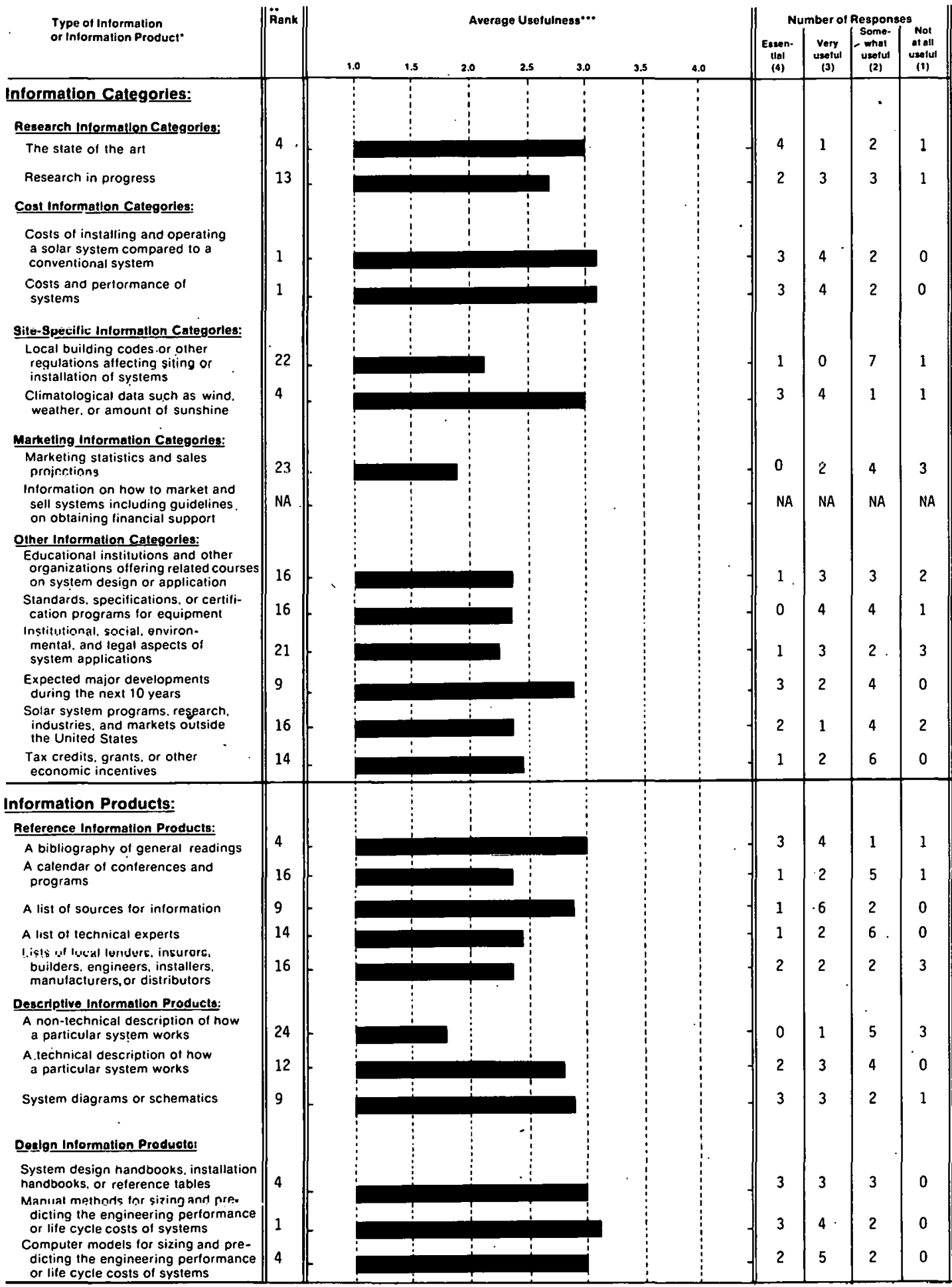

Each sample frame of users was questioned on information and information products in the context of their specitic technology. For example. biomass sample frames were asked about "a bibliography os ang

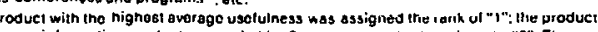
highest ranking was then assigned a " 4 :"

... Average usetulness was calculated by assigning the responses on a 1-4 scale trom a "4" for "essential" 10 a "1" for "not verv useftul"

Figure 6-3. Usefulness of Selected Information Items: Industrial Process Heat Agricultural Engineers 
Question \#8. I will read a list of potential information or information products on solar systems. For each, please tell me how useful that information would be to you. Would the following be: essential, very useful, somewhat useful, or not at all useful?

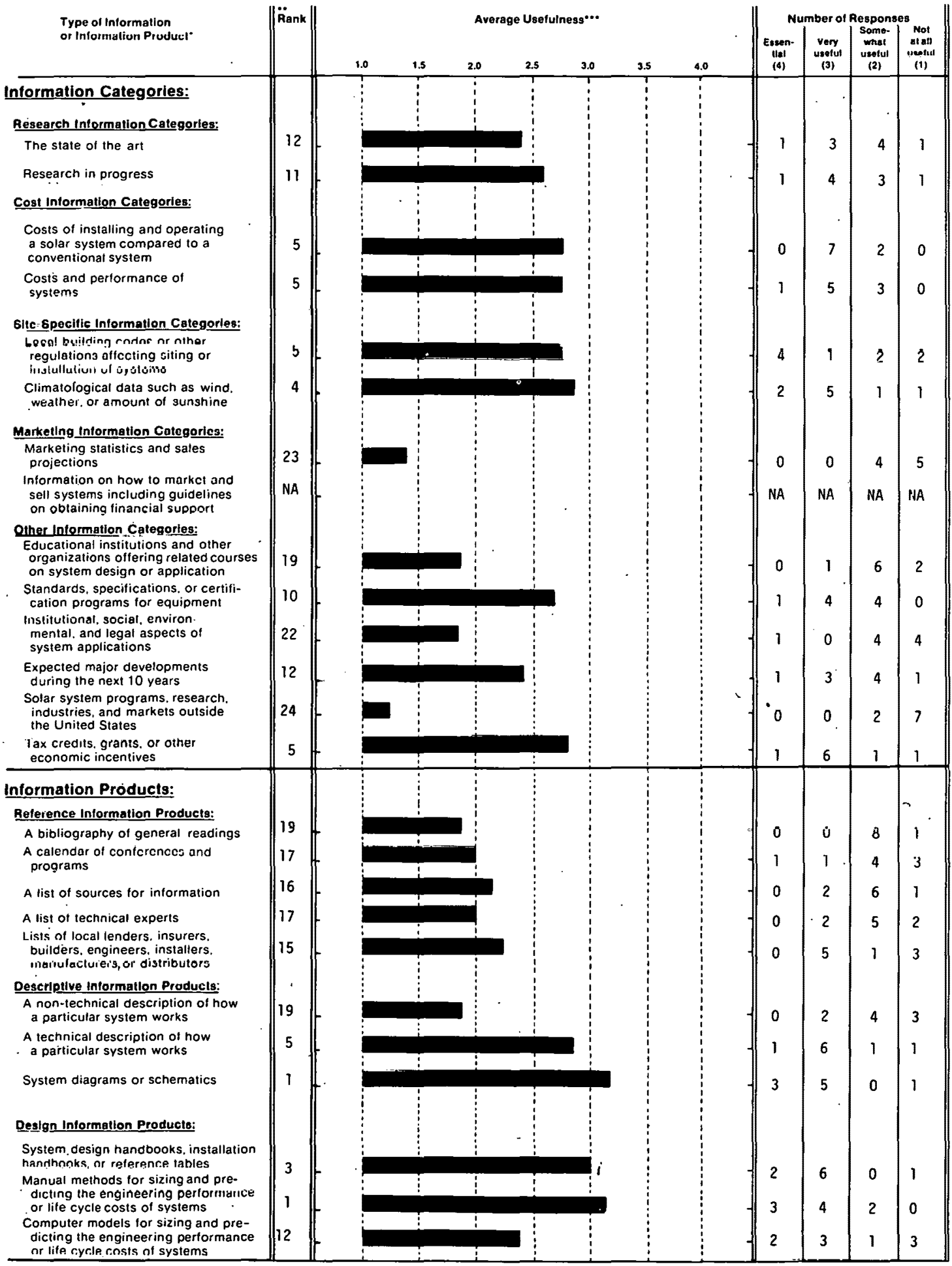

Each sampte frame of users was questioned on intormation and intormation products in the context of their specilic technology. For example, biomass sample frames were "wher assigned the rank of " 1 ": the product wignest ranking was then assigned a $\mathrm{a}$ " 4 :

Average usefulness was calculated by assigning the responses on a 1.4 gcale Irom a "4" tor "essential" to a "1" tor "not very usefur"

Figure 6-4. Usefulness of Selected Information Items: Active Solar Heating and Cooling Industrial Engineers 
Question \#8. I will read a list of potential information or information products on solar systems. For each, please tell me how useful that information would be to you. Would the following be: essential, very useful, somewhat useful, or not at all useful?

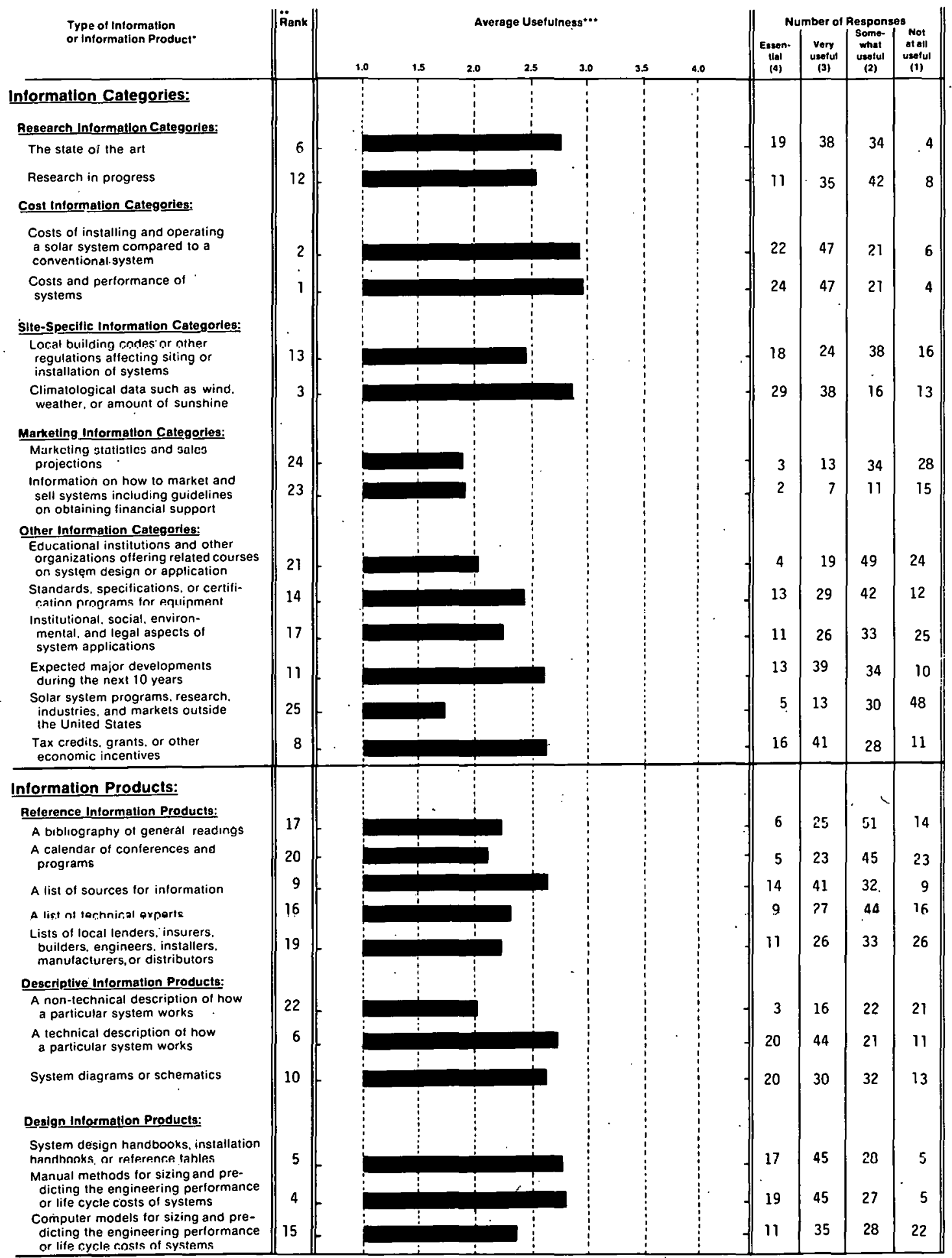

- Each sample trame of users was questioned on intormation and intormation products in the context of their specific technology For evample. biomars sample trames wore asked sboul b bibliography or general readings on biomass. "a calencar of uocoming biamass tanterenr.as and programs ". atc. " Rank-Each intormation product was assigned a rank based on average useiutness. Thus, The procuct with the highest average usefutness was assigned the rank of " 1 ": the producl highest ranking was then assigned a "4:"

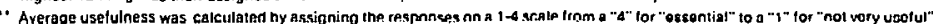


The information categories/products which were rated the highest by IPH Plant Engineers were:

- A technical description of how a particular systems works;

- Climatological data;

- Design handbooks, installation handbooks, or reference tables;

- Costs and performance of systems;

- The state of the art;

- Costs of installing and operating a solar IPH system compared to a conventional system; and

- Expected major developments during the next 10 years.

The information categories/products which were rated the highest by IPH Industriul Engineers were:

- Costs of installing and operating a solar IPH system compared to a conventional system;

- Costs and performance of systems;

- A technical description of how a particular system works;

- Design handbooks, installation handbooks, or reference tables;

- Tax credits, grants, or other economic incentives; and

- Lists of sources for information.

The information categories/products which were rated the highest by IPH Agricultural Engineers were:

- Costs of installing and operating a solar IPH system compared to a conventional system;

- Cost and performance of systems;

- Manual methods for sizing and predicting performance or costs;

- The state of the art;

- Climatological data;

- A bibliography of general readings;

- Design handbooks, installation handbooks, or ref erence tables; and

- Computer models for sizing and predicting performance or costs.

IPH Plant Engineers assigned the lowest ratings to:

- Solar energy programs, research, industries, and markets outside the United States;

- Marketing statistics and sales projections;

- Lists of local lenders, insurers, builders, engineers, installers, manufacturers, or distributors; 
- Lists of technical experts;

- Calendars of conferences and programs; and

- Computer models for sizing and predicting perform ance or costs.

IPH Industrial Engineers assigned the lowest ratings to:

- Marketing statistics and sales projections;

- Solar energy programs, research, industries, and markets outside the United States;

- Educational institutions and other organizations offering courses;

- Institutional, social, environmental, and legal aspects;

- Research in progress;

- Local bullding codes or other regulations;

- Calendars of conferences and programs; and

- Lists of local lenders, insurers, builders, engineers, installers, manufacturers, or distributors.

IPH Agricultural Engineers assigned the lowest ratings to:

- A nontechnical description of how a particular system works;

- Marketing statistics and sales projections;

- Local builaiing codes or other regulations; and

- Institutional, social, environmental, and legal aspects.

For each of these IPH Engineer groups statistical tests indicated that the ratings for these highest-rated information items were significantly $(P<0.05)$ greater than the ratings for these lowest-rated items.

It should be noted that these lower-rated items were not necessarily of no worth to the IPH Plant, Industrial, or Agricultural Engineers. For example, 4 of the 9 (44\%) IPH Agricultural Engineers thought "institutional, social, environmental . . . aspects" were either "essential" or "very useful." Thus, these information categories/products could be useful to'some IPH Engineers, but were of a lower relative priority to the entire group.

Statistical tests were also used to determine whether any of the three IPH Engineer groups rated any of these information items significantly higher (or lower) than they were rated by either of the other IPH Engineer groups or by All Engineers (IPH Industrial Engineers were also compared to SHAC Industrial Engineers). Some groups, however, tended to give higher scores in general than did other groups. To compensate for this effect, these statistical tests compared the "relative rating" given by one group to the "relative rating" given by the other groups. The procedure for calculating the relative rating is described in Appendix E. The average overall rating for IPH Plant Engineers was 2.22; for IPH Agricultural Engineers it was 2.62; for IPH Industrial Engineers it was 2.31; for SHAC Industrial Engineers it was 2.38; and for All Engineers, 2.45.

A comparison of the ratings given by the three IPH Engineer groups showed no statistically significant differences between IPH Plant Engineers and IPH Industrial Engineers. 
There were indications, however, that the IPH Industrial Engineers were more interested in "sources of information" and "technical experts," but less interested in "expected major developments" and "climatological data."

Comparea to SHAC Industrial Engineers, the ratings assigned by IPH Industrial Engineers did not differ significantly.

Compared to IPH Agricultural Engineers, IPH Plant Engineers rated "a nontechnical description" significantly $(P<0.05)$ higher and "computer models" significantly $(P<0.05)$ lower. There also were indications that the IPH Plant Engineers gave higher ratings to descriptive information, but lower ratings to reference information and design information.

Compared to IPH Agricultural Engineers, IPH Industrial Engineers assigned significantly $(P<0.05)$ higher ratings to "tax credits." Additionally, IPH Plant Engineers were more interested in descriptive information, while Agricultural Engineers were more interested in "climatological data," "a bibliography," and "computer models for sizing."

\subsection{ACQUISITION OF INPORMATION BY RESPONDENTS}

\subsubsection{Use of Selected Information Sources}

IPH Engineers were asked which of 20 different potential sources of solar information they had used in the past few years. For this question the respondents were not asked if they had obtained information on industrial process heat, but instead were asked if they had obtained any solar information from each specific source. Thus, the question sought to determine which information sources were the most familiar to the respondents. The results are shown in Figs. 6-6, 6-7, and 6-8. For the purpose of comparison, the results for SHAC Industrial Engineers (Fig. 6-9) and for All Engineers (Fig. 6-10) are also included.

The information sources mentioned most often by IPH Plant Engineers were:

- An installer, builder, designer, or manuf acturer; and

- AEE.

Few IPH Plant Engineers mentioned using any of the 20 information sources. Only 3 of the 20 sources were mentioned by more than half of the engineers in this group. Of the 86 groups included in the study, only one had less familiarity with these information resources than the IPH Plant Engineers. The information sources which received zero mentions included:

- Solar Energy Industries Association (SEIA),

- A commercial data base,

- Smithsonian Science Information Exchange (SSIE), and

- Regional Solar Energy Centers (RSECs).

The information sources mentioned most often by IPH Industrial Engineers were: 
Question \#11. In the past few years, have you obtained any type of solar information from any of the following sources?

Information Sources

Percentage Responding Yes **

Public Media:
Radio or TV
Periodicals, newspapers or magazines
Private Solar-Involved Organizations:
Private solar energy or environmental organizations
The local chapter or national headquarters of International
Solar Energy Society (ISES), including their publications
The local chapter or national headquarters of Solar Energy
Industries AsSociation (SEIA), including their publications
Contacts with Prolessionals:

An installer, builder, designer or manufacturer of solar systems

Workshops, conferences or training sessions

Information Services*:

Your vrganizational library or a local library

A commercial data base; for example, Lockneed, SDC, BRS

Smithsonian Science Information Exchange (SSIE)

A Federal library or information center; for example, the National Agricultural Library or the Environmental Data System

The Government Printing Office (GPO)

National Technical Information Service (NTIS)

Technical Information Center at Oak Ridge (TIC)

Government Solar-Involved Organizations

Directly from the U.S. Department of Energy

National Solar Heating \& Cooling Information Centel

Regional Solar Energy Centers

State Energy or Solar Offices

Other:

Some other state or local government office or publication

A public utility company

Sources for this specific sample frame**:

Association of Energy Engineers

lıslilule ul Eleculical and Elecilıurics Eıyinéérs

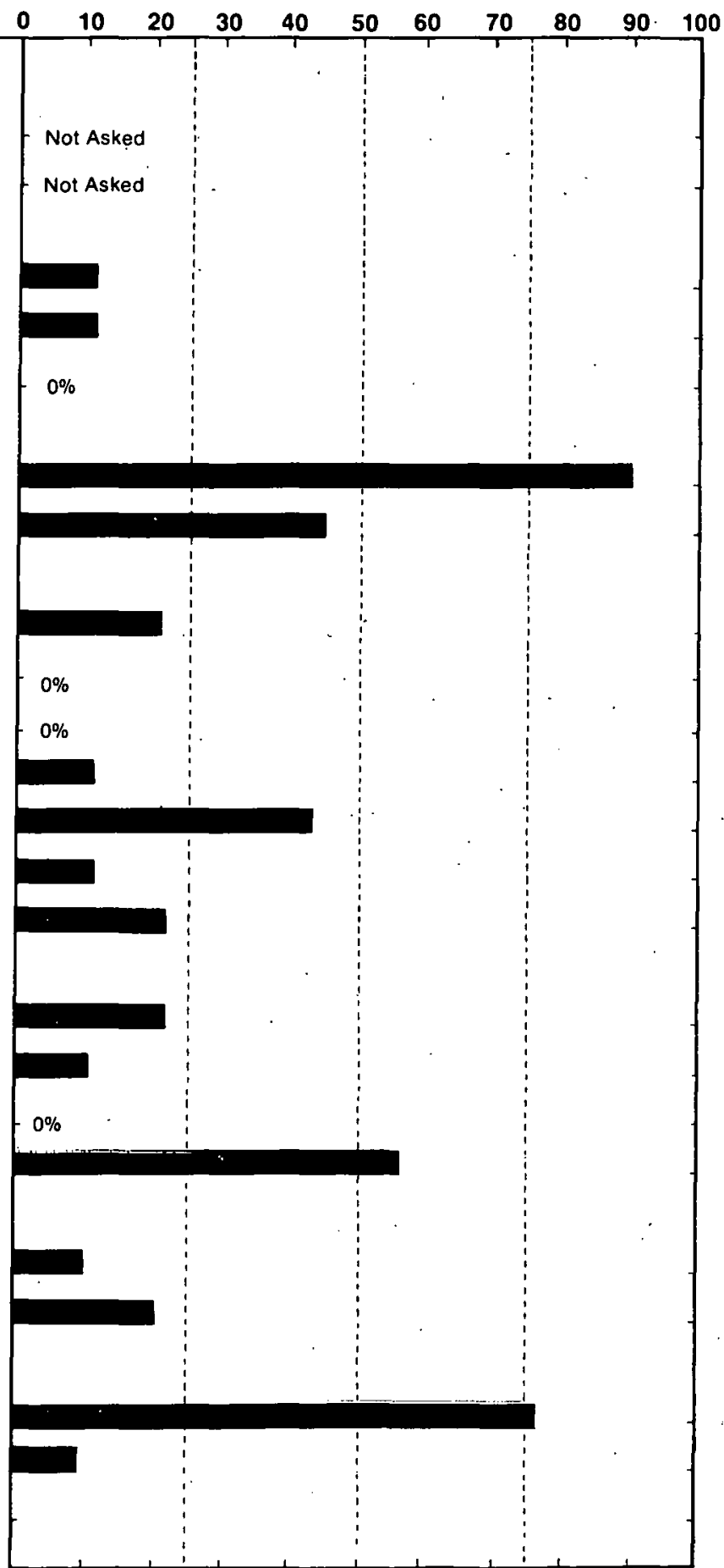

- Services and centers whose primary purpuse is lu disseminirale irifurination.

- Some sample frames were questioned about additional information sources which are applicable to their technology. For example. the manufacturers of biomass conversion equipment were also asked if they have obtained any type of solar intormation from: "the local or national office of the U.E. Dopartmont of Agriculturo, including Extension and Forestry."

*.. These data are based upon a total of 9 respondents.

Figure 6-6. Use of Selected Information Sources: Industrial Process Heat Plant Engineers 
Question \#11. In the past few years, have you obtained any type of solar information from any of the following sources?

Information Sources

Public Media:

Radio or TV

Periodicals, newspapers or magazines

Private Solar-Involved Organizations:

Private solar energy or environmental organizations

The local chapter or national headquarters of international Solar Energy Society (ISES), including their publications

The local chapter or national headquarters of Solar Energy Industries Association (SEIA), including their publications

Coritacts witl, Professionals:

An instalter, builder, designer or manufacturer of solar systems

Workshops, conferences or training sessions

Information Services*:

Your organizational library or a local library

A commercial data base: for example, Lockheed, SDC, BRS

Smithsonian Science Information Exchange (SSIE)

A Federal library or information center; for example, the National Agricultural Library or the Environmental Data System

The Government Printing Office (GPO)

National Technical Information Service (NTIS)

Technical Information Center at Oak Ridge (TIC)

Government Solar-Involved Organizations

Diseclly fium llie U.3. Deparment of tnergy

National Solar Heating \& Cooling Information Center

Regional Solar Energy Centers

State Energy or Solar Oflicies

Other:

Some other state or local government office or publication

A public utility company

Sources for this speccific samole frame**:

Association of Energy Engineers

Institute of Electrical and Elcctronics Engineers
Percentage Responding Yes ${ }^{* * *}$

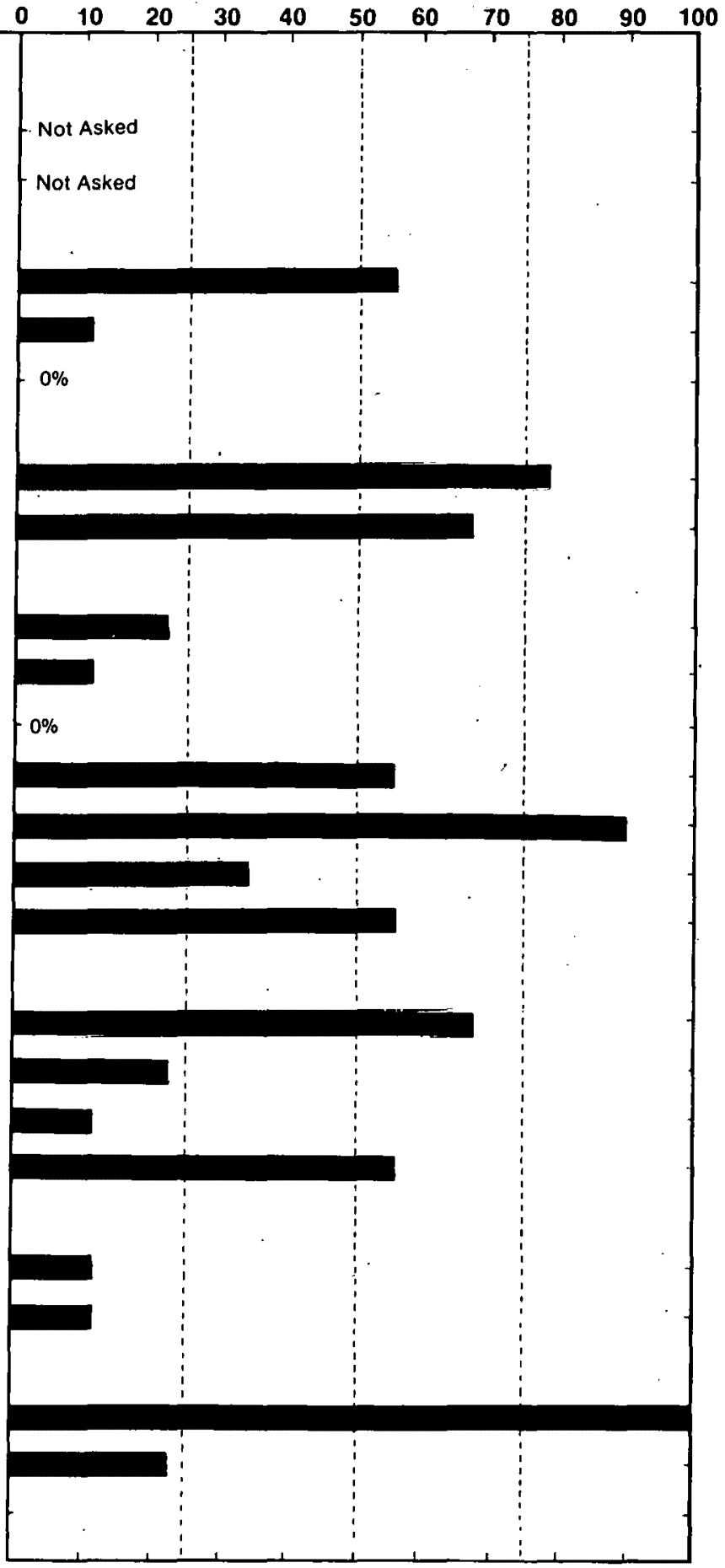

- Services and centers whose primary purpose is to disseminate information.

Some sample frames were questioned about additional information sources which are applicable to their technology. For example, the manufacturers of biomass conversion equipment were also asked it they have obtained any type of solar information from: "the local or national office of the U.S. Department of Agriculture, including Extension and Forestry."

These data are based upon a total of 9 resnondents.

Figure 6-7. Use of Selected Information Sources: Industrial Process Heat Industrial Engineers 
Question \#11. In the past few years, have you obtained any type of solar information from any of the following sources?

Information Sources

Percentage Responding Yes $\cdots$

Public Media:

Radio or TV

Periodicals, newspapers or magazines

Private Solar-Involved Organizations:

Private solar energy or environmental organizations

The local chapter or national headquarters of International Solar Energy Society (ISES), including their publications

The local chapter or national headquarters of Solar Energy Industries Association (SEIA), including their publications

\section{Contacts with Professionals}

An installer, builder, designer or manufacturer of solar systems

Workshops, conferences or training sessions

\section{Information Services*:}

Your organizational library or a local library

A commercial data base: for example, Lockheed, SDC, BRS

Smithsonian Science Information Exchange (SSIE)

A Federal library or information center; for example, the National Agricultural Library or the Environmental Data System

Tine Governmenı Prıntıng Ofrice (GPO)

National Technical Information Service (NTIS)

Technical Information Center at Oak Ridge (TIC)

Government Solar-Involved Organizations

Directly from the U.S. Department of Energy

National Solar Heating \& Cooling Information Cente

Regional Solar Energy Centers

State Energy or Solar Offices

Other:

Some other state or local government office or publication

A public utility company'

Sources for this specific sample frame**:

Association of Energy Engineers

American Societty of Agricultural Engineers

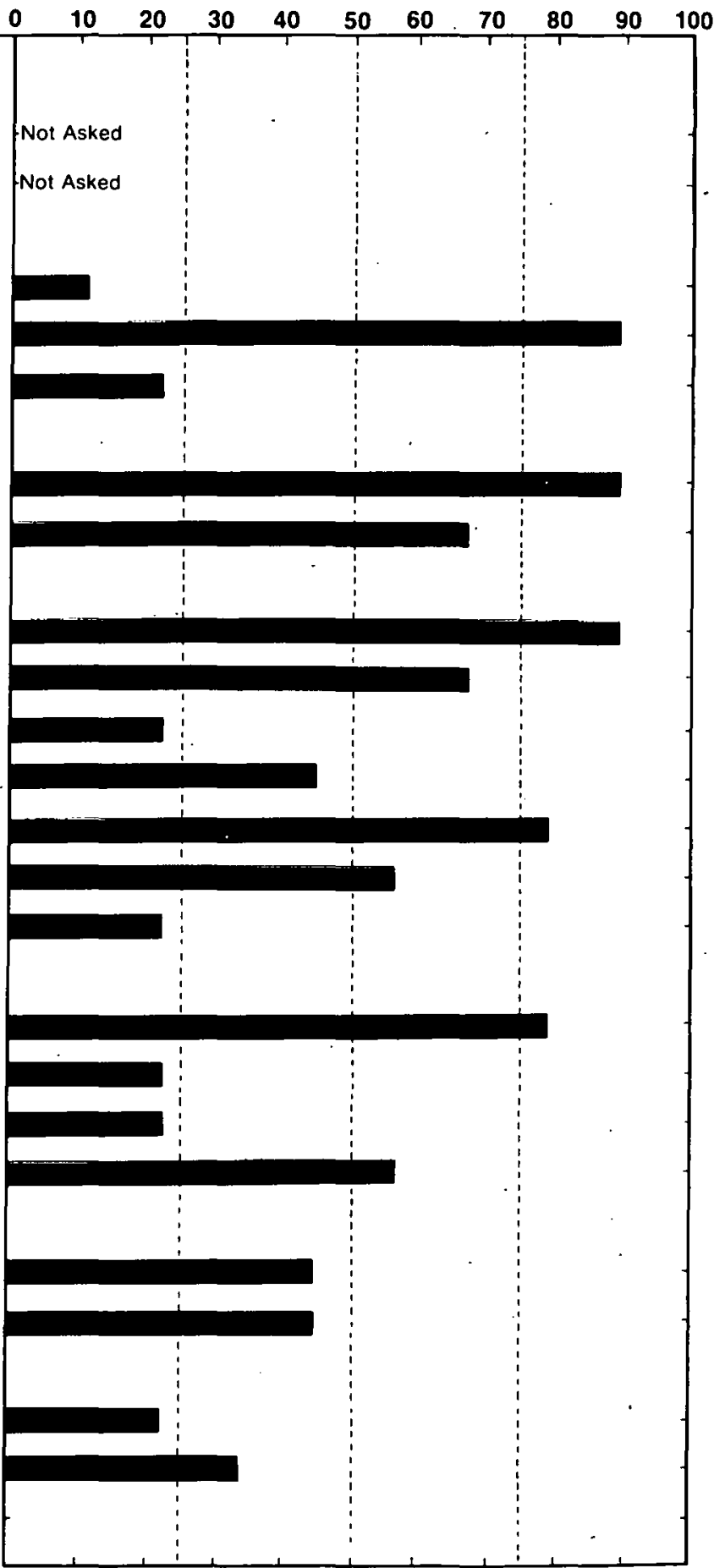

- Services and centers whose primary purpose is to disseminate intormation.

- Some sample frames were questioned about additional information sources which are applicable to their technology. For example. the manufacturers of biomass conversion equipment were also asked if they have obtained any type of solar information from: "the local or national office of the U.S. Department of Agriculture, including Extension and Forestry."

:2: These data are based upon a total of 9 respondents.

Figure 6-8, Use of Selected Information Sources: Industrial Process Heat Agricultural Engineers 
Question \#11. In the past few years, have you obtained any type of solar information from any of the following sources?

Information Sources
Percentage Responding Yes ${ }^{* *}$

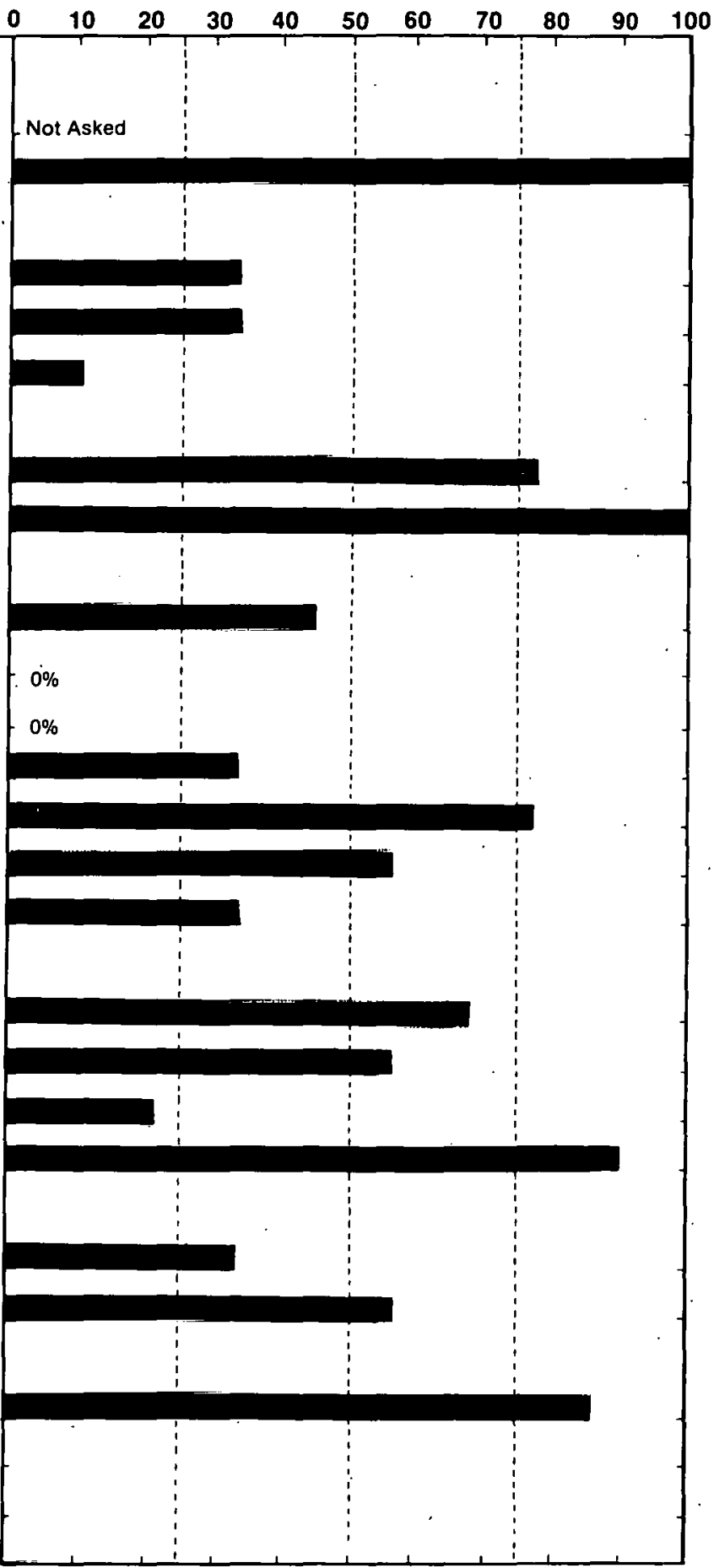

The local chapter or national headquarters of International Solar Energy Society (ISES), including their publications

The local chapter or national headquarters of Solar Energy

Industries Association (SEIA), including their publications

Contacts with Professionals:

An installer, builder, designer or manufacturer of solar systems

Workshops, conferences or training sessions

Information Services":

Your organizational library or a local library

A commercial data base; for example, Lockheed, SDC, BRS

Smithsonian Science Information Exchange (SSIE)

A Federal library or information center; for example, the National Agricultural Library or the Environmental Data System

The Government Printing Office (GPO)

National Technical Information Service (NTIS)

- Technical Information Center at Oak Ridge (TIC)

Government Solar-Involved Organizations

Dlrectly from the U.S. Department of Energy

National Solar Heating \& Cooling Information Centeı

Regional Solar Energy Centers

State Energy or Solar Offices

Other:

Some other state or local government office or publication

A public utility company

Sources for this specific sample frame**:

Association of Energy Engineers

- Services and centers whose primary purpose is to disseminate information.

Some sample frames were questioned about additional information sources which are applicable to their technology. For example, the manufacturers of biomass conversion equipment were also asked it they have obtained any type of solar information from: "the local or national office of the U.S. Department of Agriculture, including Extension and Forestry."

*.* These data are based upon a total of 9 respondents.

Figure 6-9. Use of Selected Information Sources: Active Solar Heating and Cooling Industrial Engineers 
Question \#11. In the past few years, have you obtained any type of solar information from any of the following sources?

Information Sources

Percentage Responding Yes *

\begin{tabular}{l} 
Public Media: \\
\hline Radio or TV \\
Periodicals, newspapers or magazines
\end{tabular}

Private Solar-Involved Organizations:

Private solar energy or environmental organizations

The local chapter or national headquarters of International

Solar Energy Society (ISES), including their publications

The local chapter or national headquarters of Solar Energy

Industries Association (SEIA), including their publications

Contacts.with Professionals:

An installer, builder, designer or manufacturer of solar systems

Workshops, conferences or training sessions

Information Services*:

Your organizational library or a local library

A commercial data base; for example, Lockheed, SDC, BRS

Smithsonian Science Information Exchange (SSIE)

A Federal library or information center; for example, the National

Agricultural Library or the Environmental Data System

The Government Prınting Office (GPO)

National Technical Information Service (NTIS)

Technical Information Center at Oak Ridge (TIC)

Government Solar-Involved Organizations

Directly from the U.S. Department of Energy

National Solar Heating \& Cooling Information Centeı

Regional Solar Energy Centers

State Energy or Solar Offices

Other:

Some other state or local government office or publication

A public utility company

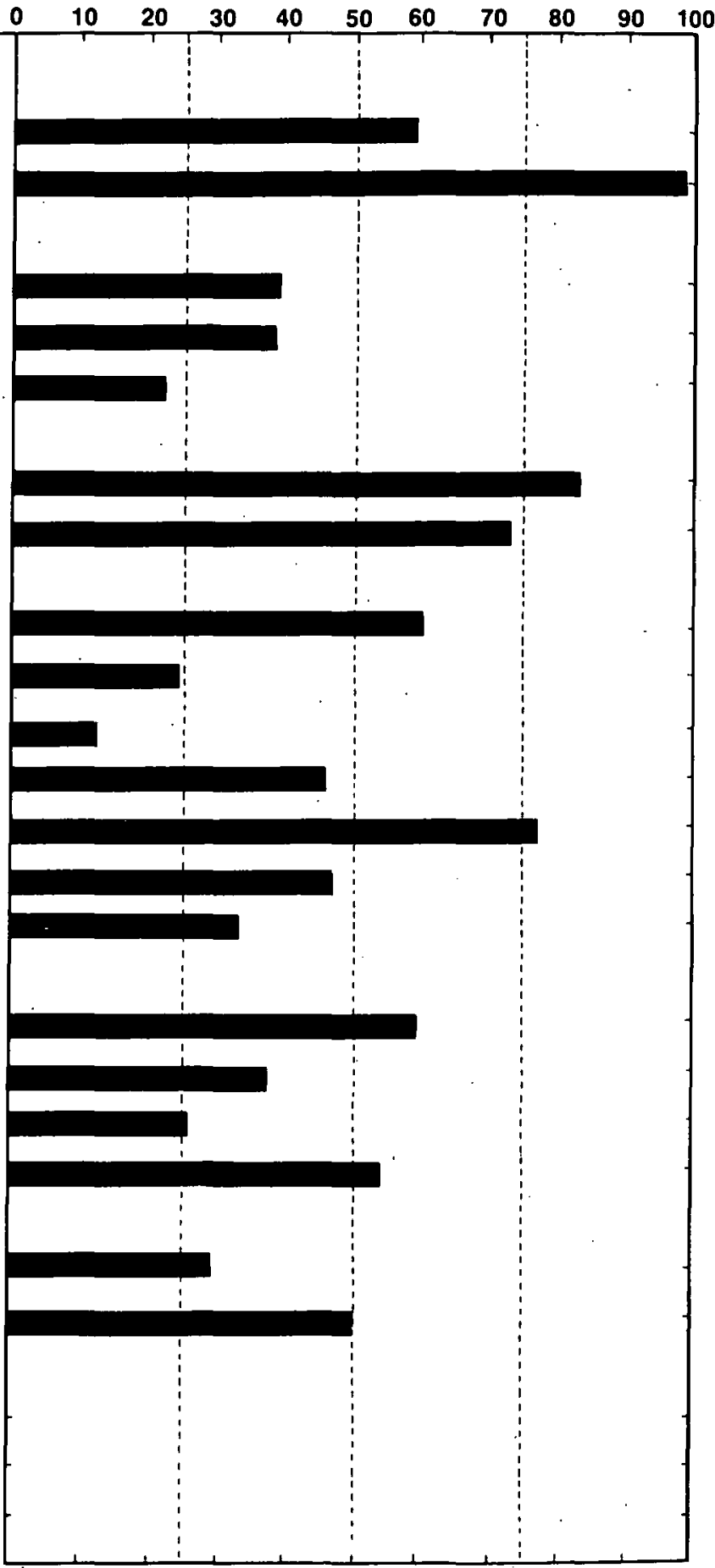

- Services and centers whose primary purpose is to disseminate intormation

- These data are based upon a lulal of 96 iespondents

Figure 6-10. Use of Selected Information Sources: All Engineers 
- AEE;

- The Government Printing Office (GPO);

- An installer, builder, designer, or manufacturer;

- Workshops, conferences, or training sessions; and

- Directly from the U.S. Department of Energy (DOE).

The information sources mentioned least of ten by IPH Industrial Engineers were:

- SEIA,

- SSIE,

- International Solar Energy Society (ISES),

- A commercial data base,

- RSECs,

- Some other state or local government office or publication, and

- A public utility company.

The information sources mentioned most often by IPH Agricultural Engineers were:

- ISES;

- An installer, builder, designer, or manufacturer;

- An organizational library or a local library;

- GPO;

- DOE;

- Workshops, conferences, or training sessions; and

- A commercial data base.

The information sources mentioned least often by IPH Agricultural Engineers were:

- Private solar energy or environmental organizations,

- SEIA,

- SSIE,

- Technical Information Center (TIC),

- National Solar Heating and Cooling Information Center (NSHCIC),

- RSECs, and

- AEE.

The one information source mentioned most often which was common to all three groups of IPH Engineers was "an installer, builder (etc.)." Both IPH Plant and IPH Industrial Engineers mentioned AEE significantly $(P<0.05)$ more often than the IPH Agricultural Engineers, but mentioned ISES, "an organizational library or a local library," and "a commercial data base" significantly $(P<0.05)$ less often. The differences in preferences for AEE and ISES probably are a direct reflection of the method of defining the sample 
(see Section 5.1.1). Although there were no statistically significant differences between IPH Plant Engineers and IPH Industrial Engineers, there were several sources with which the IPH Industrial Engineers appeared to be more familiar. Overall, IPH Plant and IPH Industrial Engineers appeared to mention fewer sources than the IPH Agricultural Engineers.

In contrast to All Engineers, significantly $(P<0.05)$ fewer IPH Plant Engineers use federal sources including "a federal library or inf ormation center," GPO, National Technical Information Service, and DOE. Other comparisons to All Engineers showed IPH Industrial Engineers mentioning ISES significantly $(P<0.05)$ more of ten and "a public utility company" significantly $(\mathrm{P}<0.05)$ less often.

The sources used by IPH Industrial Engineers did not differ significantly from those used by SHAC Industrial Engineers.

\subsubsection{Membership in Solar-Interested Oganizations}

Seven of the 9 IPH Plant Engineers were members of a professional, technical, or some other organization which has an interest in solar energy. These organizations (and the number of times mentioned) included:

- American Institute of Plant Engineers (AIPE) (4),

- American Socicty of Mechanical Engineers (2), and

- AEE (5).

Seven of the 9 IPH Industrial Engineers were members of an organization with an interest in solar energy. 'These organizations (and the number of times mentioned) included:

- Air Pollution Control Association,

- American Institute of Chemical Engineers,

- American Institute of Industrial Engineers,

- AIPE,

- American Society of Heating, Refrigerating and Air Conditioning Engineers (ASHRAE),

- AEE (6),

- National Society of Professional Engineers (NSPE) (2),

- Virginia Society of Prof essional Engineers, and

- Water Pollution Control Federation.

All 9 IPH Agricultural Engineers were members of an organization with an interest in solar energy. These organizations (and the number of times mentioned) included:

- AIPE,

- American Society of Agricultural Engineers (2),

- ASHRAE (2), 
- American Society for Metals,"

- American Welding Society,

- Arizona Solar Energy Association,

- Arkansas Professional Engineers,

- AEE,

- Institute of Electrical and Electronies Engineers,

- ISES (6),

- NSPE (2),

- New Mexico Solar Energy Association,

- Oklahoma Prof essional Engineers, and

- SEIA.

Also mentioned by one IPH Agricultural Engineer was "ISEE," an organization which could not be verified by the authors.

The two organizations mentioned by one or more respondents in all three groups of IPH Engineers were AEE and the American Institute of Plant Engineers. This strong representation for AEE, however, most probably reflected the method of sample frame development (see Section 5.1.1). Similarly, the high percentage of IPH Agricultural Engineers in ISES also could be explained by sample frame development.

\subsubsection{Exposure to Publications on Solar Energy}

During the past 6 months, 8 of the 9 (89\%) IPH Plant Engineers, all 9 IPH Industrial Engi= neers, and all IPH Agricultural Engineers had read publications which included information on solar industrial process heat. The publications they could specify (and the number of times mentioned) are displayed in Table 6-7.

Also mentioned by IPH Plant Engineers was "AEE Bulletin (about a midwestern plant using total solar power for electricity)," "Facilities Planner," "Heating, Ventilation, and Air Conditioning," and "Presidential report on Plant Energy Management, IPC publisher." "I'hese publications could not be verified by the authors.

Also mentioned by IPH Industrial Engineers were additional publications which could not be verified by the authors. These included "Advertisers Data Sheet," "American Society of Energy Conservation" publications, "Flat Plate Collector Technology Materinls," "Modern Industrial Energy," "Journal of the Association of Solar Energy Engineers," "Solar Gradient Ponds Material," and "textbooks."

Also mentioned by 1 IPH Agricultural Engineer was "Proceedings of Second Conference of SHAC Demonstration Program Contractors Review, Volume II and III," a publication which could not be verified by the authors. 
Table 6-7. PUBLICATIONS READ WHICH INCLUDED INFORMATION ON SOLAR ENERGY: NDUSTRIAL PROCESS HEAT (IPH) ENGINEERS

\begin{tabular}{|c|c|c|c|c|}
\hline \multirow{2}{*}{ Publication } & \multicolumn{3}{|c|}{ IPH Engineer Group } & \multirow{2}{*}{$\begin{array}{l}\text { Total } \\
\text { IPH }\end{array}$} \\
\hline & Plant & Industrial & Agricultural & \\
\hline Air Conditioning and Refrigeration Business & 1 & - & - & 1 \\
\hline Agricultural Engineering & - & - & 1 & 1 \\
\hline Alternative Sources of Energy & - & 1 & - & 1 \\
\hline $\begin{array}{l}\text { American Society of Heating, Refrigerating and } \\
\text { Air Conditioning Engineers (ASHRAE) publications }\end{array}$ & - & - & 1 & 1 \\
\hline ASHR AE Journal & - & 1 & - & 1 \\
\hline American Society of Mechanical Engineers journals & 1 & - & - & 1 \\
\hline $\begin{array}{l}\text { Association of Energy Engineers publications } \\
\text { (including } 1 \text { mention for Energy Engineer Magazine) }\end{array}$ & - & 2 & - & 2 \\
\hline Bornquist literature (Solaron distributor) & - & - & 1 & 1 \\
\hline Building Systems Design & - & 1 & - & 1 \\
\hline Chemical and Engineering News & 1 & - & - & 1 \\
\hline Chemical Engineering. & - & 2 & - & 2 \\
\hline Chemical Engineering Progress & - & 1 & - & 1 \\
\hline Encyclopedia of Energy by McGraw Hill & - & - & 1 & 1 \\
\hline Energy Management and Federal Energy Guidelines & 1 & - & - & 1 \\
\hline Energy User News & 2 & 2 & 1 & 5 \\
\hline Factory & 1 & - & - & 1 \\
\hline Heating, Piping and Air Conditioning & - & 2 . & 1 & 3 \\
\hline Industry Week & 1 & - & - & 1 \\
\hline Instruments and Control Systems & 1 & - & - & 1 \\
\hline $\begin{array}{l}\text { International Solar Energy Society publications } \\
\text { (including l mention for "proceedings on } \\
\text { agricultural uses") }\end{array}$ & - & $=$ & 2 & 2 \\
\hline Machine Design & 1 & - & - & 1 \\
\hline Manufacturer's bulletins & - & - & 1 & 1 \\
\hline Mechanical Engineering & 1 & - & - & 1 \\
\hline New Mexico Solar Energy publications & - & - & 1 & 1 \\
\hline Plant Energy Management & 3 & 1 & 1 & 5 \\
\hline Plant Engineering & 7 & 1 & - & 8 \\
\hline Power & 1 & 1 & 1 & 3 \\
\hline Production Engineering & - & 1 & - & 1 \\
\hline Solair Age & - & 1 & 4 & 5 \\
\hline Solar Energy & - & - & 4 & 4 \\
\hline Technology for Energy Conservation & - & - & . & 1 \\
\hline
\end{tabular}




\subsubsection{Use of Special Acquisition Methods}

The respondents were asked whether they had obtained any information (not just industrial process heat or solar energy) in the past year by computer terminal, by Computer Output Microform (COM), or by other microform (e.g., microfiche, microfilm sheets or rolls).

During the past year, the IPH Industrial Engineers appeared slightly more accustomed to using these special acquisition methods than the other two IPH Engineer groups studied. In the past year, 5 of the 9 Industrial, 4 of the 9 Agricultural, and 2 of the 9 Plant Engineers had used a computer terminal; only 1 of the 9 Industrial, 1 of the 9 Agricultural, and none of the Plant Engineers had used COM; however, 2 of the 9 Industrial, 4 of the 9 Agricultural, and 1 of the 9 Plant Engineers had used other microform. A comparison of the three groups of IPH Engineers to each other or to SHAC Industrial Engineers showed no statistically significant differences in the proportion using computer terminals, COM, or other microform.

\subsection{SUMMARY AND COMMENTS}

A total of 9 plant engineers, 9 industrial engineers, and 9 agricultural engineers were interviewed on industrial process heat. IPH Agricultural Engineers was the only group having direct involvement in industrial process heat. Their involvement level was similar to that of SHAC Industrial Engineers.

The technical area of industrial process heat generating the highest interest in all three IPH Engineer groups was "hot water," with the least interest shown in "high-temperature steam." Other areas of interest were "hot air," "refrigeration," and "low-temperature steam."

The IPH Plant Engineers gave the highest priority to receiving information on:

- A technical description of how a particular solar IPH system works;

- Climatological data;

- Solar IPH system design handbooks, installation handbooks, or reference tables;

- Costs and performance of solar IPH systems;

- The state of the art in solar IPH;

- Costs of installing and operating a solar IPH system compared to a conventional systern; and

- Expected major developments in solar IPH during the next 10 years.

IPH Industrial Engineers gave the highest priority to receiving information on:

- Costs of installing and operating a solar IPH system compared to a conventional . system;

- Costs and performance of solar IPH systems;

- A technical description of how a particular solar IPH system works;

- Solar IPH system design handbooks, installation handbooks, or reference tables; 
- Tax credits, grants, or other economic incentives for solar IPH; and

- Lists of sources for information on solar IPH.

Inf ormation assigned the highest priority by IPH Agricultural Engineers included:

- Costs and performance of solar IPH systems;

- Costs of installing and operating a solar IPH system compared to a conventional system;

- Manual methods for sizing and predicting performance or cost of solar IPH systems;

- The state of the art in solar IPH;

- Climatological data;

- A bibliography of general readings on solar IPH;

- Solar IPH system design handbooks, installation handbooks, or ref erence tables; and

- Computer models for sizing and predicting performance or cost of solar IPH systems.

IPH Plant Engineers assigned the lowest ratings to "solar energy programs, research $\therefore .$. outside the United States," "marketing statistics," "lists of local lenders (etc.)," "lists of technical experts," "calendars of conferences," and "computer models."

IPH. Industrial Engineers gave low ratings to "marketing statistics," "solar energy programs . . . outside the United States," "educational institutions," "institutional, social . . . aspects," "research in progress," "local building codes," "calendars of conferences," and "lists of local lenders (etc.)."

IPH Agricultural Engineers gave low ratings to "a nontechnical description," "marketing statistics," "local building codes," and "institutional, social . . . aspects."

The resulting picture showed that cost information was valued highly by all three groups of IPH Engineers. Ratings given by IPH Plant Engineers and IPH Industrial Engineers were similar, with no significant differences found. However, a comparison of these two groups to IPH Agricultural Engineers identified the agricultural group as somewhat less interested in descriptive information (technical and nontechnical) and more interested in methods for sizing and predicting performance (both manual methods and computer models). The lower levels of involvement by both IPH Plant and IPH Industrial Engineers may have been a factor in their greater need for descriptive information than the IPH Agricultural Engineers, whose level of involvement in solar industrial process heat was higher.

IPH Plant Engineers appeared to rely on a limited number of sources, principally "an installer, builder (etc.)," and AEE. IPH Industrial Engineers also rely on these two sources plus GPO. IPH Agricultural Engineers used many more sources, most of ten mentioning ISES, "an installer, builder (etc.)," "an organization ... library," GPO, and DOE. 
Both IPH Plant Engineers and IPH Industrial Engineers appeared to rely more on publications specifically on engineering, while IPH Agricultural Engineers frequently used solar publications. These preferences may have been biased by the sample selection procedure: both IPH Plant and Industrial Engineers were selected from -AEE sources, and IPH Agricultural Engineers were selected from ISES sources (see Section 6.1.1). 


\section{SECTION 7.0}

\section{SOLAR INDUSTRIAL PROCESS HEAT EDUCATORS}

\subsection{DESCRIPTION OF RESPONDENTS}

\subsubsection{Description of Sample}

This section describes the results of a telephone study to determine the needs of postsecondary educators for information on industrial process heat. Nine Industrial Process Heat (IPH) Educators were interviewed.

The sample frame for IPH Educators was constructed by searching the Solar Energy Information Data Bank (SEIDB) Education Data Base [13]. Thirty-eight colleges listed courses which included industrial process heat information and identified instructors for each course. Both introductory and advanced level course instructors were included. Instructors who also appeared in Educator sample frames for other technologies were eliminated. Related Researcher and Engineer sample frames were checked for duplication of contact names, and duplicates were eliminated from the larger sample frame. After all adjustments were made, the 9 interview candidates were randomly selected from the sample frame of 33 names.

Respondents. In making the telephone calls to contact the randomly selected interview candidates, it sometimes occurred that the person could not be reached. In this event another randomly selected name was substituted for the original name. When individuals were contacted it was verified that they really had been teaching courses on industrial process heat, and that they would be needing information on industrial process heat within the next year. If they were not both involved and needing inf ormation, they were asked if they could refer the interviewer to someone else in their organization who would be an appropriate respondent. If such a referral was made, a call was then made to this new candidate; if no intraorganizational referral was made, a new candidate was randomly selected from the sample frame. The results of this process may be seen in Table 7-1.

Comparisons. For additional insight into the information needs and the information habits of these IPH Educators, results from this group are compared to the results from all of the educators interviewed in this study (All Educators). In addition to industrial process heat, the technologies included in All Educators were wind energy conversion, active solar heating and cooling, passive solar heating and cooling, photovoltaics, biomass, and solar thermal electric power. In performing any statistical comparisons, the totals for IPH Educators have been subtracted from the totals for All Educators. The data for Wind Educators and for All Educutors can be found in Appendix F.

\subsubsection{Current Status of Respondents}

Role. Six of the 9 IPH Educators were on the faculties of four-year colleges or universities, the other 3 taught at two-year colleges. Seven of them taught courses in engineering departments (mechanical, environmental, industrial and management, technology, industrial/mechanical technology, and thermal/cnvironmental). The otheir 2 educators were in an applied science department and a public affairs department. All 9 
Table 7-1. COMPLETION OF INTERVIEWS: INDUSTRIAL PROCESS HEAT EDUCATORS

Event

Number of

Candidates

Interview completed with sample frame candidate

Interview completed with ref errul curididale

Refusal or candidate termination

Contact attempted: could not reach candidate. within three

attempts or before interviews were completed

8

1

1

Subtotal

11

21

Contact attempted: invalid candidate (e.g.; inappropriate

field of interest, $\mathrm{nn}$ telephone)

TOTAL

Sample frame error rate ${ }^{a}$ (Percent)

Completion rate ${ }^{b}$ (Percent)

anvalid candidates divided by TOTAL

${ }^{\mathrm{b}}$ Completed interviews divided by Subtotal

taught courses which covered many energy topics; at least one course included solar IPH. In describing what they were presently doing in IPH, only 3 specifically mentioned teaching ( 1 teaching conferences, 2 teaching courses). Four mentioned working on solar projects ( 1 on process heat pumping projects, 1 as a designer for a DOE-funded project and other projects, 1 on a solar heating and cooling system demonstration project, and 1 in use and development of solar hot water heat). Three mentioned looking into proposals and possibilities for use of solar process heat.

Involvement. Two of the 9 (22\%) IPH Educators said that they were "very involved" in industrial process heat. Another 3 of the IPH Educators said that they were "moderately involved" in industrial process heat, thus making 5 of the $9(56 \%)$ of these educators either "very involved" or "moderately involved." This was lower than the $78 \%$ (49 of the 63) of All Educators who were either "very involved" or "moderately involved." The IPH Educators were the least involved group in comparison with all the Educator groups interviewed in this study.

Informedness. Four of the 9 (44\%) IPH Educators considered themselves "very informed," compared to 31 of the 63 (49\%) All Educators. Another 3 IPH Educators said that they were "moderâtely informed," thus making 7 of llı 9 (78\%) of thrse cducators either "very informed" or "moderately informed." This was lower than for All Educators, where 58 of the 63 (92\%) considered themselves at least "moderately informed."

One possible explanation of the lower levels of involvement and informedness than observed in All Educators is that for other technologies the teachers were generally instructors for advanced-level courses only. 


\subsubsection{Background of Respondents}

Five of the 9 (56\%) IPH Educators held doctoral degrees, 3 (33\%) held master's degrees and 1 (11\%) held a bachelor's degree. In comparison, 44 of the 63 (70\%) All Educators had doctoral degrees, 12 of the 63 (19\%) had master's degrees and 5 of the 63 (8\%) had bachelor's degrees. Six of the IPH Educators had degrees in engineering ( 2 mechanical, 1 solar, 1 industrial, 2 general), 2 had degrees in education (1 industrial), and 1 a degree in political science. Seven of the $9 \mathrm{IPH}$ Educators had received their most recent degree within the past 15 years: 2 of these within the past 5 years, 3 from 5-10 years ago, and 2 from 10-15 years ago. Two IPH Educators received their degree 15-25 years ago.

Most (6 of the 9 or 67\%) of the IPH Educators had been in their present profession (not necessarily teaching) for over 10 years. Two were in their present profession for 3-5 years and 1 for less than 2 years. In comparison, 41 of the 63 (65\%) All Educators had been in their present profession for over 10 years. All 9 gave their present profession as educator, professor, or instructor. Other professional descriptions were: department chairman (2), manager (1), solar consultant (1), solar design engineer (1), and solar installation engineer (1). Two respondents included reference to solar energy in their descriptions of profession.

\subsection{INFORMATION NEEDS OF RESPONDENTS}

\subsubsection{Technical Areas}

IPH Educators were asked to choose those areas in which they were "particularly interested in obtaining information" from a list of selected technical areas of solar industrial process heat. They seemed to be more interested in "hot water" ( 8 of the 9), "lowtemperature steam" ( 8 of the 9), and "hot air" ( 8 of the 9) than in "direct heat" (4 of the 9). Information on "high-temperature steam" (6 of the 9) and "refrigeration" (7 of the 9) were also of interest.

One IPH Educator volunteered that he/she was also interested in solar electrical generation.

\subsubsection{Types of Information}

IPH Educators were asked to name the information about industrial process heat that was important for them to obtain. All 9 volunteered one or more items of information which they considered important. Included in the items they mentioned were: information on current applications ( $3-1$ results of demonstrations, 1 case studies, and l educational information on installations); performance data (3-1 industrial heat system performance information, 1 data on actual operation of a large-scale solar heating system, and 1 "good performance data"); schematics and diagrams of particular systems; methods of analysis; life of collectors; "contact knowledge related to current trends"; new techniques; and potential applications.

Information that IPH Educators volunteered they needed but were unable to get included: climatological data (2) and information on existing IPH systems. One Educator said all information was inconvenient to obtain: it took too long to obtain and the procedures were too drawn out. 
Choice Between Specific Needs. A list of 11 types of solar industrial process heat information products and 14 types of solar industrial process heat information categories was read to each respondent. Each respondent described the usefulness of each particular item by assigning it a value of "essential," "very useful," "somewhat useful," or "not at all useful." The results are given in Fig. 7-1. For the purpose of comparison, results for All Educators are in Fig. 7-2.

IPH Educators gave the two items in the cost information category high ratings as a class. Their four top-rated inf ormation categories/products were:

- Expected major developments during the next 10 years;

- Costs of installing and operating a solar IPH system compared to a conventional system;

- Costs and performance of systems; and

- A lechrical description of how a partlcular system works.

IPH Educators gave the two items in the marketing information category low ratings as a class. The five lowest-rated inf ormation categories/products were:

- Educational institutions and other organizations offering courses;

- Marketing statistics and sales projections;

- How to market and sell solar systems;

- Standards, specifications, or certification programs; and

- Solar energy programs, research, industries, and markets outside the U.S.

Statistical tests indicated that significant $(P<0.05)$ diff erences existed between the ratings for the four highest-rated information items and the five lowest-rated information items for IPH Educators.

It should be noted that these lower-rated items were not necessarily of no worth to the IPH Educators. For example, 2 of the 9 (22\%) thought "marketing statistics" was either "essential" or "very useful." Thus, these information categories/products could be useful to some IPH Educators, but were of a lower relative priority to the entire group.

Statistical tests were also used to determine whether the IPH Educators rated any of these information items significantly higher (or lower) than they were rated by All Educators. Some groups, however, tended to give higher scores in general than did other groups. To compensate for this effect, these statistical tests compared the "relative rating" given by one group to the "relative rating" given by the other groups. The procedure for calculating the relative rating is described in Appendix E. The average overall rating IPH Educators gave to all items was 2.49, for All Educators, 2.64.

In comparing the results for IPH Educators to the results for All Educators, there were marked similarities. The two cost information items and "expected major developments" were also among the top-rated items for All Educators, where each of the seven groups of educators were asked about the same items, but for different technologies. All Educators concurred with lowest ratings for three of the five categories/products, i.e., the two marketing information items and "solar system programs ... outside the U.S." were also rated lowest by All Educators. Statistical tests indicated that, compared to All 
Question \#8. I will read a list of potential information or information products on solar systems. For each, please tell me how useful that information would be to you. Would the following be: essential, very useful, somewhat useful, or not at all useful?

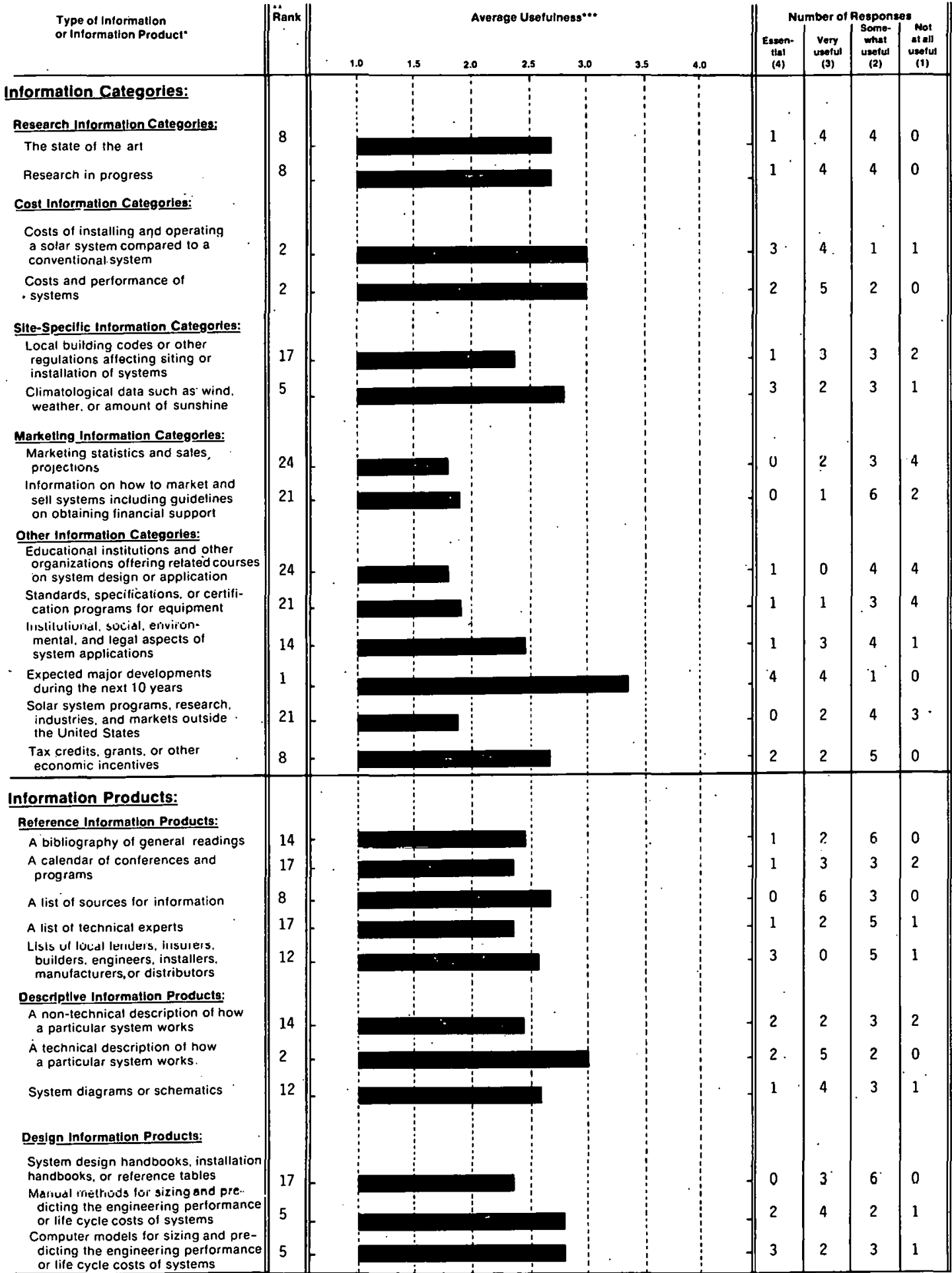

- Each sample frame of users was questioned on intormation and intormation products in the context of their specific technotogy. For exampte, biomass samplo frameo wore

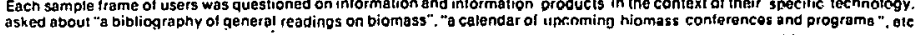

- Rank-Each intormation product was assigned a rank based on average uselulness. Thus. The product with the highesl average usefulness was assigned the rank of " 1 ": Ihe product with ine lowest average usetulness would be ranked " 25 " where all items were asked, II two or more intormation products were lied tor 2 nd. they were both assigned a " 2 ". The nex

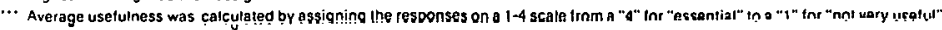

Figure 7-1. Usefulness of Selected Information Items: Industrial Process Heat Educators 
Question \#8. I will read a list of potential information or information products on solar systems. For each, please tell me how useful that information would be to you. Would the following be: essential, very useful, somewhat useful, or not at all useful?

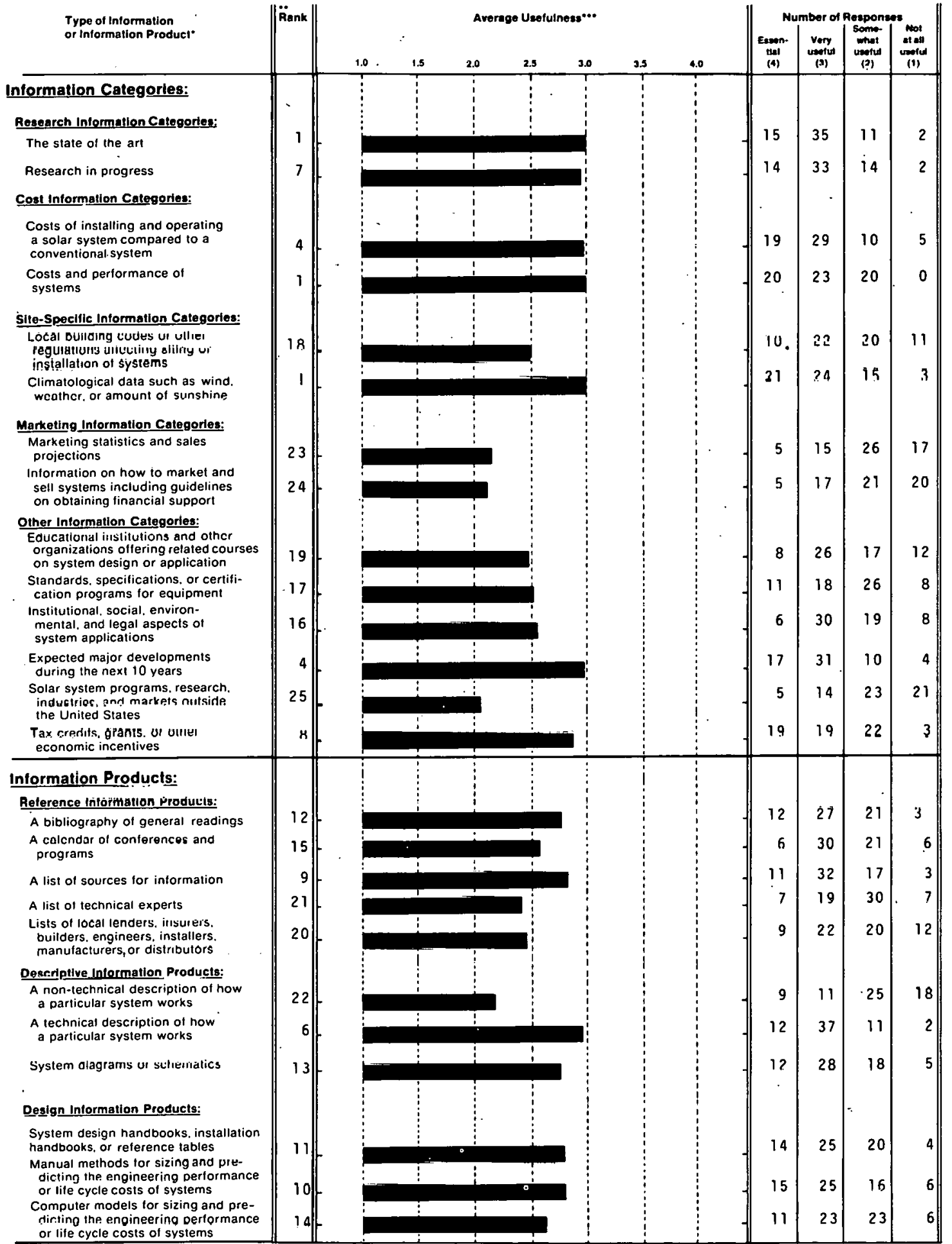

Each sample frame of users was questioned on intormation and information products in the context of their specific technology. For example. biomass sample frames were asked aboul "a bibliography of generąl readings on biomass"." "a colendar ol upcoming biomass conferences and programs". etc. Rank - Each intormation product was assigned a rank based on average usetulness. Thus. Ihe product with the highesl average usefulness was assigned the rank of "1"; the producl with the lowest average usetulness woutd be ranked " 25 " where all items were asked. 11 two of more intormation products were tied for 2 nd. they were both assigned a " $2 "$. The nex

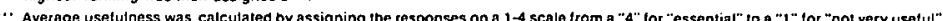

Figure 7-2. Usefulness of Selected Information Items: All Educators 
Educators, the IPH Educators rated "expected major developments" significantly $(\mathrm{P}<0.05)$ higher and "standards" and "educational institutions" significantly $(\mathrm{P}<0.05)$ lower.

\subsection{ACQUISTION OF INFORMATION BY RESPONDENTS}

\subsubsection{Use of Selected Information Sources}

IPH Educators were asked which of 20 different potential sources of solar information they had used in the past few years. For this question the respondents were not asked if they had obtained information about solar industrial process heat, but instead were asked if they had obtained any solar information from each specific source. Thus, the question sought to determine which information sources were the most familiar to the respondents. The results for IPH Educators are shown in Fig. 7-3. For comparison, those for All Educators are shown in Fig. 7-4.

The information sources mentioned most often by IPH Educators (at least 7 of the 9 had used them) were:

- Periodicals, newspapers, or magazines;

- An organizational library or a local library;

- Workshops, conferences, or training sessions;

- Directly from the U.S. Department of Energy (DOE);

- An installer, builder, designer, or manuf acturer of solar systems;

- National Technical Inf ormation Service (NTIS); and

- A public utility company.

In comparing these results to those for All Educators, it was found that all of the topmentioned sources except "public utility company" and NTIS were among the five topmentioned sources for All Educators.

The information sources mentioned least of ten by IPH Educutors were:

- Smithsonian Science Information Exchange,

- A commercial data base,

- Radio or TV,

- Solar Energy Industries Association, and

- Regional Solar Energy Centers.

Once again the results for All Educators were virtually identical. Four of these sources were also among the five lowest-rated items for All Educators (only "Radio or TV" was not). 
Question \#11. In the past few years, have you obtained any type of solar information from any of the following sources?

Information Sources

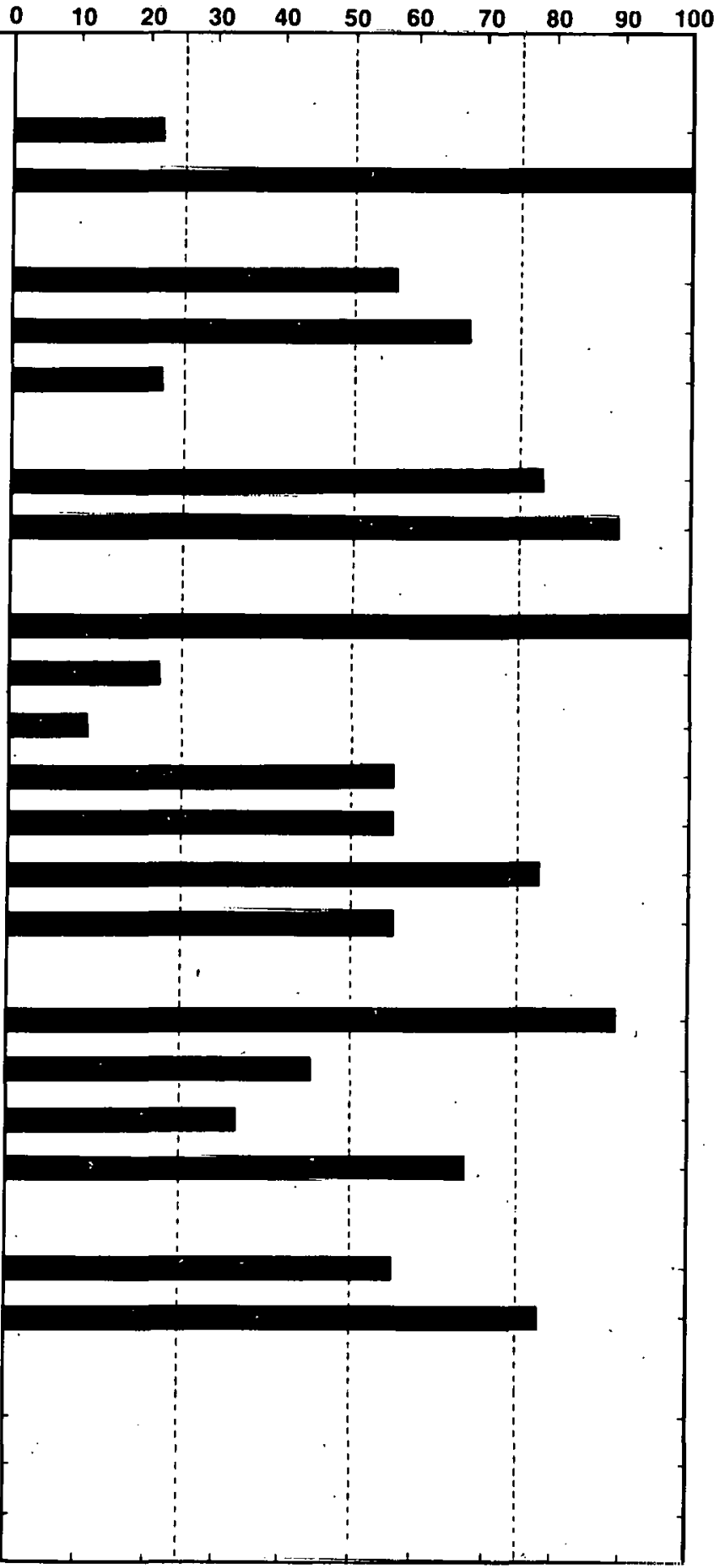

Percentage Responding Yes**

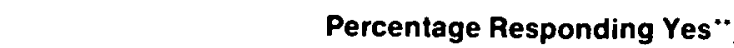

Private solar energy or environmental organizations

The local chapter or national headquarters of International Snlar Enerov Society (!SES), including their publications

The Incal chapter or national headquarters of Solar Energy Industries Association (SE|A). including theır publıćảtıóńś

\section{Contacts with Prntessinnals.}

An installer, builder, designer or manufacturer of solar systems Workshops, conferences or training sessions

\section{Information Services*:}

Your organizational library or a local library

A commercial data base; for example, Lockheed, SDC, BRS

Smithsonian Science Information Exchange (SSIE)

A Federal library or information center; for example, the National Agricultural Library or the Environmental Data System

The Government Printing Office (GPO)

National Technical Information Service (NTIS)

Technical Information Center at Oak Ridge (TiC)

Government Solar-Involved Organizations

Directly from the U.S. Department of Energy

National Solar Heating \& Cooling Information Centel

Regional Solar Energy Centers

State Energy or Solar Offices

Other:

Some other state or local government office or publication

A public utility company 
Question \#11. In the past few years, have you obtained any type of solar information from any of the following sources?

Information Sources

Public Media:

Radio or TV

Periodicals, newspapers or magazines

Private Solar-Involved Organizations:

Private solar energy or environmental organizations

The local chapter or national headquarters of International Solar Energy Society (ISES), including their publications

The local chapter or national headquarters of Solar Energy Industries Association (SEIA), including their publications

\section{Contacts with Professionals:}

An installer, builder, designer or manufacturer of solar systems

Workshops, conferences or training sessions

\section{Information Services*:}

Your organizational library or a local library

A commercial data base; for example, Lockheed, SDC, BRS

Smithsonian Science Information Exchange (SSIE)

A Federal library or information center; for example, the National Agricultural Library or the Environmental Data System

The Government Printing Office (GPU)

National Technical Information Service (NTIS)

Technical Information Center at Oak Ridge (TIC)

\section{Government Solar-Involved Organizations}

Directly from the U.S. Department of Energy

National Solar Heating \& Cooling Information Center

Regional Solar Energy Centers

State Enoryy or Solar Dffirea

Other:

Some other state or local government office or publication A public utility company
Percentage Responding Yes *"

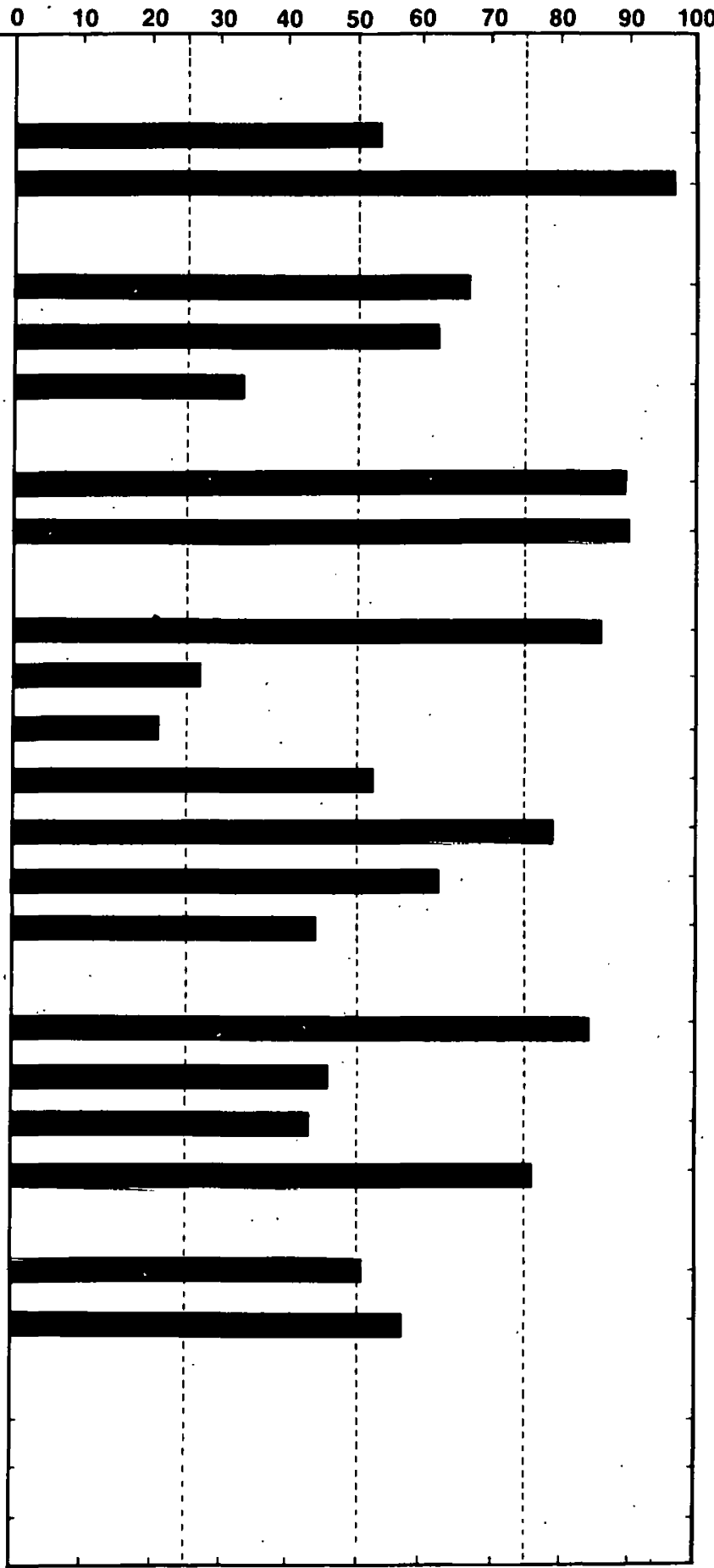

- Services and centers whose primary purpose is to disseminate information.

-These dala are based upon a total of 63 respondents. 


\subsubsection{Membership in Solar-Interested Organizations}

Eight of the 9 IPH Educators were members of a professional, technical, or other organization with an interest in solar energy. These organizations (and the number of times mentioned) included:

- American Association for the Advancement of Science;

- American Institute of Industrial Engineers;

- American Physical Society;

- American Society of Heating, Refrigerating and Air Conditioning Engineers;

- American Society of Mechanical Engineers (2);

- American Vocational Association;

- International Solar Energy Society (ISES) (4);

- Louisiana Solar Energy Council (New Orleans Chapter);

- Michigan Society of Prof essional Engineers;

- National Society of Professional Enginieers; and

- Oregon Vocational Association.

Engineering and solar energy associations (particularly ISES) were the most popular organizations with the IPH Educators.

\subsubsection{Exposure to Publications on Solar Energy}

During the past 6 months, 8 of the 9 IPH Educators had read publications which included information on industrial process heat. The publications they could specify (and the number of times mentioned) included:

- Civil Engineering journals,

- Conference proceedings,

- DOF. reports,

- Heat Transfer journals,

- Plant Energy Management,

- Plant Engineering,

- Sandia National Lab reports,

- Solar Age (3),

- Solar Energy journals, and

- Solar Engineering.

Solar energy publications (specifically Solar Age) were the most popular readings among this group of respondents. 


\subsubsection{Use of Special Aquisition Methods}

The respondents were asked whether they had obtained any information (not just industrial process heat or solar energy) in the past year by computer terminal, by Computer Output Microform (COM), or by other microform (e.g., microfiche, microfilm sheets or rolls). Few of the IPH Educators appeared accustomed to using these special acquisition methods. Three (33\%) had used a computer terminal in the past year, none had used COM, and 3 (33\%) had used other microf orms. By comparison, All Educators had 22\%, $6 \%$, and $33 \%$ using computer terminals, COM, and other microforms, respectively.

\subsection{SUMMARY AND COMMENTS}

Nine postsecondary educators teaching courses including solar industrial process heat topics were interviewed. In addition to teaching, four were working on solar IPH projects and three were looking into possibilities for use of process heat. Despite this, the IPH Educators considered themselves the least involved in their technology of any of the groups of Educators studied. IPH Educators also considered themselves less informed than did All Educators. Some of the differences between IPH Educators and All Educators may be because the IPH Educators included instructors of basic level courses, while for most other groups of Educators only instructors of advanced level courses were inter viewed.

The level of education of IPH Educators was similar to that for All Educators. Most IPH Educators had degrees in engineering and were teaching in engineering departments.

The technical areas of solar industrial process heat which most interested these educators were "hot water," "low-temperature steam," "hot air," "refrigeration," and "high temperature steam."

IPH Educators gave the highest priority to receiving information on:

- Expected major developments in solar IPH during the next 10 years,

- Costs of installing and operating a solar IPH system compared to a conventional system,

- Custs and performance of solar IPH systems, and

- A technical description of how a particular solar IPH system works.

They gave low ratings to "educational institutions," "marketing statistics and sales projections," "how to market and sell solar industrial process heat systems," "solar energy programs, research, industries, and markets outside the U.S.," and "standards, specifications, or certification programs."

In addition to the high ratings given to "a technical description" and "costs and performance," information on current applications was mentioned as important for these respondents to obtain.

IPH Educators most of ten received solar information from "periodicals, newspapers, or magazines," "an organizational library or a local library," "workshops, conferences, or training sessions," DOE, "an installer, builder, designer, or manufacturer," and NTIS. Many were members of engineering or solar energy associations. Publications such as Solar Age were the most popular publications from which these respondents received solar information. 
SE간 


\section{SECTION 8.0}

\section{STATE AGRICULTURAL OFFICE REPRESENTATIVES}

\subsection{DESCRIPTION OF RESPONDENTS}

\subsubsection{Description of Sample}

This section describes the results of a telephone study to determine the needs of representatives of State Departments of Agriculture for information on solar agricultural process heat (APH). Eight State Agricultural Office Representatives were interviewed.

The sample frame for State Agricultural Office Representatives was selected from a list provided by the Colorado Department of Agriculture [14]. The list contained contact names, phone numbers, and addresses for all 50 states. Contact names were director, chairman, or commissioner. Alaska and Hawaii were not used. The 8 interview candidates were randomly selected from a sample frame of 48 names.

Respondents. In making the telephone calls to contact the randomly selected interview candidates, it sometimes occurred that the person could not be reached. In this event another randomly selected name was substituted for the original name. When individuals were contacted, it was verified that they really had some interest in solar agricultural process heat $(\mathrm{APH})$, and that they would be needing information on APH within the next year. If they were not both involved and needing information, they were asked if they could refer the interviewer to someone else in their organization who would be an appropriate respondent. If such a referral was made, a call was then made to this new candidate; if no intraorganizational referral was made, a new candidate was randomly selected from the sample frame. The results of this process may be seen in Table 8-1. In one case, the interviewer inadvertently completed an interview with a referral candidate who was not employed by a State Department of Agriculture, and therefore could not be included in this sample.

Table 8-1. COMPLETION OF INTERVIEWS: STATE AGRICULTURAL OPFICE REPRESENTATIVES

Event

Number of

Candidates

Interview completed with sample frame candidate

Interview completed with ref erral candidate

6

Refusal or candidate termination

Contact attempted: could not reach candidate within three

attempts. or before interviews were completed

Subtotal

Contact attempted: invalid candidate (e.g.; inappropriate

field of interest, no telephone)

TOTAL

Sample frame error rate (Percent) $^{a}$

Completion rate ${ }^{b}$ (Percent)

a Invalid candidates divided by TOTAL

${ }^{b}$ Complcted interviews divided by Subtotal 
Comparisons. For additional insight into the information needs and information habits of these State Agricultural Office Representatives, results from this group are compared to the results from state level Cooperative Extension Service (CES) specialists in agriculture and information (All State Specialists) and from CES County Agricultural Agents (APH County Agents) interviewed in this study about solar agricultural process heat (see Section 8.0). The data for State Agricultural Office Representatives, All CES State Specialists, and APH County Agents can be found in Appendix F.

\subsubsection{Current Status of Respondents}

Respondents represented the following eight states:

- Calif ornia,

- lowa,

- Kanses,

- Maryland,

- Montana,

- Oregon,

- South Carolina, and

- Vermont.

Thus, these respondents were fairly well scattered across the country. In comparison, APH County Agents represented mostly the central United States, while All State Specialists (13 states) had no representation from states in New England nor the far West.

Role. Solar activities in which State Agricultural Office Representatives were currently engaged included not only APH, but active solar heating and cooling and the use of biomass energy. Three respondents were involved in providing information on APH: 1 of these was preparing a publication for farmers and setting up a demonstration project; another was operating an APH information clearing house. Two were involved with gasohol: the production of ethanol (not APH), and the use of gasohol for grain drying. Two other respondents were reviewing APH literature, and 1 was associated with farm demonstrations for heating water (APH).

Involvement. Two of the 8 (25\%) State Agricultural Office Representatives said that they were "very involved" in solar agricultural process heat, 1 was "moderately involved," and the other 5 were "slightly involved."

Informedness. Three of the 8 (38\%) State Agricultural Office Representatives stated that they were cither "very infurmcd" or "moderulely informed." Five were only "slightly informed." APH County Agents were similarly not very well informed about APH, while All State Specialists were more informed about solar energy generally.

Need for Information. All respondents indicated they would need information on solar APH on the job during the next year. Five of the 8 (62\%) State Agricultural office Representatives expected to need information on solar APH outside the job as well as on the job. This was about the same level of expected off-the-job information need that was found for APH County Agents (5 of the 9,56\%). All State Specialists (7 of the 18, $39 \%)$ were less likely to need solar information outside of their jobs. 


\subsubsection{Background of Respondents}

Three of the State Agricultural Office Representatives held master's degrees, 1 held a PhD., and 3 held bachelor's degrees ( 1 held no degree). The proportion of advanced degree holders (beyond bachelor's) was about the same for these respondents as for APH County Agents (50\% and 56\%, respectively), but much lower than for All State Specialists (83\%). Only 3 of the State Agricultural Office Representatives had received their most recent degree in agricultural fields: agricultural education, animal nutrition, and agricultural engineering. Other degree fields were: chemistry, biochemistry, and political science (2). Five of the 7 degree-holders had received their most recent degree within the past 10 years, and 2 more than 35 years ago.

Two of the State Agricultural Office Representatives had been in their current profession for less than 2 years, 3 for 3-5 years, and 4 for over 6 years. In addition to stating their present professions as commissioner, administrator, or director of the State Department of Agriculture, respondents also described themselves as researcher, marketing specialist, and director of a long-range planning program.

\subsection{INFORMATION NEEDS OF RESPONDENTS}

\subsubsection{Technical Areas}

State Agricultural Office Representatives were asked to choose those areas in which they were "particularly interested in obtaining information" from a list of selected technical areas of solar agricultural process heat. Interest levels were high for all areas. Six expressed interest in all five areas about which they were asked. APH County Agents showed similarly high levels of interest (see Table 8-2).

Table 8-2. AREAS OF INTEREST: STATE AGRICULTURAL OFFICE REPRESENTATIVES AND AGRICULTURAL PROCESS HEAT (APH) COUNTY AGENTS

\begin{tabular}{lcccc}
\hline \multicolumn{1}{c}{$\begin{array}{c}\text { Technical } \Lambda \text { rea } \\
\text { of Interest }\end{array}$} & $\begin{array}{c}\text { State } \\
\text { Agricultural } \\
\text { Office Reps }\end{array}$ & \multicolumn{2}{c}{$\begin{array}{c}\text { APH } \\
\text { County } \\
\text { Agents }\end{array}$} \\
\cline { 2 - 6 } & No. & Percent & No. & Percent \\
\hline Total Respondents & 8 & 100 & 9 & 100 \\
\hline Livestock sheiter heating & 7 & 88 & 7 & 78 \\
Crop drying & 7 & 88 & 7 & 78 \\
Greenhouses & 7 & 88 & 7 & 78 \\
Food processing & 7 & 88 & 6 & 67 \\
Grain drying & 6 & 75 & 8 & 89 \\
\hline
\end{tabular}

Some State Agricultural Office Representatives volunteered that they were also interested In: irrigation and pumping powcr, alcohol distillation (gasohol), water heating, solar storage, farm home heating, and photovoltaics. 


\subsubsection{Types of Information}

State Agricultural Office Representatives were asked to name the information about solar APH that was important for them to obtain. Seven of the 8 volunteered one or more items of information which they considered important. Topics mentioned included: fruit and vegetable dehydration, economics and cost effectiveness, solar heating of stock watering tanks in winter, solar alcohol production, uses of solar energy for reducing moisture in corn mash, practical developments in farm solar collector design and installation, types of materials that produce best results, and insolation for specific areas. Three respondents expressed the importance of any and all information that relates specifically to farm applications.

Information that State Agricultural Office Representatives volunteered they needed but were unable to get included: a list of sources of information and nontechnical information on system effectiveness and "re-usability."

Choice Belween Specific Needs. A list of 11 types of solar APH information products and 14 types of solar APH information categories was read to each respondent. Each respondent described the usefulness of each particular item by assigning it a value of "essential," "very useful," "somewhat useful," or "not at all useful." The results are displayed in Fig. 8-1. For the purpose of comparison, results for APH County Agents are shown in Fig. 9-1, those for All State Specialists in Fig. 9-3 (Section 9.0).

The five top-rated information categories/products selected by the State Agricultural Office Representatives were:

- Lists of sources for information;

- Tax credits, grants, or other eçonomic incentives\}

- Costs and perf ormance of systems;

- A nontechnical description of how a particular system works; and

- System diagrams or schematics.

State Agricultural Office Representatives assigned the lowest relative ratings to:

- Solar energy programs, research, industries, and markets outside the United States;

- How to market and sell solar systems;

- Marketing statistics and sales projections; and

- Institutional, social, environmental, and legal aspects.

Statistical tests indicated that all five of the top categories/products were rated significantly $(P<0.05)$ higher than were the four lowest-rated items.

It should be noted that these lower-rated items were not necessarily of no worth to the State Agricultural Office Representatives. For example, 4 of the 8 (50\%) thought "local building codes" were "very useful." Thus, these information categories/products could be useful to some State Agricultural Office Representatives, but were of a lower relative priority to the entire group. 
Question \#8. I will read a list of potential information or information products on solar systems. For each, please tell me how useful that information would be to you. Would the following be: essential, very useful, somewhat useful, or not at all useful?

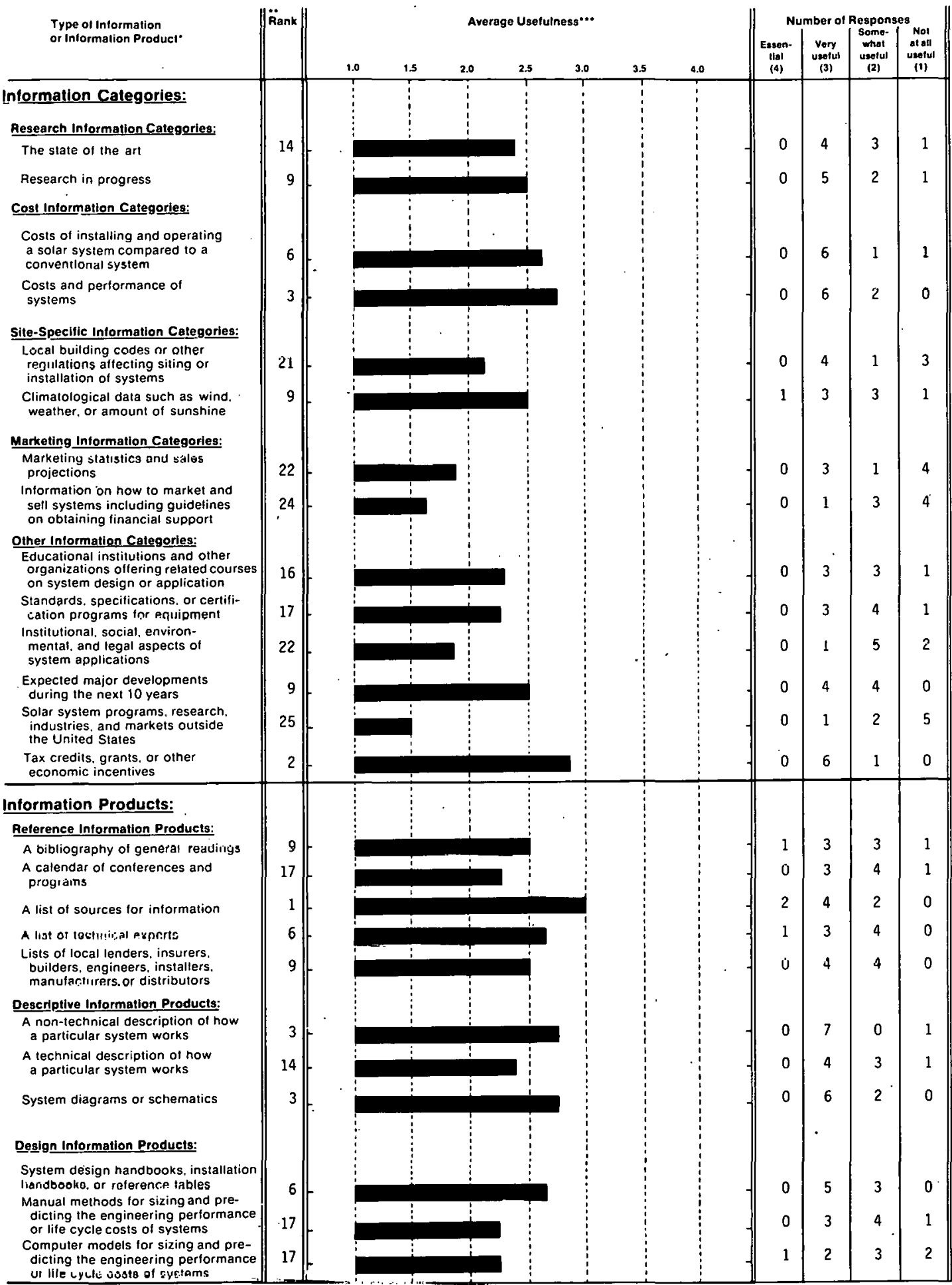

Each sample frame ol users was questiontu on intormation and intrirmation products in the context ol theit specilic technology. For example. biomass sample trames wëre ast.od abnill "a bibliography ol general readings un tiomaso"." "a calendar of upcomina biomass conterences uliu jiograms ". etc.

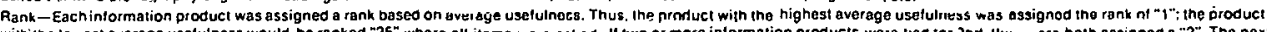
heghest ranking was then assigned a "4:"

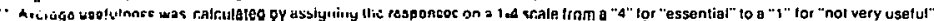

Figure 8-1. Usefulness of Selected Information Items: State Agricultural Office Representatives 
Statistical tests were also used to determine whether the State Agricultural Office Representatives rated any of these information items significantly higher (or lower) than they were rated by the APH County Agents or by All State Specialists. Some groups, however, tended to give higher scores in general than did other groups. To compensate for this effect, these statistical tests compared the "relative rating" given by one group to the "relative rating" given by the other groups. The procedure for calculating the relative rating is described in Appendix E. The average overall rating for State Agricultural Office Representatives was 2.38, slightly higher than the 2.27 average of All State Specialists, but lower than the 2.66 average for APH County Agents.

In comparing the results for State Agricultural Office Representatives to the results for All State Specialists and APH County Agents, all three groups gave high ratings to "costs and performance of systems" and "economic incentives," and low ratings to "instítutional, social, environmental, and legal aspects." Statistical tests showed that the State Agricultural Office Representatives rated "eduartional institutions" significantly $(P<0.05)$ higher than did All State. Sperialists and rated "cumputer modèls" significantly $(P<0.05)$ higher than they were rated by $\mathrm{APH}$ County Agents. There seemed to be evidence that State Agricultural Office Representatives werc more interested in reference products and descriptive costs than All State Specialists were.

\subsection{ACQUISTTION OF INFORMATION BY RESPONDENTS}

\subsubsection{Use of Selected Information Sources}

State Agricultural Office Representatives were asked which of 21 different potential sources of solar information they had used in the past few years. For this yuestion the respondenls were not asked if they had nhtained information on sular APH, But instead were asked if they had obtained any solar information from each specific source. Thus, the question sought to determinc which information sources were the most fumiliar to the responients, The rosults are shown in Flg. 8-2. For comparison, results for APH County Agents and All State Specialists are in Figs. 9-4 and y-6 (Section 9.0).

The information sources mentioned most of ten by State Agricultural Office Representatives were:

- Inited Staté Drpartment uf Agriculture (USDA);

- Periodicals, newspapers, or magazines;

- State energy or solar offices; and

- A public utility company.

There were seven other sources which $75 \%$ or more of the respondents had used. The information sources mentioned least of ten by State Agricultural Office Reprcsentatives were:

- A commercial data base,

- International Solar Energy Society.(ISES), and

- National Solar Heating and Cooling Information Center (NSHCIC). 
Question \#11. In the past few years, have you obtained any type of solar information from any of the following sources?

Information Sources

Percentage Responding Yes ${ }^{* * *}$

Public Media:

Radio or TV

Periodicals, newspapers or magazines

Private Solar-Involved Organizations:

Private solar energy or environmental organizations

The local chapter or national headquarters of International Solar Energy Society (ISES), including their publications

The local chapter or national headquarters of Solar Energy Industries Association (SE|A), including their publications

\section{Contacts with Professionals:}

An instafler, builder, designer or manufacturer of solar systems

Workshops, conferences or training sessions

Information Services":

Your organizational library or a local library

A commercial data base; for example, Lockheed, SDC, BRS

Smithsonian Science Information Exchange (SSIE)

A Federai library or information center; for example, the National

Agricultural Library or the Environmental Data System

The Government Printing Office (GPO)

National Technical Information Service (NTIS)

Technical Information Center at Oak Ridge (TIC)

Government Solar-Involved Organizations

Directly from the U.S. Department of Energy

National Solar Heating \& Cooling Information Center

Regional Solar Energy Centers

Stale Entergy or Solar Officu:

Other:

Some other state or local government office or publication

A public utility company

Sources for this specific sample frame**:

USDA, including the Cooperatlve Exlelısivin Service

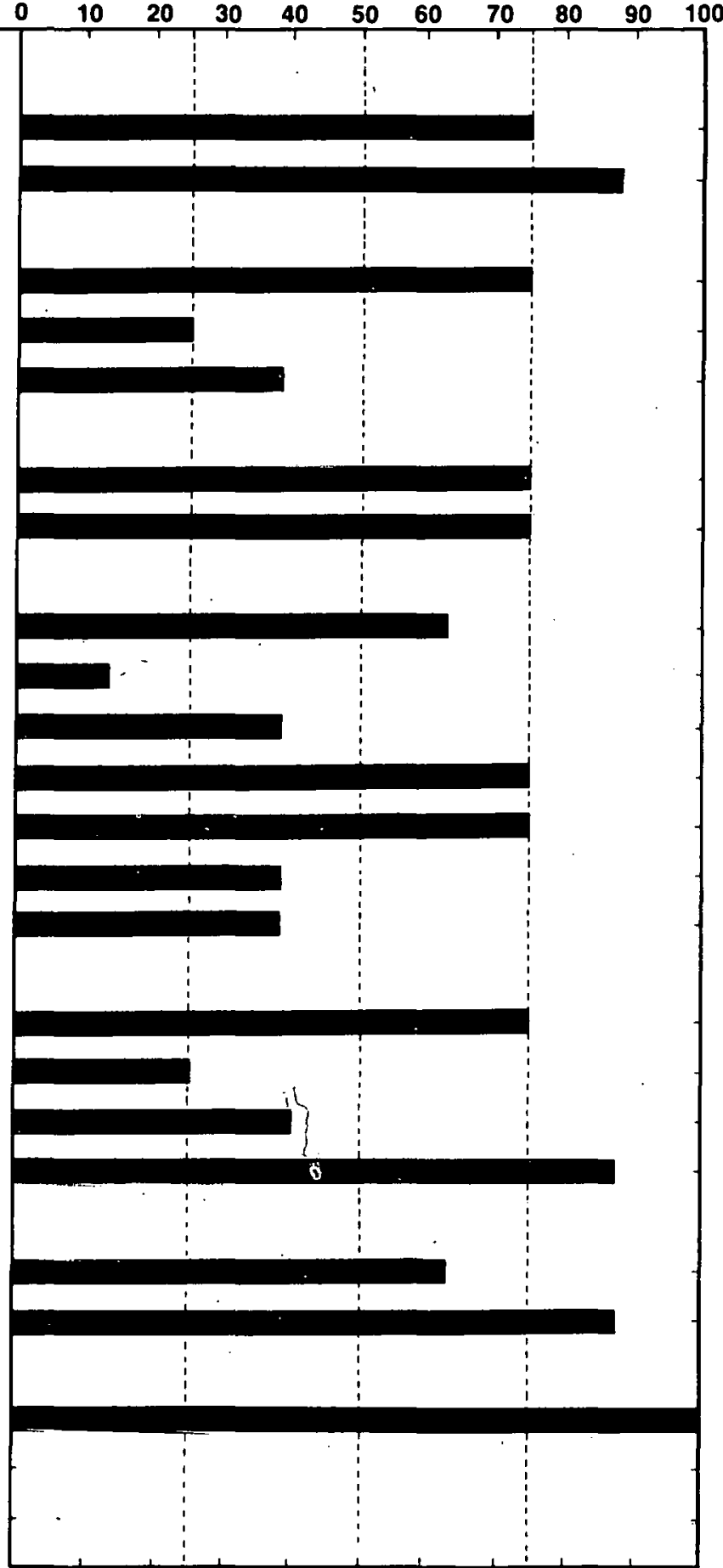

- Services and centers whose primary purpose is to disseminate information.

- Some sample frames were questioned about additional information sources which are applicable to their technology. For example, the manufacturers of biomass conversion equipinent were also asked it they have obtaıned any lype of solar information from: "the local or national office of the U.S. Department of Agriculture, including Extension and Forestry."

... These dald die based upon a total of 8 iresnondents.

Figure 8-2. :Use of Selected Information Sources: ' State Agricultural Office Representatives 
State Agricultural Office Representatives relied heavily on USDA for solar information, as did Extension Service Offices. However, their overall average across all sources (.61) was much higher than was that of the APH County Agents (.43), and thus they appeared to make more use of more sources. The State Agricultural Office Representatives were significantly $(P<0.05)$ more likely to use both "a federal library" and Regional Solar Energy Centers (RSECs) than were APH County Agents. They were significantly $(P<0.05)$ less likely to use both other libraries and "some other state or local government office" than were All State Specialists.

\subsubsection{Membership in Solar-Interested Organizations}

Three of the 8 (38\%) State Agricultural Office Representatives interviewed were members of a prof essional, technical, or other organization with an interest in solar energy. These organizations (each mentioned by only one respondent) included:

- Americain Assuclation for the Advancement of Science,

- American Society of Agricultural Engineers,

- National Association of State Departments of Agriculture, and

- North American Scientific Council for Agricultural Technology.

No solar-specific organizations were mentioned, which was also typical of APH County Agents.

\subsubsection{Exposure to Publications on Solar Energy}

During tlie past $\dot{b}$ months, ail of the State Agricultural Office Representatives had read publications which included information on solar APH. The publications they could specify (each named by only one respondent) included:

- Archer-Daniel-Midland Company publications,

- U.S. Department of Energy (DOE) publications,

- Hoard's Dairyman,

- Kansas Energy Office publications,

- Kansas State University Extension Service publications,

- Progressive Farmer,

- Solar Energy for Agriculture; Review of Research (by W. K. Trotter, USDA Economics, Statistics, and Coopcratives Service \#67), and

- USDA reports.

\subsubsection{Use of Special Acquisition Methods}

'The respondents were asked whether they had obtained any information (not just APH or solar energy) in the past year by computer terminal, by Computer Output Microform (COM), or by other microform (e.g., microfiche, microfilm sheets or rolls). Few of the State Agricultural Office Representatives appeared accustomed to using these special 
acquisition methods, a trait common to most groups included in this study. In the past year, none of the 8 had used computer terminals, only 1 had used COM, and 2 had used other microf orms. Som ewhat larger proportions of All State Specialists had used each of the three forms. Significantly more $(P<0.05)$ State Specialists had used computer terminals than State Agricultural Office Representatives. The employment of State Specialists at state universities may be a factor in their higher use of all three acquisition methods.

\subsection{SUMMARY AND COMMENTS}

Eight representatives from State Agricultural Offices were interviewed. All were involved in some aspect of providing information on solar agricultural process heat (APH), although most were only slightly involved in this area and not very informed. Most respondents expected to need information on solar APH off the job as well as on the job. Most respondents held top positions in the State Department of Agriculture.

State Agricultural Office Representatives assigned the greatest utility to information on:

- Lists of sources for information on solar APH;

- Tax credits, grants, and other economic incentives for solar APH applications;

- Costs and performance of solar APH systems;

- A nontechnical description of how a particular solar APH system works; and

- Solar APH system diagrams or schematics.

They gave low ratings to: marketing information, "APH programs . . outside the United States," and "institutional, social, environmental, and legal aspects of solar agricultural process heat installations."

State Agricultural Office Representatives most often received solar information from USDA, "periodicals, newspapers, or magazines," "state energy or solar offices," and "a public utility company." These respondents appeared to be seeking out more information sources and needing both technical information for themselves as well as nontechnical information for-public awareness distribution to the rural public. They obtained much of their information from professional agricultural organizations and publications, in addition to DOE and USDA. 


\section{SEP1*}




\section{SECTION 9.0}

\section{COUNTY AGENTS, COOPERATIVE EXTENSION SERVICE}

\subsection{DESCRIPTION OF RESPONDENTS}

\subsubsection{Description of Sample}

This section describes the results of a telephone study to determine the needs of county agricultural agents in the Cooperative Extension Service (CES) for information on solar agricultural process heat (APH). Nine APH County Agents were interviewed.

The sample frame for APH County Agents was selected from the County Agents Directory [15] which lists CES staff members by state and county. In order to eliminate urban counties, the County and City Data Book [16] was consulted. From this source, any counties which had 35 percent or less of total land area in farms were eliminated from consideration. The 2,160 remaining rural counties were reduced to 300 by systematic random selection of every seventh county. (Counties were listed in alphabetical order within states, which were also in alphabetical order.) Every fifth county was then selected as a candidate for the solar agricultural process heat information study.* Senior Agricultural Agents (rather than Home Economics Agents, 4-H Agents, or Youth Agents) were identified for each county. The 9 interview candidates were randomly selected from a sample frame. of 60 names.

Respondents. In making the telephone calls to contact the randomly selected interview candidates, it sometimes occurred that the person could not be reached. In this event another randomly selected name was substituted for the original name. When individuals were contacted, it was verified that they would be needing information on APH within the next year. If they were not both involved and needing information, they were asked if they could refer the interviewer to someone else in their organization who would be an appropriate respondent. If such a referral was made, a call was then made to this new candidate; if no intraorganizational referral was made, a new candidate was randomly selected from the sample frame. The results of this process may be seen in Table 9-1.

Comparisons. For additional insight into the information needs and the information habits of these APH County Agents, results from this group are compared to the results from state-level CES specialists in agriculture and inf ormation (All State Specialists) and from all of the CES county agricultural agents interviewed in this study (All County Agents). Other technologies included in All County Agents were active solar heating and cooling, wind, passive solar heating and cooling, and biomass energy. In performing any statistical comparisons, the totals for APH County Agents have been subtracted from the totals for All County Agents. Comparisons between APH County Agents and State Agricultural Office Representatives, who were also sampled for information needs on solar APH, are contained in Section 8. The data for APH County Agents, All County Agents, and All State Specialists can be found in Appendix F.

*The remaining counties were divided into similar groups, and studies were conducted on wind energy, active solar heating and conling, passive solar heating and cooling, and biomass energy. The results of these studies are reported in other volumes. 
Table 9-1. COMPLETION OF INTERVIEWS: AGRICULTURAL PROCESS HEAT COUNTY AGENTS

Event

Number of

Candidates

Interview completed with sample frame candidate

Interview completed with referral candidate

0

Refusal or candidate termination

0

Contact attempted: could not reach candidate within three

attempts or before interviews were completed

Subtotal

Contact attempted: invalid candidate (e.g.; inappropriate

field of interost, no teleplivite)

TOTAL

Sample frame error rate

Completion rate

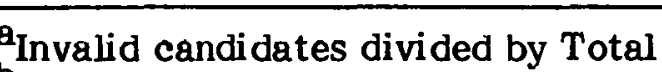

$\mathrm{b}_{\text {Completed interviews divided by Subtotal }}$

\subsubsection{Current Status of Respondents}

Respondents represented counties in the following eight states:

- Idaho,

- Kansas (2),

- Nebraska,

- North Carolina,

- Oklahoma,

- South Dakota,

- Tennessee, and

- Texas.

Il will be noted that neither Northeastern nor far Western stater were sampled. All County $\Lambda$ gents accounted for 24 states, picking up somewhat more representation of the West. Similarly, All State Specialists did not include representatives from New England or the far West. (Geographic distribution by state of respondents in each of the County Agents' and State Specialists' groups are shown in Table B-l, Appendix B.)

Role. Three of the $y$ APH County Agents were gathering information and/or identifying sources of information on agricultural process heat and distributing information to the public. Other activities mentioned included: research on tobacco curing, use of peanut dryers, grain drying (usually classified as agricultural process heat), promoting solar APH research, working with farmers to plan solar APH projects, and preparing for solar APH experiments. 
Involvement. Two of the 9 (22\%) respondents said that they were "moderately involved" in solar agricultural process heat. The other 7 were "slightly involved." While none of the APH County Agents were "very involved," 33\% (6 of the 18) of All State Specialists were. This higher degree of involvement may be accounted for by the fact that State Specialists were asked about involvement in solar technologies generally, rather than just in solar agricultural process heat. Involvement levels of County Agents in other technologies were similar (29\%, 13 of the 45 were at least "moderately involved") to APH County Agents.

Informedness. Seven of the 9 (78\%) APH County Agents stated that they were only "slightly inf ormed" about solar APH. Two (22\%) were "moderately informed." Similarly, All County Agents were not very well informed about their respective solar technologies (only 10 of the 45 or $22 \%$ at least "moderately informed"), while significantly $(P<0.05)$ more All State Specialists (15 of the 18 or 83\%) were at least "moderately informed" than were APH County Agents.

Need for Information. All respondents indicated they would need solar APH information on the job during the next year. Five (56\%) of the 9 APH County Agents indicated they. would also need information on solar agricultural process heat outside the job. This level of off-the-job information need was about the same as that found for All County Agents (21 of the 45 or $47 \%$ ), but higher than for All State Specialists (7 of the 18 or $39 \%$ ).

\subsubsection{Background of Respondents}

Five of the APH County Agents held master's degrees, the remainder held bachelor's degrees. Three had received their most recent degree in agriculture (animal husbandry) or agricultural education (2), 2 in animal science, 2 in adult education, 1 in biology, and 1 in engineering. Four of the 9 had received their most recent degrees within the past 10 years, 2 from $10-20$ years ago, and 3 over 20 years ago.

Seven APH County Agents had been in their current profession for over 10 years, 2 for 3-5 years. Although their current profession might be assumed to be "county agricultural agent," professional statements included educator and agricultural professional, as well as Extension Agent.

\subsection{INFORMATION NEEDS OF RESPONDENTS}

\subsubsection{Technical Areas}

APH County Agents were asked to choose those areas in which they were "particularly interested in obtuining information" from a. list of selected technical areas of solar agricultural process heat technology. Six expressed interest in all five areas about which they were usked. Eight of the 9 respondents were interested in "grain drying," 7 were interested in "livestock shelter heating," "crop drying," and "greenhouses." The topic of lowest interest ( 6 of the 9 ) was "food processing."

Three APH County Agents volunteered that they were also interested in solar heating of residences. 


\subsubsection{Types of Information}

APH County Agents were asked to name the information about solar agricultural process heat technologies that was important for them to obtain. Eight of the 9 volunteered one or more items of information which they considered important. Responses ranged from "basic inf ormation" to "technical aspects" and included: breakthroughs, research results, new approaches for grain drying and swine house heating, identification of best solar collectors for agricultural applications, low-cost systems for installation on existing farms (retrofit), and comparison between solar and other sources for agricultural process heat.

Two APH County Agents volunteered that there was information they needed but were unable to get. This information included: any technical information, economics of solar $\mathrm{APH}$, costs and performance of different systems, and new plans for systems.

Choice Between Specific Needs. A list of 11 types of solar agricultural process heat information products and 11 types of solar APH information categories was read to each respondent. Each respondent described the usefulness of each particular item by assigning it a value of "essential," "very useful," "somewhat useful," or "not at all useful." The results are displayed in Fig. 9-1. For the purpose of comparison, results for All County Agents are in Fig. 9-2, and those for All State Specialists in Fig. 9-3.

APH County Agents named both items in the cost category as the most important. The five top-rated information categories/products were:

- Costs of installing and operating a solar APH system compared to a conventional system;

- Costs and performance of systems;

- Tax credits, grants, or other economic incentives;

- A nunlechnical description of how a particular system works; and

- Lists of technical experts.

"Lists of suurces for information" and "system diagrams and schematics" also were ranked high.

APH County Agents assigned the lowest relative ratings to:

- Computer models for sizing and predicting performance or costs;

- Local building codes or other regulations;

- Calendars of conf erences and programs; and

- Institutional, social, environmental, and lcgal aspects.

Statistical tests indicated that all five of the top categories/products were rated significantly $(P<0.05)$ higher than were the four lowest rated items.

It should be noted that thesc lower-rated items were not necessarily of no worth to the APH County Agents. For example, 3 of the 9 (33\%) thought "local building codes" was either "essential," or "very useful." Thus, these information categories/products could be useful to some of the APH County Agents, but were of a lower relative priority to the entire group. 
Question \#8. I will read a list of potential information or information products on solar systems. For each, please tell me how useful that information would be to you. Would the following be: essential, very useful, somewhat useful, or not at all useful?

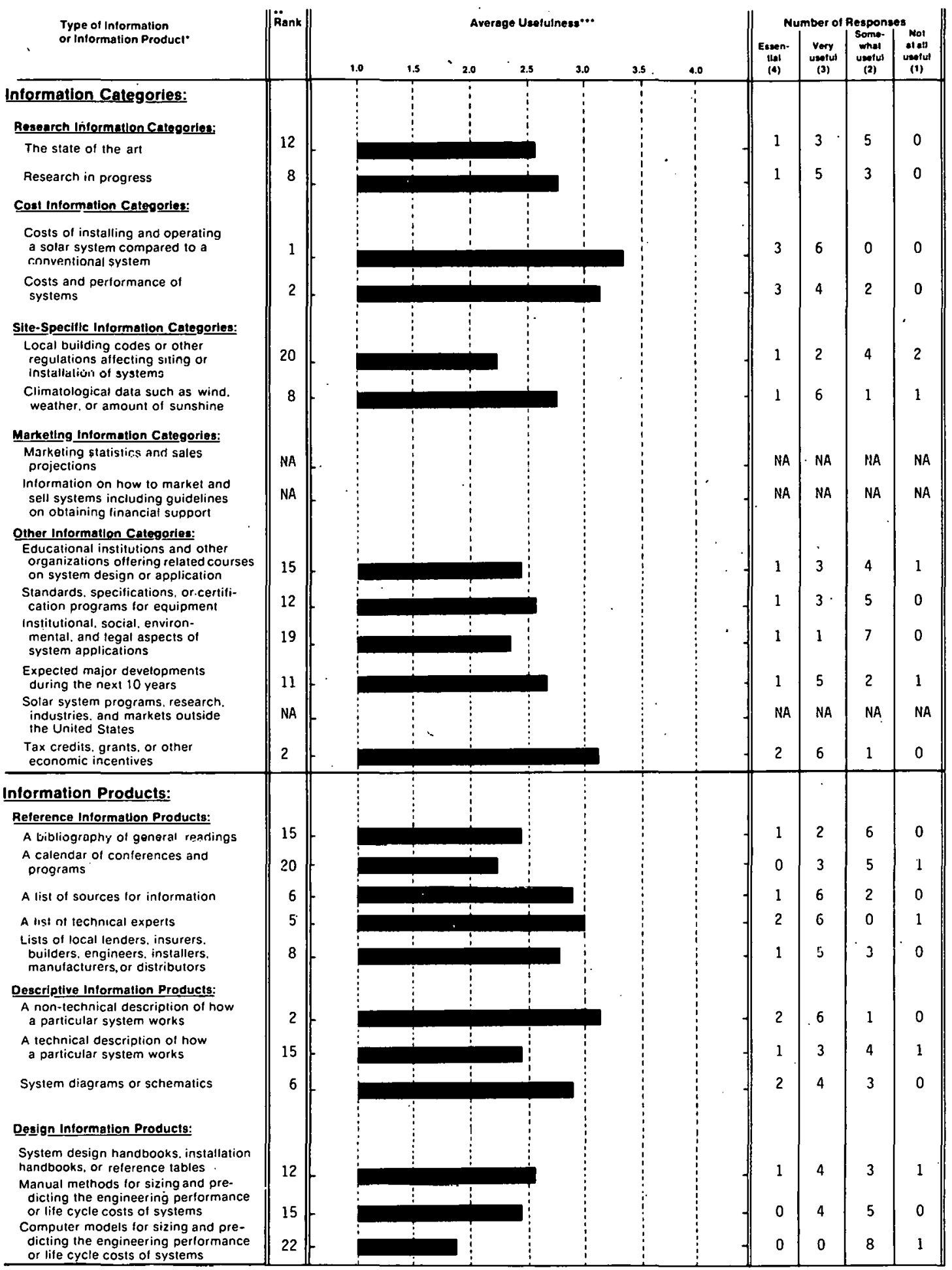

Each soungle tramc of users was nurestioned on information and information products in the context of their specilic technology. For example, biomass sample lrames were

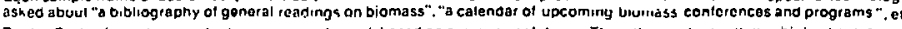

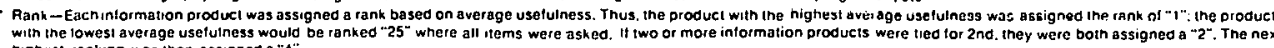

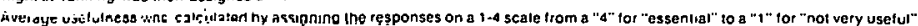

Figure 9-1. Usefulness of Selected Information Items: Agricultural Process Heat Cooperative Extension Service County Agents 
Question \#8. I will read a list of potential information or information products on solar systems. For each, please tell me how useful that information would be to you. Would the following be: cssential, very uselul, somewhat useful, or not at all useful?

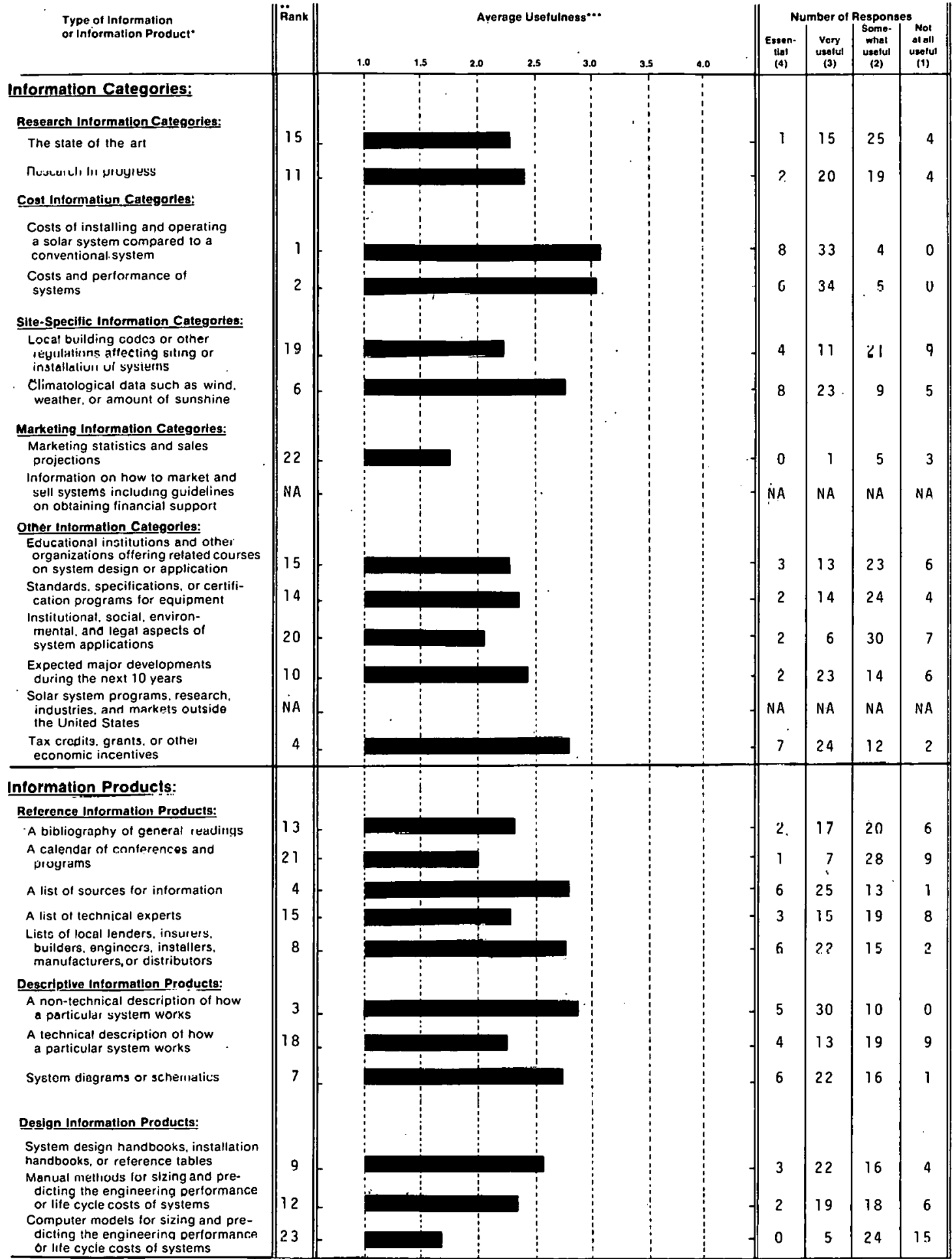

- Each sample lrame of usets was questioned on information and intormation products in the context of their specific technology. For example. biomass sample trames were asked about "a bibliography of general readings on biomass", "a calendar of upcoming biomass conferences and programs". etc. Rank - Each intormalion product was assigned a rank based on average usetulness. Thus, the product with the highest average usetulness was assigned the rank of "1": Ine product
with the lowest average useturness would be ranked " 25 " where all items were asked. It two or more inlormation products were tied for 2 nd. they were both assigned a "2". The next

Average usefutness was calculateo by assigning the responses on a $1-4$ scale trom a " 4 " for "essential" to a " " " for "not very useful".

Figure 9-2. Usefulness of Selected Information Items: All Cooperative Extension Service County Agents 
Question \#8. I will read a list of potential information or information products on solar systems. For each, please tell me how useful that information would be to you. Would the following be: essential, very useful, somewhat useful, or not at all useful?

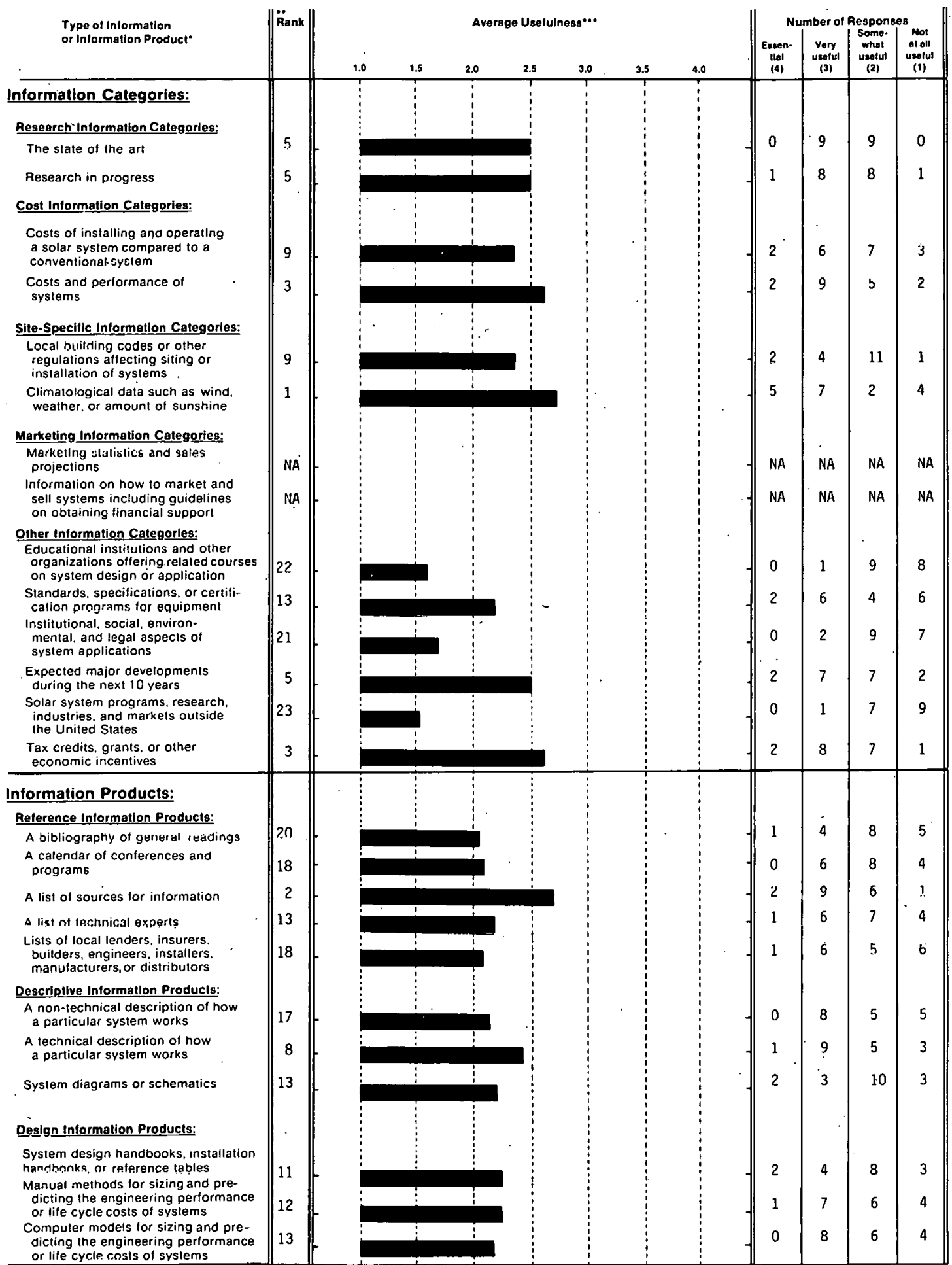

Each sample trame of users was questiuried on inlormation and information proflucls in the context of their specilic technology. For example, biomass sample trames were asked about "a bibliography of genetal reaoings uni liümass". "a colondar of upcoming hinmass conterences and programs ", etc.

"Rank-Each information producl was assigned a rank based on average usefulness. Thus, The product with the highest average usefulness was assigned the rank of "1": Ine prooucl with the lowest average usefulness would be ranked "25" where all items were asked. If two or more intormation products were tied tor 2 nd. Iney were both assigned a "2". The nex

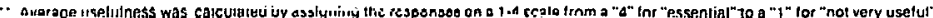

Figure 9-3. Usefulness of Selected Information Items: All Cooperative Extension Service State Specialists 
Statistical tests were also used to determine whether the APH County Agents rated any of these information items significantly higher (or lower) than they were rated by All County Agents or by All State Specialists. Some groups, however, tended to give higher scores in general than did other groups. To compensate for this effect, these statistical tests compared the "relative rating" given by one group to the "relative rating" given by the other groups. The procedure for calculating the relative rating is described in Appendix E. The average overall rating for APH County Agents was 2.66, higher than that of All County Agents (2.47) or All State Specialists (2.27).

The results for APH County Agents were quite similar to the results for All County Agents. Statistical tests indicated that the only statistically significant differences in ratings given to individual information items by APH County Agents compared to All County Agents was the significantly $(P<0.05)$ higher ratings of "lists of technical experts" by APH County Agents.

Ratlngs of APH County Agents differed significantly from those of All State Specialists in that APH County Agents rated "a nontechnical description" significantly $(P<0.05)$ higher and "computer models" significantly $(\mathrm{P}<0.05)$ lower. APH County Agents also appeared to give higher ratings to "costs of installing," "lists of local lenders (etc.)," and "a list of technical experts," but to give lower ratings to "local building codes," "state of the art," "climatological data," "expected major developments," and "a technical description."

\subsection{ACQUISITION OF INFORMATION BY RESPONDENTS}

\subsubsection{Use of Selected Information Sources}

APH County Agents were asked which of 21 different potential sources of information they had used in the past few years. For this questiun the respondents were not asked if they had obtained information on solar agricultural plocess heat technologies, but instead were asked if they had obtained any solar information from each specific source. Thus, the question sought to determine which information sources were the most familiar to the respondents. The results are presented in Fig. 9-4. For comparison, results for All County Agents and All State Specialists are in Figs. 9-5 and 9-6.

'I'he inf ormation sources mentioned most of ten by APH County Agents were:

- United States Department of Agriculture (USDA);

- Periodicals, newspapers, or magazines;

- Directly from the U.S. Department of Encrgy (DOE);

- Radio or TV;

- An installer, builder, designer, or manufacturer of solar systems;

- The Government Printing Office (GPO); and

- State energy or solar offices.

The information sources mentioned least often by APH County Agents (no more than 1 of the 9 had used them) were: 
Question \#11. In the past few years, have you obtained any type of solar information from any of the following sources?

Information Sources

Percentage Responding Yes ...

Workshops, conferences or training sessions

Information Services*:

Your organizational library or a local library

A commercial data base: for example, Lockheed, SDC. BRS

Smithsonian Science Information Exchange. (SSIE)

A Federal library or information center; for example. the National Agricilltural Library or the Environmental Data System

The Government Printing Office (GPO)

National Technical Information Service (NTIS)

Technical Information Center at Oak Ridge (TIC)

\section{Government Solar-Involved Organizations}

Directly from the U.S. Department of Energy

National Solar Heating \& Cooling Information Center

Regional Solar Energy Centers

State Energy or Solar Offices

Other:

Some other state or local government office or publication

A public utility company

Sources for this specific sample frame**:

USDA, including the Cooperative Extension Service

State Agricultural Office

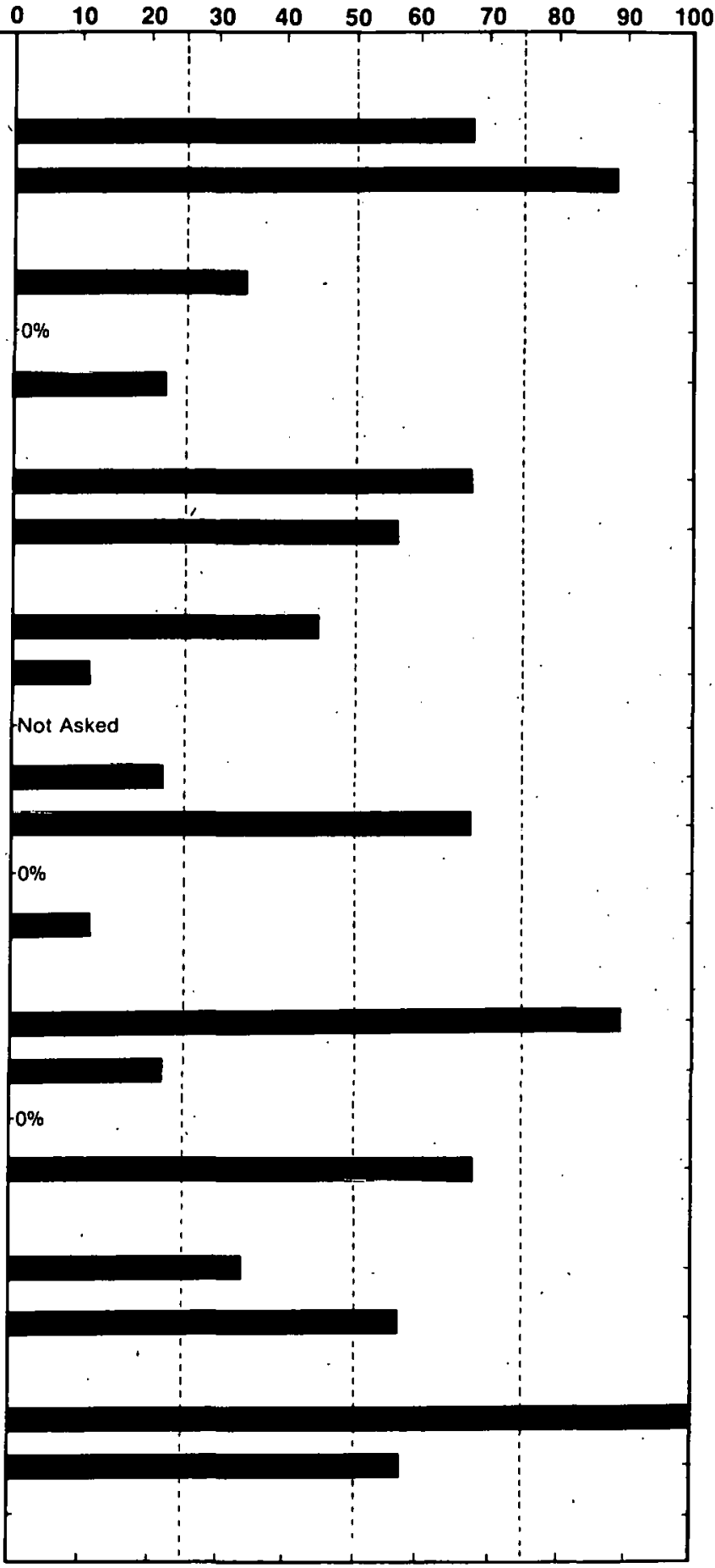

- Services and centers whose primary purpose is to disseminate information.

- Some sample frames were questioned about additional information sources which are applicable to their technology. For example. the manufacturers of biomass conversion equipment were also asked it they have obtained any type of solar information from: "the local or national nffice of the U.S. Department of Agriculture, including Extension and Forestry."

... These data are based upon a total of 9 responcienss.

Figure 9-4. Use of Selected Information Sources: Agricultural Process Heat Cooperatlve Extension Service County Agents 
Question \#11. In the past few years, have you obtained any type of solar information from any of the following sources?

\section{Information Sources}

Information Sources
Public Media:
Radio or TV
Periodicals, newspapers nr magazines
Private Solar-Involved Organizations:
Private solar energy or environmental organizations
The local chapter or national headquarters of International
Solar Energy Society (ISES), including their publications
The local chapter or national headquarters of Solar Energy
Industries Association (SEIA), including their publications
Contaclo with Professiunals:

An installer, builder, designer or manufacturer of solar systems

Workshops, conferences or training sessions

Information Services*:

Your organizational library or a local library

A commercial data base; for example, Lockheed, SDC, BRS

Smithsonian Science Information Exchange (SSIE)

A Federal library or information center; for example, the National Agricultural Library or the Environmental Data System

The Government Printing Office (GPO)

National Technical Information Service (NTIS)

Technical Information Center at Oak Ridge (TIC)

Government Solar-Involved Organizations

Directly from the U.3. Department of Energy

National Solar Heating \& Cooling Information Centel

Regional Solar Energy Centers

State Energy or Solar Offices

Other:

Some other state or local government office or publication

A public utility company

Sources for this specific sample frame**:

USDA, including the Cooperative Extension Service

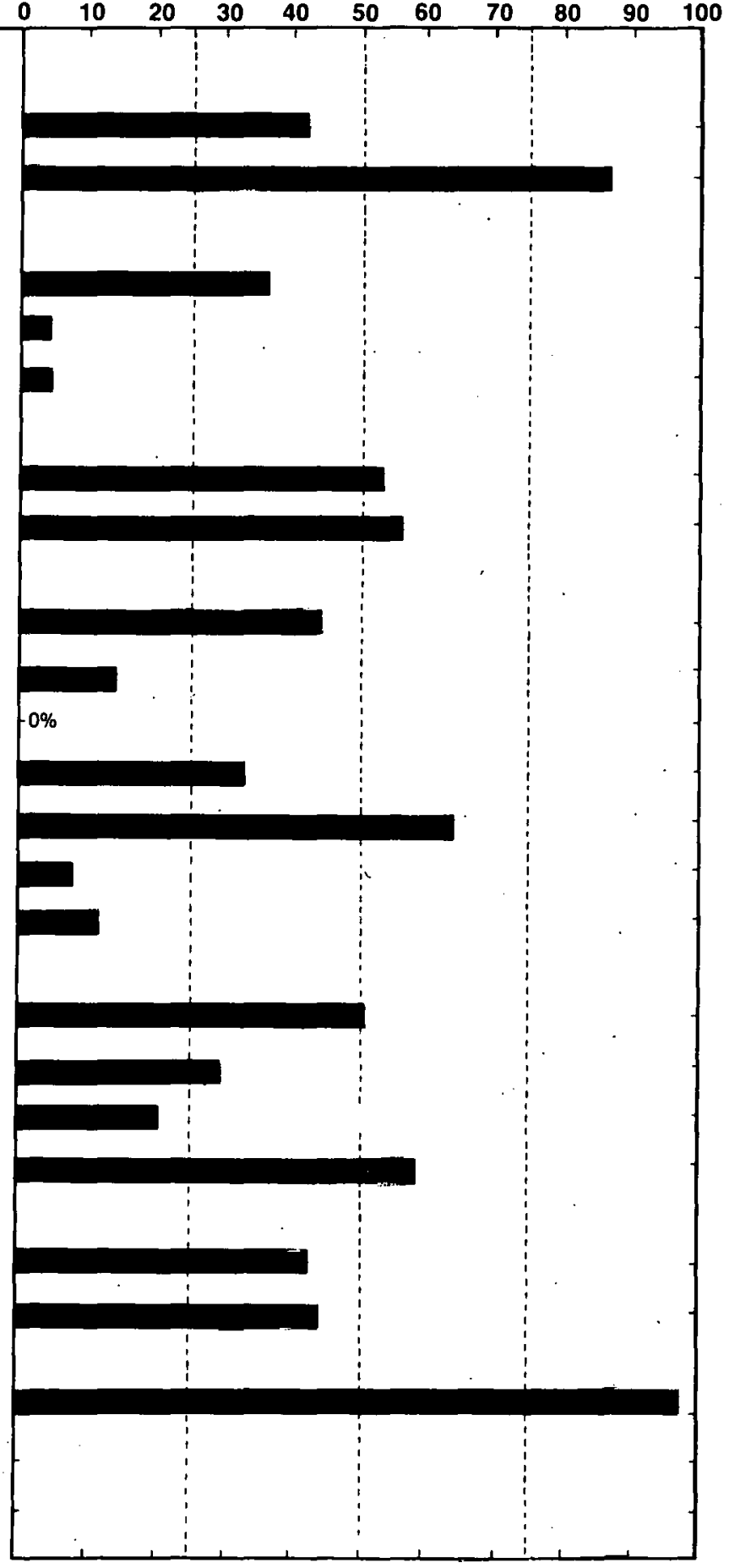

- Services and centers whose primary purpose is to disseminate information.

- Some sample frames were questioned about additional information sources which are applicable to their technology For example, the manufacturers of biomass conversion equipment were also asked if they have obtained any type of solar information from: "the local or national office of the U.S. Department of Agriculture, including Extension and Forestry."

These data are based upon a total of 45 respondents.

Figure 9-5. Use of Selected Information Sources: All Cooperative Extension Service County Agents 
Question \#11. In the past few years, have you obtained any type of solar information from any of the following sources?

Information Sources

Percentage Responding Yes ${ }^{\cdots *}$

Public Media:

Radio or TV

Periodicals, newspapers or magazines

Private Solar-Involved Organizations:

Private solar energy or environmental organizations

The local chapter or national headquarters of International Solar Energy Society (ISES), including their publications

The local chapter or national headquarters of Solar Encrgy

Industries Association (SEIA), including their publications

Contacts with Professionals:

An installer, builder, designer or manufacturer of solar systems

Workshops, conferences or training sessions

Information Services":

Your organizational library or a local library

A commercial data base; for example, Lockheed, SDC, BRS

Smithsonian Science Information Exchange (SSIE)

A Federal library or information center; for example, the National

Agricultural Library or the Environmental Data System

The Government Printing Office (GPO)

National Technical Information Service (NTIS)

Technical Information Center at Oak Ridge (TIC)

Government Solar-Involved Organizations

Directly from the U.S. Department of Energy

National Solar Heating \& Cooling Information Center

Regional Solar Energy Centers

State Ënergy or Solar Uffices

Other:

Some other state or local government office or publication

A public utility company

Sources for this specific sample frame* *:

USDA, including the Cooperative Extension Service

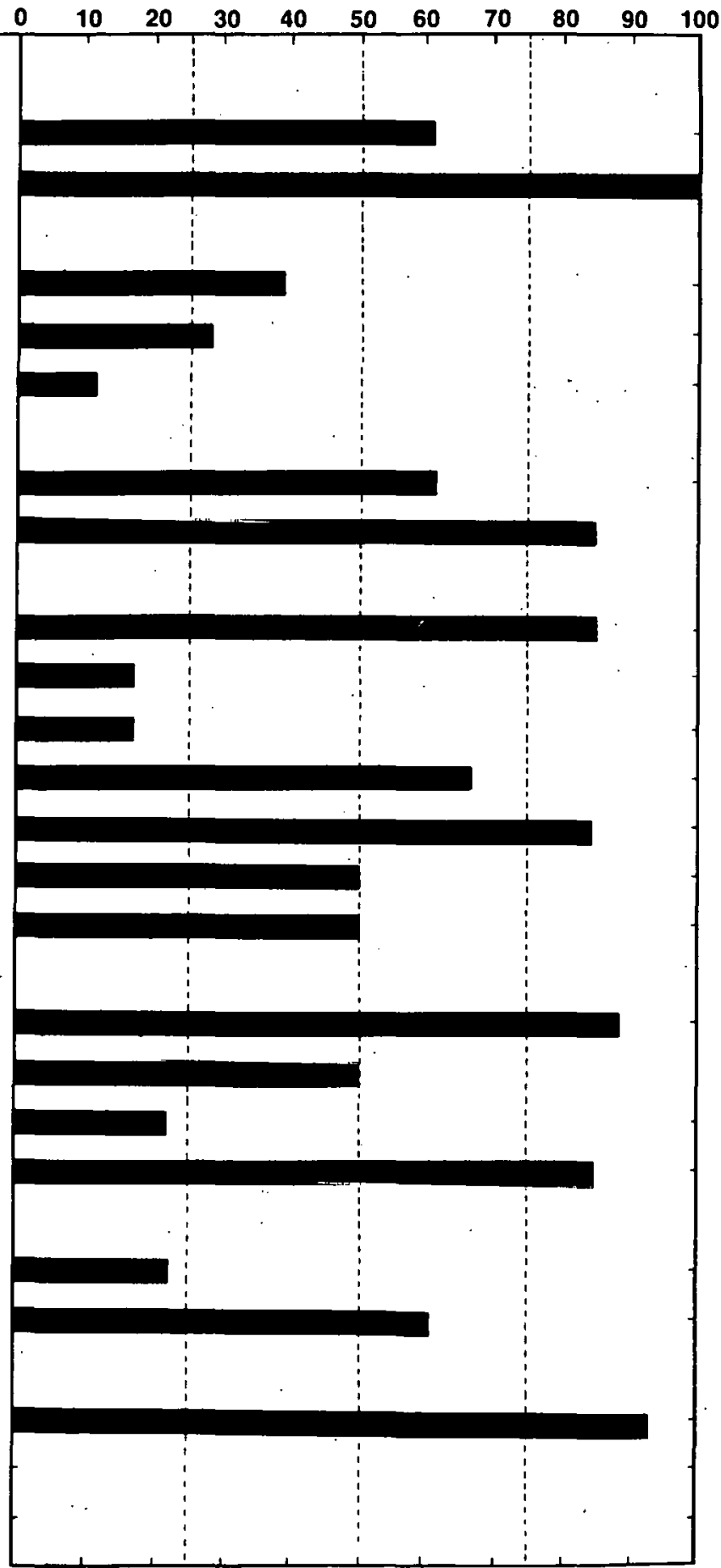

- Services and centers whose primary purpose is to disseminate information.

- Some sample frames were questioned about additional information sources which are applicable to their technology. For example, the manufacturers of biomass conversion equipment were also asked if they have obtained any type of solar information trom: "the local or national office of the U.S. Department of Agriculture, including Extension and Forestry:

*** These data are hased upuiri a total of 18 roopondents. 
- International Solar Energy Soci ety (ISES),

- National Technical Information Service (NTIS),

- Regional Solar Energy Centers (RSEC),

- A commercial data base, and

- Technical Information Center (TIC).

In reviewing Figs. 9-4 through 9-6, all three groups made high use of USDA, "periodicals (etc.)," GPO, and "state energy or solar of fices." APH County Agents made significantly $(\mathrm{P}<0.05)$ more use of DOE than did All County Agents. All State Specialists were significantly $(P<0.05)$ more likely to have used "radio or TV" and NTIS.

\subsubsection{Membership in Solar-Interestcd Organizatiuns}

Five of the $\dot{y}$ ArH County Agents interviewed were members of a professional, technical, or other organization with an interest in solar energy. These organizations (and the number of times mentioned) included:

- Alpha Zeta (agricultural professionals fraternity),

- National Association of County Agricultural Agents (2), and

- Texas County Agents Association.

Also mentioned was Kansas "EAAA," an organization which could not be verified by the authors. The absence of solar-specific organizations was typical of County Agents.

\subsubsection{Exposure to Publications on Solar Energy}

During the past 6 months, 8 of the 9 APH. County Agents had read publicutions which included information on solar agricultural process heat. The publications they could specify (and the number of times mentioned) included:

- Crops and Soils,

- Extension publications,

- Irrigation Age,

- Kansas Solar Energy Commission publications,

- Kansas State Extension Engineering Department publications,

- Progressive Fürmer, and

- Southeast Farm Press publications.

Also mentioned were several publications which could not be verified by the authors. These included "former stnckmen," "Farney's papers," and a publlcation on work at Oakland State on greenhouses. No solar-specific or general interest publications were named. 


\subsubsection{Use of Special Acquisition Methods}

The respondents were asked whether they had obtained any information (not just agricultural process heat or solar energy) in the past year by computer terminal, by Computer Output Microform (COM), or by other microform (e.g., microfiche, microfilm sheets or rolls). Few of the APH County Agents appeared accustomed to using these special acquisition methods, a trait common to All County Agents. In the past year, only 2 of the 9 had used computer terminals, and none had used COM or other microf orms. Somewhat larger proportions of All State Specialists had used each of the three forms, but differences were not statistically significant.

\subsection{SUMMARY AND COMMENTS}

Nine senior agricultural agents in County CES Offices were interviewed. Most had only slight involvement with solar agricultural process heat applications. They were, however, in the process of identifying sources of information and planning experiments on solar APH.

Agricultural Process Heat County Agents were interested in a variety of solar APH applications. They assigned the greatest utility to inf ormation on:

- Costs of installing and operating a solar APH system compared to a conventional system;

- Costs and performance of solar APH;

- Tax credits; grants, and other economic incentives for solar APH applications;

- A nontechnical description of how a particular solar APH system works; and

- Lists of technical experts in solar agricultural process heat applications.

They gave low ratings to "computer models," "local building codes," "calendars of conferences and programs," and "institutional, social, environmental, and legal aspects."

APH County Agents were similar to County Agents in other solar technologies in stressing the importance of cost and incentives information and nontechnical descriplivis. In their role as information disseminatnrs, County Agents may be reflecting the kinds of inf ormation their constituents need.

APH County Agents most often receive solar information through USDA, DOE, and "periodicals, newspapers, and magazines." Most were members of extension or agricultural organizations and these organizations and various farm/agricultural publications also provided them with some solar information. 
SER갑 


\section{SECTION 10.0}

\section{REFERENCES}

1. Belew, William W.; Wood, Barbara L. Solar Information User Priority Study. SERI/TR-751-472. Golden, CO: Solar Energy Research Institute; May 1980.

2. Belew, William W.; Wood, Barbara L.; Marle, Terry L.; Reinhardt, Carol L. General Solar Information User Study. SERI/TR-751-753. Golden, CO: Solar Energy Research Institute; March 1981.

3. Solar Energy for Agricultural and Industrial Process Heat, Program Summary. DOE/CS-0053. Washington, DC: Department of Energy; September 1978.

4. Current Research Information System (Data Base). USDA Lockheed: File 60. Washington, DC: United States Department of Agriculture; 75-79/May.

5. Smithsonian Science Information Exchange (Data Base). Lockheed: File 65. Washington, DC: The Smithsonian Institute; 75-79/Mar.

6. Energy Research in Progress (Data Base). DOE/RECON: File 15. Washington, DC: U.S. Department of Energy; Spring/Summer 1979.

7. Solar Energy Technical Information Dissemination Program. Reference Directory: Solar Thermal Power. MeLean, VA: MTTRE Corporation; April 1979.

8. Manufacturers Data Base, Solar Energy Information Data Bank (SEIDB). Golden, CO: Solar Energy Research Institute; Spring/Summer 1979.

9. Belew, William W.; Wood, Barbara L.; Marle, Terry L.; Reinhardt, Carol L. Active Solar Heating and Cooling Information User Study. SERI/TR-751-747: Golden, CO: Solar Energy Research Institute; January 1981.

10. Who's Who in Engineering. Third Edition. New York: Engineers Joint Council; 1977.

11. The AEE Directory of Energy Prof essionals, 1979-1980. Atlanta, GA: The Association of Energy Engineers. Fairmont Press; 1979.

12. 1979 Directory of the American Section of the International Solar Energy Society, Inc. Killeen, TX: American Section of the International Solar Energy Society, Inc., American Technological University; February, 1979.

13. Education Data Base, Solar Energy Information Data Bank (SEIDB). Golden, CO: Solar Energy Research Institute; Spring/Summer 1979. Also available in hard copy as the National Solar Energy Education Directory. SERI/SP-42-141. Golden, CO: Solar Energy Research Institute; January 1979.

14. "State Departments of Agriculture." Denver, CO: Colorado Department of Agriculture; 1977. 
15. County Agents Directory. 63rd Edition. Flossmor, IL: C.L. Mast, Jr.; 1978.

16. County and City Data Book, 1977 (A Statistical Abstract Supplement). Washington, DC: U.S. Department of Commerce, Bureau of the Census. U.S. Government Printing Office; 1977. 
APPENDIX A

GROUPS INCLUDED

IN STUDY 
S리눈

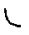


The following table (Table A-1) lists the 86 groups included in this study of solar information users. Major headings are the same as those of individual reports. Ten separate reports analyzing the study results by technology will be issued.

In general, results for each group are reported in only one volume, although comparisons to similar groups in other technologies are of ten part of the analysis. There are two exceptions: the results for Concentrating Collector Manufacturers are discussed in both the Solar Thermal Electric Power and the Industrial and Agricultural Process Heat reports; the results for Total Nonconcentrating Collector Manufacturers are discussed in both Active Solar Heating and Cooling and the Industrial and Agricultural Process Heat reports.

\section{Table A-1. GROUPS STUDIED}

A. Photovoltaics

1. DOE-Funded Researchers

2. Non-DOE-Funded Researchers

3. Researcher Manufacturers

4. Manufacturers

5. Electric Power Engineers

6. Utilities

7. Educators

B. PASSIVE SOLAR HEATING AND COOLING

1. Federally Funded Researchers

2. Manufacturers

3. Architects

4. Builders

5. Educators

6. Cooperative Extension Service (CES) County Agents

7. Homeowners with Passive Systems

C. ACTIVE SOLAR HEATING AND COOIING

1. DOE-Funded Researchers 
Table A-1. GROUPS STUDIED (Continued)

C. ACTIVE SOLAR HEATING AND COOLING (cont.)

2. Non-DOE-Funded Researchers

3. Heating and Cooling System Manufacturers

4. Water Heating System Manufacturers

5. Nonconcentrating Collector Manufacturers (see also Industrial and Agricultural Process Heat)

6. Other Component Manufacturers

7. Distributurs

8. Instaillers

9. Architects

10. Builders

11. Planners

12. Heating, Ventilating, and Air Conditioning Engineers

13. Industrial Engineers

14. Utilities

15. Educators

16. CES County Agents

17. Homeowners with Space Heating Systems

18. Homeowners with Water Heating Systems

19. Owners/Managers of Buildings (with SHAC Systems)

\section{BIOMASS RNERGY}

1. Federally Funded Researchers in Production and Collection

2. Federally Funded Researchers in Conversion

3. Nonfederally Funded Researchers in Production and Collection

4. Nonf ederally F unded Researchers in Conversion

5. Production and Collection Equipment Manufacturers 
Table A-1. GROUPS STUDIED (Continued)

D. BIOMASS ENERGY (cont.)

6. Conversion Equipment Manufacturers

7. State Forestry Offices

8. Private Foresters

9. Forest Products Engineers and Consultants

10. Educators

11. CES County Agents

12. Owners/Managers of Biomass Systems

\section{E. SOLAR THERMAL RLECTRIC POWER}

1. DOE-F unded Researchers

2. Non-DOE-Funded Researchers

3. Concentrating Collector Manufacturers (see also Industrial and Agricultural Process Heat)

4. Electric Power Engineers

5. Utilities

6. Educators

\section{F. INDUSTRIAL (IPH) AND AGRICULTURAL (APH) PROCESS HEA'I'}

1. IPH Researchers

2. APH Researchers

3. Concentrating Collector Manufacturers (see also Solar Thermal Electric Power)

4. Total Nonconcentrating Collector Manuf acturers (see also Active Solar Heating and Cooling)

5. Plant Engineers (IPH)

6. Industrial Engineers (IPH)

7. Private Agricultural Engineèrs (IPH) 


\section{Table A-1. GROUPS STUDIED (Continued)}

\section{F. INDUSTRIAL (IPH) AND AGRICULTURAL (APH) PROCESS HEAT (cont.)}

8. Educators (IPH)

9. State Agricultural Offices (APH)

10. CES County Agents (APH)

\section{G. WIND ENERGY}

1. DOE-Funded Researchers

2. Nüi-DOE-Funded Kesearchers

3. Manufacturers

4. Distributors

5. Wind Engineers

6. Electric Power Engineers

7. Utilities

8. Educators

9. CES County Agents

10. Small Wind Energy System Owners

\section{H. OCEAN ENERGY SYSTEMS}

1. DOE-Fundéđ Researchẹrs

2. Non-DOE-Funded Researchers

\section{ENBRGY STORAGE}

1. DOE-Funded Researchers

2. Non-DOE-Funded Researchers

\section{J. GENERAL SOLAR}

1. Loan Officers

2. Real Estate Appraisers 
Table A-1. GROUPS STUDIED (Concluded)

\section{J. GENERAL SOLAR (cont.)}

3. Tax Assessors

4. Insurers

5. Lawyers

6. Nonsolar Utilities

7. Public Interest Groups

8. CES State Agricultural Specialists

9. CES State Inf ormation Specialists

10. State Energy/Solar Offices (Western SUN states)

11. State Energy/Solar Offices (MASEC states)

12. State Energy/Solar Offices (NESEC states)

13. State Energy/Solar Offices (SSEC states) 
SझR1* 
APPENDIX B

STUDY DEVELOPMENT

AND PROCEDURE 


\section{SEPI}


This Appendix describes several aspects of the way in which the studies were developed and conducted.

\section{FACTORS IN STUDY DESIGN}

Studies of $\mathbf{8 6}$ groups, each interested either in one of nine specific solar technologies or in solar energy in general, provided an extremely broad view of the information needs of the solar community. Although the sample size of nine respondents per group was small, the data still proved to be quite adequate for planning purposes. It was possible to determine which information was the most important to the respondents and what was the best channel for disseminating that inf ormation. There were a number of valid statistical tests that could be made, both to compare the priorities a group gave to different information items and to compare the priorities different groups gave to the same item.

Several major factors resulted in the decision to conduct a study with these characteristics. First, there were very few data available on the information needs and information-acquiring activities of the various segments of the solar community, and those data that did exist were related almost exclusively to the area of active solar heating and cooling. Many people had strong opinions as to which information products should be developed first, but data obtained directly from the information users was virtually nonexistent. Due to this general lack of information, most of the potential users of the findings of these studies could not define highly specific questions that they needed to have answered by these studies. Instead, baseline data was needed. It did not make sense to ask a researcher detailed questions on whether he needed a calendar of solar events to be updated monthly or updated quarterly, when no one knew whether he even needed calendars at all. Thus, the lack of baseline data dictated that most of the potential users of study findings framed their questions at the level of "What information do you need the most?" For such a level of questions there was obviously no great need to use large sample sizes to obtain extremely precise, quantitative answers. Since qualitative data would be quite adequate, there was no need for a large sample size.

Further, there was a need to obtain this baseline data as rapidly as possible so that realtime programmatic decisions about development of information products and data bases could be based upon data rather than conjecture. As a result, the decision was made to conduct the studies by telephone in an attempt to speed up the data collection process. Interviewing by telephone also had the result of improving the response rates (over those using a mail questionnaire).

Thus, these factors dictated the final study design: a broad-based study (the final number of groups included, 86, was determined primarily by the number of meaningful sample frames that could be constructed) to collect qualitative data by obtaining completed telephone interviews, with approximately 9 randomly selected respondents from each of the 86 groups being interviewed.

\section{Impact on Questionnaires}

As a result of using telephone interviews to conduct the studies, it was necessary to limit the number of questions to be asked. Telephone interviews had to be kept relatively short (preferably under 20 minutes) to keep the respondents from prematurely terminating the interview. Even if a respondent did not hang up in mid- questionnaire, his attention span could be tried severely by lengthy interviews; respondents would then answer 
questions without much thought in order to terminate the interview as rapidly as possible. In the final study the interviews took an average of about 18 minutes to complete (with a range from 10 minutes to 50 minutes) and incorporated very simple question formats, sometimes open-ended questions. For each of the 86 studies a separate and distinct sample frame, letter of introduction, and questionnaire were developed and separate computer runs and analyses were performed.

Perhaps a more important effect of deciding to do a telephone study was the necessity of using interviewers without solar backgrounds to conduct the study. With almost 800 interviews to be conducted, each requiring an average of 35 to 40 minutes to complete an 18-minute interview (due to callbacks, referrals, busy signals, wrong numbers, etc.), there was too much effort required to conduct the interviews using internal staff. Thus, the effort had to be contracted. The choice was whether to conduct the interviews by contracting solar experts (who would not know anything about interviewing techniques) or by contracting a professional telephone interview firm (whose interviewers would not know anything about solar energy). Due to the significantly lower cost and to the significantly reduced chance of biasing the responses, it was decided to use a professional telephone interview firm.

As a consequence of this decision, there were some problems caused by using nonsolar interviewers to pose questions of solar experts. If a respondent asked for a question to be clarified, the interviewer could not assist. Instead, the interviewer could only repeat the question. The biggest problem involved the open-ended questions. Sometimes the interviewer simply did not understand what the respondents were talking about. Interviewers were brief ed in solar terminology and instructed to ask respondents to spell out words the interviewers did not understand. Nevertheless, some of the verbatims (i.e., quotes from the respondents that were copied down verbatim by the interviewers) were not intelligible. For example, one interviewer recorded "small square train feeders" when the respondent really said "small-scale terrain features," another recorded "nel lenses" instead of "Fresnel lenses." To minimize errors in translation, all of the questionable verbatim items listed in this report were reviewed and verified by Solar Energy Research Institute (SERI) technical experts. However, based upon listening to live interviews and comparing the results to the verbatims, usually the interviewers were able to transcribe the salient points of the responses.

\section{Impact on Statistical Characteristics}

The sample size of nine respondents per group was limiting for the analyst. To illustrate the lack of precision in the results, if five of the nine respondents answered "yes" to a particular question, there was a $95 \%$ chance that the true proportion saying "yes" was between 0.212 and $\mathbf{0 . 8 6 2}$. Obviously, this was an extremely wide confidence interval. For such a small sample size, it was not feasible to make national estimates (e.g., the number of Industrial Process Heat Researchers in the country who need bibliographies), and it was not meaningful to construct cross-classification tables (e.g., "type of information needed" versus "degree of informedness"). Because of these small sample sizes, the authors were sometimes forced to propose hypotheses rather than draw conclusions.

Nonetheless, the results were extremely useful when taken as qualitative, baseline results. Certain statistical tests could still be performed (see Appendix E). One could test whether Industrial Process Heat Researchers wanted "state-of-the-art" information significantly more than they wanted "marketing statistics." Several tests could be made comparing one group with another. Thus, one could test whether Passive Architects 
wanted cost data significantly more than did Active Solar Heating and Cooling Architects. This type of a comparison usually highlighted basic differences between technologies. One could also test whether Industrial Process Heat Researchers responded differently from All Researchers.

Comparisons of this type were valuable for several reasons. First, they allowed the comparison of the information needs of a relatively unknown group against those of a more familiar group. For example, the information needs of Wind Manufacturers were easier to understand when compared to the more familiar information needs of Solar Heating and Cooling Manufacturers.

Second, if one can establish basic similarities in information habits and the types of information needed, it will eventually become possible to use the results of other information science studies. For example, many studies have detailed the types of information researcher's need and the ways of getting information to them. Thus, if Industrial Process Heat Researchers were quite similar in needs to All Researchers, it was an indication that many of the well-known findings for researchers in general may also apply for Industrial Process Heat Researchers.

\section{STUDY DEVELOPMENT}

There were several tasks which had to be completed before the studies could be conducted. These tasks are described in the following subsection.

\section{Development of Sample Frames}

Sample frame development was the single most difficult, time-consuming task in the entire study. As discussed in Section 2.2, the initial attempt was to obtain lists of the names, addresses, and phone numbers of members of as many meaningful groups as possible. A total of about 86 such sample frames was the maximum that could be developed adequately within a reasonable amount of time.

The services of ref erence and research librarians were used in this process, much of it on a subcontractor basis. Over 200 documentary sources (printed, published and unpublished sources, and data bases) were consulted. Staff searched the Solar Energy Information Center and Denver-area public and academic libraries to examine directories, catalogs, periodicals, and data bases. Directories of prof essionals, organizations and associations, and solar-related individuals and groups were examined, both to obtain sample frames and to obtain individual names. Periodicals were searched both to identify associations whose members might be eligible for sample frames and to identify authors who could be contacted because they represented certain target groups. Various data bases were identifed which contained names of individuals categorized by sample frame categories (e.g.; educators, researchers, manufacturers). Lists of conference attendees were accumulated. Sample frames were also constructed by establishing numerous personal contacts with professional, technical, and special interest organizations; with authors of solar articles; technical staff at SERI; federal offices; publishers; solar groups; at least thirty state solar and state energy offices, etc.

Both the Mid-American Solar Energy Complex (MASEC) and the Northeast Solar Energy Center were subcontracted to provide additional names and addresses. Western SUN also provided many names on a voluntary basis. The Southern Solar Energy Center was asked 
to participate on either a contractual or a voluntary basis, but declined. Additionally, the Technical Information Dissemination (TID) program subcontracted a consulting firm to develop lists of members of the solar community. Although the resulting lists were significantly smaller than had been anticipated, they provided valuable backup information for some sample frames. The National Solar Heating and Cooling Information Center provided several of the data bases and other lists used.

It sometimes occurred that the person contacted was not in the presumed field: for example an installer was no longer involved with solar energy. The proportion of the time that this or a similar sample-frame error occurred has-been calculated for each group and is included in the section documenting the results for the group. Sample frame error included such factors as no known telephone number, individual not in the specified field or specified employment sector, etc. Averaging over all groups, $20 \%-25 \%$ of the candidates in the sample frames were no longer valid.

\section{Pilot Testing}

In August 1979 Market Opinion Research (MOR) conducted a pilot test by doing telephone studies of 10 groups ( 9 respondents for each). The groups were:

- Wind: Engineers,

- Wind: County Extension Agents,

- Active Solar Heating and Cooling: DOE-Funded Researchers,

- Active Solar Heating and Cooling: Installers,

- Active Solar Heating and Cooling: Utilities,

- Active Solar Heating and Cooling: Educators,

- Active Solar Heating and Cooling: Commercial Building Owners,

- Passive Solar Heating and Cooling: Equipment Mạnufacturers,

- Solar Industrial Process Heat: Industrial Engineers, and

- General Solar Energy: Lawyers.

These groups were selected specifically to test a range of questionnaires, the peculiarities of selected sample frames, and the receptiveness of certain target groups to telephone interviews on solar energy. The persons contacted in the pilot were not contacted in the full study.

The pilot test proved very useful. There were no major revisions resulting, but several refinements improved the interview procedure and the questionnaire content and format. The interviews were completed within a reasonable time, an average of about 18 minutes per interview. The most important finding of the pilot test was the enthusiasm of the respondents for solar energy. Most respondents were very cooperative and were excited about receiving solar information. Because of this attitude interviewers had no difficulty in getting respondents through long lists of information products and sources or in keeping respondents on the telephone to finish the interview.

SERI personnel visited MOR while the pilot test was being conducted, personally participating in monitoring interviews, reviewing tape recordings of previously conducted interviews, and debriefing interviewers. Based upon these inputs, several changes were made 
in the basic questionnaire concept, resulting in changes for each of the 86 distinct questionnaires. Among these changes were the addition of a question designed to defuse the respondent by allowing expression of the respondent's individual concerns, deleting two questions which were not working, changing the sequence of a few questions, making a few small wording changes to sharpen questions, and changing MOR's suggested questionnaire format in order to minimize interviewer errors.

Upon realizing that there was more sample frame error than had been anticipated, the screening procedure was revised to a double screening procedure. Only people who said they needed solar information within the next year, and who were truly in the proper group (e.g., "an educator teaching industrial process heat courses") were to be interviewed. The rules for handling referrals were revised to allow interviews with intraorganizational referrals only.

Perhaps the most important change was in the interviewer training procedure. More specific instructions were developed for each question so that the interviewers would know the real point of the question, would ask the question properly, and would know what to emphasize. Lists of words being mispronounced by the interviewers were developed. Specific interviewers with pronunciation problems were singled out for additional coaching. Because of the interviewers' lack of familiarity with solar energy terminology, glossaries and other background information on solar energy were provided to interviewers.

\section{Interviewer Training and Monitoring}

The MOR interviewers used for these studies were all experienced interviewers. They went through three separate training sessions: a pilot test briefing, a pilot test debriefing (with question and reaction session), and a full study briefing. The full study briefing was held in four separate sessions so that the interviewers could be trained in small groups. SERI representatives were present for and assisted with the second two sessions.

These training sessions covered the purpose of the study, question wording, recording procedures, the screening procedure, and pronunciation of unfamiliar words. The training was built around the use of an annotated briefing questionnaire. Notes concerning each question were written on a questionnaire, which the interviewer studied during the briefing. Additional written materials covered included a list of solar energy terms, a list of common solar acronyms, and $a$ lisl of wülds for pronunciation reminders.

\section{$\underline{\text { Randomized Selection of Respondents }}$}

Once the sample frames were developed for each group, a random sample of 30 to 40 potential respondents was drawn by systematic sampling. (If the sample frame for a group only had 30 to 40 names in the beginning, this step was omitted.) These reduced sample frames were then forwarded to MOR. At MOR, these randomly selected names were put through a second randomization process which assigned the order in which these names were to be called. The MOR process used systematic sampling to identify the first nine candidates for interviewing: the total number of potential candidates was divided by nine to obtain "i," the "skip interval." Starting from a random point (R), every $i^{\text {th }}$ name then became one of the first nine candidates.

An initial call and up to two callbacks (at different times of day on different days of the week) were made attempting to reach each designated respondent. If an interview was not completed after three attempts, the interviewer took the questionnaire to the inter- 
viewing supervisor. The supervisor then designated the next person in the sequence as the substitute candidate: if the $(R+i)^{\text {th }}$ person could not be reached, the $(R+i+1)^{\text {th }}$ became the replacement candidate. If after three attempts to reach the substitute, no interview was completed, this process was repeated. (This time the $(R+i+2)^{\text {th }}$ person would become the candidate, etc.) For the entire study, 54\% of the completed interviews were with the originally designated respondent and $26 \%$ were with the first substitute. The remainder were completed with a second or higher substitute.

There is evidence that for some sample frames MOR did not use a random starting point to commence the skip interval, but instead used the sequence of $1^{s t},(1+i)^{\text {th }},(1+2 i)^{\text {th }}$, etc., names for initial candidates. Such a practice clearly does not conform to professional standards. This practice was not critical in those sample frames with a large initial size or no particular order, since SERI did a. valid random subsampling to reduce the sample size to 30 or 40 . In small sample frames or in frames with a definite pattern, however, this procedure could have caused biases. All seven of the Cooperative Extenslon Service sample frames were arranged in a state-by-state order. As a result of not randomly changing the starting point, there was a strong tendency towards sampling from the sulle states for these sample frames. The final distribution of CES respondents by state is shown in Table B-l. Some clustering did occur for some states. Thus, for these groups results were geographically biased.

\section{STUDY PROCEDURE}

The procedure was the same for each study. Each of the potential respondents was sent a letter of introduction one to three weeks bef ore they were telephoned (see Appendix C). This letter explained that the person was selected as a candidate and may be called by MOR, that MOR was calling for SERI, the purpose of the call, the type of inf ormation being sought, and that the respondent's identity would be kept confidential.

The telephone interviews were conducted in one of MOR's two telephone rooms, with each individual interviewer in an acoustically insulated booth. Throughout the study, interviews were monitored by MOR's phone room supervisors. They were responsible for randomly listening to interviews to determine whether the operators were conducting the interviews correctly. If mistakes were being made, the supervisor explained the proper procedure to the interviewer. The supervisors were able to monitor ealls without the interviewers knowing they were being monitored.

Candidates were telephoned during business hours (except for homeowners who were called during the early evening and weekends). If the interview candidate could not be contacted in the initial call, as many as two additional callbacks were made. These callbacks were made at different times of the day and on different days of the week. If no interview was completed after three attempts, a substitute candidate replaced the initial candidate and the process started over. If a secretary indicated the candidate would be in later at a specified time and day, the callback was scheduled correspondingly. If a candidate was too busy to talk when initially contacted, an appointm ent was made to call back at a specified time. Only $3 \%$ of the candidates contacted refused to be interviewed or terminated the interview bef ore it was completed. Once a candidate was contacted, a screening procedure was used to verify that the respondents being interviewed actually represented the group to which they ostensibly belonged. For example, a respondent who was presumably an educator teaching courses in solar industrial process heat was read the following statement at the beginning of the interview: 
Table B-1. COOPERATIVE EXTENSION SERVICE (CES): STATES

REPRESENTED IN SAMPLES ${ }^{\mathfrak{a}}$ (Number of Respondents)

\begin{tabular}{|c|c|c|c|c|c|c|c|c|c|c|}
\hline \multirow[b]{2}{*}{ State } & \multicolumn{6}{|c|}{ County Agents } & \multicolumn{3}{|c|}{ State Specialists } & \multirow[b]{2}{*}{$\begin{array}{c}\text { All } \\
\text { CES }\end{array}$} \\
\hline & $\begin{array}{l}\text { Bio- } \\
\text { mass }\end{array}$ & Wind & $\mathrm{APH}$ & $\begin{array}{l}\text { Pas- } \\
\text { sive }\end{array}$ & $\begin{array}{l}\text { Ac- } \\
\text { tive }\end{array}$ & Total & $\begin{array}{l}\text { Infor- } \\
\text { mation }\end{array}$ & $\begin{array}{l}\text { Agricul- } \\
\text { tural }\end{array}$ & Total & \\
\hline Alabama & - & 1 & - & 1. & - & 2 & - & - & - & 2 \\
\hline Calif ornia & - & 1 & - & - & - & 1 & - & - & - & 1 \\
\hline Colorado & - & 1 & - & - & 1 & 2 & - & - & - & 2 \\
\hline Connecticut & - & - & - & - & - & - & 1 & - & 1 & 1 \\
\hline Delaware & - & - & - & - & - & - & - & 1 & 1 & 1 \\
\hline Georgia & - & - & - & 1 & - & 1 & - & - & - & 1 \\
\hline Idaho & - & - & 1 & - & - & 1 & 1 & 1 & 2 & 3 \\
\hline Illinois & - & 1 & - & - & - & 1 & - & - & - & 1 \\
\hline Indiana & 2 & 1 & - & 1 & 1 & 5 & - & - & - & -5 \\
\hline Iowa & - & 1 & - & - & - & 1 & - & - & - & 1 \\
\hline Kansas & - & - & 2 & - & 1 & 3 & - & - & - & 3. \\
\hline Kentucky & - & 1 & - & 1 & - & 2 & 1 & 1 & 2 & 4 \\
\hline Louisiana & - & - & - & - & - & - & 1 & - & 1 & 1 \\
\hline Maryland & 1 & - & - & - & - & 1 & - & - & - & 1 \\
\hline Michigan & - & 1 & - & - & - & 1 & 1 & 1 & 2 & 3 \\
\hline Minnesota & - & - & - & 1 & 1 & 2 & - & - & - & 2 \\
\hline Missouri & - & 1 & - & - & - & 1 & - & - & - & 1 \\
\hline Montana & 1 & - & - & - & 1 & 2 & - & - & - & 2 \\
\hline Nebraska & - & - & 1 & 1 & 1 & 3 & 1 & 1 & 2 & 5 \\
\hline New Mexico & 1 & - & - & - & - & 1 & - & - & - & 1 \\
\hline New York & - & - & - & - & - & - & 1 & 1 & 2 & 2 \\
\hline N. Carolina & - & - & 1 & 1 & - & 2 & - & - & - & 2 \\
\hline Ohio & 1 & - & - & - & 1 & 2 & - & - & - & 2 \\
\hline Oklahoma & - & - & 1 & - & - & 1 & 1 & - & 1 & 2 \\
\hline Oreguli & 1 & - & - & - & - & 1 & - & - & - & 1 \\
\hline S. Carolina & - & - & - & - & - & - & - & 1 & 1 & 1 \\
\hline S. Dakota & - & - & 1 & 1 & 1 & 3 & 1 & - & 1 & 4 \\
\hline Tennessee & 1 & - & 1 & 1 & - & 3 & - & - & - & 3 \\
\hline Texas & 1 & - & 1 & - & 1 & 3 & - & 1 & 1 & 4 \\
\hline W. Virginia & - & - & - & - & - & - & - & 1 & 1 & 1 \\
\hline Sample Size & & & & & & & & & & \\
\hline by Technology & 9 & 9 & 9 & 9 . & 9 & 45 & 9 & 9 & 18 & 63 \\
\hline $\begin{array}{l}\text { Total States } \\
\text { Represented }\end{array}$ & 8 & 9 & 8 & 9 & 9 & 24 & 9 & 9 & 13 & $30^{\mathrm{a}}$ \\
\hline
\end{tabular}

astates not represented in any CES samples are: Arizona, Arkansas, Florida, Maine, Massachusetts, $\overline{M i s s i s s i p p i, ~ N e v a d a, ~ N e w ~ H a m p s h i r e, ~ N e w ~ J e r s e y, ~ N o r t h ~ D a k o t a, ~ P e n n s y l v a n i a, ~ R h o d e ~}$ Island, Utah, Vermont, Virginia, Washington, Wisconsin, and Wyoming. Alaska and Hawaii were not included in the sample frame. 
Hello (respondent's name). This is (interviewer's name) of Market Opinion Research. A week or so ago you were sent a letter from the Solar Energy Research Institute describing a survey of solar energy information needs and requesting your participation.

Your name has been provided to us. as someone who has been teaching courses related to solar industrial process heat. Is that correct?

If the respondent answered "yes," the interview continued. If the respondent answered "no," then the respondent was not interviewed but instead was asked if there was another person within the same university who was teaching courses related to solar industrial process heat. If the initial candidate could give the name of another person, the ref erral person (or "referral") was called as a substitute for the initial candidate. If no intraorganizational ref erral was given, another candidate was telephoned.

A second screen was used to eliminate those people who did not feel they would be needing information in the near future. For example, industrial process heat respondents were asked the following two questions:

- In the next year do you expect to need information on solar industrial process heat systems for your job?

- In the next year do you expect to need information on solar industrial process heat systems outside your job?

If the answer to both questions was "no," the interview was terminated and a substitute candidate telephoned. No request for a ref erral was made.

Once an interview was completed, the questionnaire was reviewed for completeness by the phone room supervisor. Incomplete questionnaires were returned to interviewers to recall the respondents.

Completed questionnaires were forwarded from the phone rooms to the Coding Department where they were checked in and assigned a unique identification number. They were subsequently sent to the Data Entry Department where they were keyed directly into computer data files. Since no computerized editing system could prevent the incorrect entry of a data value that was within the proper range (e.g., entering a " 3 " when the correct number was a " 2 " but where the numbers " $1, "$ " 2, " " 3, " and " 4 " are all valid numbers), SERI did a random sample of supposedly correct values to verify that they were correct. Out of 225 allowable values reviewed, only 1 had been incorrectly entered. Once the data were entered on the computer file, data tables were printed and analyzed.

Nonuniform Group Sample Size. The study was originally designed to sample nine respondents from each group. For most groups this was done correctly. Upon analysis of the completed questionnaires, however, it was sometimes apparent that a respondent obviously belonged in a group other than the one in which originally sampled. This was generally due to two simultaneous errors: a sample frame error and a screening error.

First, the person was included on the wrong sample frame. For example, a person listed as doing non-DOE-funded research could have received DOE funding af ter the sample frames were completed. Second, the screening process did not successfully remove this person from the Non-DOE-Funded Researchers; instead the interview was completed. 
During the interview the respondent mentioned that he was receiving DOE funds for his/her research. As a result the analyst received eight interviews completed with NonDOE-Funded Researchers and one completed with a DOE-F unded Researcher.

For such cases, the dissimilar interview was removed from the original group (in the example above, the Non-DOE-Funded Researchers). If there was another group into which that interview naturally fit (above, the. DOE-Funded Researchers), the interview was included with the interviews for the second group. Although the added interview did not have exactly the same probability of selection as did the original interviews, the resulting inaccuracy was minimal given the qualitative nature of the data. 


\section{SEPI䋨}


APPENDIX $\mathrm{C}$

\section{LETTER OF INTRODUCTION}




\section{SERI}


All potential respondents from the initial sample frames were sent the following letter (see Fig. C-1) from one to three weeks prior to being contacted by telephone. There are three phrases (underlined in this example) which were changed to describe the group and the solar technology. For example, "a researcher" was changed to read "a manufacturer" or "an educator," etc., as appropriate for the specific sample frame. Similarly, "passive solar heating and cooling" read "photovoltaics" or "wind energy systems," etc., according to the technology about which this potential respondent was to be interviewed. About 3,500 such letters were mailed over a period of several weeks. Less than 100 were returned as undeliverable.

It should be noted that in cases where the actual respondent was a referral, the respondent had not necessarily received this letter.

There were numerous telephone calls to the Solar Energy Research Institute (SERI) from people who had received this letter. Most volunteered they were eager to participate (and concerned that they had not yet been called) or that they wanted study results. A few volunteered ref errals or gave the best times for them to be called. 
September, 1979

\section{Dear Colleague:}

The Solar Energy Research Institute (SERI) is currently developing a Solar Energy Information Data Bank (SEIDB). The SEIDB is designed to include many categories of solar information and will serve the needs of a variety of groups: among them, researchers, manuf acturers, architects, builders, lawyers, and hom eowners. Services provided to you by the SEIDB may include an inquiry response service, computer access to models or large sets of data and free brochures, handbooks, etc.

The U.S. Department of Energy has defined solar energy as encompassing technologies which involve both direct and indirect uses of sunlight; information for all of the following technologies will be included in the SEIDB:

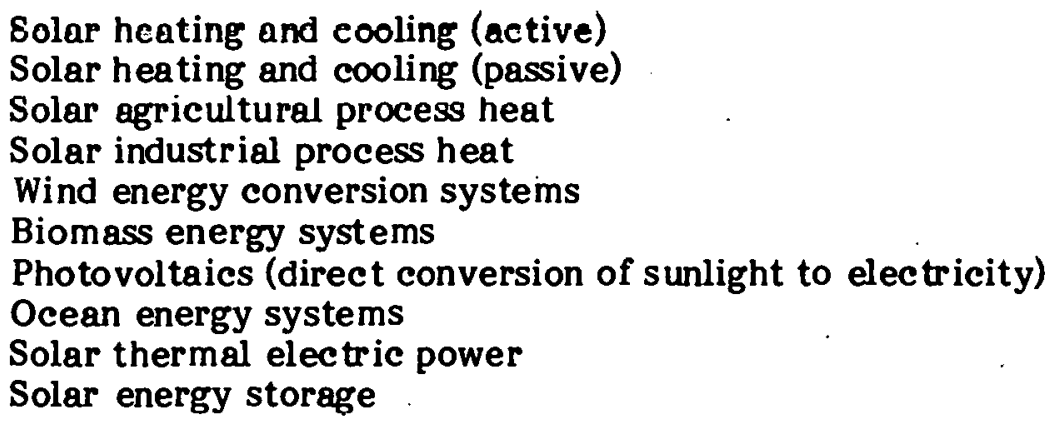

So that this data bank can be developed to meet your present or future solar information needs, SERI is surveying information users like yourself. You have been selected as a candidate for this interview because you are a researcher with an active or potential in terest in passive solar heating and cooling.

We believe your participation in this survey will be beneficial to you and to the country. If called, you will have an opportunity to express your opinions and to define your solar information needs. This will help us ensure that the data bank will be responsive to the needs of researchers as well as those of other groups.

Market Opinion Research of Detroit, Michigan, has been chosen to conduct this survey for SERI. A trained interviewer may contact you within two weeks to interview you. The telephone interview will last no more than 20 minutes. You can be assured that your responses to this survey are strictly confidential. No names will be used in reporting the results.

If you have questions about this survey, its purpose, or the interview methods to be used, please feel free to contact me at (303) 231-1155. Thank you for your assistance.

Sincerely,

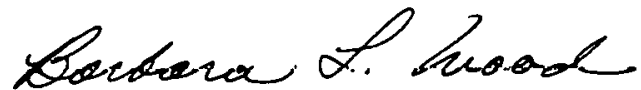

Barbara L. Wood,

Staff Market Research Infor mation Specialist, Information Dissemination Branch, Information Systems Division 
APPENDIX D

STUDY QUESTIONNAIRE 


\section{SERI}


A different questionnaire was developed for each distinct group in this study. These questionnaires were very similar, however, in that the same type of information was being sought from each of the groups. The individual questionnaires were developed by constructing a core questionnaire, then making appropriate revisions, additions, and deletions to produce a distinctly tailored questionnaire for each group.

Two sample questionnaires are provided in this appendix. The first is for the solar industrial process heat groups and the second is for the solar agricultural process heat groups. The basic difference between these questionnaires is in Question 6, which either asks about applications for industrial process heat (IPH) or agricultural process heat (APH). The manufacturers discussed in this report were asked about active solar heating and cooling, or about solar energy in general, rather than about process heat. Otherwise their questionnaires were similar.

The questionnaires used in the IAPH studies were very similar to those used for the other studies. The two instruments which follow (see Figs. D-1 and D-2) contain ref erences to solar industrial or agricultural process heat in Questions 1 through 9. Questionnaires that were used for respondents from other technologies substituted ref erences to their appropriate technologies instead of to industrial or agricultural process heat.

Certain variations were made in the solar industrial and agricultural process heat questionnaires for different IAPH groups in Questions 8a, 8b, and 11, in that certain items were not asked of groups if the item seemed inappropriate. For example, Industrial Process Heat Researchers were not asked Question 8b (11) about "how to market," and Agricultural Process Heat Cooperative Extension Service (CES) County Agents were not asked Question 11 (7) about Smithsonian Science Information Exchange (SSIE). While it would have been less complicated to have all questions asked of all respondents, concern over questionnaire length and the desire to avoid asking questions that were not relevant to the group led to deleting questions wherever possible. Questions that were not asked of each group may be noted in the data tables (Appendix F) whenever an individual group shows no entries for that item.

Slight variations in wording were made on the questionnaire of each individual group. For example, in Question 11(18), which asked if information had been obtained from "some other state or local government office or publication," the phrase "other than your own" was inserted for APH State Agricultural Office Representatives and APH CES County Agents.

\section{Standard Core Questionnaire}

Question 5. This question asked, "What is the most important information that could be provided to you about solar industrial or agricultural process heat?" This question allowed respondents to volunteer the information need that came to mind spontaneously, without reflecting any of the biases of the questionnaire designers as to what was the most important. Most of the time, however, it did not result in an answer which could be compared to another respondent's answer: for nine respondents, there were typically seven or eight distinct answers given. Since each respondent did not rate each of these items, it was impossible to determine which of these information needs was the most important. Afforded a second thought, respondents often gave items they had mentioned as "most important" in Question 5 a lower rating in Question 8 than they gave to items that they had not even mentioned in Question 5. As a result, the data from Question 5 could not provide a valid measurement of the most important information items which 
1. In the next year do you expect to need information on solar industrial process heat...

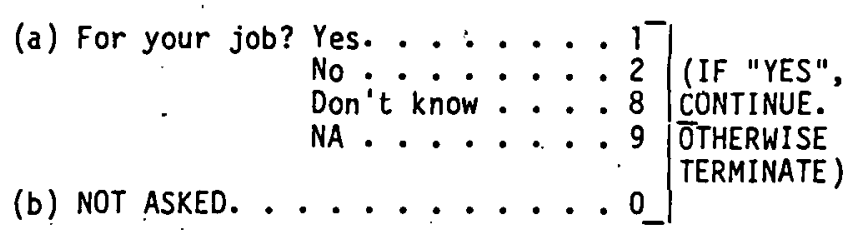

31

32
Very involved. . . . . . . . .4 Moderately involved or ...:. . . 3 Slightly involved. . . . . . . . 2 Not at all involved. (VOLUNTEERED) . I Don't know. .......... 8 NA. . . . . . . . . . . : : .

3. What are you doing in the field of solar enerqy for industrial prncess heat? (ASK AS OPEN ENU)

4. How well informed would you say you are about solar energy for industrial process heat? Would you say you are:

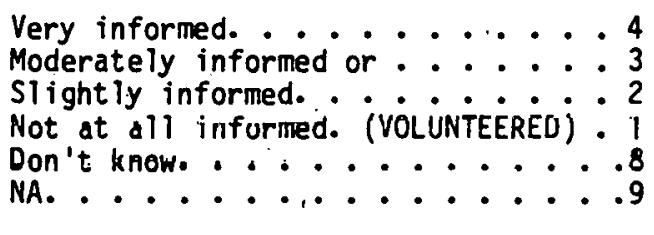
slight ly informed. Not at all infurmed. (VOLUNTEERED) - I

Don't know. . . .........8

NA. .............. . . .

5. What is the most important information that could be provided to you about solar industrial process heat? (INTERVIEWER: THIS INCLUDES INFORMATION WHICH COULD BE PROVIDED BY AN INFORMATION CENTER)

1st mention

and mention 
Cd 2

$1-10$ as 1

6. For which of the following areas of solar industrial process heat are you 11-75 B1k particularly interested in obtaining information? (READ LIST. CIRCLE 11-75 BIk ONE RESPONSE PER ITEM.)

\begin{tabular}{|c|c|c|c|}
\hline Yes & No & $\begin{array}{l}\text { Don't } \\
\text { Know }\end{array}$ & NA \\
\hline 1 & 2 & 8 & 9 \\
\hline $\begin{array}{l}1 \\
1 \\
1 \\
1 \\
1\end{array}$ & $\begin{array}{l}2 \\
2 \\
2 \\
2 \\
2\end{array}$ & $\begin{array}{l}8 \\
8 \\
8 \\
8 \\
8\end{array}$ & $\begin{array}{l}9 \\
9 \\
9 \\
9 \\
9\end{array}$ \\
\hline
\end{tabular}
$77-80 \mathrm{Job}$ Cd 3

(1) Hot water

(2) Low-temperature steam (UNDER 350 DEGREES $F$ )

(3) High-temperature steam

(4) Hot air (UNDER 350 DEGREES F)

(5) Direct heat (OVER 650 DEGREES F)

(6) Refrigeration

1-10 as 1

11-19 B1k 20

Are there any other areas of solar Industrial process heat for which you are especially interested in obtaining information? (SPECIFY)

(1st Mention)

45-51 B1k

(2nd Mention)

7. What publications have you read in the past six months that include information on solar industrial process heat?

None............... 001

Read, but can't remember titles . 002 (VOLUNTEERED)

1st Mention

Read too many to name .....003 (VOLUNTEERED)

(ASK) Which are most important?

(RECORD TITLES)

Names publications (RECORD TITLES) 004

\section{2nd Mention}

3rd Mention

Figure D-1. Questionnaire (continued) 
8a. I will read a list of potential information products on solar industrial process heat. For each, please tell me how useful that information would be to you. Would the following be: essential, very useful, somewhat useful or not at all useful? (READ LIST. ROTATE. CIRCLE ONE RESPONSE PER ITEM.)

\begin{tabular}{|c|c|c|c|c|}
\hline ssential & $\begin{array}{c}\text { Very } \\
\text { Useful }\end{array}$ & $\begin{array}{c}\text { Somewhat } \\
\text { Useful }\end{array}$ & $\begin{array}{l}\text { Not } \\
\text { At All } \\
\text { Useful. }\end{array}$ & $\begin{array}{l}\text { Don't } \\
\text { Know }\end{array}$ \\
\hline
\end{tabular}

(1) A bibliography of general readings on solar industrial process heat applications. - . - . 4

(2) A list of sources for information on solar industrial process heat. . . 4

(3) A calendar of upcoming solar industrial process heat conferences and programs. . . .

2

(4) Diagrams or schematics of a solar industrial process heat system..... a particular solar industrial process heat system works. ....

(6) A technical description of how a particular solar industrial process heat system works. .

2

1

8944

(7) Lists of local lenders, insurers, builders, installers or distributors for solar industrial process heat systems. . : ...

2

1

8945

(8) Solar industrial process heat design handbooks, installation handbooks, or

(9) A list of technical experts in solar industrial process heat.: 4

2

3

2

3

(1)

2

1

8

$9 \quad 52$

(11) Computer models for sizing and predicting the eng̣ineering performance or life cycle costs. . .

2

Figure D-1. Questionnaire (continued) 
8b. I will next read a list of types of information on solar industrial process heat. 548 For each, please tell me how useful information of that type would be to you. Would the following be: essential, very useful, somewhat useful or not at all useful?

(READ LIST. ROTATE. CIRCLE ONE RESPONSE PER ITEM).

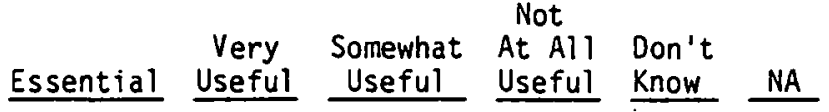

(1) Educational institutions and other organizations offering courses on solar industrial process heat. . . 4

(2) Solar industrial process heat research currently in progress. - . 4

(3) The state-of-the-art in solar industrial process heat. ...

(4) Costs and performance of solar industrial process heat installations. . .4

(5) Costs of installing and operating a solar industrial process heat system compared to a conventional system. . 4

3

3

3

3

3

2

1

8

959

(6) Local building codes or other regulations affecting siting or installation of solar industrial process heat

systems .... 4

(7) Tax credits, grants, or other economic incentives for solar industrial process heat applications ... . 4

(8) Standards, specifications, or certification programs for solar industrial process heat equipment and installations...

2

1

8

(9) Marketing statistics and sales projections for solar industrial process heat equipment. ....

(10) Solar industrial process heat programs, research, industries and markets outside the United States. , , 4

(11) Information on how to market and sell solar industrial process heat systems, including guidelines on obtaining

financial support. .....

(12) Institutional, social, environmental, and legal aspects of solar industrial process heat applications. . . . 4

(13) Expected major developments in solar industrial process heat during the next ten years....

(14) Climatological data such as wind, weather, or amount of sunshine. . 4 
$-$

Cd 4

$1-10$ as 1

9. Is there solar industrial process heat information which you need but are not able to get?

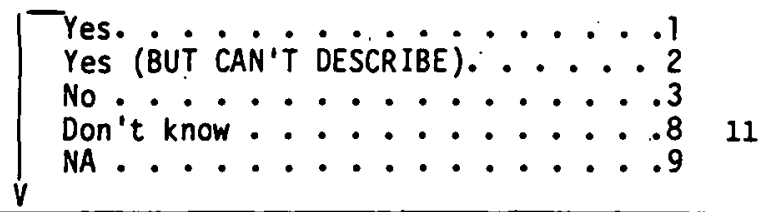

(IF YES) What information do you need?

1st. mention

2nd mention

10. In the past yeai have yuu ublalned any information, not just solar, in the following forms? (READ LIST. CIRCLE ONE RESPONSE PER ITEMM)

Yes No $\begin{aligned} & \text { Don't } \\ & \text { Know }\end{aligned}$

(a) On-line access to a central data bank via computer terminal

$12 \quad 8 \quad 9$

(b) Microform from a computer, sometimes referred to as $C-0-M$

(c) Other microforms, for example, microfiche, microfilm sheets or rolls

Figure D-1. Questionnalre (continued) 
Cd 4

11. Solar information refers to information about any solar technology, and

factors which may relate to its use such as weather, economics, legislation, architecture, environment, etc. In the past few years, have you obtained any type of solar information from any of the following sources? (READ LIST. CIRCLE ONE RESPONSE PER ITEM.)

(1) Your organizational library or a local library. .

(2) A public utility company... $\frac{\text { Yes }}{1} \frac{\text { No }}{2}$. Know $\frac{N A}{8} \frac{1}{9}$ 17

(3) An installer, builder, designer or manufacturer of solar systems. .$$
12 \quad 8 \quad 9 \quad 18
$$

(4) Workshops, conferences or training sessions: .

(5) A commercial data base, for example, Lockheed, SDC, BRS. .

(6) A federal library or information center, for example, the National Agricultural Library or the Environmental Data System. .

(7) Smithsonian Science Information Exchange (SSIE) . . . $11^{\cdot} 2389$

(8) The Government Printing Office (GPO) : .

How would you evaluate the service you received from GPO?

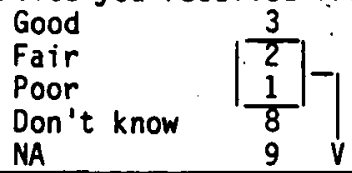

lst Mention

2nd Mention

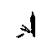

(9) National Technical Information Service (NTIS). . .

\begin{tabular}{|l}
\hline How would you evaluate the service you received from NIIS? \\
Good \\
Fair \\
Poor \\
Don't know \\
NA
\end{tabular}


(Cont 'd)

(10) Technical Information Center at 0ak Ridge (TIC)... TI Th $\frac{\text { Yes }}{2} \frac{\text { know }}{8} \frac{\text { NA }}{9}$

How would you evaluate the service you received from TIC?

$\begin{aligned} & \text { Good } \\ & \text { Fair } \\ & \begin{array}{l}\text { Don't know } \\ \text { NA }\end{array}\left|\begin{array}{c}\frac{3}{2} \\ \frac{1}{8}\end{array}\right|-\mid \\ & 9\end{aligned} \mid$

What are some of the reasons you do not consider their service "good"?

lst Mention

2nd Mention

(11) National Solar Heating and Cooling Information Center. $\quad \mid\left[\begin{array}{lllll}1 & 2 & 8 & 9 & 30\end{array}\right.$

How would you evaluate the service you received fro
Good
Fair
Poor
Don't know
NA

What are some of the reasons you do not consider their service "good"?

1st Mention

2nd Mention

(12) Regional Solar Energy Centers. . .

How would you evaluate the service you received from your regional center?

\begin{tabular}{l|l} 
Good & $\frac{3}{2}$ \\
Fair \\
Pnor \\
Don't know & $\begin{array}{l}2 \\
1 \\
\text { NA }\end{array} \mid$ \\
\hline
\end{tabular}

What are some of the reasons you do not consider their service "good"?

lst Mention

2nd Mention 
$\operatorname{cd} 4$

(Cont'd)

(13) Directly from the U. S. Department of Energy. . .

(14) Radio or TV ......

(15) Periodicals, newspapers or magazines. . . . .

(16) Private solar energy or environmental organizations . . .

(17) State Energy or Solar Offices . .

(18) Some other state or local government office or publication.1

(19) The local chapter or national headquarters of the International Solar Energy Society (ISES), including their publications....

(20) The local chapter or national headquarters of the Solar Energy Industries Association (SEIA), including their publications. . .

(21) NOT ASKED . . . . . . . . . . . . . . . . . . . . . 042

(22) NOT ASKED ................................ 043

(23) NOT ASKED . . . . . . . . . . . . . . . . . . . . . 044

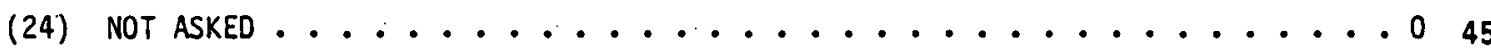

Figure D-1. Questionnaire (continued) 
In conclusion, I would like to ask you some questions about yourself. Your answers will be kept completely confidential.

Dla. What is the highest level of education you have cormpleted? (DO NOT READ) 8th grade or less....... 01

Some high school ...... 02

High school graduate ...... 03

Post high school vocational/

Technical............04 48-49

Attended coll lege/University:

No degree. ........ 05

Associate (2 year junior/

Comunity, college) . : . . 06

Bachelors........ 07

Masters. .......... 08

Ph.0/Doctorate ....... 09

JD/LLD ............. 10

Other

11

Don't know .......... 98

NA.............. 99

D1b. In what field is your most recent degree?

Dlc. In what year did you get that degree?

\begin{tabular}{c|c} 
(RECORD) & Verb. \\
(YEAR) & $50-51$
\end{tabular}

D2a. Please describe your present profession by completing the following staternent: "Based on my total education and experience, I now regard myself professionally as a (ain). -" (AVOID USING JOB TITLE IF POSSIBLE).

Verb.

D2b. How many years have you been in this profession? (CIRCLE CODE)

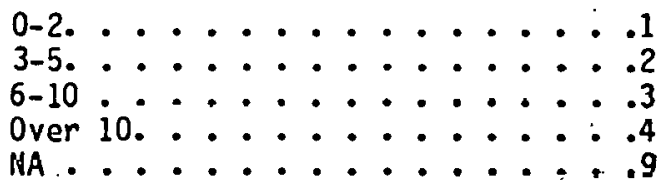

Figure D-1. Questionnaire (continued) 
D3. Do you belony to any professional, technical, or other organizations which have an interest in solar?

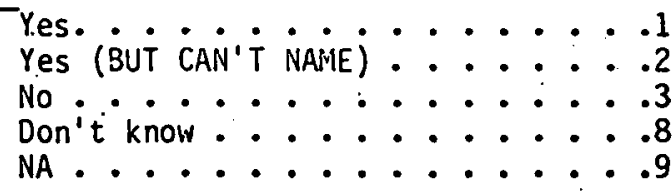

a. What organizations?

1st Mention

2nd Mention

CL

3rd Mention

4th Mention

54-69 BIk

Thank you very much for your time.

Figure D-1. Questionnaire (concluded) 
1. In the next year, do you expect to need information on solar agricultural process heat... (a) For your job? Yes. .....

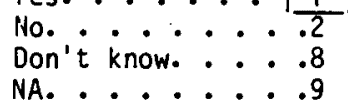

(b) Outside of your job?
Yes. . . . T T

No ...... 2

Dun' $l$ kriüw ... 8

NA..... 9
(IF "YES"

TO EITHER, CONTINUE OTHERWISE

TERMINATE

2. To what extent are you currently involved with solar agricultural process heat? Would you say you are:
Very involved. . . . . . . .4

Moderately involved, or. .....3

Sl ightly involved. . . . . . . . 2

Not at a.l1 invol.ved (VOLUNTEERED). . I

Don't know......, , . .

$\mathrm{NA}_{2},+\ldots, \ldots, \ldots, \ldots, \ldots$

3. What are you doing in the field of solar agricultural process heat? (ASK AS OPEN END)

4. How well informed would you say you are about solar agricultural process heat? Would you say you are:
Very informed ........ 4 Moderately informed, or .... 3 Slightly informed . . . . . . 2 Not at all informed (VOLUNTEERED) Don't know. ........... 0

NA. ............. 9

1st Mention

Znd Mention

Figure D-2. User Questionnaire 
Cd $2 \quad 1-10$ as 1 $11-75$ Blk

$76 \mathrm{Cd}$ 非

6. For which of the following areas of solar agricultural process heat are you $77-80$ Job \# particularly interested in obtaining information? [READ LIST. CIRCLE ONE RESPONSE PER ITEM.]

$\begin{array}{ccc}\text { Yes } & \text { No } \\ 1 & & 2 \\ 1 & & 2 \\ 1 & & 2 \\ 1 & 2 \\ 1 & & 2\end{array}$
Don't Know NA

Cd 3 $1-10$ as 1

(1). Livestock shelter heating

(2) Grain drying

(3) Crop drying

(4) Greenhouses

(5) Food processing

$\begin{array}{ll}8 & 9 \\ 8 & 9 \\ 8 & 9 \\ 8 & 9 \\ 8 & 9\end{array}$

11-26 B1k

Are there any other areas of solar agricultural process heat for which you are especially interested in obtaining information?

(SPECIFY)

1st Mention

2nd Mention

7. What publications have you read in the. past six months that include information on solar agricultural process heat?

None. . ........ 001

Read but can't remember titles. 002 (VOLUNTEERED)

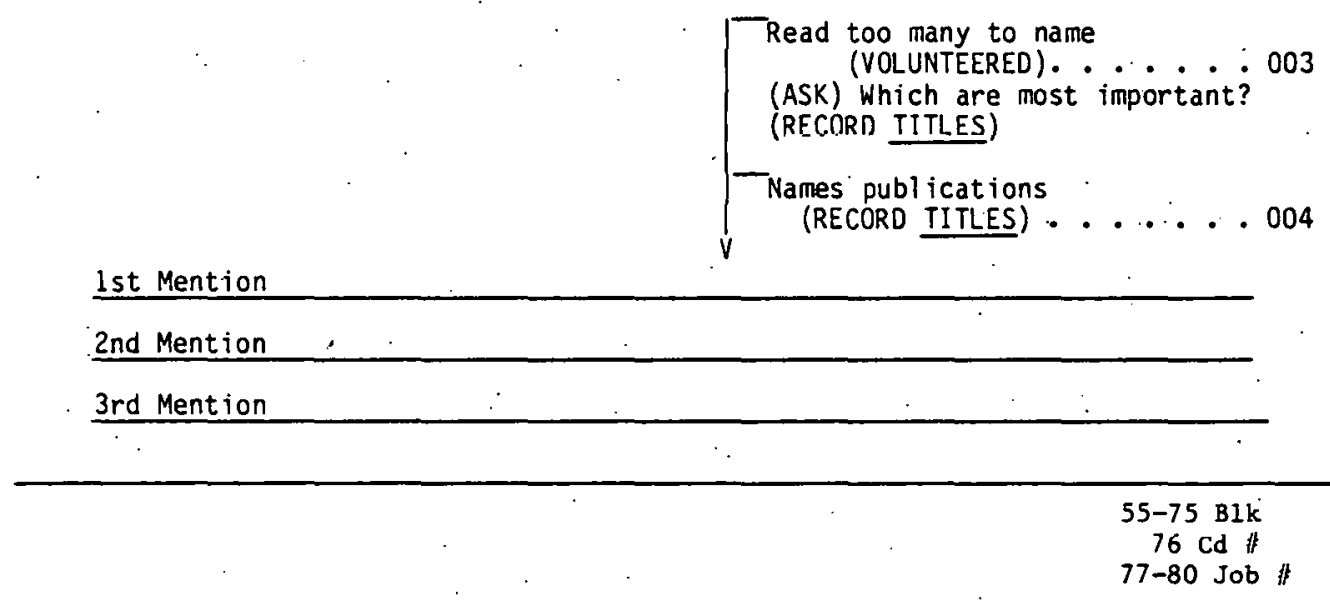

Figure D-2. User Questionnaire (continued) 
Cd 1

8a. I will read a list of potential inforination products on solar agricultural process

heat. For each, please tell me how useful that information would be to you: Would

the following be: essential, very useful, somewhat useful, or not at all. useful?

(READ LIST. ROTATE. CIRCLE ONE RESPONSE PER ITEM)

$\begin{array}{cccc}\begin{array}{c}\text { Very } \\ \text { Essential Somewhat At All }\end{array} \begin{array}{c}\text { Don't } \\ \text { Useful Useful }\end{array} \text { Useful } & \begin{array}{c}\text { Know } \\ \text { UnA }\end{array}\end{array}$

(1) A bibliography of general readings on solar agricultural process

heat.. .

4

3

2

1

8

943

(2) A list of sources for information on solar agricultural process heat. . 4

(3) A calendar of upcoming solar agricultural process heat conferences and proyrams. . . . 1

3

2

1

8

944

(4) Diagrams or schematics of a solar agricultural process heat system. . 4

(5) A non-technical description of how a particular solar agricultural process system works. .

(6) A technical description of how a particular solar agricultural process system works. . .

(7) Lists of lenders, insurers, builders, engineers, installers, manufacturers or distributors for solar aqricultural process heat systems.....

(8) Solar agricultural process heat design handbooks, installation handbooks, or reference tables....

$4:$ agricultural process heat

applications. ..

Manual methods for sizing and predicting the engineering performance or life cycle costs of solar agriculzural process systems. .

(11) Computer models for sizing and predicting the engineering performance or life cycle costs...

$1 \quad 8 \quad 9 \quad 50$

\section{Figure D-2. User Questionnaire (continued)}


Cd.1

8b. I will next read a list of types of information on solar agricultural process heat. For each, please tell me how useful information of that type would be to you. Would the following be: essential, very useful, somewhat useful or not at all useful? (READ LIST. ROTATE. CIRCLE ONE RESPONSE PER ITEM).

\begin{tabular}{ccc} 
Eery & $\begin{array}{c}\text { Somewhat At All Don't } \\
\text { Usential Useful }\end{array}$ Useful Useful Know \\
\hline
\end{tabular}

(1) Educational institutions and other organizations offering courses on solar agricultural process heat . . .4

(2) Solar agricultural process heat research currently in.process. . . 4

(3) The state-of-the-art in solar agricultural process heat...

(4) Costs and performance of solar agricultural process heat installations....

(5) Costs of installing and operating a solar agricultural process heat system compared to a conventional system. . 4

(6) Local building codes or other regulations affecting siting or installation of solar agricultural process heat systems....

$$
2
$$$$
1
$$$$
8 \quad 9 \quad 55
$$

Tax credits, grants, or other economic incentives for solar agricultural process heat applications... 4

(8) Standards, specifications, or certification programs for solar agricultural process heat equipment and installations......

(9) Marketing statistics and sales projections for solar agricultural process heat equipment. ...

\section{4}

(10) Solar agricultural process heat prograns, research, industries and markets outside the United States. . 4

(11) Information on how to market and sell solar agricultural process heat systems, including guidelines on obtaining financial support. . . 4 4

(12) Institutional, social, environmental, and legal aspects of solar agricultural process heat applications. - 4

(13) Expected major developments in solar agricultural process heat during the next ten years. ..... 4

(14) Climatological data such as wind, weather, or amount of sunshine... 4

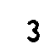

3

3

3

3

$$
2
$$

1

$8 \quad 962$

3

3

3

3

3

3

3.

2

$$
1
$$

8

965

$\begin{array}{lllll}2 & 1 & 8 & 9 & 66\end{array}$

Figure D-2. User Questionnaire (continued) 
9. Is there solar agricultural process heat Tyes. . . . . . . . . . 1 information which you need but are not Yes (BUT CAN'T DESCRIBE) ....2 able to get?

No $. . \cdots \cdot . \cdot 3$

Don't know............ 81

NA............ 9

y

(IF YES) What information do you need?

1st Mention

2nd Mention

10. In the past year, have you obtained arly infurmation. not just solar, in the following forms? (READ LIST. CIRCLE ONE RESPONSE PER ITEM)

$$
\text { Yes No Non't } \begin{aligned}
& \text { Don } \\
& \text { NA }
\end{aligned}
$$

(a) On-line access to a central data bank via computer terminal

(b) Microform from a computer, sometimes referred to as $C-0-M \quad 1 \quad 2,8$

(c) Other microforms, for example, microfiche, microfilm sheets or rolls

Figure D-2. User Questionnaire (continued) 
11. Solar information refers to information about any solar technology, and factors which may relate to its use such as weather, economics, legislation, architecture, environinent, etc. In the past few years, have you obtained any type of solar information froin any of the following sources? [READ LIST. CIRCLE ONE RESPONSE PER [TEM.]

(1) Your organizational library or a local library. .

\begin{tabular}{|c|c|c|c|}
\hline Yes & No & $\begin{array}{l}\text { Don't } \\
\text { Know }\end{array}$ & NA \\
\hline 1 & 2 & 8 & 9 \\
\hline 1 & 2 & 8 & 9 \\
\hline
\end{tabular}

(2) A public utility company. . solar systems. .

(5) A commercial data base, for example, Lockheed, SDC, BRS. - $1 \quad 2 \quad 8 \quad 9 \cdot 21$

(6) A Federal library or information center, for example, the National Agricultural Library or the Environmental Data System. .

(7) Smithsonian Science Information Exchange (SSIE) • • • $\quad \begin{array}{llllll} & 1 & 2 & 8 & 9 & 23\end{array}$

(8) The Government Printing Office (GPO) . ...

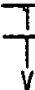

How would you evaluate the service you received from GPO?

\begin{tabular}{|c|c|}
\hline $\begin{array}{l}\text { Good } \\
\text { Fair } \\
\text { Poor } \\
\text { Don't know } \\
\text { NA }\end{array}$ & $\begin{array}{l}\frac{3}{2} \\
\frac{1}{8} \\
9\end{array}$ \\
\hline
\end{tabular}

What are some of the reasons you do not consider their service "good"?

1st Mention

2nd Mention

Verb.

(9) National Technical Information Service (NTIS). • * , I

\begin{tabular}{|l}
\hline How would you evaluate the service you received from (NTIS)? \\
Good \\
Fair \\
Poor \\
Don't know \\
NA
\end{tabular}

Figure D-2. User Questionnalre (continued) 
(10) Technical Information Center at Oak Ridge (TIC)...

\begin{tabular}{|l|}
\hline How would you evaluate the service you received from TIC? \\
Good \\
Fair \\
Poor \\
Don't know \\
NA
\end{tabular}

(11) National Solar Heạting and Cooling Information Center. $\mid \begin{array}{lllll}1 & 2 & 8 & 9 & 30\end{array}$

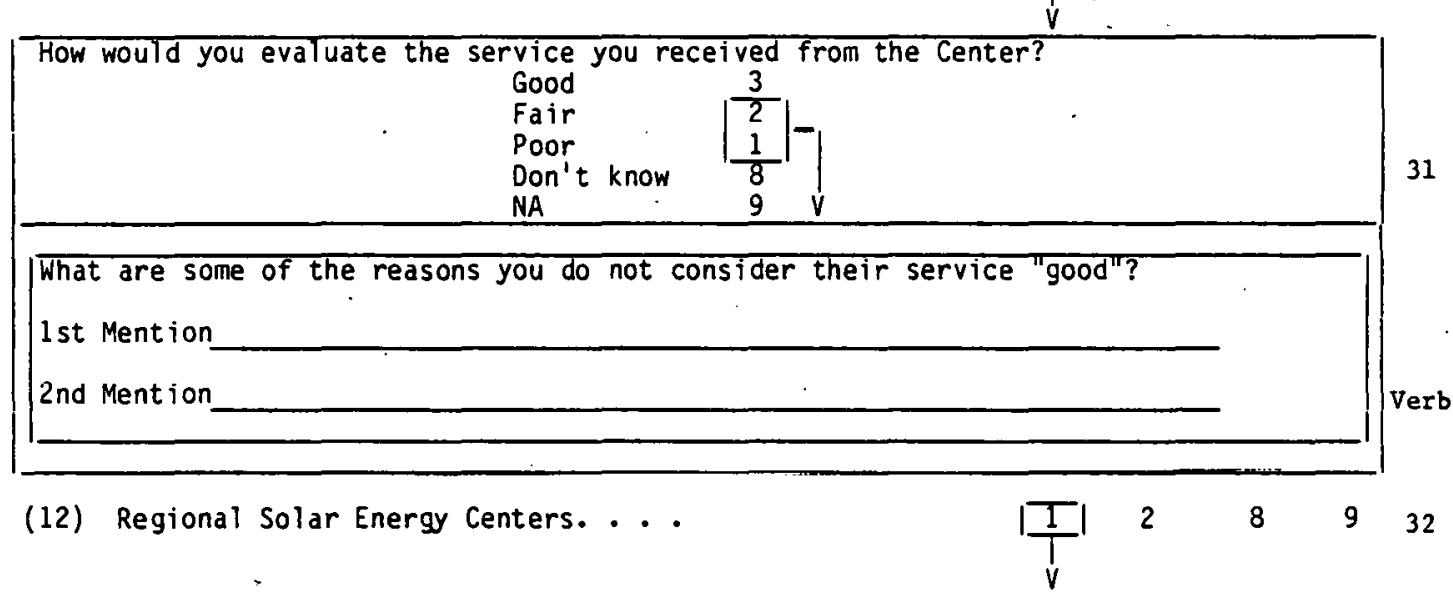

How would you evaluate the service you received from your regional center?

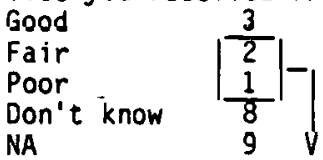

Verb.

What are some of the reasons you do not consider their service "good"?

1st Mention

2nd Mention

Verb.

Figure D-2. User Questionnaire (continued) 
Cd 4

(13) Directly from the U. S. Departinent of Energy. . .

$\frac{\text { Yes }}{1} \frac{\text { No }}{2} \frac{\begin{array}{c}\text { Don't } t \\ \text { Know }\end{array}}{8} \frac{\text { NA }}{9_{34}}$

(14) Radio or TV ........

$\begin{array}{lllll}1 & 2 & 8 & 9 & 35\end{array}$

(15) Periodicals, newspapers or magazines. ... $2 \quad 8 \quad 9 \quad 36$

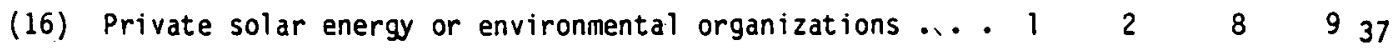

(17) State Energy or Solar Offices... . $\quad 1 \quad \begin{array}{lllll} & 2 & 8 & 9 & 38\end{array}$

(18) Some other state or local government office or publication.1 $2 \begin{array}{llll}2 & 8 & 9\end{array}$ (other than your own)

(19) The local chapter or national headquarters of the International Solar Energy Society (ISES), including their publicalions.:-.. $\quad 1 \quad 2 \quad \begin{array}{llll}9 & 9\end{array}$

(20) The local chapter or national headquarters of the Solar Energy Industries Association (SEIA), including their publications. . . $\quad 1 \quad 2.8989$

(21) USDA, including the Cooperative Extension Service. • • $11 \quad 2 \quad 8 \quad 8 \quad 942$

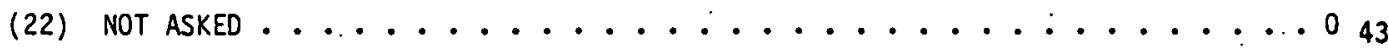

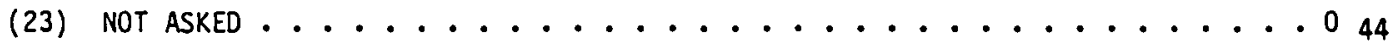

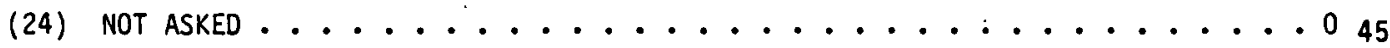

Figure D-2. User Questionnaire (continued) 
Cd 4

In conclusion, I would like to ask you sone questions about yourself. Your answers will be kept completely confidential.

0la. What is the highest level of education you have completed? (DO NOT READ) 8th grade or less....... 01

Sorne high school ...... 02

High school graduate...... 03

Post high school vocational/

Technical.........04

Attended college/University:

No degree. ........ 05

Associate (2 year junior/

Community college) .....06

Bachelors.........007

Masters.........08 08

Ph.D/Doctorate .......09

JD/LLD ............ 10

Other

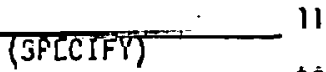

Uon't know .............. 98

NA.............. 99

D1b. In what field is your most recent degree?

D1C. In what year did you get that degree?

$\left.\frac{(\text { RECORD) }}{(\text { YEAR) }}\right|_{50-51} ^{\text {Verb }}$

D2a. Please describe your present profession by completing the following statement: "Based on my total education and experience, I now regard myself professionally as a (an):" POSSIBLE). ." (AVOID USING JOB TITLE IF

Verb.

D2b. How many years have you been in this protession? (CIRCLE CODE)

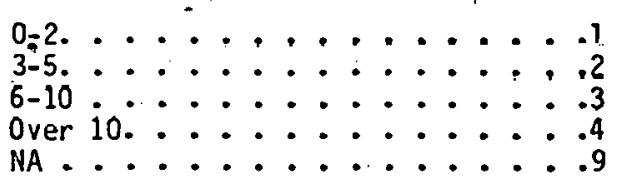

Figure D-2. User Questionnaire (continued) 
D3. Do you belony to any professional, technical, or other oryanizations which have an interest in solar?

V

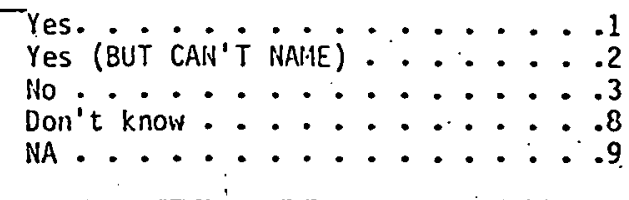

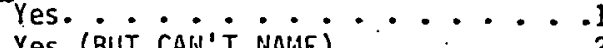

NATE $\cdot \cdot \cdot \cdot \cdot \cdot .2$

Don't know

NA............. ...

a. What organizations?

1st Mention

2nd Mention

3rd Mention

4th Mention

CL

54-69 B1K

Thank you very much for your time.

Figure D-2. User Questionnaire (concluded) 
could be provided to the respondent. Theref ore, this report refers to the responses to Question 5 as "information which was important for the respondents to obtain."

Question 6. In this question, a list of different solar industrial or agricultural process heat (IAPH) applications was read to the respondent, and the respondent was asked which application he/she was particularly interested in obtaining information for. After this was completed, respondents were asked, "Are there any other areas of solar IAPH for which you are particularly interested in obtaining information?" Responses to this question fell into one of two areas: additional IAPH applications of intercst or specific types of information wanted. The former were discussed with other results from Question 6; the latter were included with the responses from Question 5.

Question 8. In this question a list of up to 25 specific information products or types of information was read to the respondent. The respondent rated eash item as "essential," "very useful," "somewhat useful," or "not at all useful" as it applied to himself. In contrast to Qucstion 5, this question assessed each respondent's ratings for each of a set of items that the study designers thought might be important to the respondents. Question 8 did not allow respondents to add and rate items not already on the list. To reduce the possibility of introducing bias due to item order within Question 8, the interviewers rotated their starting point by randomly selecting which item would be read to the respondent first. Items in Question $8 \mathrm{a}$ were rotated separately from those in Question 8b.

Question 9. This question asked, "Is there any solar IAPH information which you need but are not able to get?" Unfortunately, this question just did not work. Answering Questions $8 a$ and $8 b$ required the respondent to assign a rating to each of 22-25 information items. By the time the respondents had completed Question 8 they were usually starting to get fatigued with the interview. As a result many did not ancwcr Question 9 at all.

Question 11. In this question respondents were not asked if they had obtained solar information from the Solar Energy Research Institute (SERI). The principal reason was the probability of obtaining biased responses. All respondents had received a letter describing the Solar Energy Inf ormation Data Bank (SEIDB) and introducing SERI. It was felt that many respondents would attempt to encourage information flows from SERI by responding positively when asked whether they had used SERI as an information sourcewhether or not they actually received information directly from SERI. Since explaining the nature of SERI and the SEIDB was necessary to promote a good response rate, no questions about SERI were included.

In Question 11, items 21-23 require some explanation: they are shown as "NOT ASKED" on the sample questionnaire (readers may note that data for items 21-23 does occur on the tables in Appendix $\mathrm{F}$ for some groups). These items were left open for the inclusion of specific organizations which seemed most appropriate for each group. Table D-1 lists the organizations, the respondent groups, and the question numbers for each item used for the groups covered in this report. 
Table D-1. SRLECTED ORGANIZATIONS ABOUT WHICH INDUSTRIAL AND AGRICULTURAL PROCESS HEAT (IAPH) RESPONDENTS WERE ASKED

\begin{tabular}{lcc}
\hline \multicolumn{1}{c}{ Group } & Item $^{\text {a }}$ & \multicolumn{1}{c}{ Organization } \\
\hline APH Researchers & 21 & $\begin{array}{c}\text { U.S. Department of } \\
\text { Agriculture(USDA), } \\
\text { including the } \\
\text { Cooperative Extension } \\
\text { Service (CES) }\end{array}$ \\
IPH Plant Engineers & & Association of Energy \\
& & Engineers (AEE) \\
IPH Industrial Engineers & 21 & AEE \\
& 21 & Institute of Electrical and \\
& 22 & Electronics Engineers \\
Active Solar Heating and & & (IEEE) \\
Cooling Industrial Engineers & & AEE \\
IPH Agricultural Engineers & 21 & AEE \\
& 21 & American Society of \\
State Agricultural Office & 22 & Agricultural Engineers \\
Representatives & 21 & USDA, including CES \\
APH CES County Agents & 21 & USDA, including CES \\
All CES County Agents & 21 & USDA, including CES \\
& 22 & State Agricultural Office \\
All CES State Specialists & 21 & Representatives \\
\hline
\end{tabular}

$a_{\text {The number of the item in which the group was asked about the particular organiza- }}$ tion. For example, 21 is Item 21 of Question 11. 


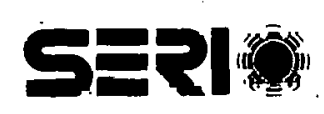


APPENDIX E

STATISTICAL TESTING 


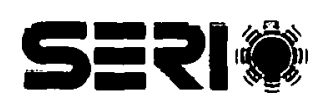

. 
Despite the small sample sizes, selected statistical tests could be used. All of these tests used a 5\% rejection region unless otherwise noted. Thus, if a test result indicated that a difference between two means was statistically significant $(P<0.05)$, it meant that there was only a one-out-of-twenty chance that the two means were not different. Actual calculations were made with the Statistical Package for the Social Sciences (SPSS) sof tware and other computer packages.

The tests conducted fell into three main types: tests of proportions between two groups, t-Tests between two groups, and Paired t-Tests within a group. Each of these are discussed below.

For all except Question 8, tests of proportions were used. For example, the proportion of Industrial Process Heat Researchers using computer terminals was compared to the proportion of Agricultural Process Heat Researchers using computer terminals. If the sample sizes were small, Exact Binomial Tests were used. When the sample sizes were larger (e.g., a comparison of Industrial Process Heat Researchers to All Researchers), ChiSquare Tests were used.

For analysis of the results from Question 8, t-Tests were used. In Question 8 each respondent was asked to describe the usefulness of up to 25 information products/categories as either "essential," "very useful," "somewhat useful," or "not at all useful." The "average usefulness" rating that the group assigned an item was then calculated by assigning the responses a "4" for "essential," a "3" for "very useful," a "2" for "somewhat useful," and a "l" for "not very useful," then calculating the average for the entire group. A t-Test was used to determine whether group A rated a specific information item significantly higher (or lower) than it was rated by group B. Some groups, however, tended to give higher scores in general than did other groups. To compensate for this effect, these statistical tests compared the "relative rating" given by one group to the "relative rating" given by the other groups. The relative rating given by a group to a particular item was calculated as follows: take the average usefulness rating the group gave that item (for example, suppose "a bibliography" received a 3.15 rating), then subtract the average overall rating this group gave to all items (suppose the average rating the group gave all items was 2.75); the difference was the relative rating (for this example $3.15-2.75=+0.40$ ). The $t-T e s t$ then was used for the comparison of the relative rating group A gave to the item to the relative rating group $B$ gave the item.

For the tests of proportions (or the t-Tests involving Question 8), if group A was being compared to group B and group A was a subset of group B (e.g., a comparison of Industrial Process Heat Researchers to All Researchers), the totals for group A were subtracted from the totals for group $B$ and the proportions (or the relative ratings) for group $B$ were recalculated from the adjusted totals.

For Question 8 it sometimes occurred that the researcher wanted to compare the rating a group gave one item to the rating they gave another item. For example, did Industrial Process Heat Educators rate "lists of sources for information" significantly higher (or lower) than they rated "lists of technical experts"? This test was conducted using a Paired t-Test. 


\section{SEPI策}




\section{APPENDIX F \\ SOLAR NDUSTRIAL AND \\ AGRICULTURAL PROCESS HEAT \\ DATA TABLES}




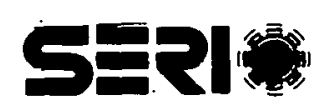

$\checkmark$ 
In the following data tables, each table entry shows counts and percentages displayed in the format $\left(\%^{\#)}\right.$, where $\%$ is the column percentage for each group and \# is the number of respondents in each group who gave the response shown in the row title. Each column shows the results for an individual group or for a combination of groups.

Table F-1 lists the groups and combinations for which data are shown in the data tables. Table F-2 shows which groups are included in each of the combination groups listed in Table F-1. Table F-3 lists the data tables and Fig. F-1 contains the data tables themselves. 
Table F-1. GROUPS AND COMBINATION GROUPS WTH DATA INCLUDED IN APPENDIX F

- Group

Report Section

Industrial Process Heat Researchers (IPH RES)

3.0

Agricultural Process Heat Researchers (APH RES)

3.0

Total Industrial and Agricultural Process Heat

Researchers (TOTAL IAPH RES)

3.0

All Researchers (ALL R ES)

3.0

Concentrating Collector Manufacturer Representatives

(CONC COLL MAN.UF)

4.0

Total Nonconcentrating Collector

Manufacturer Representatives (TOTAL NCONC COLL MANUF)

5.0

All Manufacturer Representatives (ALL MANUF)

Industrial Process Heat Plant Engineers (IPH PLANT ENG)

$4.0,5.0$

Industrial Process Heat Industrial Engineers (IPH INDUS ENG)

6.0

6.0

Active Solar Heating and Cooling Industrial Engineers

(SHAC INDUS ENG)

6.0

Industrial Process Heat Agricultural Engineers. (IPH AGRIC ENG)

6.0

All Engineers (ALL ENG)

6.0

Industrial Process Heat Educators (IPH EDUC).

7.0

All Educators (ALL EDUC)

7.0

Agricultural Process Heat State Agricultural Office

Representatives (APH STATE AGRIC OFF)

8.0

Agricultural Process Heat Cooperative Extension Service (CES) County

Agents (APH CES CO AGENT)

9.0

All CES County Agents (ALL CES CO AGENT)

9.0

All CES State Specialists (ALL CES STATE SPEC)

9.0 
Table P-2. COMBINATION GROUPS

Total Industrial And Agricultural Process Heat Researchers (TOTAL IAPH RES)

Industrial Process Heat (IPH) Researchers

Agricultural Process Heat (APH) Researchers

All Researchers (ALL RES)

Photovoltaics (PV) DOE-Funded Researchers

PV Non-DOE-F unded Researchers

PV Researcher Manufacturers

Biomass Federally Funded Production and Collection Researchers

Biomass Federally Funded Conversion Researchers

Biomass Nonfederally Funded Production and Collection Researchers

Biomass Nonf ederally Funded Conversion Researchers

Wind DOE-Funded Researchers

Wind Non-DOE-F unded Researchers

Solar Thermal Electric Power (STEP) DOE-Funded Researchers

STEP Non-DOE-F unded Researchers

Ocean Energy DOE-Funded Researchers

Ocean Energy Non-DOE-F unded Researchers

Solar Energy Storage DOE-Funded Researchers

Solar Energy Storage Non-DOE-F unded Researchers

Active Solar Heating and Cooling (SHAC) DOE-Funded Researchers

SHAC Non-DOE-F unded Researchers

Passive Federally Funded Researchers

IPH Researchers

APH Researchers

Total Nonconcentrating Manufacturer Representatives (TOTAL NCONC COLL MANUF)

SHAC Heating/Cooling System Manufacturer Representatives

SHAC Water Heating System Manufacturer Representatives

SHAC Nonconcentrating Collector Manufacturer Representatives

All Manufacturer Representatives (ALL MANUF)

PV Manufacturer Representatives

Biomass Production and Collection Equipment Manufacturer Representatives

Biomass Conversion Equipment Manufacturer Representatives

Wind Manufacturer Representatives

STEP and IPH Concentrating Collector Manuf acturer Representatives 
Table F-2. COMBINATION GROUPS (Concluded)

SHAC Heating/Cooling System Manuf acturer Representatives

SHAC Water Heating System Manuf acturer Representatives

SHAC Nonconcentrating Collector Manufacturer Representatives

SHAC Other Component Manufacturer Representatives

Passive Manufacturer Representatives

All Engineers (ALL ENG)

PV Electric Power Engineers

Biomass Forest Products Engineers and Consultants

Wind Engineers

Wind Electric Power Engineers

STEP Engineers

SHAC Heating, Ventilating and Air Conditioning Engineers

SHAC Industrial Engineers

IPH Plant Engineers

IPH Industrial Engineers

IPH Agricultural Engineers

State Level Cooperative Extension Service (CES) Agricultural Specialists (Ágricultural Engineers)

All Educators (ALL EDUC)

PV Educators

Biomass Educators

Wind Educators

STEP Educators

SHAC. Educators

Passive Edurators

IPH Educators

All Cooperative Extension Service County Agents (ALL CES CO AGENT)

Biomass CES County Agents

. Wind CES County Agents

SHAC CES County Agents

Passive CES County Agents

APH CES County Agents

All Cooperative Extension Service State Specialists (ALL CES STATE SPEC)

State Level CES Agricultural Specialists

State Level CES Information Specialists 
Table F-3. LIST OF DATA TABLES

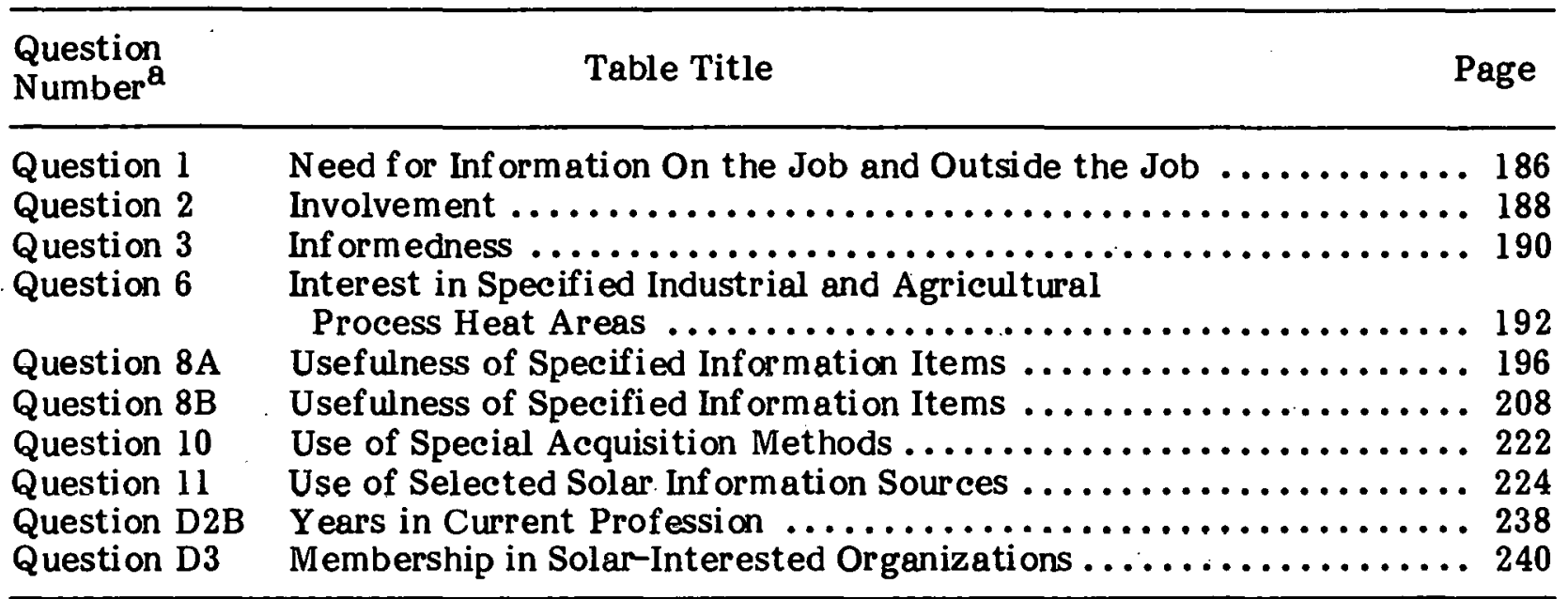

${ }^{a}$ See Appendix D, Figs. D-1 and D-2 for the wording of each question. 
(OCTOBER, 1979)

NEED FOR INFORMATION ON THE JOB AND OUTSIDE THE JOB (QUES-IDN 2 )

INDUSTRTAL AND AGRICULTURAL
PROCESS HEAT

YES FOR JOB

NO FOR $M O B$

DON'T KNOW/NA

QIB TOTAL

:YES OUTSIDE JOB

DON'T KNOW/NA

YES, JOB + OUTSIDE

IPH APH IOATAL ALL

$$
100.100 \text {. } 100.10181
$$

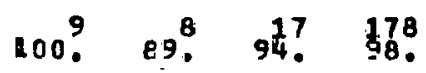

$1^{2}$

$$
11.50^{1} \cdot 12
$$$$
\text { 100. } 100 \text { ? } 1 \frac{117}{00} \text {. }
$$$$
22^{2} .222^{2} \quad 41^{48}
$$$$
56.555^{5} \quad 51.0
$$$$
22.222^{2} \cdot 3^{9} .
$$$$
22^{2} .22^{2} .39 \text {. }
$$

CONC TOTAL ALL
COLL NCONC MANUF
MANUF COLL

$$
\begin{aligned}
& 100 \text {. } 100.100^{96} \\
& \text { 100. } 97^{8} .97^{\circ} . \\
& \text { 3. } 2 \text {. }
\end{aligned}
$$

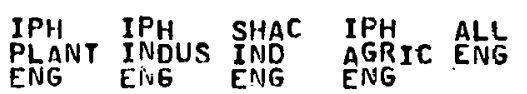

$$
1009100 \% 100 \% 100 \% 1006
$$

$1009.100^{9} .100^{9} .1000^{9} 97^{9}$.

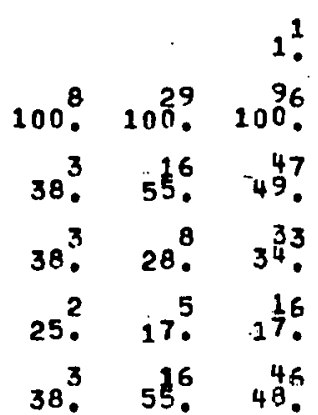

$\begin{array}{rr}100 . & 100^{62} \\ 44^{4} & 47^{9} \\ 56 . & 44^{27} \\ & 10^{6} . \\ 44^{4} & 426\end{array}$

Figure F-1. Industrial and Agricultural Process Heat Data Tables 


$$
\text { (OCTOBER. 1979) }
$$

$T-001$

NEED FOR INFORMATION ON THE JOB AND OUTSIDE THE JOB (QUESTION 1 )

INDUSTRIAL AND AGRICULTURAL
PROCESS HEAT (CONTINUED)
YES FOR JOB
NO FOR JOB
DON'T KNOW/NA
O1B TOTAL
YES OUTSIDE JOB
NO OUTSIDE JOB
DON'T KNOW/NA
YES, JOB + OUTSIOE

\begin{tabular}{|c|c|c|c|c|c|}
\hline $\begin{array}{l}\text { IPH } \\
\text { EDU }\end{array}$ & ALLUC & $\begin{array}{l}\text { APH } \\
\text { STATE } \\
\text { AGRIC } \\
\text { OFF }\end{array}$ & $\begin{array}{l}\text { APH } \\
\text { CES } \\
\text { COD } \\
\text { AGENT }\end{array}$ & $\begin{array}{l}\text { A.L' } \\
\text { cES } \\
\text { Con } \\
\text { AGENT }\end{array}$ & $\begin{array}{l}\text { ALL } \\
\text { ČES } \\
\text { STATEE } \\
\text { SPEC }\end{array}$ \\
\hline 10 & $100^{63}$ & 100. & $100^{9}$ & 100 & $100^{18}$ \\
\hline 100 & $100^{63}$ & $100^{8}$ & $100^{9}$ & 98. & $100^{10}$ \\
\hline
\end{tabular}

\begin{tabular}{|c|c|c|c|c|}
\hline & & & 21 & \\
\hline $\begin{array}{c}405 \\
100^{\circ}\end{array}$ & $100^{8}$ & $100^{\circ}$ & $\begin{array}{r}45 \\
100^{\circ}\end{array}$ & $100^{18}$. \\
\hline 69. & $63^{5}$ & . $566^{5}$ & ${ }_{47}^{21}$ & $39 ?$ \\
\hline 27. & $25{ }^{2}$. & $33^{3}$ & 49 & $5^{10}$. \\
\hline $4^{2}$ & $13^{1}$. & 111 & $4^{2} \cdot$ & $\epsilon$ \\
\hline 691 & $63^{5}$ & 56. & $\begin{array}{r}20 \\
44\end{array}$ & $39 ?$ \\
\hline
\end{tabular}

Figure F-1. Industrial and Agricultural Process Heat Data Tables (continued) 


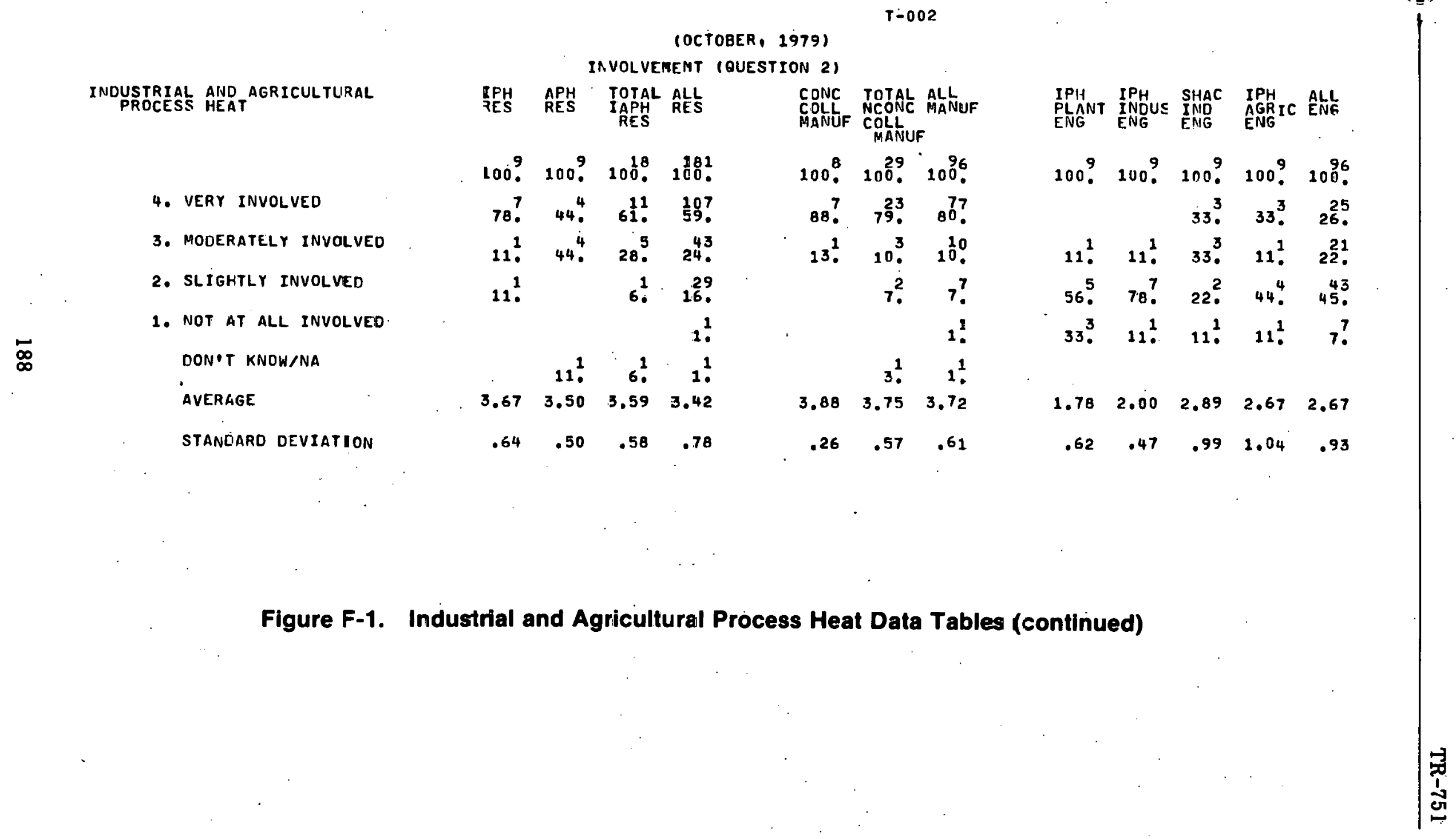




\begin{tabular}{|c|c|c|c|c|c|c|}
\hline \multirow[b]{2}{*}{$\begin{array}{l}\text { INOUSTRIAL AND AGRICULTURAL } \\
\text { PROCESS HEAT (CONTINUEDS) }\end{array}$} & & & $\begin{array}{l}\text { COCTO } \\
\text { MENT }\end{array}$ & $\begin{array}{l}9791 \\
\text { ON } 21\end{array}$ & \multicolumn{2}{|c|}{$T-002$} \\
\hline & IPOH & ELLUC & $\begin{array}{l}\text { APH } \\
\text { STATE } \\
\text { AGRIC } \\
\text { OFF }\end{array}$ & $\begin{array}{l}\text { APH } \\
\text { CES } \\
\text { CDO } \\
\text { AGENT }\end{array}$ & $\begin{array}{l}\text { ALL } \\
\text { CES } \\
\text { CEQENT }\end{array}$ & $\begin{array}{l}\text { ALL } \\
\text { ÇES } \\
\text { ŞATE } \\
\text { SPEC }\end{array}$ \\
\hline & 1009 & 100 & $100^{8}$ & 1009 & 100 & $100^{18}$ \\
\hline 4. VERY INVOLVED & $22^{2}$ & $43 ?$ & $25{ }^{2}$ & & 2. & $33^{6}$ \\
\hline 3. MODERATEL.Y INVOLVED & $33^{3}$ & 35 & $13 !$ & $22^{2}$ & 27. & $39 ?$ \\
\hline 2. SLIGHTLY INVOLVED. & $44^{4}$ & $22^{\frac{1}{4}}$ & 63. & $78 ?$. & 712 & $28^{5}$ \\
\hline $\begin{array}{l}\text { 1. NOT AT ALL INVOLVED } \\
\text { DON'T KNOW/NA }\end{array}$ & & & & & & \\
\hline AVERAGE & 2.78 & 3.21 & 2.63 & 2.22 & 2.31 & 3.06 \\
\hline STANDARD DEVIATION & .77 & .76 & .84 & .42 & .51 & .76 \\
\hline
\end{tabular}

Figure F-1. Industrial and Agricultural Process Heat Data Tables (continued) 


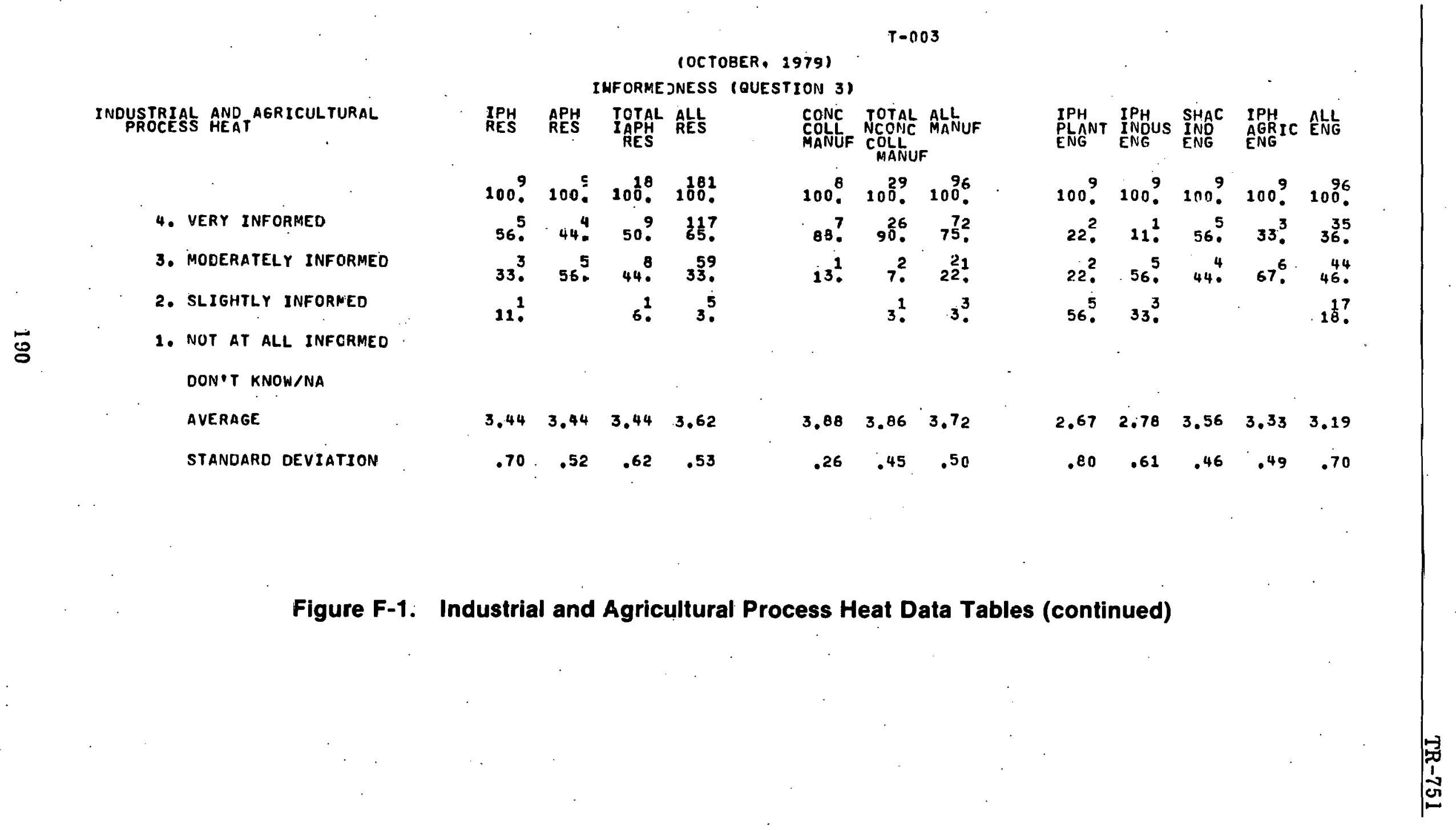




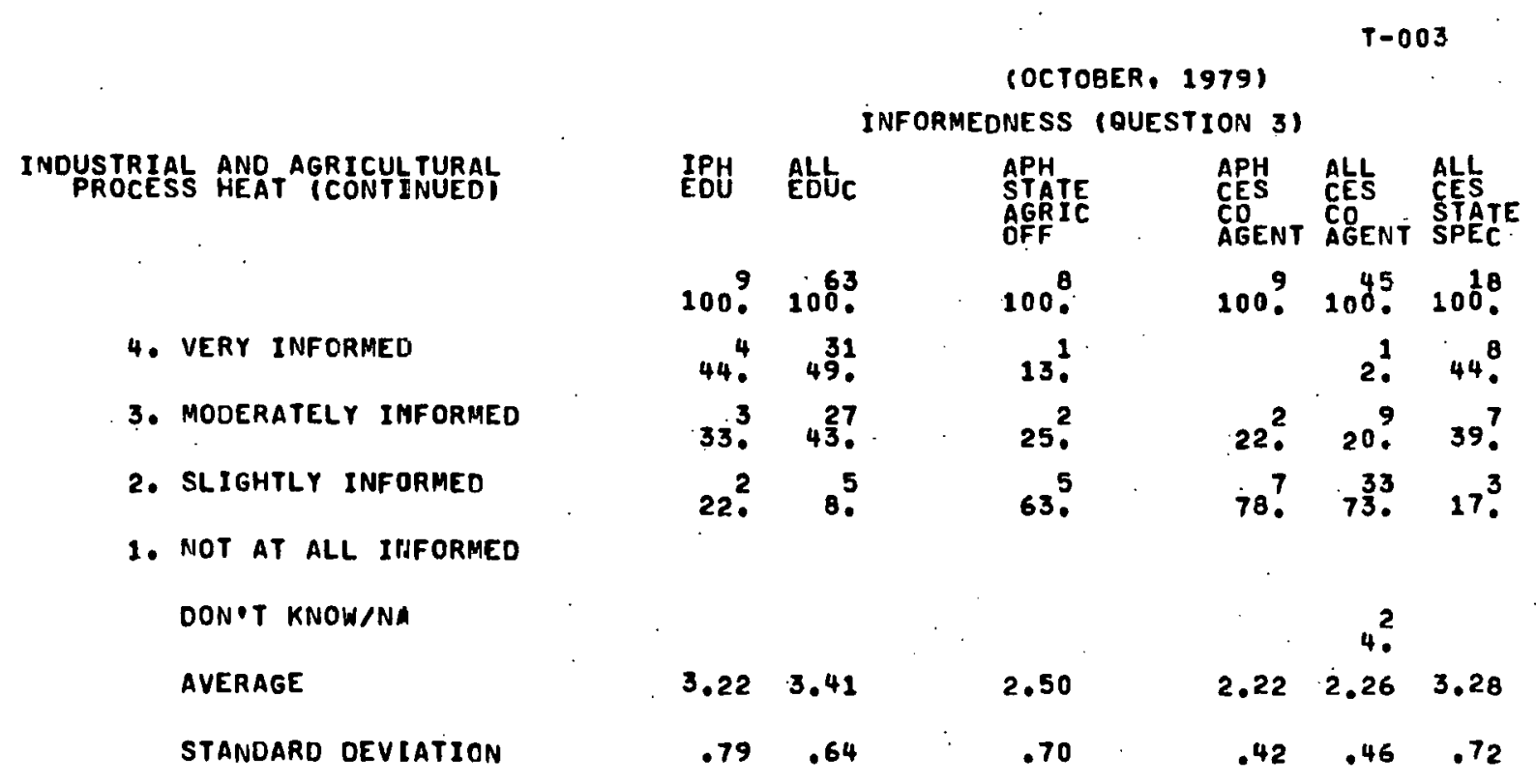

Figure F-1. Industrial and Agricultural Process Heat Data Tables (continued) 
(OCTOBER, 1979$)$.

INTEREST IN SPECIFIEO INDUSTRIAL AND AGRICULTURAL PROCESS HEAT (OUESTION 6)

INOUSTRIAL AND AGRICULTURA-

HOT WATER

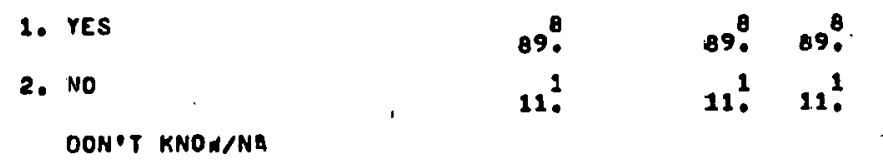

LOM-TEMPERATURE STEAM
1. YES

2. No

OONPT KNOU/NA

HIGH-IEMPERATURE STEAL

1. YES

2. NO DON'T KNOW/NE

HOT AIR

1. YES

2. No

DON'T.KNOW/NA

DIRECT HEAT

1. YES

2. No

DON'T KNOWNA

REFAIGERATION

2. YES

2. No

DON'T KNOH.NA
IPH APH IOTAL ALL
RES RES IAPH RES CONC TOTAL ALL
RES

IPH IPH SHAC IPH ALIC ALL
PAANT INDUS IND
ENG
ENG ENG

100 . 100 . 100 . 108 ?

B9. $69^{8}$ B9. $89^{\circ}$.

11. 11 . 11. 11 .

78? 78 ? 78 ?

$22^{2} \quad 22^{2} 22^{2}$

36.578 ?

$144^{4} 22^{2}$

$57^{6} .67^{18}$.

$333^{3} 33^{9}$.

$-1.22^{2}$

19. 78 .

22. 19.

36. $\quad 36.55$.

44. $44^{4} .44^{4}$.

$67^{6} \quad 67^{6} \quad 67^{6}$

$33^{3} \quad 533^{3} \quad 35^{3}$.

$560^{5} \quad 89^{8}$

$44^{4} .11$.

78. 74.

22. 26 .

13? $22^{2}$.

67. $78^{\circ}$.

33. $30^{\mathrm{B}}$

56. $56^{5} \quad 56^{5}$

11 . $\quad 11$. $1: ?$

78. 78 . 76 ?

$22^{2} \quad 22^{2} \quad 2 \varepsilon^{2}$
67. 78 ?

33. $22^{2}$

Figure F-1. Industrial and Agricultural Process Heat Data Tables (continued) 
INTEREST IN SPECIFIED INOUSTRIAL AND AGRICULTURAL PROCESS HEAT IOUESTION 6 ! INOUSṪRIAL AND AGRICULTURAL

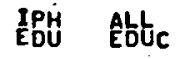
APH
STAATE
AGR
OFF $\begin{array}{ll}\text { APH } & \text { ALL } \\ \text { CES CLLS } & \text { CES CESS } \\ \text { CDO COANE } & \text { CO } \\ \text { AGENT AGENT SPEC }\end{array}$

HOT MATER $1000^{9} \cdot 100$ ?
1. YES
89. 89.8
2. NO
$11^{2} 11$.
DON T KNOW/NE

LOW-TEMPERATURE STEAM
1. YES
2. NO
89. 89.
DON'T KNOW/NA
11. 11 !

hIG T-TEMPERATURE STEAM

1. YES

2. No

DON'T KNOW/NA

67. $\quad 677^{6}$

$33^{3} . \quad 33^{3}$

HOT AIR
2. YES
2. NO
89. $89^{\circ}$.
11 . 11 ?
DON'T KNOW/NA

OIRECT HEAT

1. YES

2. No

DON'T KNOW/NA

44. $44^{4} \cdot$

56. 56.

REPRIGERATION
1. YES
2. NO
$\begin{array}{rr}78^{7} & 78^{7} \\ 22^{2} & 22^{2}\end{array}$
DONPT KNOW/NA

Figure F-1. Industrial and Agricultural Process Heat Data Tables (continued) 
(OCTOBER, 1979 )

INTEREST IN SPECIFIED INDUSTRIAL AND AGRICULTURAL UESTION 6)

INDUSTRIAL ANO AGRICULTURAL
PROCESS HEAT OPH APH TOTAL ALL
RES RES TAPH RES
RES

CONC TOTAL ALL

MANUF COLL MANUF

LIVESTOCK SHELTER HEATING

i. YES

2. NO

DON T KNOW/NA

GRAIN DRYING
i. YES

2. NO

DON T KNOWINA

CROP DRYING

1. YES

2. NO

DON'T KNOW/NA

GREENHOUSES
1. YES
2. NO

DONPT KNOW/NA

FOOD PROCESSIMG
1. YES
2. NO

DONיI KNOW/NA

IPH IPH SHAC IPH
PLANT INDUS INND ALR ALIC ENG
ENG ENG
ENG ENG
$56^{5} \quad 56^{5} \quad 56^{5}$

$44^{4} .44^{4} .44^{4}$.

$67^{6} \cdot 67^{6} \cdot 67^{6}$.

$33^{3} .33^{3} .33^{3}$

$67^{6} \cdot 67^{6} \cdot 67^{6}$.

$33^{3} .33^{3} \cdot 33^{3}$

$22^{2} \cdot 22^{2} \cdot 22^{2}$

$78^{7} \quad 78^{7} \cdot 73^{7}$

56. $56.56^{5} \cdot$

44. $44^{4} .44$.

Figure F-1. Industrial and Agricultural Process Heat Data Tables (continued) 
(OCTOBER, 1979)

INTEREST IN SPECIFIED INDUSTRIAL ANO AGRICULTURAL

INDUSTRIAL AND AGRICULTURAL
PROCESS HEAT ICONTINUED

IPH ALL EDC

APH
STATE
AGRIC
OFF

APH ALL ALL ACES

$100^{8}$

ÁGENT AGENT SPEC

LIVESTOCK SHELTER HEATING

1. YES

2. NO

DON T KNOW/NA

100 ? 100 ?

88. $\quad 78^{7} \quad 78^{7}$ ?

13. $22^{2} \quad 22^{2}$

GRAIN DRYING
1. YES

2. NO

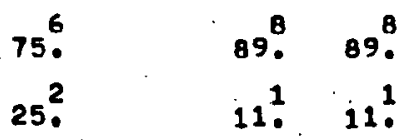

CROP DRYING
1. YES
2. NO
DONIT KNOW/NA

$\begin{array}{rrr}88^{7} & 78^{7} & 78^{7} \\ 13^{1} & 22^{2} & 22^{2}\end{array}$

GREENHOUSES
1. YES
2. NO
DON T KNOH/NA

$\begin{array}{rrr}88^{7} & 78^{7} & 78^{7} \\ 13^{1} & 22^{2} & 22^{2}\end{array}$

FCOD PROCESSINE
1. YES
2. NO

$\begin{array}{rrr}88^{7} & 67^{6} & 67^{6} \\ 13^{1} & 33^{3} & 33^{3}\end{array}$

DON IT KNOW/NA

Figure F-1. Industrial and Agricultural Process Heat Data Tab́les (continued) 


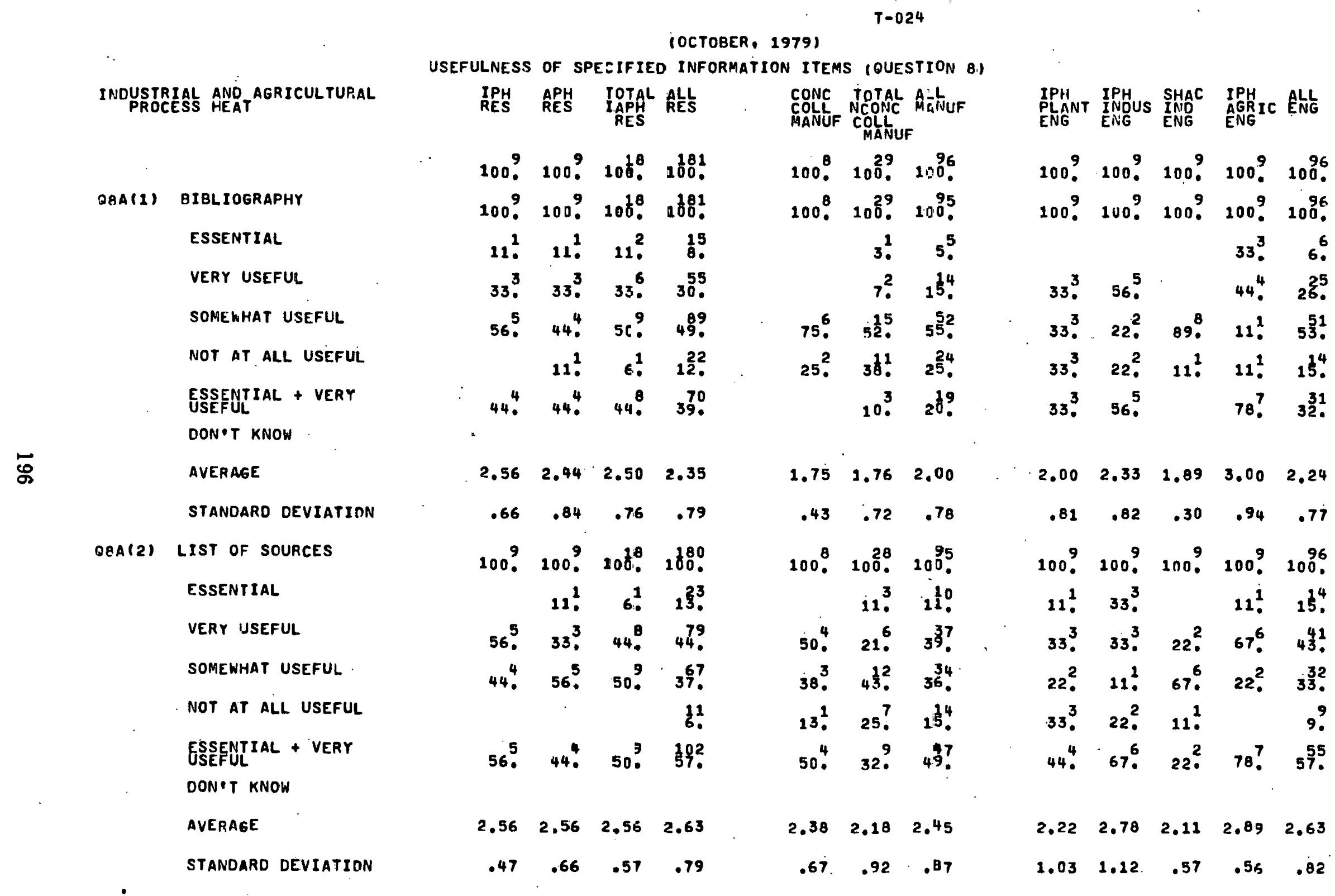

SCALE: ESSENTIAL $=4$, VERY U.SEFUL $=3$, SOMEWHAT USEFUL $=2$, NOT AT ALL USEFUL $=1$

Figure F-1. Indústrial and Agricultural Process Heat Data Tables ịcontinued) 
(OCTOBER, 1979)

USEFULNESS OF SPECIFIED INFORMATION ITEMS (OUESTION B)

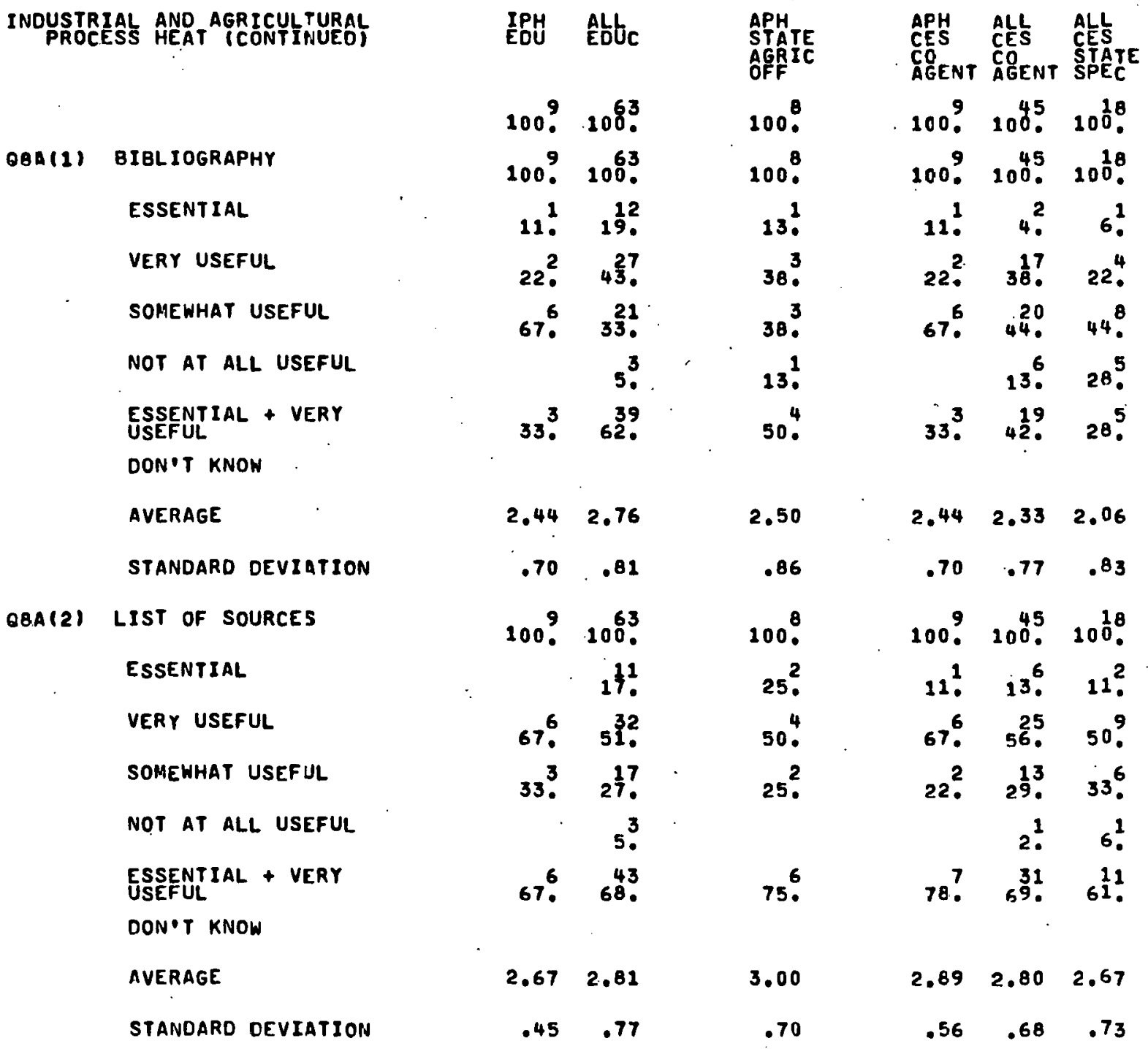

SCALE: ESSENTIAL $=4$, VERY USEFUL $=3$, SOMEWHAT USEFUL $=2$, NOT AT ALL USEFIUL $=1$

Figure F-1. Industrial and Agricultural Process Heat Data Tables (continued) 
(OCTOBER, 1979)

USEFULNESS OF SPECIFIED INFORMATION ITEMS - CONTINUED (QUESTION B)

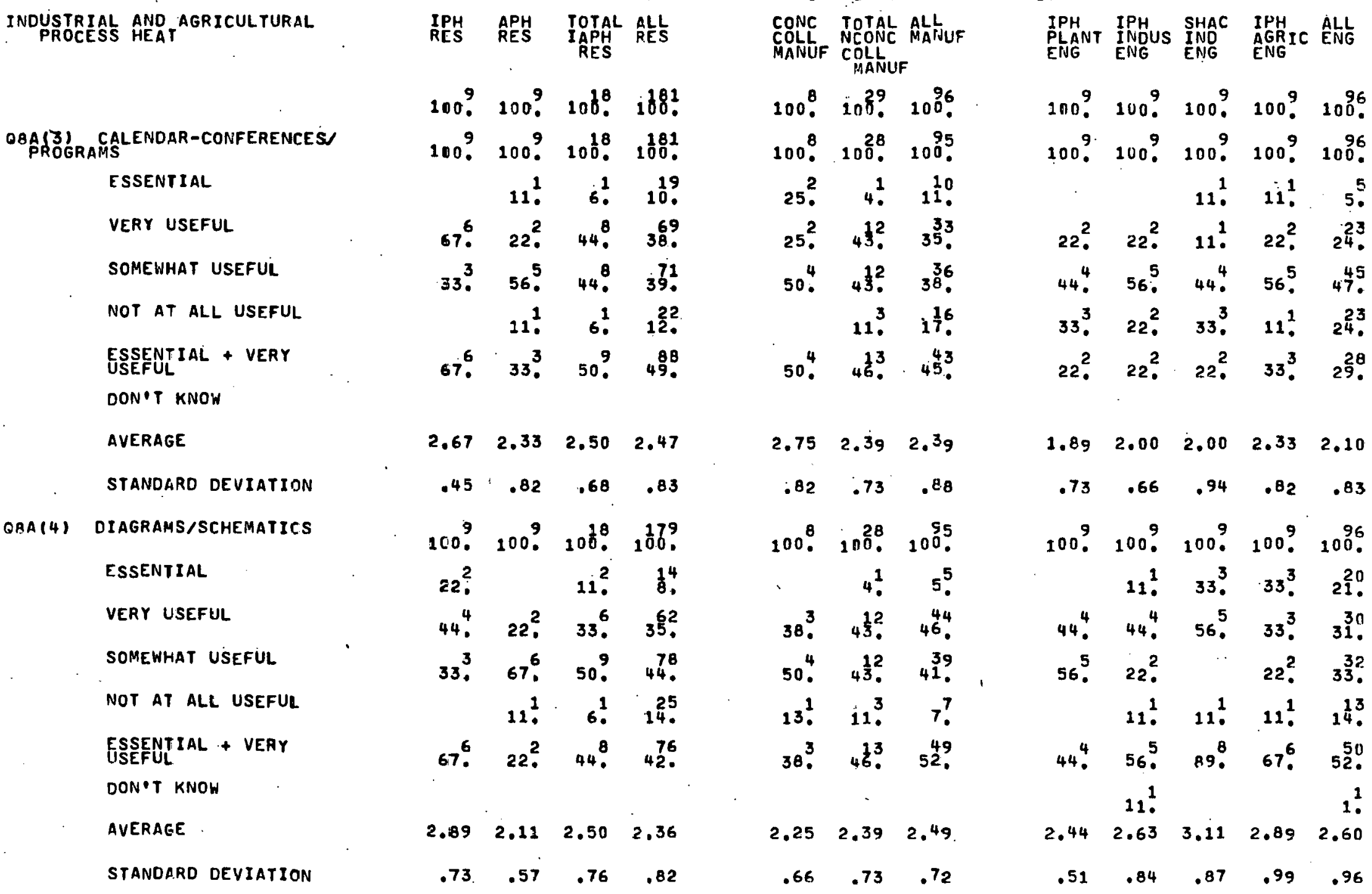

SCALE: ESSENTIAL $=4$, VERY USEFUL $=3$, SOMEWHAT LSEFUL $=2$, NOT AT ALL USEFUL $=1$

Figure F-1. Indusirial and Agricultural Process Heat Data Tables (continued) 
(OCTOBER, 1979)

USEFULNESS OF SPECIFIED INFORMATION ITEMS : CONTINUED (QUESTION B)

\begin{tabular}{|c|c|c|c|c|c|c|c|}
\hline \multirow{2}{*}{\multicolumn{2}{|c|}{$\begin{array}{l}\text { INDUSTRIAL AND AGRICULTURAL } \\
\text { PROCESS HEAT ICONTINUEOS }\end{array}$}} & IPH & ALLLC & $\begin{array}{l}\text { APH } \\
\text { STIEE } \\
\text { AGRRIC } \\
\text { OFF }\end{array}$ & $\begin{array}{l}\text { APH } \\
\text { CES } \\
\text { CEO } \\
\text { AGENT }\end{array}$ & $\begin{array}{l}A L L \\
\text { CES } \\
\text { CEO } \\
A G E N T\end{array}$ & $\begin{array}{l}\text { ALL } \\
\text { CEES } \\
\text { STATE } \\
\text { SPEC }\end{array}$ \\
\hline & & 100 ? & $100^{63}$ & $100{ }^{8}$ & $1000^{\circ}$ & 100 & $100^{18}$ \\
\hline \multicolumn{2}{|c|}{ QBA (3) CALENDAR-CONFERENCESI } & $100 ?$ & $100^{63}$ & $100^{8}$ & 1009 . & 100. & 100 \\
\hline & ESSENTIAL & 11 & $10^{6}$ & 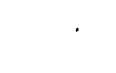 & & 21 & \\
\hline & VERY USEFUL & $33^{3}$ & 480 & $38^{3}$ & $33^{3}$ & $16 ?$ & $33^{6}$ \\
\hline & SOMEWHAT USEFUL & $33^{3}$ & 33 & $50^{4}$ & $56{ }^{5}$ & 628 & $44^{8}$ \\
\hline & NOT AT ALL USEFUL & $22^{2}$ & $10^{6}$ & $13^{1}$ & $11 ?$ & $20{ }^{9}$ & $22^{4}$ \\
\hline & $\begin{array}{l}\text { ESSEENTIAL + VER: } \\
\text { USEFUL } \\
\text { DON'T KNOW }\end{array}$ & $44^{4}$. & s7. & $38{ }^{3}$ & $33^{3}$ & 18. & $33^{6}$ \\
\hline & AVERAGE & 2.33 & 2.57 & 2.25 & 2.22 . & 2.00 & 2.11 \\
\hline & STANDARD OEVIATION & .95 & .79 & .66 & .63 & .66 & .74 \\
\hline QBA (4) & DIAGRAMS/SCHEMATICS & 100 ? & $100^{63}$ & 100. & 1009 & 100. & $100^{18}$ \\
\hline & ESSENTIAL & $11 !$ & $19 ?$ & & $22^{2}$. & $13^{6}$ & $i 1^{2}$. \\
\hline & VERY USEFUL & $44^{4}$. & $44^{20}$ & $75^{6}$ & $44^{4}$ & «9. & $17^{3}$ \\
\hline & SOMEWHAT USEFUL & $33^{3}$ & $29^{18}$ & $25^{2}$ & $33^{3}$. & 36 & $5 \frac{10}{0}$. \\
\hline & NOT AT ALL USEFUL & $11^{1}$ & $8^{5}$ & & & $2^{1}$ & $17^{3}$. \\
\hline & $\begin{array}{l}\text { ESSENTIALL + VERY } \\
\text { DSEFUL } \\
\text { DONOT KNOW }\end{array}$ & 56. & $63^{40}$. & $75^{6}$. & 67.6 & 628 & $28^{5}$ \\
\hline & AVERAGE & 2.56 & 2.75 & 2.75 & 2.89 & 2.73 & 2.22 \\
\hline & STANOARO OEVIATION & .81 & .84 & .43 & .73 & .72 & .85 \\
\hline
\end{tabular}

SCALE: ESSENTIIAL $=4$, VERY USEFUL $=3$, 'SOMEWHAT USEFUL $=2$, NOT AT ALL USEFUL $=1$

Figure F-1. Industrial and Agricultural Process Heat Data Tables (continued) 
IOCTOBER, 19791

USEFULNESS OF SPECIFIED IPJORMATION ITEMS - CONTINUED (DUESTION E)

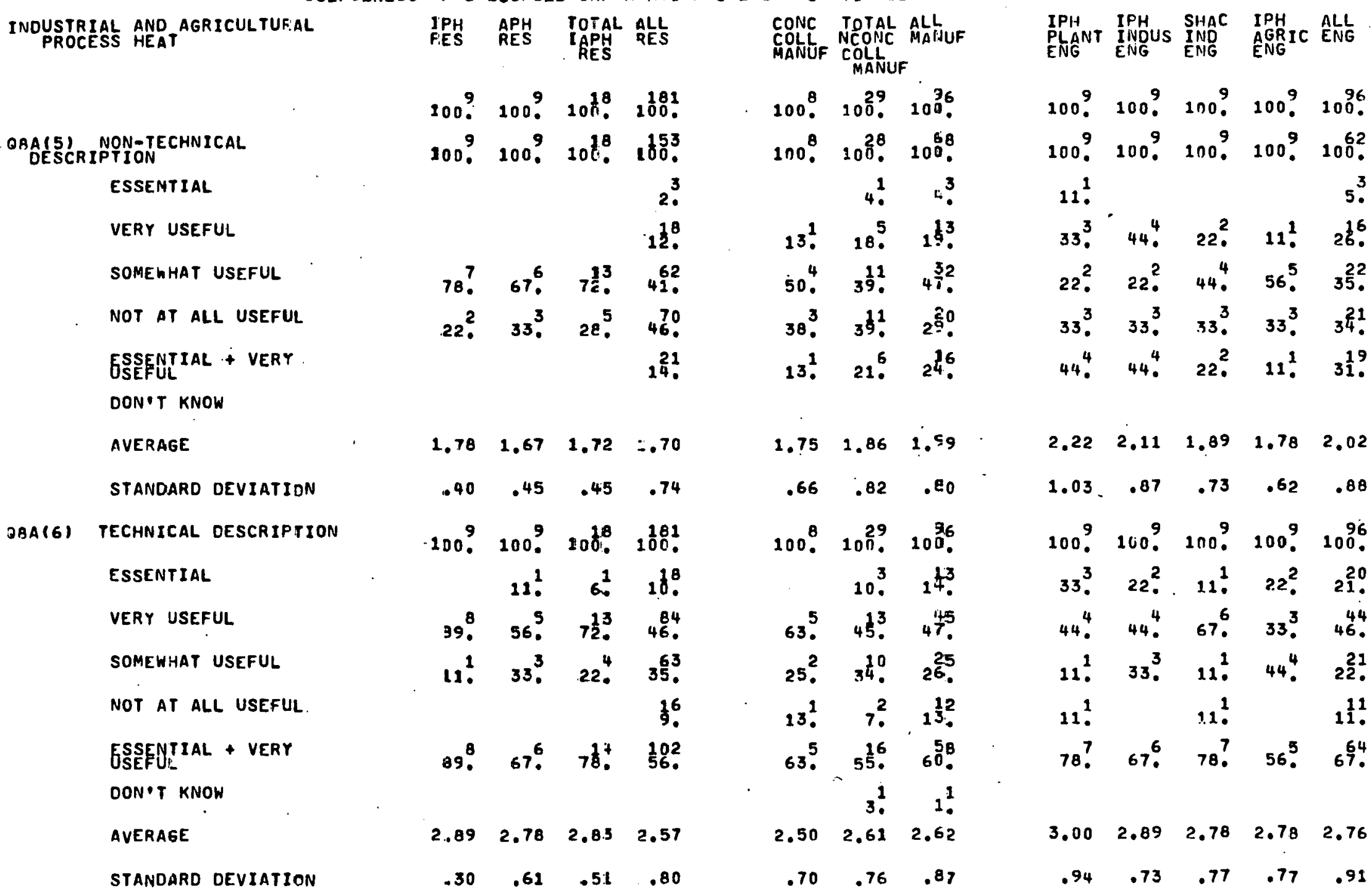

SCALE: ESSENTIAL $=4$, VERY USEFUL $=3$, SOMEWHAT USEFUL $=2$, NOT AT ALL USEFUL $=1$

Figure F-1. Industrial and Agricultural Process Heat Data Tables (continued) 
(OCTOBER, 1979)

USEFULNESS OF SPECIFIED INFORMATION ITEMS - CONTINUEO (RUESTION B)

\begin{tabular}{|c|c|c|c|c|c|c|c|}
\hline \multirow{2}{*}{\multicolumn{2}{|c|}{$\begin{array}{l}\text { INDUSTRIAL AND AGRICULTURAL } \\
\text { PROCESS HEAT (CONTINUEOI }\end{array}$}} & EPH & ALL & $\begin{array}{l}\text { APH } \\
\text { STATE } \\
\text { AGRIL } \\
\text { OFF }\end{array}$ & $\begin{array}{l}\text { APH } \\
\text { CES } \\
\text { CED } \\
\text { AGENT }\end{array}$ & $\begin{array}{l}A L L \\
C E S S \\
C D O \\
\text { CEENT }\end{array}$ & $\begin{array}{l}\text { ALL } \\
\text { CLES } \\
\text { STATE } \\
\text { SPEEC }\end{array}$ \\
\hline & & $1000^{9}$ & $100^{63}$ & $100^{8}$ & $100 ?$ & 100 & $100^{18}$. \\
\hline \multicolumn{2}{|c|}{$\begin{array}{l}\text { DAA (5) NON-TECHNICAL } \\
\text { OESCRIPTION }\end{array}$} & 1009 & $100^{63}$ & $100^{8}$ & 1009 & $100^{45}$ & $100^{18}$ \\
\hline \multicolumn{2}{|c|}{ ESSENTIAL } & $22^{2}$ & 14. & & $22^{2}$ & $11^{5}$ & \\
\hline \multicolumn{2}{|r|}{ VERY USEFUL } & $22^{2}$ & $17 !$ & $88 ?$ & $67^{6}$. & $67^{30}$. & $44^{8}$ \\
\hline \multicolumn{2}{|r|}{ SOMEWHAT USEFUL } & $33^{3}$ & 405 & & 11 & $22^{10}$ & 28 . \\
\hline \multicolumn{2}{|r|}{ NOT AT ALL USEFUL } & $22^{2}$ & 29. & 13 & & & \\
\hline \multirow{2}{*}{\multicolumn{2}{|c|}{$\begin{array}{l}\text { ESSENTIAL + VERY } \\
\text { USEFUL } \\
\text { DON.T KNOW }\end{array}$}} & $44^{4}$. & 320 & $88^{7}$ & 89. & 78 & \\
\hline & & & & & & & \\
\hline \multicolumn{2}{|r|}{ AVERAGE } & 2.44 & 2.17 & 2.75 & 3.11 & 2.89 & 2.17 \\
\hline \multicolumn{2}{|r|}{ STANDARD DEVIATION } & 1.07 & 1.01 & .66 & .57 & .56 &.$\theta_{2}$ \\
\hline \multirow[t]{9}{*}{$O B A(6)$} & TECHNICAL DESCRIPTION & 1009. & $100^{63}$ & $100^{8}$ & 100 . & $100^{45}$ & $100^{18}$ \\
\hline & ESSENTIAL & $22^{2}$ & 19 & & 112 & 9. & $6 !$ \\
\hline & VERY USEFUL & 56. & 597 & $50^{4}$. & $33^{3}$ & 293 & 50 . \\
\hline & SOMEWHAT USEFUL & $22^{2}$ & $17 !$ & 38. & $44^{4}$ & 429 & 28 . \\
\hline & NOT AT ALL USEFIJ! & & $3^{2}$ & 131 & $11 !$ & 209 & $7^{3}$ \\
\hline & \multirow{2}{*}{$\begin{array}{l}\text { ESSENTIAL + VERY } \\
\text { USEFUL } \\
\text { OON?T KNOW }\end{array}$} & $78 ?^{7}$ & $\begin{array}{l}49 \\
78 .\end{array}$ & $50^{4}$ & $44^{4}$. & $38 ?$ & 56. \\
\hline & & & 2 & & & & \\
\hline & AVERAGE & 3.00 & 2.95 & 2.38 & 2.44 & 2.27 & 2.44 \\
\hline & STANDARD DEVIATION & .66 & .71 & .67 & .84 & .87 & .84 \\
\hline
\end{tabular}

SCALE: ESSENTIAL $=4$, VEZY USEFUL $=3$, SOMEWHAT USEFUL $=2$, NOT AT ALL USEFUL $=1$

Figure F-1. Industrial and Agricultural Process Heat Data Tables (continued) 
(OCTOBER, 1979 )

USEFULNESS DF SPECIFIED INFOFMATION ITEMS - CONTINUED (QUESTION B)

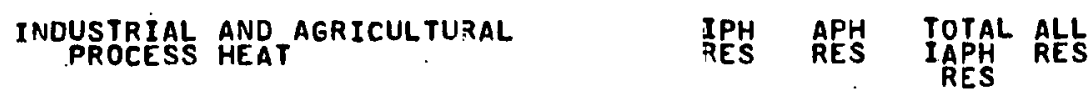

QRA (7) LISTS OF SUPPLIERS ESSENTIAL

VERY USEFUL

SOMEWHAT USEFUL

NOT AT ALL USEFUL

ESSENTISAL + VEFYY

DON'T KNOW

กั้

\section{STANDARD DEVIATION}

QRA(B) HANDBDOKS/TABLES

\section{ESSENTIAL}

VERY USEFUL

SOMEHHAT USEFUL

NOT AT ALL USEF JL

ESSENTIIAL + VEFY

DON'T KNOW

AVERAgE

STANDARD DEVIATION

$\begin{array}{rrrr}100^{9} & 100^{9} & 100^{8} & 160^{81} \\ 100^{9} & 100^{9} & 100^{18} & 100^{146} \\ 11^{1} & 11^{1} & 11^{2} & 12 \\ 20^{2} & 33^{3} & 28 . & 27^{5} \\ 56^{5} & 33^{3} & 44^{8} & 38^{\circ} \\ 11^{1} & 22^{2} & 17^{3} & 27^{3} \\ 33^{3} & 44^{4} & 39^{7} & 35^{\circ}\end{array}$

$2.33 \quad 2.33 \quad 2.33 \quad 2.16$

$\begin{array}{llll}.82 & .95 \quad .89 \quad .92\end{array}$

$100^{9} \cdot 100^{9} \cdot 100^{18} \cdot 100$.

11. 6. ${ }^{1}$ ?

44. $56^{5}$. 50 \% 35?

$56.533^{3} \quad 44^{8}$. 36.

171

$44^{4} \quad 67^{6} .56 .464$

1

$\begin{array}{llll}2.44 & 2.78 & 2.61 & 2.39\end{array}$

$\begin{array}{llll}.51 & .61 & .59 & .07\end{array}$
CONC TOTAL ALL MANUF NCOLL MAN

100. $100^{29} .100^{\circ}$.

$100 \% 100^{29}, 100^{9}$

21. $20^{19}$.

63. $48^{4} .38^{36}$

25. 14. 28?

13. $17^{5} .1 \frac{13}{4}$.

63. 69.575

1.

$2.50 \quad 2.72 \quad 2.64$

$.70 \quad .99 \quad .95$

$100^{8} 10^{29} \cdot 100^{96}$.

3. 9 .

50. $45^{3} \cdot 42^{40}$.

25. $31^{2} .343$

25. $21^{2} \cdot 15^{14}$.

$50^{4} \quad 48^{4} .51^{49}$.

$\begin{array}{lll}2.25 & 2.31 & 2.46\end{array}$

$.82 \quad .83 \quad .84$

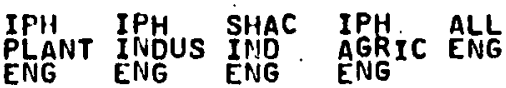

100 . 100 \% 100 \% 100 \% $100^{96}$ $100^{9} 100$. $100^{9}$. 100 \% $100^{96}$.

11. $22^{2} \quad 11^{11}$

$22^{2} .56^{5} .22^{2} \cdot 27^{26}$.

56. $22^{2} \cdot 11^{1} \quad 22^{2} \quad 34^{33}$.

$44^{4} \quad 44^{4} \cdot 33^{3} \cdot 33^{3} \quad 27^{26}$

$33^{3} .56^{5}, \quad 44^{4} . \quad 39$.

$\begin{array}{lllll}1.56 & 2.00 & 2.22 & 2.33 & 2.23\end{array}$

$\begin{array}{lllll}.48 & 1.05 \quad .92 & 1.16 & .97\end{array}$

100 . 100 . 100, 100 \% 1005

33. $222^{2}$. $33^{3}$. 18 ?

$78^{7} .33^{3}, 67^{6}, \quad 33^{3}, 47^{45}$

$22^{2} 22^{2} . \quad 33^{3} .29$.

$11.211^{1} \quad 5$.

78 . $67^{6} .69^{8} .67^{6} .65^{62}$

$2.78 \quad 2.89 \quad 3.00 \quad 3.00 \quad 2.78$

$\begin{array}{lllll}.40 & .99 & .81 & .81 & .79\end{array}$

SCALE: ESSENTIAL $=4$, VERY USEFUL $=3$, SOMEWHAT LSEFUL $=2$, NOT AT ALL USEFUL $=1$

Figure F-1. Industrial and Agricultural Process Heat Data Tables (continued) 


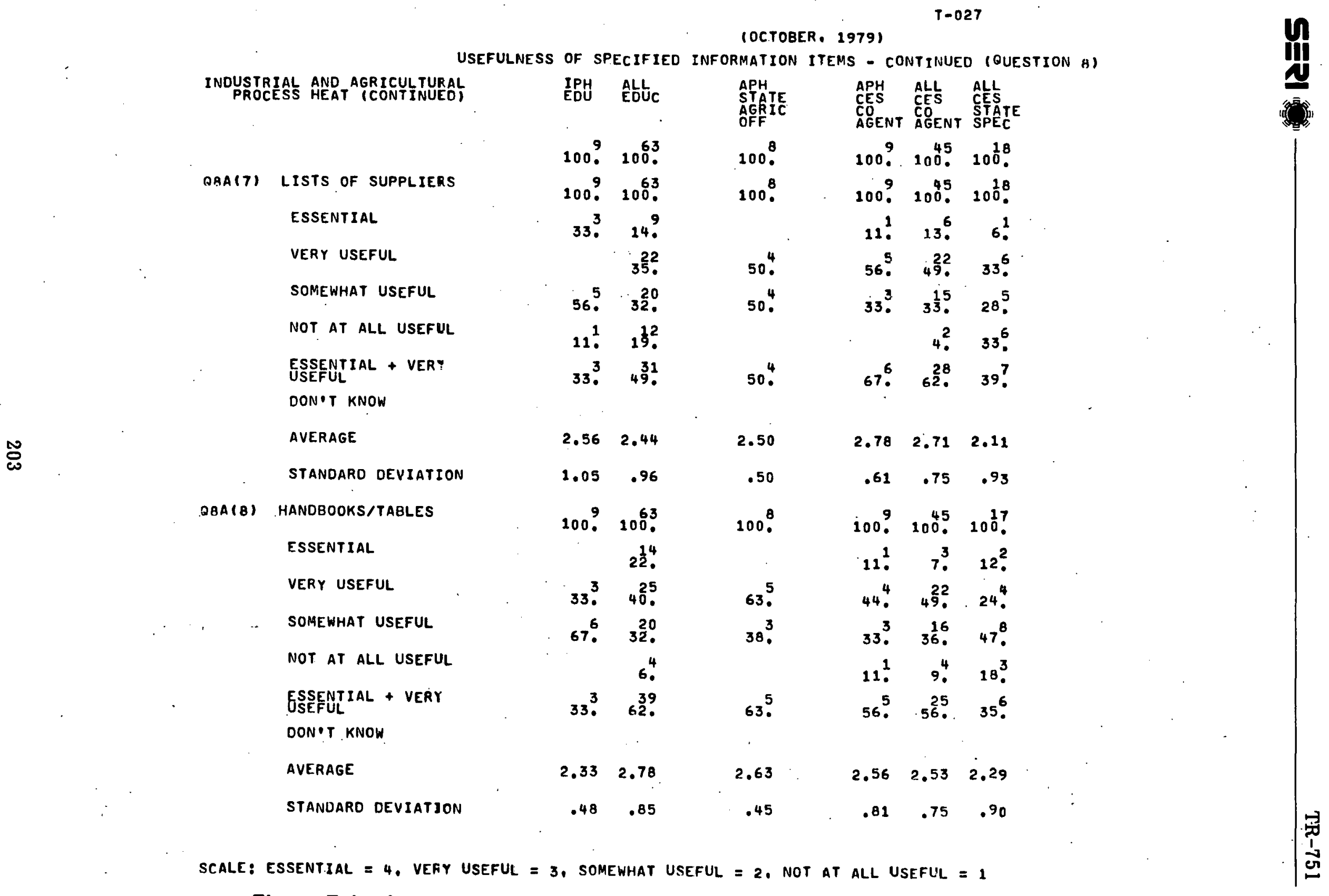

Figure F-1. Industrial and Agricultural Process Heat Data Tables (continued) 
IOCTOBER, 1979

USEFULINESS OF SPECIFIED INFORMATION ITEMS - CONTINUED (UUES-ION B) $\begin{array}{ll}\text { INOUSTRIAL AND AGRICULTURAL } & \text { IPH APH TOTAL ALL } \\ \text { PROCESS HEAT } & \text { IAPH RES }\end{array}$

QBA(9) TECHNICAL EXPERTS LIST

ESSENTIAL

VERY USEFUL

SOMEWHAT USEFUL

NOT AT ALL USEFUL

ESSEFNTIAL + VERY

DON P KNOW
AVERAGE

STANCARD DEVIATION

QAA(10) MANUAL METHODS

ESSENTIAL

VERY USEFUL

SOMEWHAT USEFUL

NOT AT ALL USEFUL

ESSENTIAL + VERY

DONOT KNOW

AVERAGE

STANGARD DEVIATION
$1009100 \% 100^{18} \cdot 1001$

$100^{9} 100^{9} \cdot 100^{8} \cdot 180^{8}$.

$\begin{array}{ccc}11 . & 1 & 16 \\ 0 & 9\end{array}$

33. $22^{2} \cdot 28^{5} \cdot 36^{6}$

$67^{6} .44^{4} \quad 5 \frac{10}{6} .42$

22. $11^{2} \cdot 15^{2}$.

$33^{3} \quad 33^{3} \quad 33^{6} \quad 45^{8}$

$\begin{array}{llll}2.33 & 2.22 & 2.28 & 2.39\end{array}$

$\begin{array}{llll}.48 & .92 \quad .72 \quad .85\end{array}$

100 . 200 . $106^{8}, 2181$.

$33^{3} . \quad 17^{3} .17^{30}$.

78. $22^{2} . \quad 50^{9} \quad 3^{65}$.

$22.233^{3} .28 .525$.

$11.60^{1} \quad 133$.

$78^{7} \quad 56^{5} .6 ?^{2} \cdot .52$.

$2.78,2.78 \quad 2.78 \quad 2.51$

$\begin{array}{llll}.40 & 1.02 \quad .77 & .96\end{array}$
CONC TOTAL ALL

MOLNUF NCONC ARN

$100^{8} 100^{29} \cdot 100^{96}$

$100^{8} .100^{29} .100^{96}$

13. $11^{1}$.

63. $\quad 24$ ? $\quad 31^{30}$.

13. $48^{14} .38^{36}$

13. 28.28 . 28.

75. 24 ? $43^{4}$.

$2.75 \quad 1.97 \quad 2.34$

$.82 \quad .70 \quad .93$

$100.100^{28} \cdot 100^{9}$.

13. $7^{2} \quad 20$.

63. $33^{11}$. 36.

13. $32.022^{2} 7^{2}$

13. $21^{6} .17^{16}$.

$75^{6} .46^{13} .563$

$\begin{array}{lll}2.75 \quad 2.32 & 2.59\end{array}$

$.82 \quad .89 \quad .98$ $\begin{array}{lll}\text { IPH } & \text { IPH } & \text { SHAC } \\ \text { PLANT INH } & \text { IPHS IND } \\ \text { ENG } & \text { ALRIC ENG } \\ \text { ENG } & \text { ENG } & \text { ENG }\end{array}$ $1009.1009 .1009 .1009 .100 \%$ $1009.100^{9}, 1009$. 1009 . 1096 . 11. 11.9 ? $11^{1} \quad 11^{1} \quad 22^{2} \quad 22^{2} \cdot 22^{27}$ $56^{5} .67^{6} . \quad 56.567^{6}, \quad 46^{4}$. 33. $11^{1} 222^{2}$ 13. 11. $22^{2} \quad 22^{2} \quad 33^{3} \quad 38^{36}$

$\begin{array}{lllll}1.78 & 2.22 & 2.00 & 2.44 & 2.30\end{array}$ $\begin{array}{lllll}.62 & .79 & .66 & .70 & .86\end{array}$ 100 . 100 . 100 ? 100 ? $100^{96}$. 11. $33^{3} . \quad 33^{3} .20^{9}$. 44. $67^{6} .444^{4} \quad 44^{4} .47^{45}$. 56. $22^{2} .22^{2} \cdot 28$. $22^{2} .5$ 44. 78.78 . 78 ? $67^{64}$.

$\begin{array}{lllll}2.44 & 2.67 & 3.11 & 3.11 & 2.81\end{array}$

$\begin{array}{lllll}.51 & .93 & .74 & .74 & .81\end{array}$

SCALE: ESSENTIAL $=4$, VEAY USEFUL $=3$, SOMEMHAT USEFUL $=2$, NOT AT ALL USEFUL $=1$

Figure F-1. Industrial and Agricultural Process Heat Data Tables (continued) 
(OCTOBER, 1979)

USEFULNESS OF SPECIFIED INFORMATION ITEMS - CONTINUED (QUESTION B)

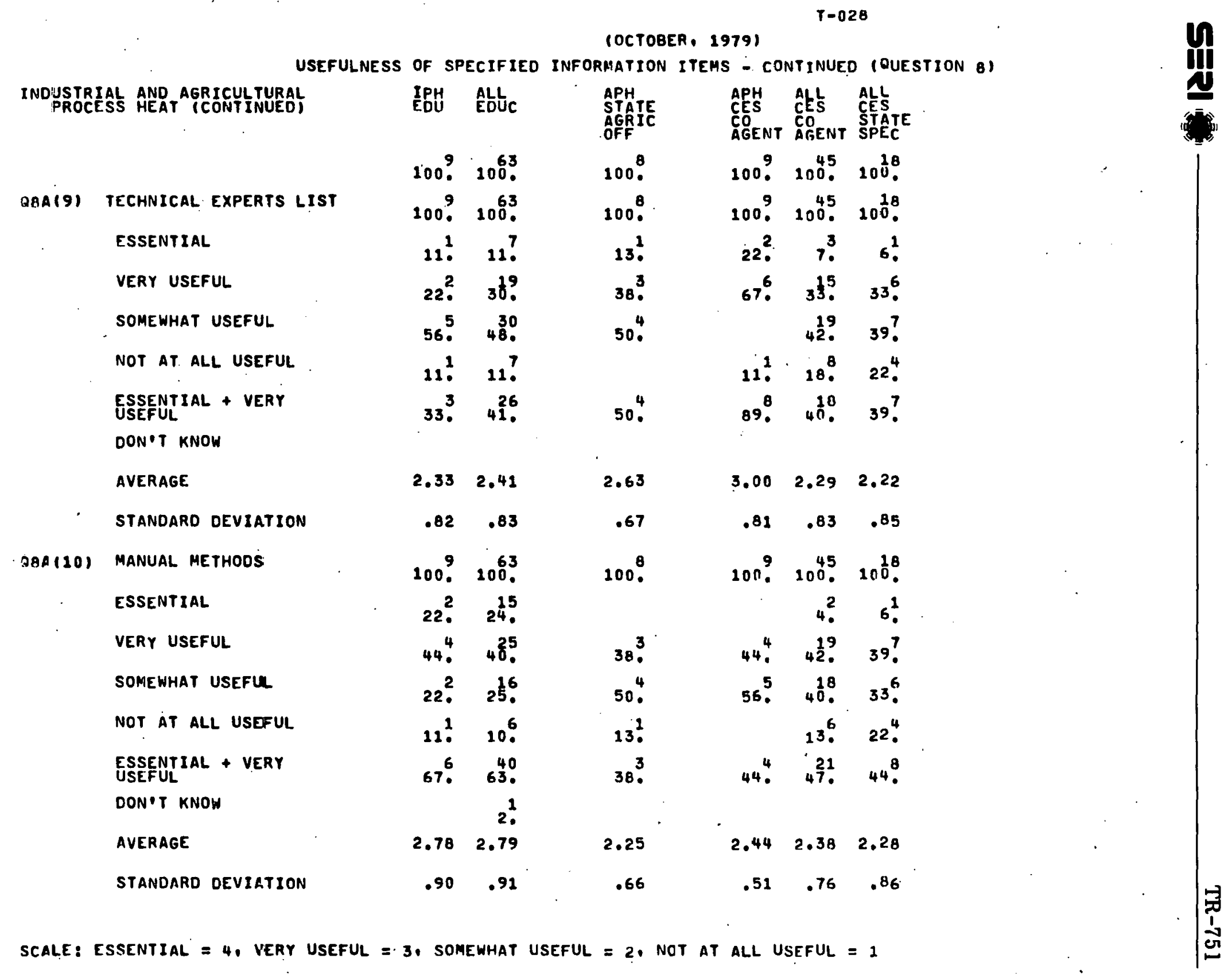

Figure F-1. Industriai and Agricultural Process Heat Data Tables (conlinued) 


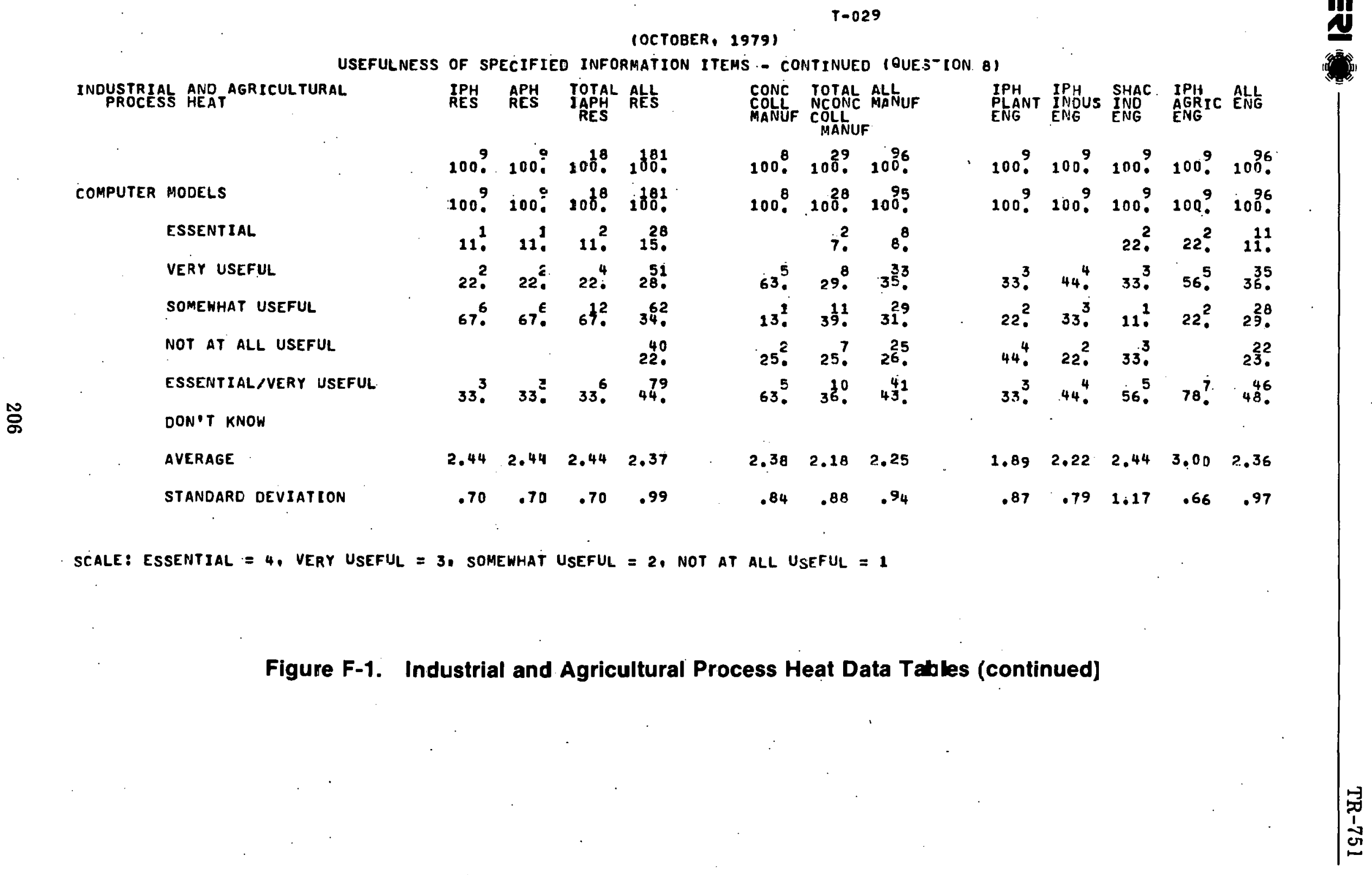




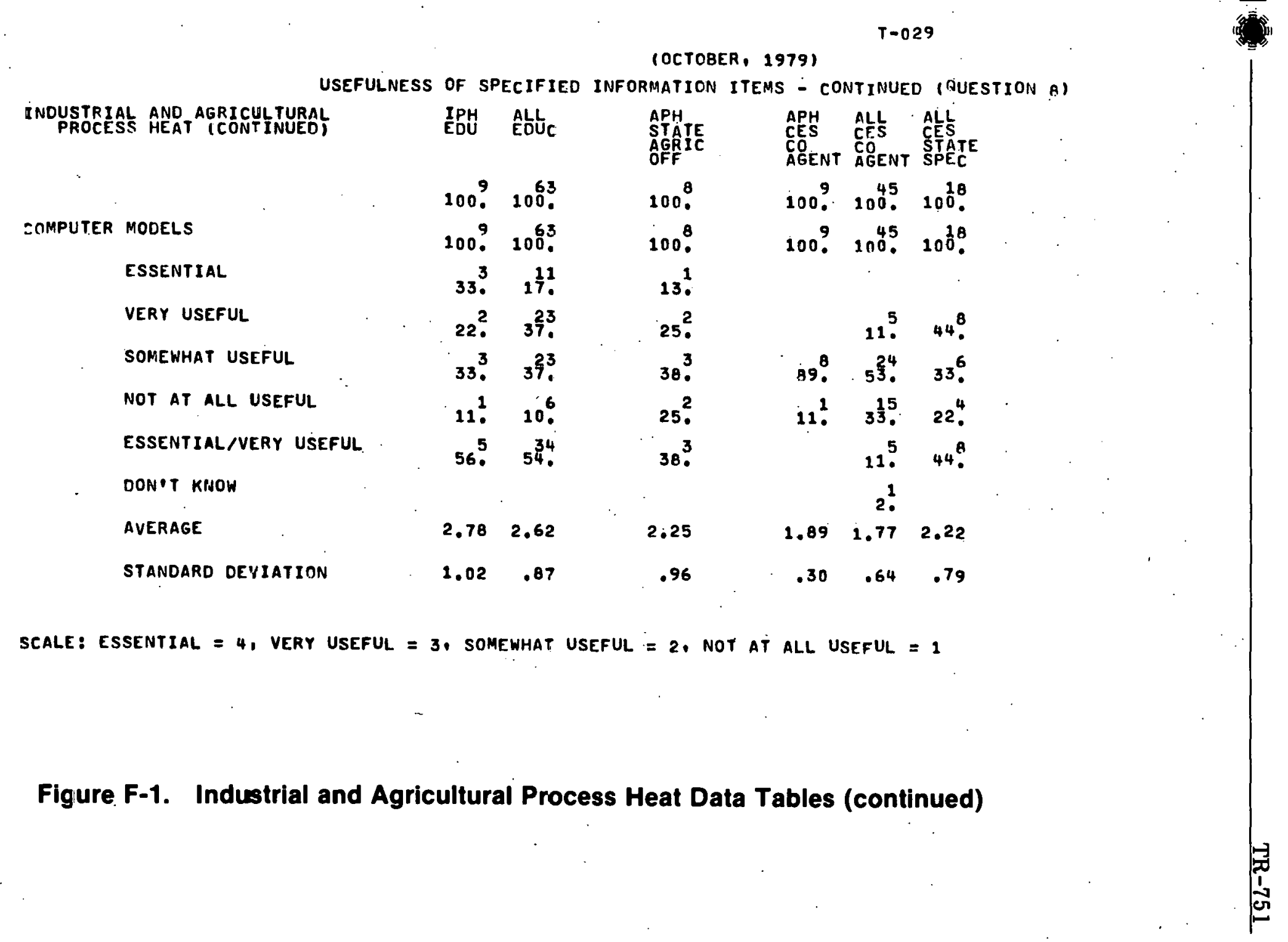


(OCTOBER, 1979)

USEFULNESS OF SPECIFIEO INFORMATION ITEMS - CONTINUED (QUESTEON A)

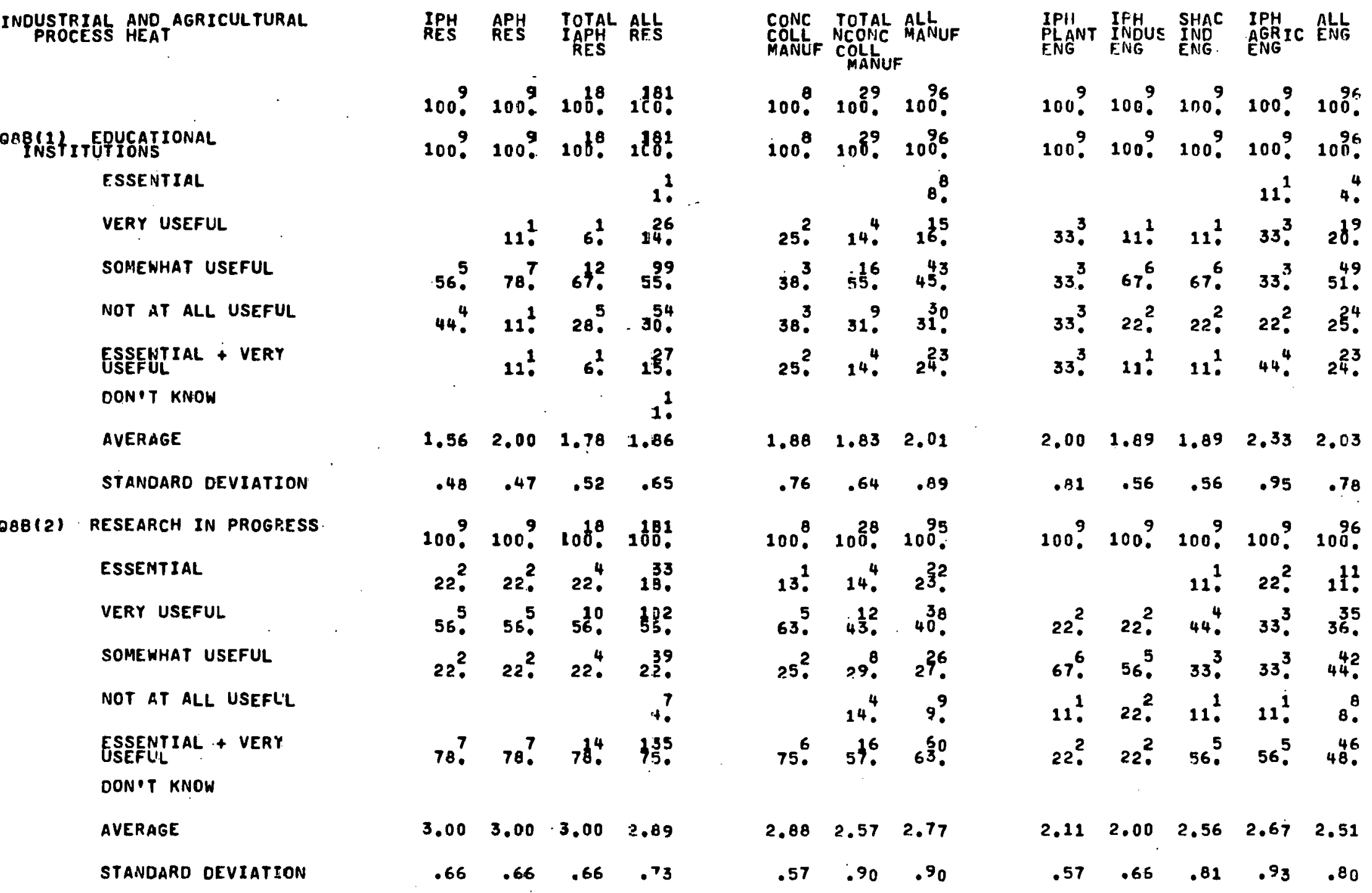


(OCTOBER, 1979$)$

USEFULNESS OF SPECIFIED INFORMATION ITEMS - CONTINUED (QUESTION B)

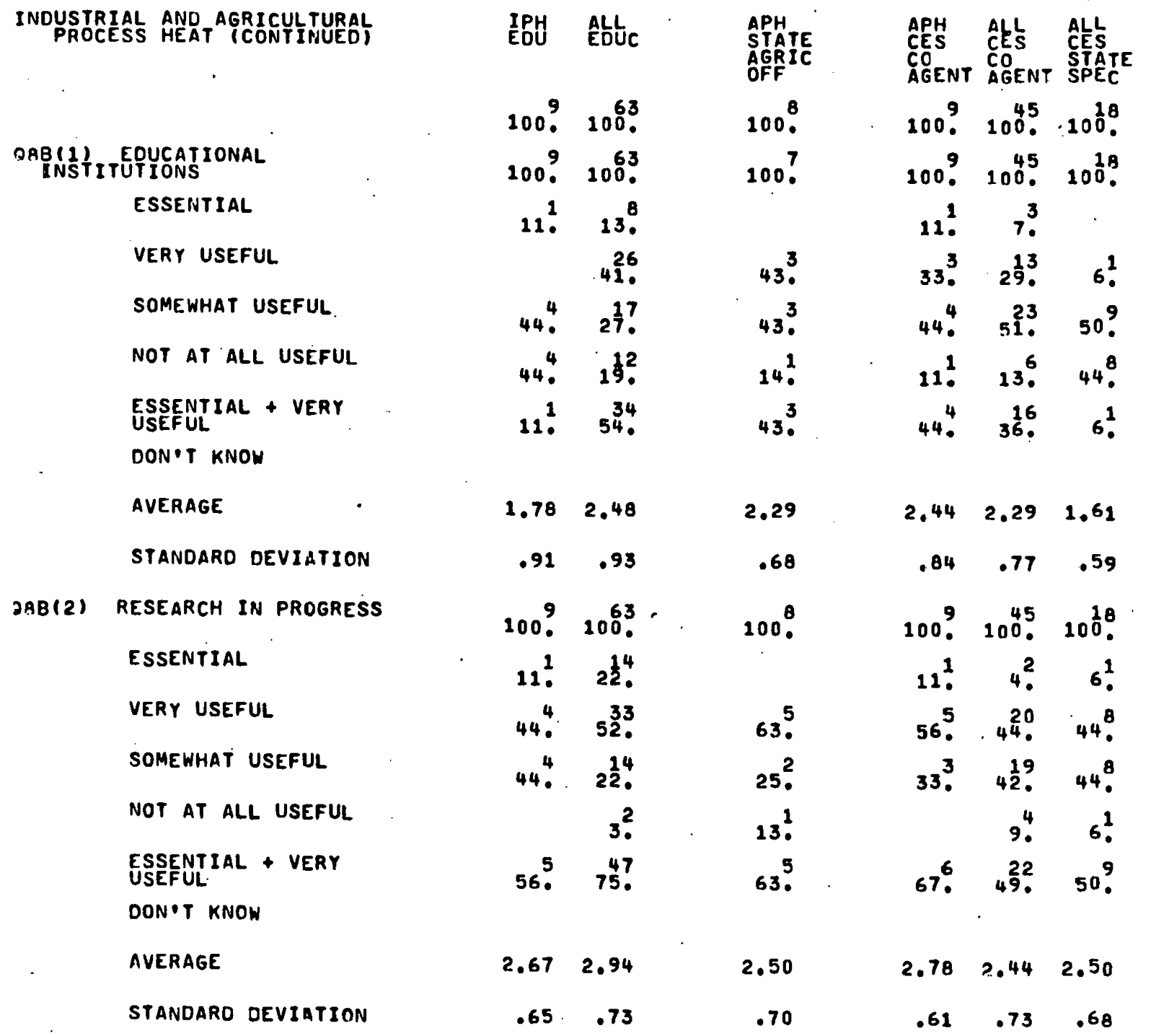

SCALE: ESSENTIAL $=4$, VERY USEFUL $=3$, SOMEWHAT USEFUL $=2$, NOT AT ALL USEFUL $=1$

Figure F-1. Industrial and Agricultural Process Heat Data Tables (continued) 


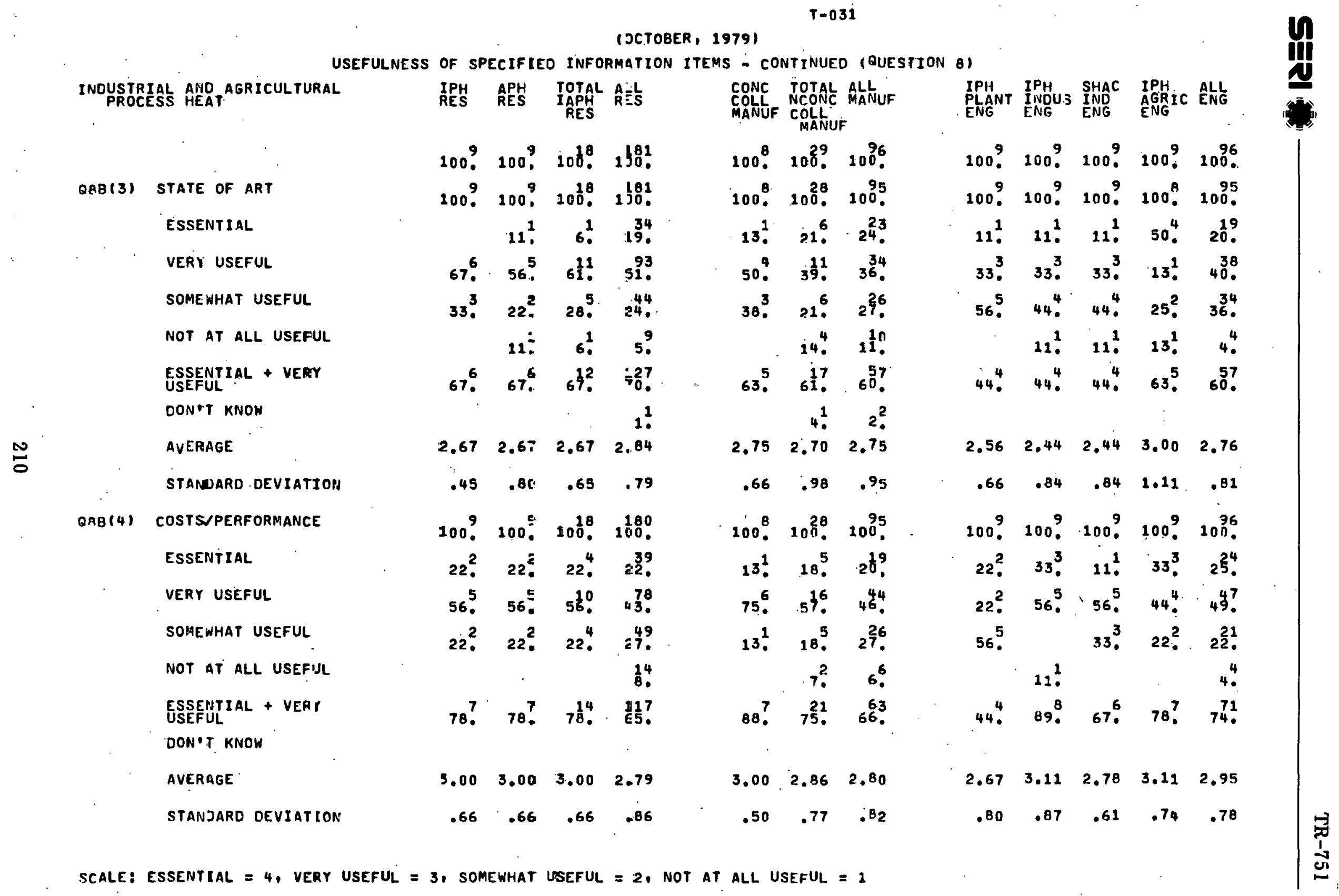

Figure F-1. Industrial and Agricultural Process Heat Data Tables (continued) 
(OCTOBER, 1979$)$

SCALE: ESSENTIAL $=4$, VERY USEFUL $=3$, SOMEWHAT USEFUL $=2$, NOT AT ALL USEFUL $=1$

USEFULNESS OF SPECIFIED INFORMATION ITEMS - CONTINUED (QUESTION B)

INDUSTRIAL AND AGRICULTURAL
PROCESS HEAT ICONTINUEDI

QBB (3) STATE OF ART

ESSENTIAL

VERY. USEFUL

SOMEWHAT USEFUL

NCT AT ALL USEFUL

ESSENTIAL + VERY

DON'T KNOH

AVERAGE

STANOARD DEVIATION

QRB (4) COSTS/PERFORMANCE

ESSENTIAL

VERY USEFUL

SOMEWHAT USEFUL

NOT AT ALL USEFUL

ESSENTIAL + VERY

DONOT KNOW

AVERAGE

STANDARD DEVIATION
IPH ALL

$1000^{9} 100^{63}$

100 . $100^{63}$

$11.24^{15}$.

$44^{4} .565$

44. 17 ?

3 .

56.5790.

$2.67 \quad 3.00$

$.65 \quad .73$

$22^{2} .320$

56.537.

$22.22^{20}$.

$75^{6}$.

25 .

78 . 68.

$75^{6}$

2.75

.43

13.

50.

.38

$3.00 \quad 3.00$

$.66 \quad .79$
100 . $100^{63}$

$\begin{array}{lll}\text { CPHS } & \text { ALL } & \text { ALL } \\ \text { CES } & \text { CES } & \text { SESATE } \\ \text { COGENT AGENT SPEC }\end{array}$

$100^{\circ} 100^{45} 100^{18}$.

100 ? $100^{45} 100^{18}$.

11. 2 ?

33. $33^{\frac{15}{5}} 50$.

56.56 .50 .

$44^{4} . \quad 36.50$.

$2.56 \quad 2.29 \quad 2.50$

$.66 \quad .65 \quad .50$

100 . $100^{45} .100^{18}$.

33. $13^{6} .11$ ?

$44^{4} .76 .509$.

$22^{2} . \quad 11.520^{5}$.

11 .

$.74 \quad .50 \quad .82$

Figure F-1. Industrial and Agricultural Process Heat Data Tables (continued) 


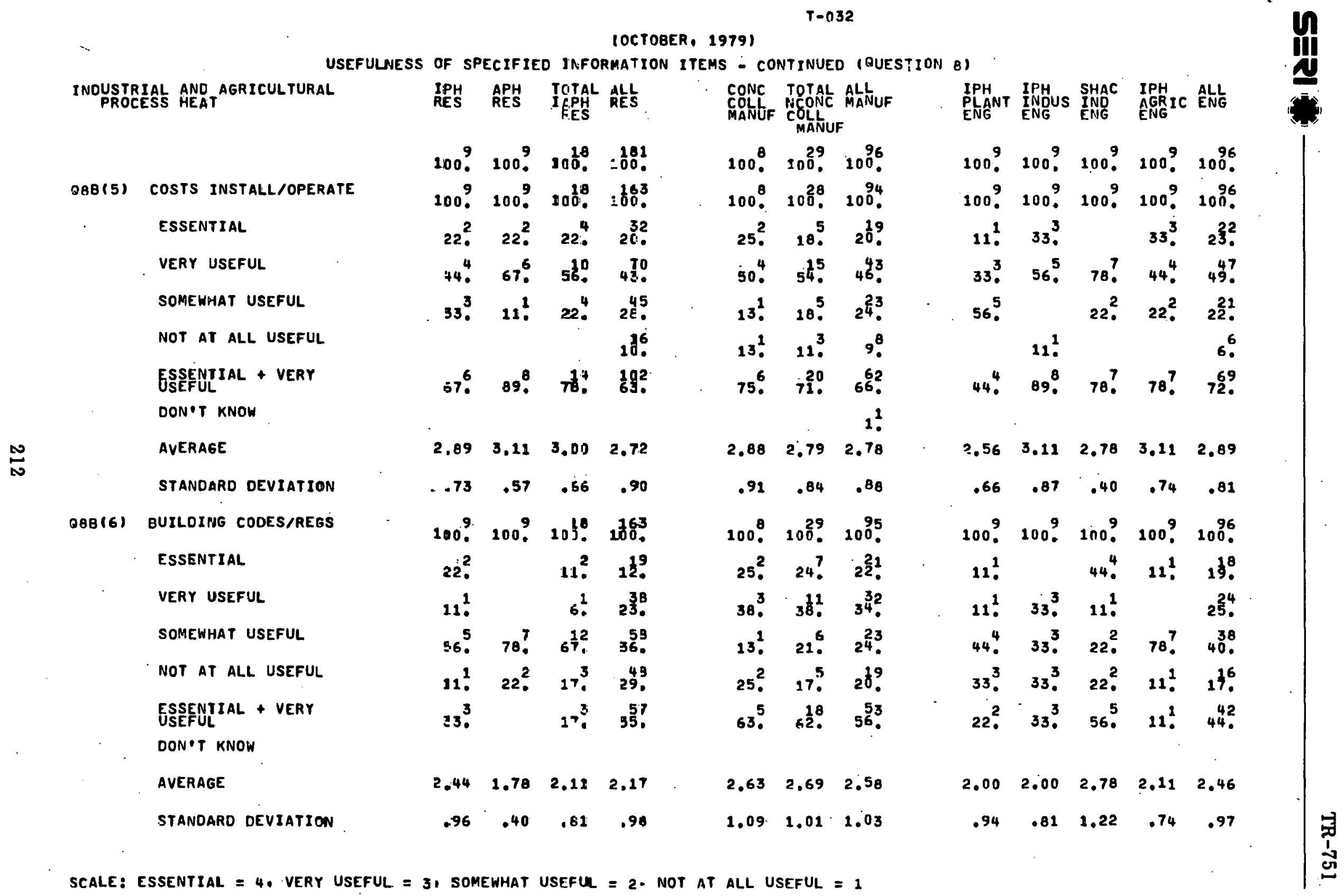

Figure F-1. Industrial and Agricultural Process Heat Data Tables (continued) 
(OCTOBER, 1979)

USEFULNESS OF SPECIFIED INFORMATION ITEMS - CONTINUED (OUESTION 8 :

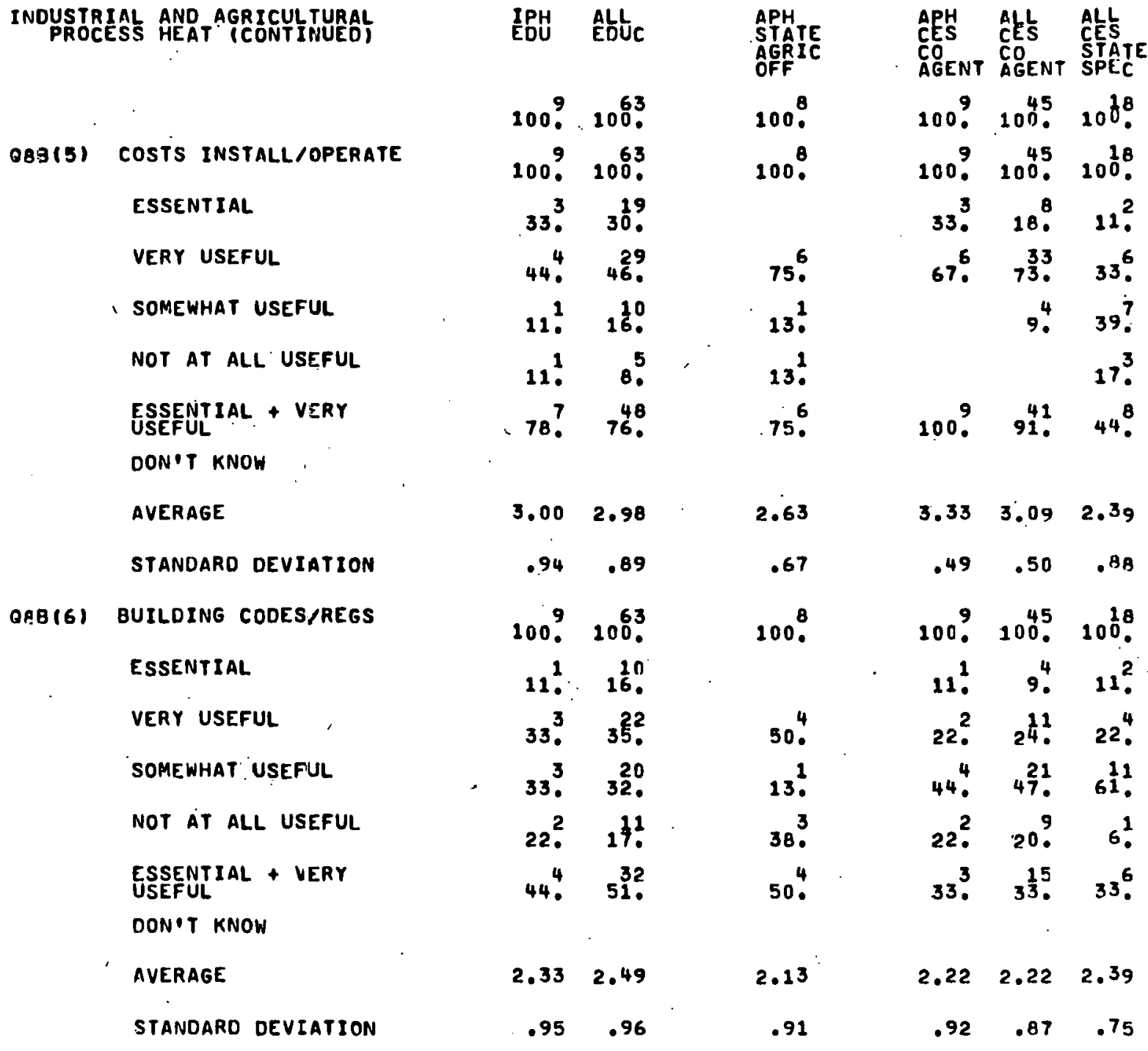

SCALE: ESSENTIAL $=4$, VERY USEFUL $=3$, SOMEWHAT USEFUL $=2$, NOT AT ALL USEFUL $=1$

Figure F-1. Industrial and Agricultural Process Heat Data Tables (continued) 
(OCTOBER, 1979$)$

USEFULNESS DF SPECIFIEL INFORRATION ITEMS - CONTINUED (RUESTION 8)

INDUSTRIAL ANO AGRICULTURAL
PROCESS HEAT

$\begin{array}{lll}\text { IPH APH } & \text { TOTALL ALL } \\ \text { RES RES IEPH RES } & \end{array}$

$100^{9} 100^{9} 100^{8} \cdot 180^{8}$.

QBB(7) TAX/ECONOMIC INCENTILE

ESSENTIAL

VERY USEFUL

SOMEWHAT USEFUL

NOT AT ALL USEFUL

ESSENTIAL + VERY

DON'T KNOW

AVERAGL
STANDARD DEVIATION
$38 B(8)$ STANDAROS/SPECS
ESSENTIAL
VERY USEFUL
SOMEWHLT USEFUL
NOT AT ALL USEFUL
ESSENTIAL + VERY
USEFUL
DON T HNOW
AVERAGE
STANDAFD DEVIATION

\section{0 . 100 , $100^{8}$. 100 .}

33. $22^{2} .28 .25 ?$

$22^{2} .11^{2}, 27^{4}$.

67. $33^{3} .50$. $30^{52}$

$22^{2} .11^{2} \cdot 25^{40}$

33. $44^{3}, \quad 39$ ? $44^{71}$.

$\begin{array}{llll}2.67 & 2.44 & 2.56 \quad 2.36\end{array}$

$\begin{array}{lll}.93 & 1.07 \quad \mathrm{i} .00 \quad 1.01\end{array}$

100 . 100 ? $103^{8}, 1863$.

$11^{1} \cdot 11^{1} \cdot 11^{2} \cdot 11^{8}$.

$22^{2} .33^{3} .28 .534$.

$56.565 . \quad 56 . \quad 33$.

11 . 6.23 ?

33. $44^{4} .49$ ? $45^{3}$.

$2.33 \quad 2.56 \quad 2.44 \quad 2.33$

$\begin{array}{llll}.82 \quad .66 & .77 \quad .95\end{array}$
CONC TOTAL ALL

MANUF COLL

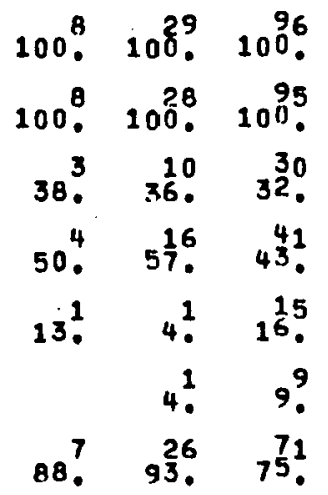

$\begin{array}{lll}3.25 & 3.25 \quad 2.97\end{array}$

$.66 \quad .68 \quad .91$

$100.8029 .100^{8} 6$

$63^{5} .31 .930^{29}$.

13. $\quad 28.8 .29$.

$13^{1} .33^{10} .32^{3}$.

$133^{1} \quad 7_{0}^{2} \quad 8^{8}$

756.597 .597

$3.25 \quad 2.83 \quad 2.81$

$1.08 \quad .94 \quad .96$ $\begin{array}{lll}\text { IPH } & \text { IPH } & \text { SHAC IPH } \\ \text { PLANT INDUS IND } & \text { ALR IC ENG } \\ \text { ENG } & \text { ENG } & \text { ENG } \\ \text { ENG } & \end{array}$

$1009100^{9} 100^{9}, 10091096$ $100^{3} 1009$ : $170 \% 100 \% 1096$

$11^{1}$ 11. $11^{1}$. $11^{1} \cdot 17^{16}$

33. $67^{6} .67^{6} \cdot 22^{2} \quad 43^{4}$.

44. $11^{1} \cdot 11^{1}$. $67^{6}, 29^{28}$

11. $11^{1}$. $11^{1}$. $11^{1}$

$44^{4} \quad 78^{7} \cdot 78^{7} \quad 33^{3} \cdot 59^{\circ}$

$\begin{array}{lllll}2.44 & 2.78 & 2.78 & 2.44 & 2.65\end{array}$

$\begin{array}{lllll}.84 & .77 & .77 & .70 & .87\end{array}$

$100 \% 100 \% 100 \% 1009.100^{9}$

$11^{1}$ 1.1. $14^{1}$.

11. $33^{3}$. $44^{4} \cdot 44^{4} .30^{29}$

$\begin{array}{rrrr}78^{7} & 44^{4} \cdot \quad 44^{4} & 44^{4} . & 44^{\circ}\end{array}$

$22^{2} \quad 11^{1}-13^{2}$

$22^{2} \cdot 33^{3} \cdot 56^{5} \cdot 44^{4} \cdot 44^{42}$

$2.33 \quad 2.11 \quad 2.67 \quad 2.33 \quad 2.45$

$\begin{array}{lllll}.67 & .74 \quad .65 \quad .67 \quad .87\end{array}$

SCALE: ESSENTIAL $=4$, VERY USEFUL $=3$, SOMEWHAT USEFUL $=2$, NOT AT ALL USEFUL $=1$

Figure F-1. Industrial and Agricultural Process Heat Data Tables (continued) 
(OCTOBER, 1979$)$

USEFULNESS OF SPECIFIEO INFORMATION ITEMS - CONTINUED (OUESTION B)

\begin{tabular}{|c|c|c|c|c|c|c|c|c|}
\hline \multicolumn{2}{|c|}{$\begin{array}{l}\text { INDUSTRIAL AND AGRICULTURAL } \\
\text { PROCESS HEAT (CONTINUED) }\end{array}$} & \multirow{2}{*}{$\begin{array}{l}\text { IPH } \\
100 ?\end{array}$} & \multirow{2}{*}{$\begin{array}{l}\text { ALLUC } \\
\text { EDUC } \\
100 .\end{array}$} & \multirow{2}{*}{$\begin{array}{l}\text { APH } \\
\text { STATE } \\
\text { AGRIC } \\
\text { OFF } \\
100^{\circ}\end{array}$} & \multirow{2}{*}{\multicolumn{2}{|c|}{$\begin{array}{l}\text { APH } \\
\text { CES } \\
\text { COO } \\
\text { AGENT } \\
100 .\end{array}$}} & \multirow{2}{*}{$\begin{array}{l}\text { ALL } \\
\text { CES } \\
\text { COO } \\
\text { AGENT } \\
100 .\end{array}$} & \multirow{2}{*}{$\begin{array}{l}\text { ALL } \\
\text { CEES } \\
\text { SSTATE } \\
\text { SPEC } \\
100^{18}\end{array}$} \\
\hline & . & & & & & & & \\
\hline $08 B(7)$ & TAX/ECONOMIC INCENTIVE & $100^{9}$ & $100^{63}$ & $100 \%$ & & $100 ?$ & $100^{4}$ & $100^{18}$ \\
\hline . & ESSENTIAL & $22^{2}$ & 30 & . & & $22^{2}$ & $16^{7}$ & $11^{2}$ \\
\hline & VERY USEFUL & $22^{2}$ & $30^{19}$ & $86^{6}$ & & $67^{6}$ & $53^{24}$ & \\
\hline & SOMEWHAT USEFUL & 56. & 35 & $14 !$ & & $11^{1}$ & $2^{12}$ & $39 ?$ \\
\hline & NOT AT ALL USEFUL & & 5 & & & & $4 ?$ & \\
\hline & $\begin{array}{l}\text { ESSENTIAL + VERY } \\
\text { OSEFUL }\end{array}$ & $44^{4}$ & 60 & $86^{6}$ & & $89^{8}$ & 69. & \\
\hline & DON'T KNOW & & & & & & & \\
\hline & AVERAGE & 2.67 & 2.86 & 2.86 & . & 3.11 & 2.80 & 2.6 \\
\hline & STANDARD DEVIATION & .80 & .89 & .32 & & .57 & .74 & \\
\hline $08 B(8)$ & STANDAROS/SPECS & $100^{9}$ & 1003 & $100^{8}$ & & 1009 & 100 & $100^{18}$ \\
\hline & ESSENTIAL & $11^{1}$ & $17^{1}$ & & & $11^{1}$ & & \\
\hline & VERY USEFUL & 11 . & 29. & 38 . & & $33^{3}$ & $31^{14}$ & \\
\hline & SOMEWHAT USEFUL & $33^{3}$ & $41^{26}$ & $50^{4}$ & & 56 & $5 \frac{24}{3}$ & $22^{4}$ \\
\hline & NOT AT ALL USEFUL & & $13^{8}$ & $13^{1}$ & . & & 9. & \\
\hline & $\begin{array}{l}\text { ESSENTIAL + VERY } \\
\text { OSEFUL }\end{array}$ & $22^{2}$ & 46. & $38^{3}$ & & $44^{4}$. & 36 & $44^{8}$. \\
\hline & DON T KNOW & & & & & & 2 & \\
\hline & AVERAGE & 1.89 & 2.51 & 2.25 & & 2.56 & 2.32 & \\
\hline & STANDAF:O OEVIATION & .99 & 91 & .66 & & .66 & .69 & \\
\hline
\end{tabular}

SCALE: ESSENTIAL $=4$, VERY USEFUL $=3$, SOMEWHAT USEFUL $=2$, NOT AT ALL USEFUL $=1$

Figure F-1. Industrial and Agricultural Process Heat Data Tables (continued) 


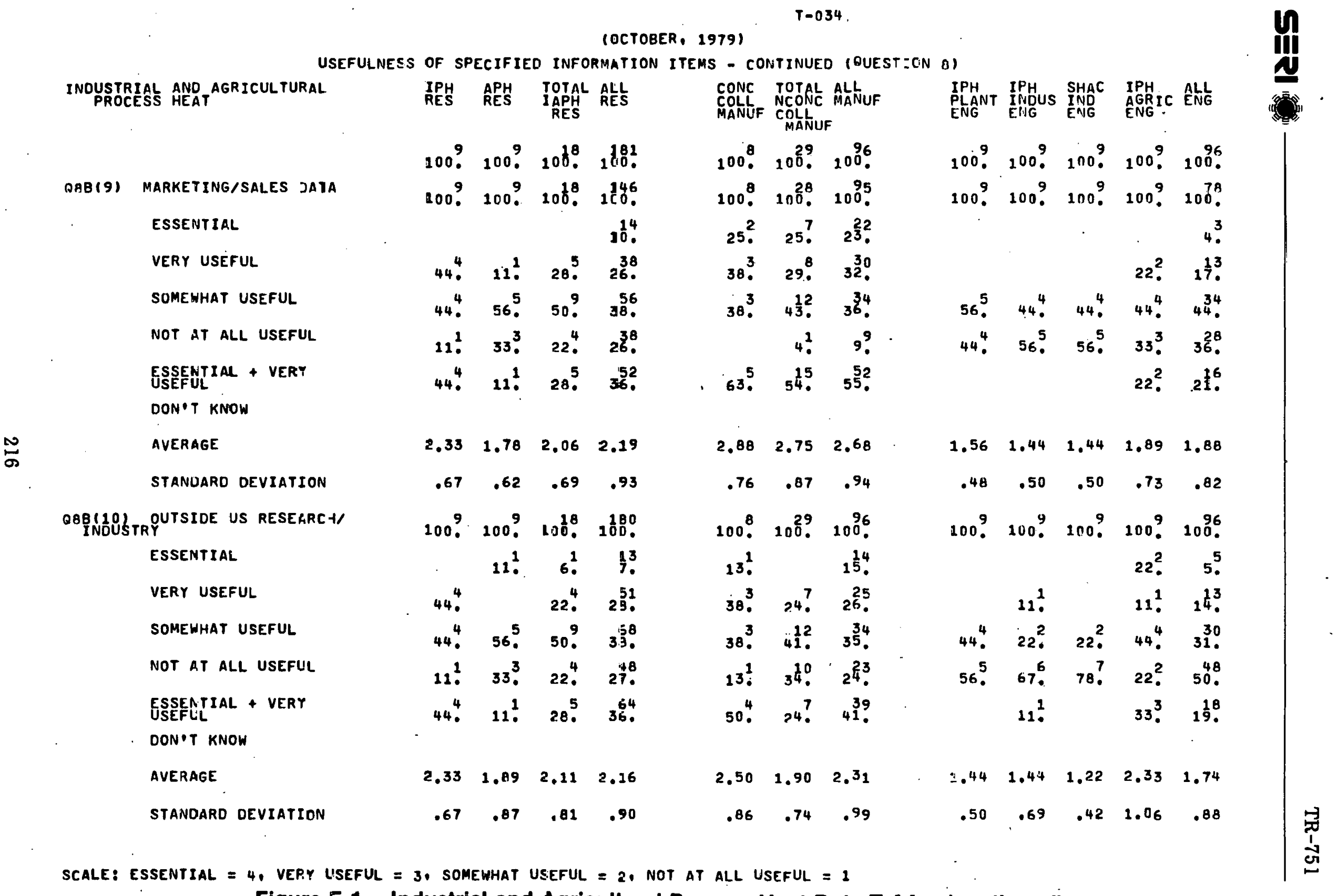

Figure F-1. Industrial and Agricultural Process Heat Data Tables (continued) 
(OCTOBER, 1979)

USEFULNESS OF SPECIFIED INFORMATION ITEMS - CONTINUEO (OUESTION B)

\begin{tabular}{|c|c|c|c|c|c|c|c|}
\hline \multirow{2}{*}{\multicolumn{2}{|c|}{$\begin{array}{l}\text { INOUSTRIAL ANO AGRICULTURAL } \\
\text { PROCESS HEAT (CONTINUEEO) }\end{array}$}} & EPH & ALLUC & $\begin{array}{l}\text { APH } \\
\text { S.TATE } \\
\text { AGRIC } \\
\text { OFF }\end{array}$ & $\begin{array}{l}\text { APH } \\
\text { CEES } \\
\text { CDO } \\
\text { AGENT }\end{array}$ & $\begin{array}{l}A L L \\
C E S S \\
C D \\
C E E \text { S }\end{array}$ & $\begin{array}{l}\text { ALL } \\
\text { CES } \\
\text { STATE } \\
\text { SPEC }\end{array}$ \\
\hline & & 100 ? & $100^{6 .}$ & $100^{8}$ & $100 ?$ & 100 & $100^{18}$ \\
\hline \multirow[t]{9}{*}{ DBB $(9)$} & MARKETING/SALES OATA & 100 ? & 1003 & $100^{8}$. & & & \\
\hline & ESSENTIAL & & $\theta^{5}$ & & & & \\
\hline & VERY USEFULL & $22^{2}$ & 24. & $38^{3}$ & & & \\
\hline & SOMEWHAT USEFLL & $33^{3}$ & 416 & $133^{1}$ & & & \\
\hline & NOT AT ALL USEFUL & $44^{4}$ & $27 ?$ & $50^{4}$. & & & \\
\hline & $\begin{array}{l}\text { ESSENTIAL + VERY } \\
\text { USEFUL }\end{array}$ & $22^{2}$ & 320 & $38^{3}$ & & & \\
\hline & DON'T KNOW & & & & & . & \\
\hline & AVERAGE & 1.78 & 2.13 & 1.88 & & & \\
\hline & STANUARD DEVIATION & .78 & .89 & .91 & & & \\
\hline \multicolumn{2}{|c|}{ OBBI10 ZNOUSTRYUTSIDE US RESEARCH/ } & 100 ? & 2003 & $100^{8}$. & & & $100 \%$ \\
\hline & ESSEINTIAL & & $8^{5}$ & & & & \\
\hline & VERY USEFUL & $22^{2}$ & $22^{\frac{1}{4}}$ & $133^{1}$ & & & $6 !$ \\
\hline & SOMEWHAT USEFUL & $44^{4}$. & $37^{23}$ & $25{ }^{2}$. & & & $41 ?^{7}$ \\
\hline & NOT AT ALL USEFUL & $33^{3}$ & 33 & $63^{5}$ & & & $53^{9}$ \\
\hline & $\begin{array}{l}\text { ESSENTIIAL + VERY } \\
\text { USEFUL }\end{array}$ & $22^{2}$ & 30. & $13^{1}$ & & & $s^{1}$ \\
\hline & DON?T KNOK & & & & & & \\
\hline & AVERAGE & 1.89 & 2.05 & 1.50 & & & 1.53 \\
\hline & STANDARD DEVIATION & .73 & .92 & .70 & & & .60 \\
\hline
\end{tabular}


(JCTOBER, 1979 )

USEFULMESS OF SPECIFIED INFORMATION ITEMS - CONTINUEO (OUESTION 8 )

\begin{tabular}{|c|c|c|c|c|c|c|c|c|c|c|c|c|c|}
\hline \multicolumn{2}{|c|}{$\begin{array}{l}\text { INDUSTRIAL AND AGRICULTUR.AL } \\
\text { PROCESS HEAT }\end{array}$} & $\underset{R E S}{\text { IFH }}$ & $\begin{array}{l}\text { APH } \\
\text { RES }\end{array}$ & $\begin{array}{l}\text { TOTAL } \\
\text { IJPH } \\
\text { RES }\end{array}$ & 虫吕S & $\begin{array}{l}\text { CONC } \\
\text { COOLLF } \\
\text { MANUF }\end{array}$ & \multicolumn{2}{|c|}{$\begin{array}{l}\text { IDTAL ALL } \\
\text { NCONC MAFUF } \\
\text { COLL MANUF }\end{array}$} & \multirow{2}{*}{$\begin{array}{l}\text { IPH } \\
\text { PLANT } \\
\text { ENG } \\
100^{9}\end{array}$} & \multirow{2}{*}{$\begin{array}{l}\text { IPH } \\
\text { INDOS } \\
\text { ENG } \\
1009 \\
100 .\end{array}$} & \multirow{2}{*}{$\begin{array}{l}\text { SHAC } \\
\text { IHDO } \\
\text { ENG } \\
100^{9}\end{array}$} & \multirow{2}{*}{$\begin{array}{l}\text { IPH } \\
\text { AGR IC } \\
\text { ENG. } \\
1009\end{array}$} & \multirow{2}{*}{$\begin{array}{l}\text { ALL } \\
100^{96}\end{array}$} \\
\hline & & 100 . & $100 ?$ & $108^{8}$. & 1802 & $100 \%$ & 1029 & $100^{96}$ & & & & & \\
\hline \multirow[t]{9}{*}{$O B B(11)$} & INFO ON MARKETINE & & 100 ? & $1000^{9}$ & $200^{13}$ & $100^{8}$ & 100. & $100^{95}$ & & & & & 1005 \\
\hline & ESSENT IAL & & & & $17 !^{3}$ & $13^{2}$ & 21.6 & $2^{23}$ & & & & & \\
\hline & VERY USEFUL: & & & & & 38. & $25 ?^{7}$ & 187 & & & & & $20 ?$ \\
\hline & SOMEWHAT USEFEL & & $33^{3}$ & $33^{3}$ & 39. & $50^{4}$. & 391. & 35 & & & & & \\
\hline & NOT AT ALL USEFUL & & 67. & $67^{6}$. & 44. & & $14^{4}$ & 243 & & & & & \\
\hline & $\begin{array}{l}\text { ESSENNTIAL + VERY } \\
\text { USEFUL }\end{array}$ & & & & $17 ?^{3}$ & $50^{4}$. & 46. & 49 & & & & & \\
\hline & DON'T KNOW & & & & & & & & & & & & \\
\hline & AVERAGE & & 1.33 & 1,33 & 1.87 & 2.63 & 2.54 & 2.40 & & & & & 1.6 \\
\hline & STANDERD DEVIATICN & & .48 & .48 & 1.07 & .67 & .97 & 1.08 & & & & & \\
\hline \multirow[t]{8}{*}{$\begin{array}{l}\text { OBB }(12) \\
\text { LEGAL }\end{array}$} & INST/SOCIAL/ENVIRON: & $1000^{9}$ & 100 . & 100. & 1263 & $100^{8}$. & 1028. & $100^{95}$. & 1009 & $100 ?$ & $100{ }^{9}$ & $100^{9}$. & 1095 \\
\hline & ESSENTIJAL & & & & $8^{3}$ & & $7^{2}$ & 99 & & & $11 \%$ & 11. & \\
\hline & VERY UISEFUL & & $22^{2}$ & $11^{2}$ & 31 & $38^{3}$ & $29^{8}$. & 254 & 11 . & $22^{2}$. & & $33^{3}$ & \\
\hline & SOMEWHAT USEFUL & $100 \%$ & $67^{6}$. & $83^{5}$. & 43 & $50^{4}$ & $3^{\frac{11}{9}}$. & 431 & $78 ?$ & $44^{4}$. & $44^{4}$ & $22^{2}$ & \\
\hline & NOT AT ALL USEFUL & & $11^{1}$ & 6 & $\begin{array}{r}25 \\
16 .\end{array}$ & $13^{1}$ & $25 ?^{7}$ & 221 & $11 !$ & $33^{3}$ & $44^{4}$ & $33^{3}$ & \\
\hline & $\begin{array}{l}\text { ESSENTIAL + VERY } \\
\text { USEFUL } \\
\text { DONPT KNOW }\end{array}$ & & $22^{2}$. & $11^{2}$ & 394 & $30^{3}$ & 36. & 35 & 11 . & $22^{2}$ & $11 !$ & $44^{4}$. & \\
\hline & AVERAGE & 2.00 & 2.12 & 2.06 & 2.31 & 2.25 & 2.18 & 2.22 & 2.00 & 1.89 & 1.78 & 2.22 & \\
\hline & STANDARD OEVIATICN & & .57 & .38 & $.8+$ & .66 & .88 & .89 & .47 & .73 & .91 & 1.03 & \\
\hline
\end{tabular}

SCALE: ESSENTIAL $=4$, VER USEFUL $=3$, SOMEWHAT, USLFUL $=2$, NOT AT ALL USEFUL $=1$

Figure F-1. Industrial and Agricultural Process Heat Data Tables (continued) 
(OCTOBER, 1979 )

USEFULNESS OF SPECIFIED INFORMATION ITEMS - CONTINUED (DUESTION B)

INDUSTRIAL AND AGRICULTURAL
PROCESS HEAT (CONTINUED)

IPH ALU

APH
STATE
AGRIC
OFF

ESSENTI AL

VERY USEFUL

SOMEWHAT USEFUL

NOT AT ALL USEF JL

ESSENTIAL + VERY

DON?T KNOW

AVERAGE

STANDARD DEVIATION

QBB(12) INST/SOCIAL/ENVIRON/

ESSENTIAL

VERY USEFUL

SOMEWHAT USEFUL

NOT AT ALL USEFUL

ESSENTIAL + VERY

DON T KNOW

AVERAGE

STANDARD DEVIATION
1009.100.

$100^{9} \cdot 100^{63}$

8

11.217 .

67. $33^{21}$

$22.2 \quad 320$

11.35.

100 .

$100^{8}$

8.

09.11

.56 .94

$100^{9} \cdot 100^{63}$

$111.10^{6}$

$33^{3} 48^{30}$

44. $30^{19}$

$11^{1} 13^{8}$

44. 57.

$2.44 \quad 2.54$

$.84 \quad .83$

13.

38.

50.

$13^{2}$.

1.63

.68

$100^{8}$.

$13^{1}$

63.

25.

$13^{1}$.

1.88

.58 $\begin{array}{lll}\text { APH } & \text { ALL } & \text { ALL } \\ \text { CES } & \text { CES } & \text { CESS } \\ \text { COO CONT CO } & \text { STATE } \\ \text { AGENT AGENT SPEC }\end{array}$

$1000^{\circ} \cdot 100^{45} 100^{18}$.
$100^{9}, 100^{45} \cdot 100^{18}$.

$111^{1} \quad 4^{2}$.

$111^{1} \quad 13^{6} .11^{2}$.

$78 . \quad 67.0509$.

16. 39 ?

$22^{2} .18^{8} .11^{2}$.

$2.33 \quad 2.07 \quad 1.72$ 


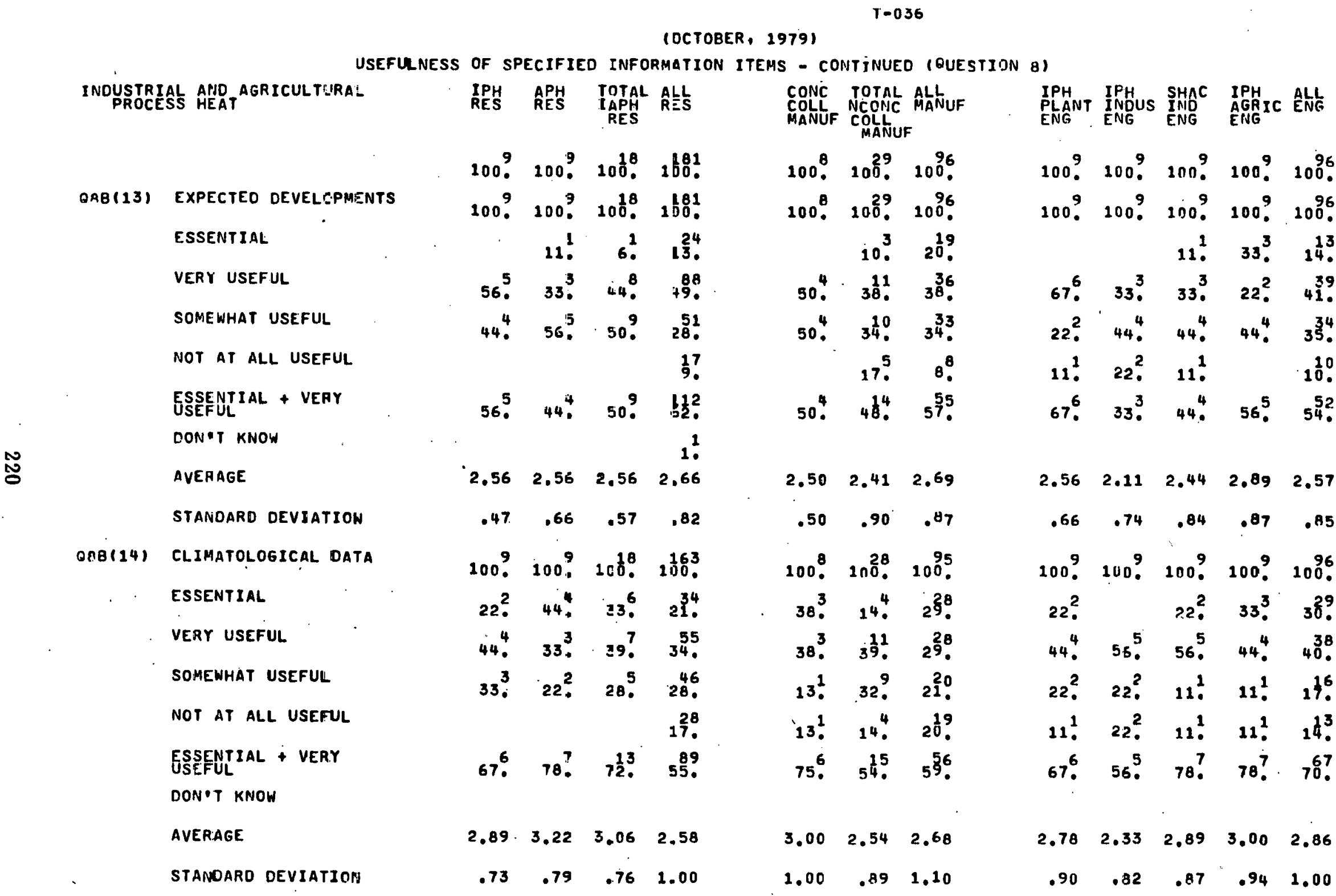


IOCTOBER, 19791

USEFULNESS OF SPECIFIED INFORMATION ITEMS - CONTINUED (DUESTION B)

\begin{tabular}{|c|c|c|c|c|c|c|c|}
\hline \multicolumn{2}{|c|}{$\begin{array}{l}\text { INOUSTRIAL AND AGRICULTURAL } \\
\text { PROCESS HEAT ICONTINUEDI }\end{array}$} & IPH. & ELUU & $\begin{array}{l}\text { APH } \\
\text { STÁTE } \\
\text { AGRIC }\end{array}$ & \multirow{2}{*}{$\begin{array}{l}\text { APH } \\
\text { CES } \\
\text { CO } \\
\text { AGENT } \\
100^{\circ}\end{array}$} & \multirow{2}{*}{$\begin{array}{l}\text { ALL } \\
\text { CES } \\
\text { CO } \\
\text { AfENT } \\
100^{45} \\
\text {. }\end{array}$} & \multirow{2}{*}{$\begin{array}{l}\text { ALL } \\
\text { CES } \\
\text { STATE } \\
\text { SPEC } \\
100 \text {. } \\
10\end{array}$} \\
\hline & & $100 ?$ & $100^{63}$ & $100^{\circ}$ & & & \\
\hline QAB (13) & EXPECTED DEVELOPMENTS & 1009 & $100^{63}$ & $100^{\circ}$ & $100 ?$ & 100 & $100^{18}$ \\
\hline & ESSENTIAL & $44^{4}$ & 27. & & $1 i^{1}$ & $4^{2}$ & $21^{2}$ \\
\hline & VERY USEFUL & $44^{4}$. & 49. & $50^{4}$ & $56^{3}$ & $33^{23}$ & $399^{7}$ \\
\hline$\cdot$ & SOMEWHAT USEFUL & $11^{1}$ & 160 & $50^{4}$ & $22^{2}$ & $\hat{3}_{1}^{14}$ & $39 ?$ \\
\hline & NOT A.T ALL USEFUL. & & $6^{4}$ & & 11 & $13^{6}$ & $11^{2}$ \\
\hline & $\begin{array}{l}\text { ESSENTIAL + VERY } \\
\text { USEFUL }\end{array}$ & $89^{8}$ & 76 & $50^{4}$. & $67^{6}$ & 25 & 50 ? \\
\hline & DON'T KNOW & & & & & & \\
\hline & AVERAGE & 3.33 & 2.98 & 2.50 & 2.67 & 2.47 & 2.50 \\
\hline & STANDARD DEVIATION & .68 & .84 & .50 & .80 & .76 & .83 \\
\hline $088(14)$ & CLIMATOLOGICAL DATA & $100^{9}$ & $100^{63}$ & $100^{8}$ & $100^{9}$ & 100 & $100^{18}$ \\
\hline$\cdot$ & ESSENTIAL & $33^{3}$ & 331 & $13^{1}$ & $12^{1}$ & $18^{8}$ & $28^{5}$ \\
\hline & VERY USEFUL & $22^{2}$ & $38^{24}$ & $38^{3}$ & $67^{6}$ & $51^{33}$ & $39^{7}$ \\
\hline & SOMEWHAT USEFUL & $33^{3}$ & $24^{15}$ & 38 & $11^{1}$ & 20 ? & $11^{2}$ \\
\hline & NOT AT ALL USEFUL & $11^{1}$ & $5^{3}$ & $13^{1}$ & 121 & $11^{5}$ & $22^{4}$ \\
\hline & $\begin{array}{l}\text { ESSENTIAL + VERY } \\
\text { USEFUL }\end{array}$ & 56 & 72 & $50^{4}$ & $78^{7}$ & 69. & $67^{12}$. \\
\hline & DON•T KNOW & & & & & & \\
\hline & AVERAGE & 2.78 & 3.00 & 2.50 & 2.78 & 2.76 & 2.72 \\
\hline & STANDARO DEVIATION & 1.02 & .87 & .86 & .77 & .85 & 1.10 \\
\hline
\end{tabular}

Industrial and Agricultural Process Heat Data Tables (continued) 
IOCTOBER, 19791

INOUSTRIAL AND AGRICUL TURAL
PROCESS HEAT

USE OF SPECIAL ACQUISITION METHODS (QUESTION 10) $\begin{array}{lll}\text { IPH APH } & \text { TOTAL ALL } & \text { CONC TOTAL ALL } \\ \text { PES RES } & \text { IAPH RES } & \text { COLL NCONC AANUF }\end{array}$ MANSTF COLL MA

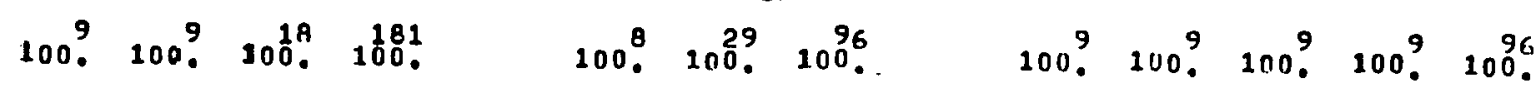

O1OA COMPUTER TERMINAL
1. YES
2. NO.
8. DON'T KNOW/NA

$$
\begin{array}{rrrr}
33^{3} & 44^{4} \cdot & 39 ?^{7} & 34^{62} \\
67^{6} & 55^{5} & 61^{1 !} & 114^{6}
\end{array}
$$$$
25^{2} \cdot 24^{7} \cdot 232
$$$$
22^{2} \cdot 56^{5} \quad 11^{1} \cdot 44^{4} \cdot 34^{3} .
$$$$
75^{6} \quad 76^{22} \quad 77 \text {. }
$$

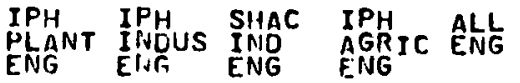

$1000^{9} 1009.100 \% 1009.100^{96}$

Q1OB MICROFDRM - COMPUTEF
1. YES
2. NO
8. DON'T KNOW/NA

$$
\begin{aligned}
& \text { 11. } \quad 6.96 \\
& 78^{7} \quad 78.778^{4} .865 . \\
& \text { 11. } 22^{2} .17^{3} \quad 6^{10}
\end{aligned}
$$

$$
\begin{array}{rrr}
13^{1} & 7^{2} & 5^{5} \\
75^{6} & 90^{2} & 9 ?^{8} \\
13^{1} & 3^{1} & 4^{4}
\end{array}
$$

$$
\begin{aligned}
& 111^{1} \quad 11^{1} 1^{13} . \\
& 100 \text {. } 89^{8} .100^{9} . \quad 78^{7} .81^{8} . \\
& 11 \text {. 5. }
\end{aligned}
$$

PIOC OTHER MICROFORM
1. YES
2. NO
Q. DON T KNOW/NA

$$
\begin{aligned}
& 44^{4} \cdot 33^{3} \cdot 39^{7} \cdot 40^{72} \cdot \cdots \quad 38^{3} \cdot 10^{3} \cdot 2^{10} \cdot \\
& 56.56 .510 .58 \% \\
& \text { 11: } \quad 6.1 \text {. } \\
& 63^{5} \quad 86.5 .976 \\
& \text { 3. } 1 \text {. }
\end{aligned}
$$

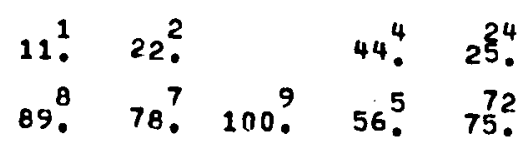

Figure F-1. Industrial and Agricultural Process Heal Data Tatles (continued) 
(OCTOBER, 1979)

USE OF SPECIAL ACQUISITION METHODS (QUESTION 10)

INDUSTRIAL AND AGRICULTURAL
IPROCESS HEAT ICONTINUEDI

IPH ALL ELUC

APH
STATE
AGRIC
OFF

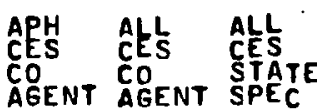

$1009.100^{63}$

$100^{8}$

100 ? 100 . $100^{18}$.

Q1OA COMPUTER TERMINAL

1. YES

33. $22^{14}$

22. $12^{2} .44^{8}$.

2. NO

B. DON T KNOW/NE

67.79

$100^{8}$

$788^{7}$. $38.56 \%$

Q10B MICROFORM - COMPUTER

1. YES

2. NO

8. DONIT KNOW/NA

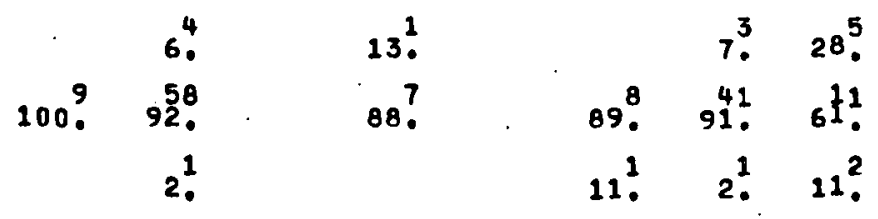

A1OC OTHER MICROFORM
1. YES
2. NO
8. DONPT KNOW/NA

2.5.

$9.33^{6}$.

676.672

75.

100.941 .672

Figure F-1. Industrial and Agricultural Process Heat Data Tables (continued) 
T-039

(OCTOBER, 1979$)$

USE OF SELECTED SOLAR INFORMATION SOURCES (QUESTION 11)

INOUSTRIAL AND AGRICULTURAL
PROCESS HEAT

Q11(1) LIBRAFY (ORG/LOCAL)

1. YES

2. NO

B. DON T KNOW

Q11(2) PUBLIC UTILITY
1. YES
2. NO
8. DON'T KNOW

Q11 (3) INSTALLER/BUILDER,

1. YES

2. NO

B. DON T KNOW

Q11(4) WORKSHOPS/CONFEREACE:S
1. YES
2. NO
8. DON'T KNOW

IPH APH TOTAL AL

CONC TOTAL ALL

MANUF COLL

\begin{tabular}{|c|c|c|c|}
\hline $100^{9}$ & $100^{9}$ & $10 t^{8}$ & ${ }_{183}^{13}$ \\
\hline $100^{9}$ & $100 ?$ & $10 C^{18}$ & $\begin{array}{l}179 \\
1010^{\circ}\end{array}$ \\
\hline $89^{\circ}$ & $100^{9}$ & 947 & $\begin{array}{l}150 \\
84 .\end{array}$ \\
\hline $11^{1}$ & & $\epsilon^{1}$ & 168 \\
\hline
\end{tabular}

100. 1009.1000 .180

46. 44. 44. 5 . $^{\circ}$.

$56.565 .56 . \quad 4 \xi^{5}$

1.

100. 100. 100.101800

$78.767^{6} .72, \quad 617$.

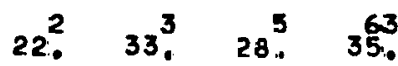

$100^{8} .100^{29}, 100^{96}$

$100^{8} .100^{29} .100^{9} 6$

$75^{6} .721 .663$

$25^{2} .288^{8}-34^{33}$.

1

$$
\begin{array}{rrr}
100 . & 100^{29} . & 100^{96} \\
63^{5} . & 5 \frac{15}{2} . & 4 \frac{41}{3} . \\
38^{3} . & 48^{4} . & 575
\end{array}
$$

$100.1029 .100^{9}$.

$100^{8} .834 .695$.

$17^{5} .31^{3}$ ?

100. 100 \% $100^{18}, 180$ ?

$100^{3}, 100,100^{2}, \quad 153$,

12!
$100^{8} \cdot 10^{29} \cdot 100^{56}$

88. $79 . \quad 75^{2}$

13. 21.625.

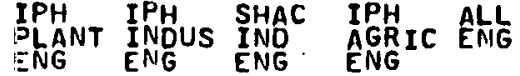
100. $1000^{9} 100$. $100^{9} .100^{96}$ 100 . 100 . 100. 100 . 100 . $22^{2} . \quad 22^{2} . \quad 44^{4} . \quad 89^{8} .64^{61}$. $78^{?} . \quad 78^{7} .56^{5} \quad 11^{1} . \quad 36^{35}$

$100^{9} .100^{9} .100^{9} .100^{9} .100^{96}$. $22.212^{2} . \quad 566^{5} . \quad 44^{4} . \quad 50^{40}$. $78^{7} .89^{8} . \quad 44^{4} . \quad 566^{5} . \quad 50$. 100. $100^{9} .100^{9} .1000^{9}$. $100^{96}$. 89. $78^{7} . \quad 78^{7} . \quad 89.89^{8}$. $11^{1} . \quad 22^{2}, \quad 22^{2}, \quad 11^{1} \cdot \quad 1^{3}$.

1309.1009 .100 . 100 . $100^{96}$

$44^{4} .67^{6} .100 .967^{6}, 72.9$

$56.533^{3} . \quad 33^{3} \cdot 28$.

Figure F-1. Industrial and Agricultural Process Heat Data Tables (continued) 
(OCTOBER, 1979)

USE OF SELECTED SOLAR INFORMATION SOURCES (QUESTION 11)

INDUSTRIAL AND AGRICULTURAL
PROCESS HEAT (CONTINUEDI

A12(1) LIBRARY (ORG/LOCAL)

1. YES

2. ND

8. DON,T KNOW

Q11(2) PUBLIC UTILITY

$$
\text { 1. YES }
$$

2. 10

8. DON?T KNOW

OQ113

1. YES

2. NO

8. DON T KNOW

Q11(4) W.JRKSHOPS/CONFERENCES

\section{YES}

2. NO

8. DON'T KNOW
IPH ALU

APH
STATE
AGRIC
OFF

$100 ? \quad 100$.

$100^{9} .1003$

100 ? 86.

14 .

$100^{9} \cdot 100^{63}$

78.556.

$22^{2} .43^{27}$

$100^{9} \cdot 100^{63}$

78 . 896

$22^{2} .11^{7}$.

$100^{9} .100^{63}$

69. 90.

11. $10^{6}$.

$100^{8}$

$100^{8}$.

63.

$38^{3}$

$100^{8}$

$75^{6}$

$25^{2}$ $\begin{array}{ll}\text { APH ALL ALL } & \text { ALL } \\ \text { CCES ÇES } & \text { CES } \\ \text { COO SOATE } & \text { CO SENT SPEC } \\ \text { AGENT AGENT SSA } & \end{array}$

$100^{\circ} 100.45100^{10}$

$100 \%$. $100.100 \%$

44. $44^{20} . \quad 8^{\frac{1}{3}}$.

$56^{5} \quad 56 . \quad 17^{3}$.

$100 \%$

1009.100 .100$.

56.20 .64 .612

$33^{3} .51^{23} .39^{7}$

$11^{1} \cdot 4^{2} \cdot$

$1009.100 .100^{18}$.

$67.653^{24} .611$.

33 . $47 . \quad 39$.

$100 . \quad 100$. $100^{45} \cdot 100^{28}$.

$75^{6} . \quad 56.55^{5} .8^{\frac{1}{3}}$.

$25.2 \quad 44^{4} . \quad 44^{20} \cdot \quad 17^{3}$.

Figure F-1. Industrial and Agricultural Process Heat Data Tables (continued) 
(OETOBER, 1979$)$

USE OF SELECTED SOLAR IPFGIRMATION SOURCES - CONTINUED (QUESTION 11 )

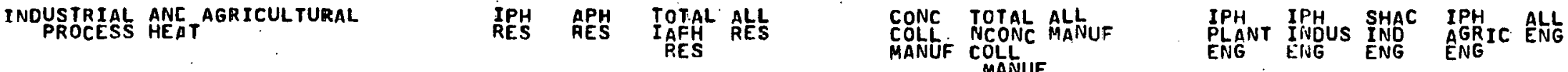

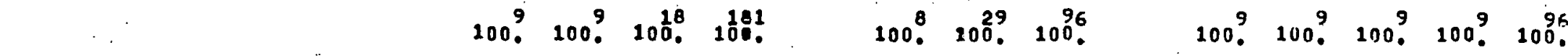

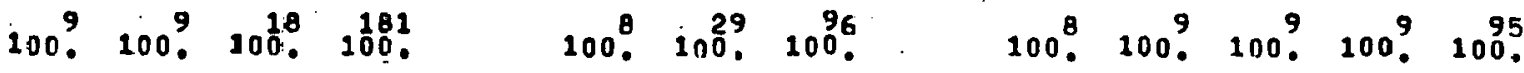

1. YES

2. NO

8. DON T KNOW

$33^{3} \quad 11^{2} . \quad 22^{4} . \quad 38_{0}^{68}$

67. $89.89^{6} \quad 78^{4} \quad \frac{110}{0}$

$255^{2}=21.6 .22$.

75. $79 . \quad 78^{6}$.

67. 24.

$2^{3}$

$100^{8} \quad 89^{8} .100 . \quad 33^{3} . \quad 7^{70}$.

Q1116) FEDERAL LIBRARY/INFO

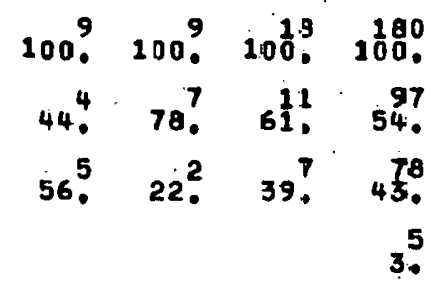

$100.100^{29} .100^{95}$.

$100^{8} .45^{3} .46^{4}$.

100. 100 . 100 \% 100 . 100 .

1. YES

2. NO

8. DON?T KNOW

$55^{6} .53^{5}$.

11. $566^{5} \quad 33^{3} \cdot 4^{4} \cdot \quad 46^{4}$.

$89^{8} . \quad 44^{4}, \quad 67^{6}, \quad 56^{5} . \quad 52$.

$1 \%$

$2^{2}$.

B11(7) SSIE - SMITHSONIAN

100 . 100 ? 100.1601

$100^{8} \cdot 10 \frac{11}{1} \cdot 100^{42}$

1009.1009

$1009.100^{\circ}$.

1. YES

$22^{2} .22^{2} \cdot 22^{4} \cdot 17$.

13. 9. $7^{3}$.

78, 78? $78^{4}$. $141^{45}$

88 . 910.39 .

$22^{2} \cdot 11^{8}$

2. NO

8. DONיT KNOW

3.

100 . 100?

78? $87^{61}$

Figure F-1. Industrial and Agricultural Process Heat Data Tables (continued) 
(OCTOBER, 1979)

$T-040$

USE OF SELECTED SOLAR INFORMATION SOURCES - CONTINUED (QUESTION I1) INDUSTRIAL AND AGRICULTURAL
PROCESS HEAT ICONTINUED

IPH: ALLUC

APH
STATE
AGRIC
OFF

APH ALL ALL

Q11(5) COMMERCIAL DATA BASE

$1009 \cdot 100^{63}$

$100^{8}$.

100 . 2005 (1000

100 ? 1003 .

$100^{\circ}$.

100. $100^{45} 100^{18}$.

1. YES

$22^{2} .22^{17}$.

$100^{9} 100^{45} 100^{18}$.

2. NO

8. DON?T KNOW

78.736

13 .

$11^{1}$. $13^{6} .17^{3}$.

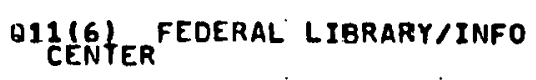

1. YES

2. No

8. DON'T KNOW

Q11(7) SSIE - SMITHSGNIAN
1. YES
2. NO
a. DON T KNOW

$\begin{array}{rr}1009 & 100^{63} \\ 56 & 52 \\ 44^{4} & 430 \\ & 48\end{array}$

$100^{8}$.

$75^{6}$.

$25^{2}$

$1009.100^{45} 100^{18}$.

$22^{2} \cdot 3^{\frac{115}{3}} \quad 6^{12}$ ?

$78.633^{30} .63$

$\begin{array}{rr}1009 & 100^{63} \\ 11^{1} & 21^{3} \\ 78 & 76 \\ 11^{2} & 36^{2}\end{array}$

$100^{8}$.

38 .

$63^{5}$. 
IOCTOBER, 19791

USE OF SELECTEO SOLAR INFORMATION SOURCES - CONTINUED (QUESTION 11)

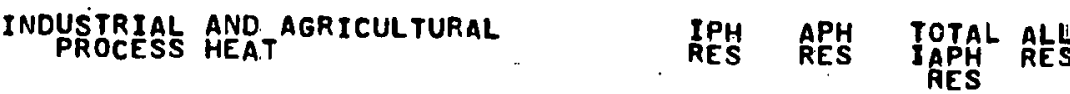

Q11 18 GPO GOV'T PRINTING OFFICE-
1. YES
2. NO
8. DONיT KNOW

N

1. YES

2. NO

8. DON?T KNOW

Q11(10) TECHNICAL INFORMRTION

1. YES

2. NO

8. DON?T KNOL

$$
\begin{aligned}
& \text { 100. } 100 \text {, } 100^{8}, 18 \varepsilon^{2} \text {. } \\
& 100 \text {. 100. } 100 \text {. 106. } \\
& \text { 89. } 78^{8} \text { ? } 8 \frac{15}{3}, \quad 74 \frac{3}{4} \text {. } \\
& \text { 11. } 11 \text { ! } 11^{2} 244^{44} \\
& \text { 11. } 6^{1} \text {. } 2^{3}
\end{aligned}
$$

CONC TOTAL ALL
COLL, NCONC MANUF
MANUF COLL

100 . $108^{9} \cdot 100^{6}$. $100 \%$ : $100^{29} \cdot 100^{96}$

88. $79^{23} \cdot 75^{72}$

$13^{1} 21.254$

IPH IPH SHAC IPH
PLANT INDUS IND ALL
ENG
ENG
ENG

$1000^{9} 1009.100^{9} 1009.1006$ 100 \% 100 ? 100 \% 100 ? $100^{9}$.

$44^{4} \quad 89^{8} .78$. 78 ? $76^{73}$.

$56^{5} \cdot 21^{1} \cdot 22^{2} \quad 22^{2} \cdot 24^{23}$

1009.1009 .1000 .1001

$100.100^{29} \cdot 100^{96}$

$1009.1009 .100^{8} \cdot 1001$

89.33 .511 .64$.

11 . $44^{4} .28 .533^{5}$

22. $12^{2} \cdot 4$ ?

$100.100^{89} \cdot 100^{96}$.

63. $43^{14} 4^{42}$.

$388^{3} 52^{15} .54^{2}$.

$2^{2}$

$100^{8} \cdot 100^{29} \cdot 100^{96}$

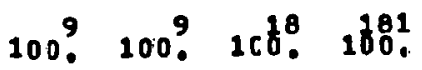

$100^{9} 1009$. 1000.1000.

89. $33^{3} . \quad 61^{12} . \quad 40^{2}$.

$11^{1} 56^{5} .33^{6} .59$.

11. $6^{1}$.
$100.100^{29} \cdot 100^{96}$.

$38^{3} .21^{6} \cdot 21^{20}$.

50. $70^{23} \quad 76^{73}$.

13 .

3.
1009. $1009.1009 .1009 .100 \%$ 100 ? 100 ? 100 ? 100? 1006

11 . 33. $56.566^{5} \quad 47^{3}$.

89. $56^{5} .44^{4} .44^{4} . \quad 51^{49}$

11 .

$2^{2}$.

1009 . 100 ?. 100 ? 1009 ? 1006

100 \% 1009. 100 \% 1009. $100^{96}$.

$22^{2} .56^{5} \quad 33^{3} \quad 22^{2} \quad 3_{3}^{32}$

67. $44^{4} \cdot 67^{6} \cdot 78^{7} \cdot 630$

11 .

Figure F-1. Industrial and Agricultural Process Heat Data Tables (continued) 
(OCTOBER, 1979 )

USE OF SELECTED SOLAR INFORMATION SOURCES - CONTINUED (QUESTION 11)

IPH ALL PUSTRIAL AND AGRICULTURAL
PROCESS HEAT ICONTINUED

DII ERE GOVPT PRINTING OFFICE:

1. YES

2. NO

8. DONIT KNOW

OII
INF́R NATIONATION SERECHNICAI
1. YES
2. NO
8. DON T KNOW

Q12119) TECHNICAL INFORMATION
1. YES
2. HO
b. DONPT KNOW

$1009.100^{63}$

100 ? $100^{63}$

56.590.

33. $13^{12}$

11 . 2 .

1009.1003

$100^{9} 100^{63}$

78.630

$22^{2} .35$.

$2^{2}$

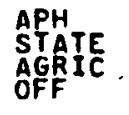

$\begin{array}{lll}\text { APH } & \text { ALL } & \text { ALL } \\ \text { CES } & C E S & C E S \\ C D O & C D & \text { SIATE } \\ \text { AGENT AGENT SPEC }\end{array}$

$100^{8}$.

$1009.200^{45} 100^{10}$.

100 .

75.

$25^{2}$

$100^{9} .100^{45} .100^{18}$.

$67^{6} . \quad 64.63^{\frac{15}{3}}$.

33. $33^{\frac{15}{5}} 17^{3}$.

$2^{1}$

$\begin{array}{rrrr}100^{8} & 1009 & 100^{45} & 100^{8} \\ 100^{8} & 100^{\circ} & 100^{4} & 100^{18} \\ 38 . & & 73 & 509 \\ 63^{5} & 89 . & 879 & 509 \\ & 110^{2} & 7 . & \end{array}$

$\begin{array}{cc}1009 & 100^{63} \\ 100^{9} & 100^{63} \\ 56 ! & 44^{28} \\ 33^{3} & 49 . \\ 19^{1} & 6 .\end{array}$

Figure F-1. Industrial and Agricultural Process Heat Data Tables (continued) 
(OCTOBER, 19791

USE OF SELECTED SOLAR INFORMATION SOURCES - CONTINUED (DUESIICN 11 )

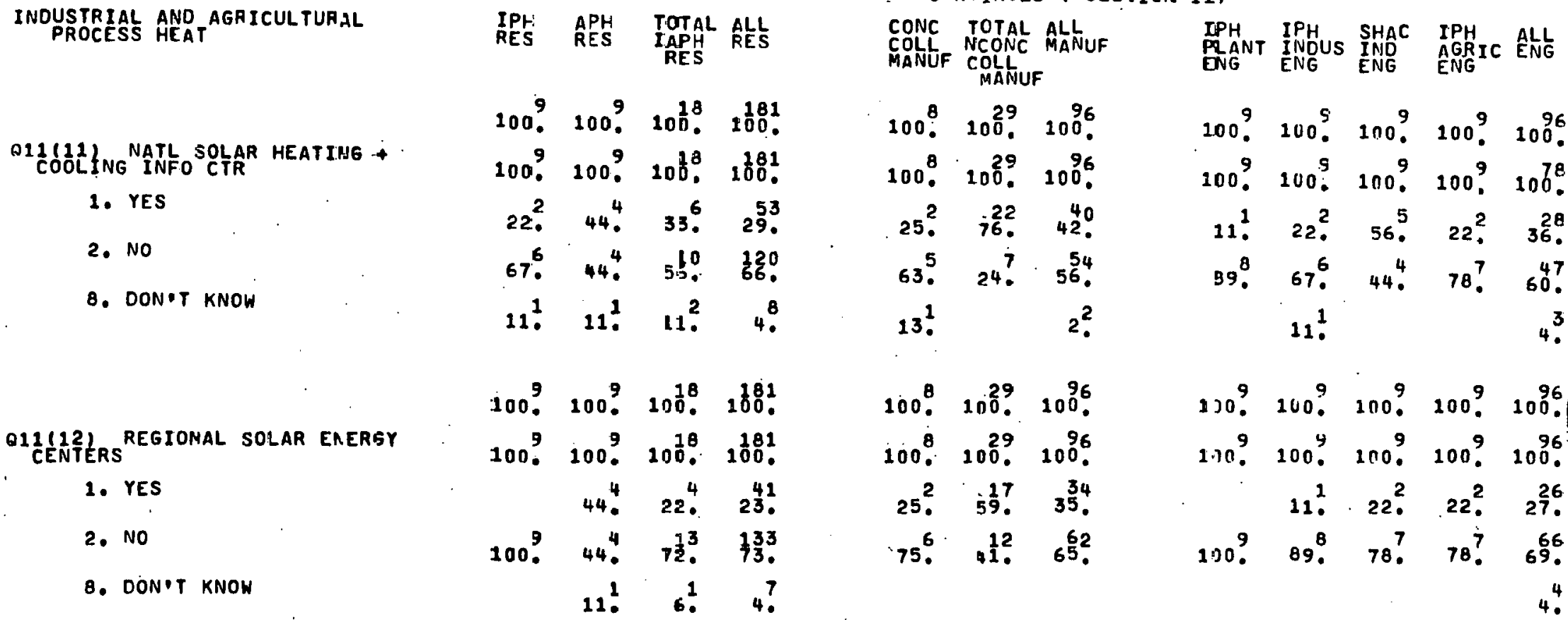

Figure F-1. Industrial and Agricultural Process Heat Data Tables (continued) 
(OCTOBER, 1979 )

$T-044$

USE OF SELECTED SOLAR INFORMATION SOURCES - CONTINUED (QUESTION 11)

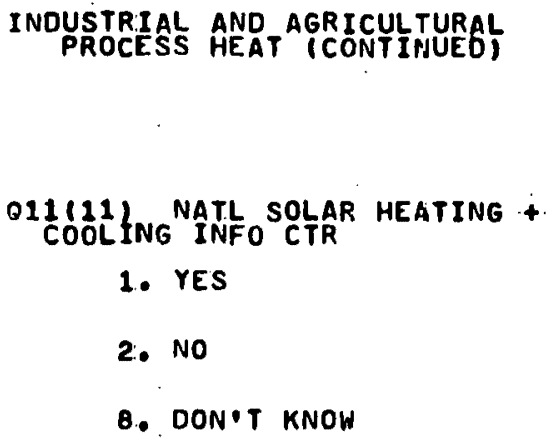

2. NO

8. DON'T KNOW

Q11(12) REGIONAL SOLAR ENERGY
IPH ALLUC

$\begin{array}{rr}1000^{9} & 100^{63} \\ 1009 & 100^{63} \\ 44^{4} & 46 . \\ 56 . & 54 . \\ & 34\end{array}$

$\begin{array}{rr}1009 & 100^{63} \\ 1009 & 100^{63} \\ 33^{3} & 43^{27} \\ 67^{6} & 544 \\ & 54 \\ & 3\end{array}$

APH
STATE
AGRIC
OFF

$100^{8}$.

$100 \%$

$25^{2}$

75.

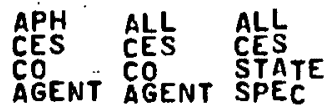

$1009.100 .100^{\frac{1}{8}}$.

$100^{9} 100^{45} 100^{18}$.

$22^{2} .29^{3} .50^{9}$.

$67^{6} \quad 67^{30} \quad 44^{\circ}$

11. $4^{2}$. $6^{1}$

1. YES

2. NO

8. DON'T KNOH

Figure F-1. Industrial and Agricultural Process Heat Data Tables (continued) 
(OCTOBER, 1979)

USE OF SELECTED SOLAR INFORMATION SOURCES - CONTINUED (DUESTION 11)

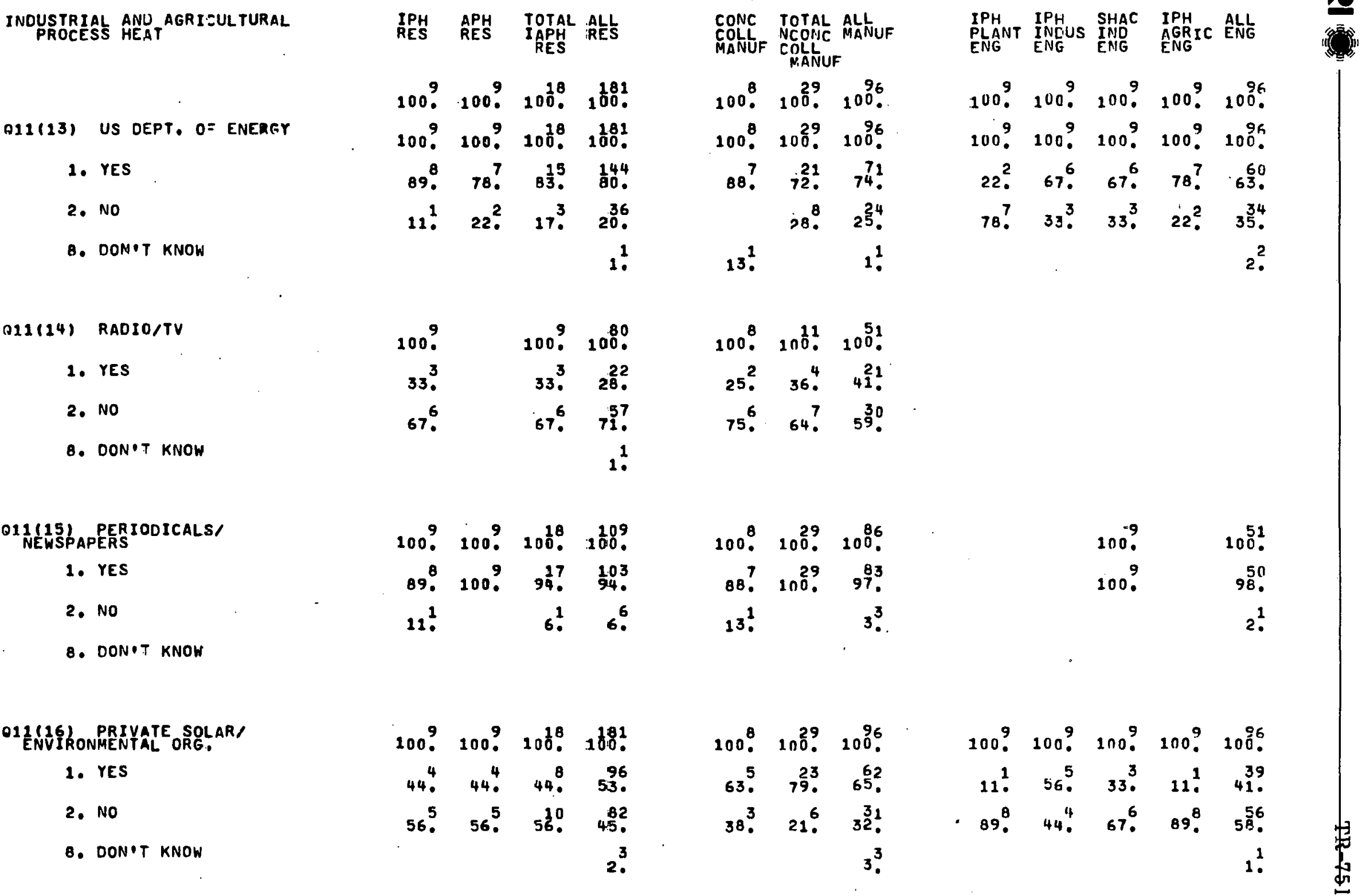

Figure F-1. Industrial and Agricultural Process Heat Data Tables (continued) 
IOCTOBER, 19791

USE OF SELECTED SOLAR INFORMATION SOURCES - CONTINUEO IOUESTION 11

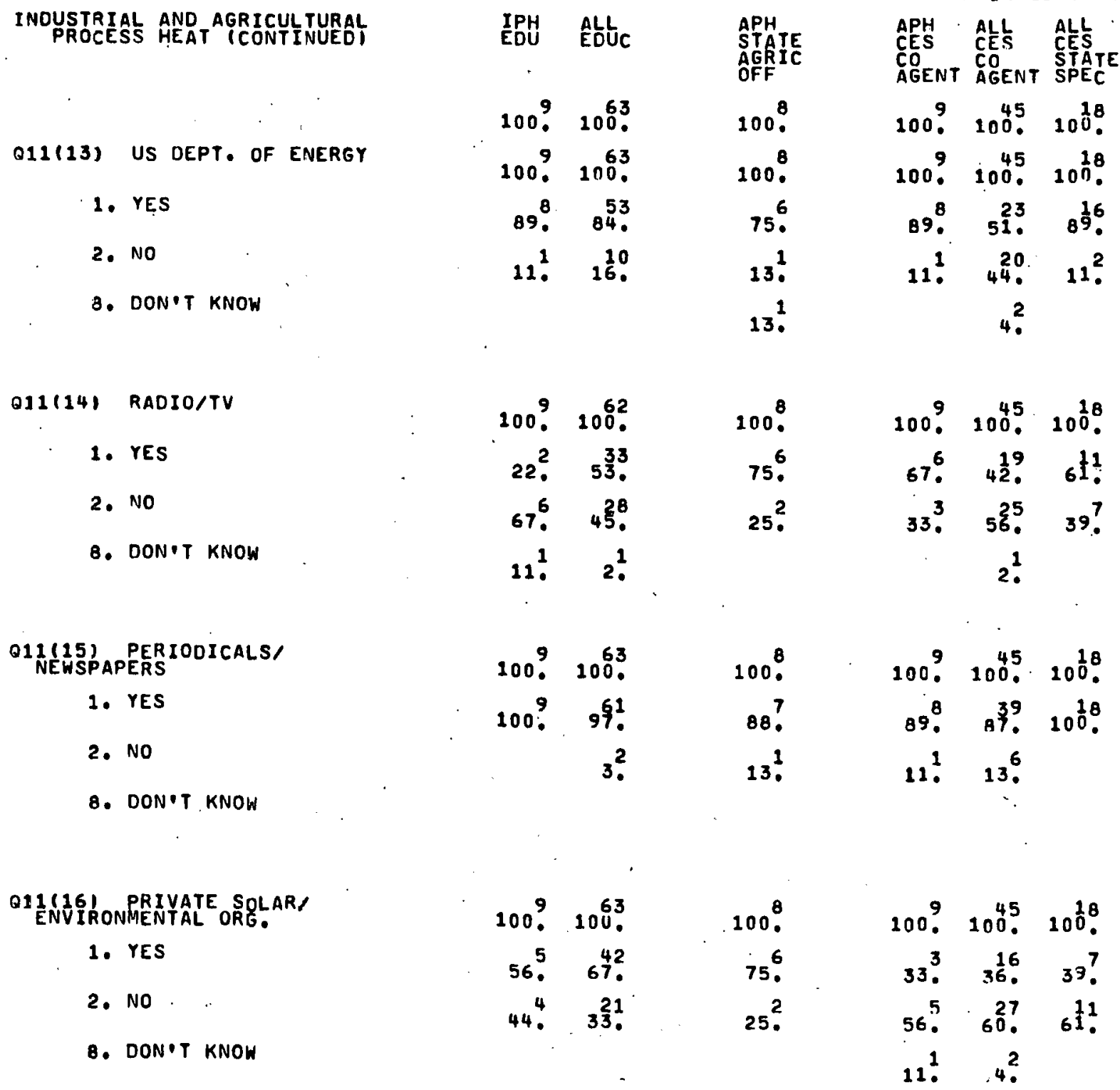

Figure F-1. Industrial and Agricultural Process Heat Data Tables (continued) 
(OCTOBER, 1979)

USE OF SELECTED SOLAR INFORMATION SOURCES - CONTINUED (QUESTION 11)

INOUSTRIAL ANO AGRICULTLRAL
PROCESS HEAT

Q11117) STATE ENERGY OR SOLAR

1. YES

2. NO

8. DON'T KNOW

Q11(18) OTHEF STATE
LOCAL GOVTT. SOURE

$$
\text { 1. YES }
$$

$\stackrel{\sim}{\omega}$
2. NO

8. DON?T KNOW

$$
\begin{aligned}
& \text { 1. YES } \\
& \text { 2. NO } \\
& \text { 8. DON T KNOW }
\end{aligned}
$$$$
\text { O1 SOCIETY-ISES SOLAR ENERGY }
$$

Q11120) SOLAR ENERGY
1. YES
2. NO
8. DON'T KNOW

IPH APH TOTAL ALL

CONC TOTAL ALLNU

MANUF COLLL MANUF

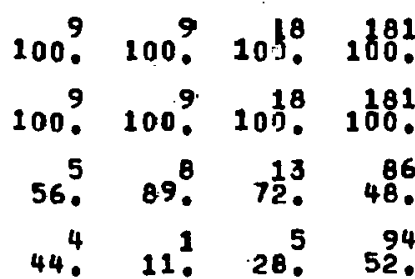

$1^{2}$

100 . $100^{29} \cdot 100^{96}$

$100^{8} .100^{29}, 100^{96}$.

$88^{7} .24 .56$.

13 . 17.540

1009.1009 ? 1000.1780 .

$44^{4} .22^{2} \quad 33^{6} \cdot 28$.

56. 78 ? $67^{2} \cdot 7_{2}^{28}$

1.

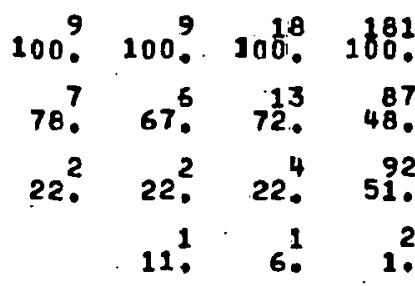

$1009100^{9} \cdot 100^{10} \cdot 100^{181}$

67. $22^{2} . \quad 44^{8}, \quad 330$.

33. 78 . 56.

$2^{3}$

$$
\begin{aligned}
& 100^{8} \cdot 100^{29} \cdot 100^{96} . \\
& 50^{4} .55^{6} .42^{40} \text {. } \\
& 50^{4} \quad 412 \quad 56 . \\
& \text { 3. } 2^{2} \text {. }
\end{aligned}
$$

$100^{8} \cdot 100^{29}, 100^{96}$.

$88^{7} .55^{\frac{1}{7}} \cdot 5^{40}$.

13. $41^{12}$. 49 ?

1.

$\begin{array}{rrr}1000^{8} & 100^{29} \cdot & 100^{96} \\ 88^{7} \cdot & 72^{21} & 47^{4} \\ 13^{1} & 28 . & 51^{2} \\ & & 2^{2}\end{array}$ $\begin{array}{ll}\text { IPH IPH SHAC IPH } & \text { SHAC } \\ \text { PLANT INDUS IND } \\ \text { ENG AGRIC ENG } \\ \text { ENG ENG ENG }\end{array}$

1009. 1009. 1009. 1009. 1006.

100 \% 100 \% 100 \% 100 \% 1006

56. $44^{4}, \quad 89^{8} .565 .56$.

$44^{4} .56 .544^{4}, 420$

$112^{2}$

$1009.1009 .100^{9}, 1009.100^{9}$.

11. $22^{2} \quad 33^{3}, 44^{4}, 30^{29}$

89. $78^{7} \cdot 67^{6} \cdot 56^{5} \quad 69^{66}$

1.

$100^{9}, 1009,100^{9}, 1009.100^{9}$.

11. $33^{3} \quad 09^{8} 38^{36}$

89. $100^{9}$. $67^{6} .11^{1} .630$.

1009.1009 .1009 .1009 .1009

11. $11^{1} \quad 22^{2} \quad 22^{21}$

89. $89^{\circ} \quad 89^{\circ} \quad 78^{7} .76^{73}$

11 .

Figure F-1. Industrial and Agricultural Process Heat Data Tables (continued) 
(OCTOBER, 1979$)$

USE OF SELECTED SOLAR INFORMATION SOURCES - CONTINUED (QUESTION 11)

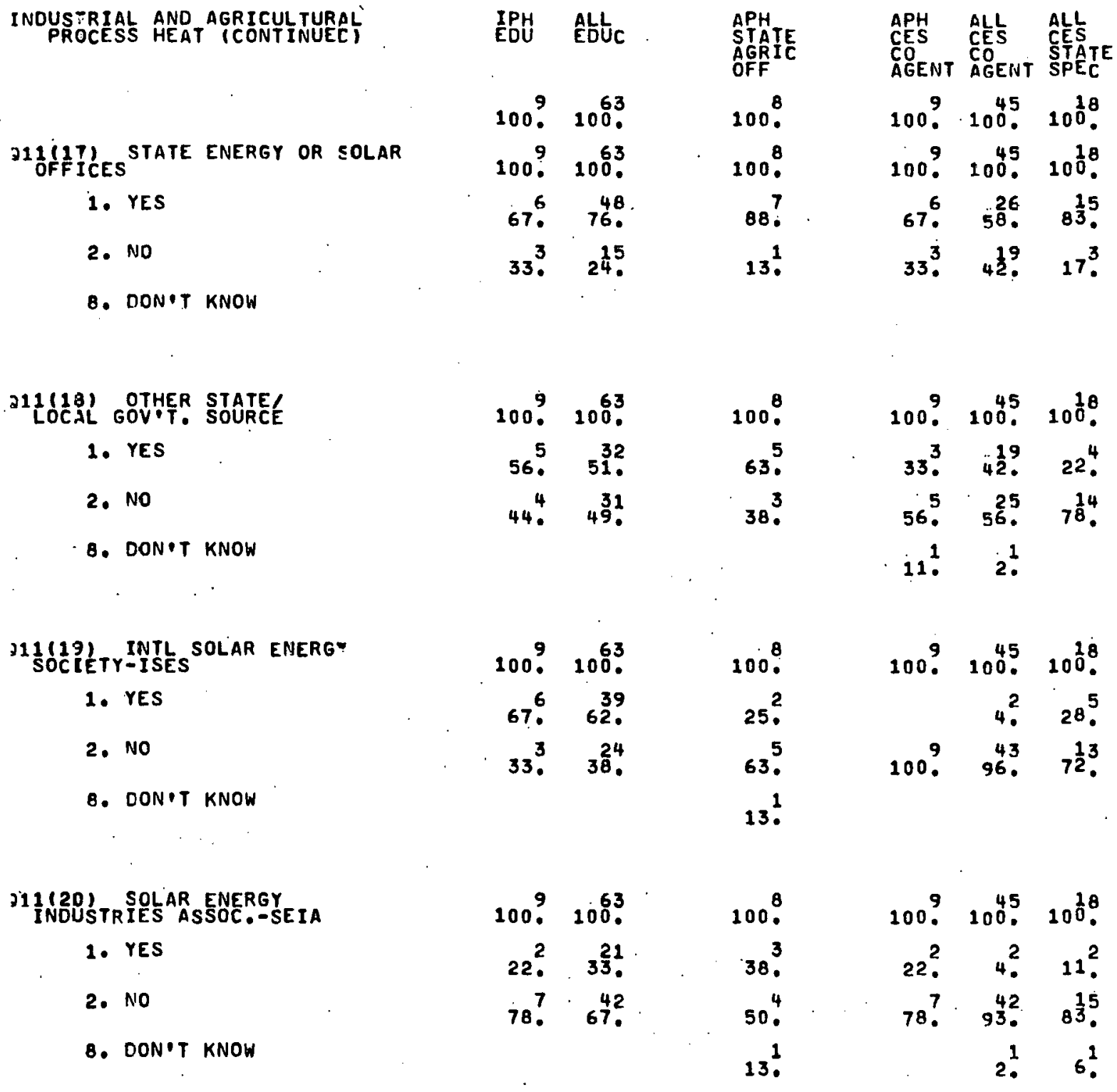

Figure F-1. Industrial and Agricultural Process Heat Data Tables (continued) 
(OCTOBER, 1979)

USE OF SELECTED SOLAR INFORMÄTION SOURCES - CONTINUED (DIJESTION 11)

INDUSTRIAL AND AGRICULTURAL
PROCESS HEAT

QI $\frac{1}{21} 211$ QLESTIONNAIRE SOURCE
1. YES
2. NO
B. DON'T KNOW

(USDA)

Q $12\{22)$ QUESTIONNAIRE SOURCE:

1. YES

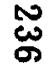

2. NO

8. DON'T KNOW

Q11 $\left.2 \xi^{23}\right)$ QUESTIONNAIRE SOURCE

1. YES

2. NO

8. DON T KNOW

Q11 $24(24)$ GUESTIONNAIRE SOURCE

1. YES

2. No

8. DON?T KNOW
IPH IPH SHAC IPH
PLANT INDUS IND AGRIC
ENG
ENG ENG ENG

$1009.1009 .100 \% 100$.

100 . 100? 100\% 100 ?

78. $1000^{9}$. $99^{8} .22^{2}$

22. 11 ? 78 ?

$(A E E)(A E E)(A E E)(A E E)$.

$1000^{9} 100^{\circ}$. $\quad 100^{9}$

11 . $22^{2}$. $33^{3}$.

89. $78^{7}$. $67^{6}$.

(IEEE)(IEEE) (ASAE)

Figure F-1. Industrial and Agricultural Process Heat Data Tables (continued) 
(OCTOBER, 1979)

USE OF SELECTED SOLAR INFORMATION SOURCES - CONTINUED (QUESTION 11)

INDUSTREAL AND AGRICULTURAL

EDU . ALboc

APH
STATE
AGRIC
OFF

APH ALL ALL CES

$100 \%$ 100? $100^{45} 100^{\circ}$

Q112(21) QUESTIONNAIRE SOURCE.

1. res USDA, including CES

$100 \%$ : 100 \% $100^{45} 100^{18}$

2. NO

$100^{8}$

100 ? 98.94 . 94 ?

8. DON?T KNOW

2. 6 .

Q1 $\frac{1}{22}(22)$ DUESTIONNAIRE SOURCE

2. res State Agricultural Office

1009

2. NO

8. DON T KNOW

Figure F-1. Industrial and Agricultural Process Heat Data Tables (continued) 


\begin{tabular}{|c|c|c|c|c|c|c|c|c|c|c|c|c|}
\hline \multirow{3}{*}{$\begin{array}{l}\text { INOUSTRIAL AND AGRICULTURAL } \\
\text { PROCESS HEAT }\end{array}$} & \multicolumn{11}{|c|}{$T-051$} & \\
\hline & $\begin{array}{l}\text { IPH } \\
\text { RES }\end{array}$ & $\begin{array}{l}\text { APH } \\
\text { RES }\end{array}$ & $\begin{array}{l}\text { IOTAL } \\
\text { IOPH } \\
\text { RES }\end{array}$ & ALL & $\begin{array}{l}\text { CONC } \\
\text { COLLL } \\
\text { MANUF }\end{array}$ & $\begin{array}{l}\text { TOTAL } \\
\text { NCONC } \\
\text { COLL } \\
\text { MANUF }\end{array}$ & $\begin{array}{l}\text { ALLN } \\
\text { ALNOF }\end{array}$ & $\begin{array}{l}\text { IPH } \\
\text { PPANT } \\
\text { ENGG }\end{array}$ & $\begin{array}{l}\text { IPH } \\
\text { INDS } \\
\text { ENG }\end{array}$ & $\begin{array}{l}\text { SHAC } \\
\text { INOC } \\
\text { ENG }\end{array}$ & $\begin{array}{l}\text { IPH } \\
A G R \text { IC } \\
E N G S\end{array}$ & ALL \\
\hline & 100 ? & 100? & $108^{8}$. & 108 & $100^{8}$ & 1009 & 1006. & 1009. & 1009 & $100^{9}$ & 100 . & $100^{96}$ \\
\hline 1. $0-2$ YEARS & & 11.1 & 6. & 6. & 13 & 3. & 9 ?. & & & & 211 & $4^{4}$. \\
\hline 2. 3-5 YEARS & 56.5 & 11 ? & $33^{6}$ & $\begin{array}{l}35 \\
19 .\end{array}$ & $13^{1}$ & 38. & 232 & $11 !$ & $33^{3}$ & $11 \%$ & $11 !$ & 17. \\
\hline 3. 6-10 YEARS & $11^{1}$ & 33 . & 22. & $\begin{array}{l}33 \\
18 .\end{array}$ & $13^{1}$ & 31 . & $22^{21}$ & $33^{3}$. & $22^{2}$. & & $33^{3}$. & 20. \\
\hline $\begin{array}{l}\text { 4. OVEA } 10 \\
\text { DON.T KNOW/NA }\end{array}$ & $333^{3}$ & 44!. & $39 ?$ & 593. & 63. & $2 B^{B}$ & $46^{44}$ & $56^{5}$ & $44^{4}$. & 89. & $44^{4}$. & 58 \\
\hline
\end{tabular}

Figure F-1. Industrial and Agricultural Process Heat Data Tables (continued) 


\begin{tabular}{|c|c|c|c|c|c|c|}
\hline \multirow[b]{2}{*}{ 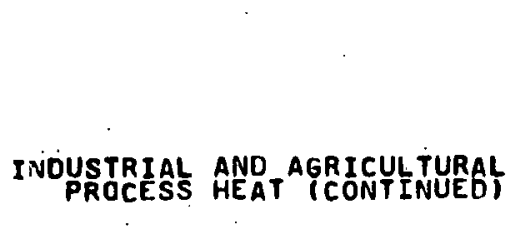 } & \multicolumn{2}{|c|}{ YEARS IN CURREN } & $\begin{array}{l}\text { lOCTO } \\
\text { PROFE }\end{array}$ & $\begin{array}{l}979) \\
\text { (OUEST: }\end{array}$ & ION D2 & \\
\hline & IPH & ALLUC & $\begin{array}{l}\text { APH } \\
\text { SYATE } \\
\text { AGRIC } \\
\text { OFF }\end{array}$ & $\begin{array}{l}\text { APH } \\
\text { CES } \\
\text { CDO } \\
\text { AGENT }\end{array}$ & $\begin{array}{l}\text { ALL } \\
\text { CESS } \\
\text { COEENT }\end{array}$ & $\begin{array}{l}\text { ALL } \\
\text { CLES } \\
\text { STATE } \\
\text { SPEC }\end{array}$ \\
\hline & $1000^{9}$ & $100^{63}$ & $100^{\circ}$. & $100^{9}$ & 1005 & $100^{18}$ \\
\hline 1. $0-2$ YEARS & $11^{1}$ & $2 !$ & $25^{2}$ & & 7 & \\
\hline 2. 3-5 YEARS & $22^{2}$ & $13^{8}$ & $388^{3}$ & $22^{2}$ & $20^{\circ}$ & $17^{3}$. \\
\hline 3. $6-10$ YEARS & & $21^{13}$. & $13^{1}$ & & $7^{3}$ & $22^{4}$. \\
\hline 4. OVER 10 & $67^{6}$ & $\begin{array}{l}41 \\
65\end{array}$ & $25^{2}$ & $788^{7}$ & 670 & $6 \frac{11}{1}$ \\
\hline
\end{tabular}

Figure F-1. Industrial and Agricultural Process Heat Data Tables (continued) 


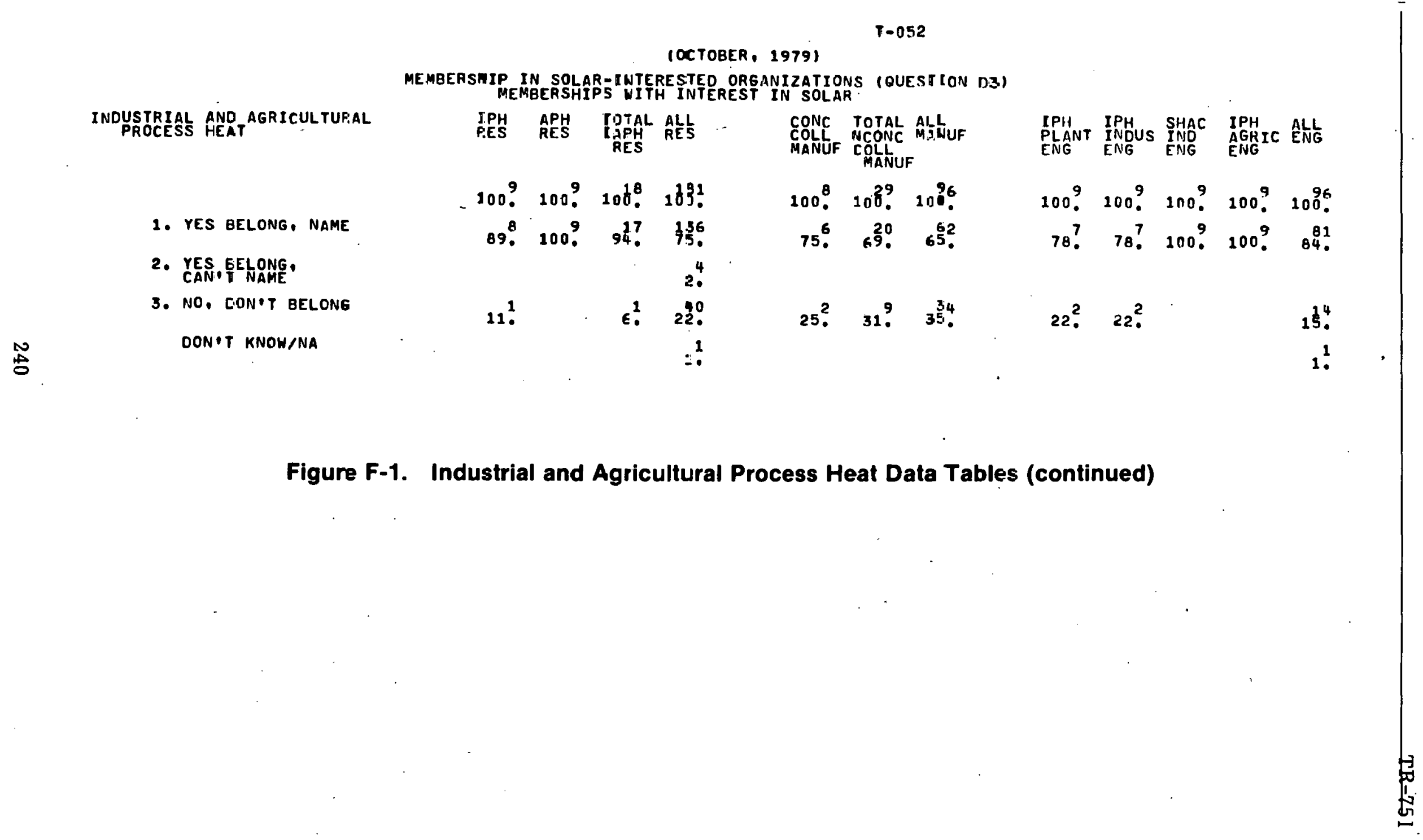




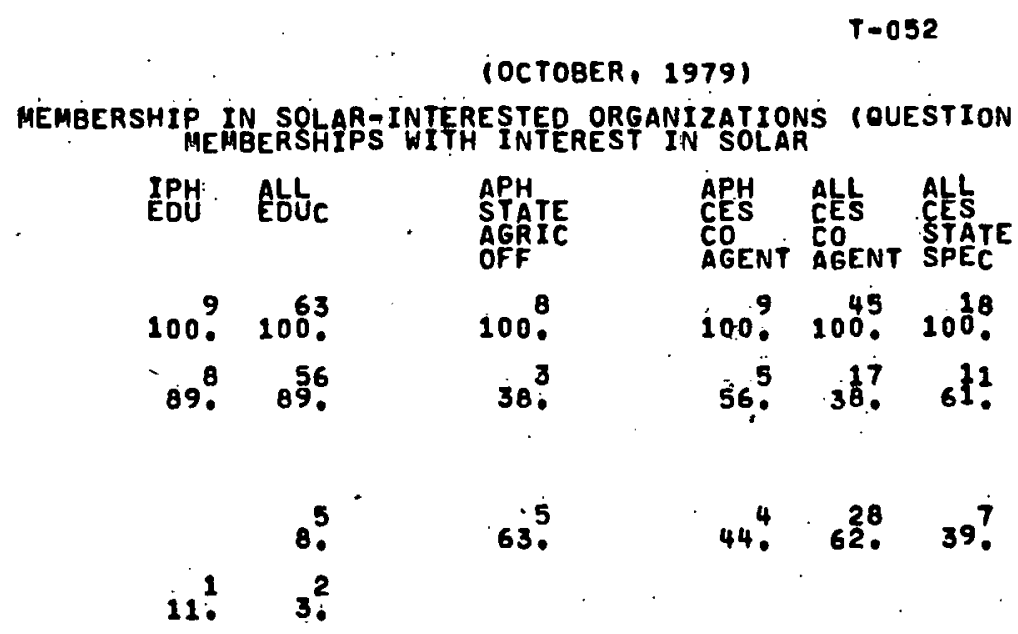

Figure F-1. Industrial and Agricultural Process Heat Data Tables (continued) 


\begin{tabular}{|c|c|}
\hline \begin{tabular}{|l|l|} 
1. SERI Report No. & 2. NTIS Accession No. \\
TR-751-751 & \\
\end{tabular} & 3. Recipient's Accession No. \\
\hline \multirow{2}{*}{$\begin{array}{l}\text { 4. Title and Subtitle } \\
\text { Industrial and Agricultural Process Heat Information } \\
\text { User Study }\end{array}$} & $\begin{array}{l}\text { 5. Publication Date } \\
\qquad \text { March } 1981\end{array}$ \\
\hline & 6. \\
\hline $\begin{array}{l}\text { 7. Author(s) } \\
\text { W. W. Belew, B. L. Wood, T. L. Marle, C. L. Reinhardt }\end{array}$ & 8. Performing Organization Rept. No. \\
\hline \multirow{2}{*}{$\begin{array}{l}\text { 9. Performing Organization Name and Address } \\
\text { Solar Energy Research Institute } \\
\text { 1617. Cole Boulevard } \\
\text { Golden, Colorado } 80401\end{array}$} & \multirow{2}{*}{$\begin{array}{l}\text { 10. Project/Task/Work Unit No. } \\
8420.11 \\
\text { 11. Contract (C) or Grant (G) No. } \\
\text { (C) } \\
\text { (G) }\end{array}$} \\
\hline & \\
\hline \multirow[t]{2}{*}{ 12. Sponsoring Organization Name and Address } & $\begin{array}{l}\text { 13. Type of Report \& Perlod Covered } \\
\text { Technical Report }\end{array}$ \\
\hline & 14. \\
\hline \multicolumn{2}{|l|}{ 15. Supplementary Notes } \\
\hline \multicolumn{2}{|c|}{$\begin{array}{l}\text { 16. Abstract (Limit: } 200 \text { words) This report describes the results of a series of telephonc } \\
\text { interviews with groups of users of information on solar industrial and agricultural } \\
\text { process heat (IAPH). These results, part of a larger study on many different solar } \\
\text { technologies, identify types of information each group needed and the best ways to } \\
\text { get information to each group. The report is } 1 \text { of } 10 \text { discussing study results. } \\
\text { The overall study provides baseline data about information needs in the solar com- } \\
\text { munity. It covers these technological areas: photovoltaics, passive solar heating } \\
\text { and cooling, active solar heating and cooling, biomass energy; solar thermal } \\
\text { electric power, solar industrial and agricultural process heat, wind energy, ocean } \\
\text { energy, and solar energy storage. An earlier study identified the 1nformatiun user } \\
\text { groups in the solar community and the priority (to accelerate solar energy com- } \\
\text { mercialization of getting information to each group. In the current study only } \\
\text { high-priority groups were examined. Results from } 10 \text { IAPH groups of respondents } \\
\text { are analyzed in this report: IPH Researchers; APH Researchers; Representatives of } \\
\text { Manufacturers of Concentrating and Nonconcentrating Collectors; Plant, Industrial, } \\
\text { and Agricultural Engineers; Educators: Representatives of State Agricultural of- } \\
\text { fices; and County Extension Agents. 'lhe data w1ll be used as input to the deter- } \\
\text { mination of information products and services the Solar Energy Research Institute, }\end{array}$} \\
\hline \multicolumn{2}{|c|}{$\begin{array}{l}\text { 17. Document Analysis the Solar Energy Information Data Bank Network, and the entire } \\
\text { a. Descriptors information outreach community should be preparing and disseminating } \\
\text { Cost ; Data Acquisition ; Data Analysis ; Data Base Management; Data Compilation ; } \\
\text { Evaluated Data ; Information Needs:Q1; Marketing Research ; Process Heat ; } \\
\text { b. Identifiers/Open-Ended Terms Sampling; Solar Industry ; Telephones; Communications ; } \\
\text { Data ; Energy ; Heat ; Industry ; Information ; Management; } \\
\text { Numerical Data } \\
\text { c. UC Categories } \\
59 \mathrm{~b}, 58 \mathrm{c}\end{array}$} \\
\hline \multirow{2}{*}{$\begin{array}{l}\text { 18. Availability Statement } \\
\text { National Technical Information Service } \\
\text { U.S. Department of Commerce } \\
5285 \text { Port Royal Road } \\
\text { Springfield, Virginia } 22161\end{array}$} & 19. No. of Pages \\
\hline & 20. Price \\
\hline
\end{tabular}

